\title{
The Effect of a Leader's Emotional Intelligence on the Subordinate's Intention to Whistleblow
}

Xin Geng

Follow this and additional works at: https://researchrepository.wvu.edu/etd

\section{Recommended Citation}

Geng, Xin, "The Effect of a Leader's Emotional Intelligence on the Subordinate's Intention to Whistleblow" (2017). Graduate Theses, Dissertations, and Problem Reports. 5660.

https://researchrepository.wvu.edu/etd/5660

This Dissertation is protected by copyright and/or related rights. It has been brought to you by the The Research Repository @ WVU with permission from the rights-holder(s). You are free to use this Dissertation in any way that is permitted by the copyright and related rights legislation that applies to your use. For other uses you must obtain permission from the rights-holder(s) directly, unless additional rights are indicated by a Creative Commons license in the record and/ or on the work itself. This Dissertation has been accepted for inclusion in WVU Graduate Theses, Dissertations, and Problem Reports collection by an authorized administrator of The Research Repository @ WVU.

For more information, please contact researchrepository@mail.wvu.edu. 


\title{
The Effect of a Leader's Emotional Intelligence on the Subordinate's Intention to Whistleblow
}

\author{
Xin Geng \\ A dissertation submitted \\ to the College of Business and Economics \\ at West Virginia University

\begin{abstract}
in partial fulfillment of the requirements for the degree of
Doctor of Philosophy in

Accounting
\end{abstract}

\begin{abstract}
A. Scott Fleming, Ph.D., Chair
Richard Riley, Ph.D.

D. Kip Holderness, Ph.D.

Presha Neidermeyer, Ph.D.

Aaron Metzger, Ph.D.

Department of Accounting
\end{abstract}

Morgantown, West Virginia

2017

Key words: emotional intelligence; leader-member exchange; trust; job satisfaction; leader group prototypicality; consequence framing; whistleblowing; financial statement fraud; asset misappropriation fraud. 


\begin{abstract}
The Effect of a Leader's Emotional Intelligence on the Subordinate's Intention to Whistleblow
\end{abstract}

\author{
Xin Geng
}

Two experiments in this dissertation examine the effect of a leader's emotional intelligence and its interaction with other constructs on the subordinate's intention to whistleblow. Results from the primary experiment indicate that when the leader is not involved in the observed accounting fraud, the subordinate is more likely to whistleblow to the leader if the leader has high emotional intelligence or high group prototypicality. The relationship between leader emotional intelligence and subordinate whistleblowing intention is stronger when the leader has high group prototypicality and is mediated by the subordinate's perceived leadermember exchange, trust in the leader, and job satisfaction. These mediations are stronger as well when the leader has high group prototypicality. In addition to the primary experiment, a supplementary experiment where the leader is involved in the observed accounting fraud demonstrates that the subordinate is less likely to whistleblow on the leader to the anonymous whistleblowing hotline if the leader has high emotional intelligence. Moreover, the subordinate is more likely to whistleblow if the consequence of the action is framed as being positive to the company than being negative to the leader when the leader has high emotional intelligence. Findings of these two experiments have strong practical implications in terms of corporate governance, internal control, and human resource management. 


\section{ACKNOWLEDGEMENTS}

First, I would like to express my sincere gratitude to West Virginia University, College of Business and Economics, and Department of Accounting for their generous financial support, without which I could not have completed my degree and dissertation.

Also, I would like to deeply thank my dissertation committee chair, Dr. Scott Fleming, for his continuous help on my study and research. His patience, motivation, and encouragement made me believe that I was able to succeed in the program and should always challenge my potential. I encountered many difficulties during my doctoral journey, but Dr. Fleming was always on my side and provided me with timely guidance. I could not have imagined having a better chair and mentor for my Ph.D. studies.

Besides my chair, I am grateful to the rest of my dissertation committee as well: Dr. Holderness, Dr. Riley, Dr. Neidermeyer, and Dr. Metzger. Their insightful comments and suggestions significantly improve my dissertation and widen my research from various perspectives. Meanwhile, my appreciation also goes to all professors and staff members in the department, college, and university who profoundly influence my Ph.D. journey.

I thank my fellow Ph.D. colleagues for their constant support and selfless help. I will not forget the days and nights when we worked hard together and had fun together. This wonderful experience will be a treasure to me forever.

Last but certainly not the least, I would like to thank my family, especially my parents. As the only child in the family, I understand that it was not easy for them to send me to the United States for higher education. Their incessant assurance of having a good life in China made me capable of concentrating on my study and research without worries. Although missing 
me a lot, my parents always put my career first and tried to provide assistance when necessary. I really appreciate their understanding and support. 


\section{TABLE OF CONTENTS}

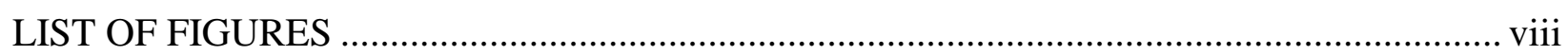

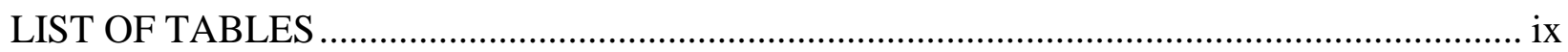

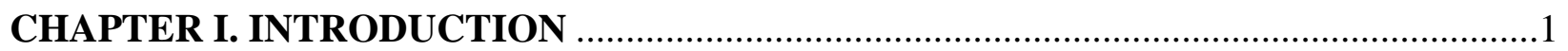

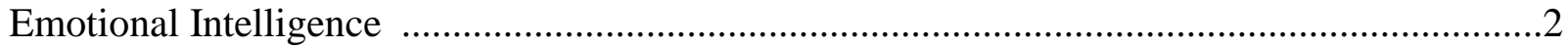

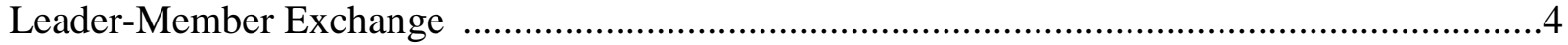

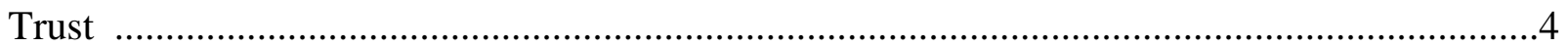

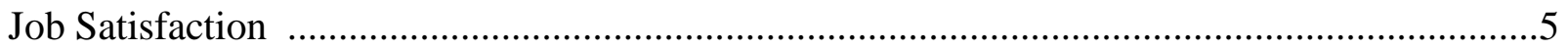

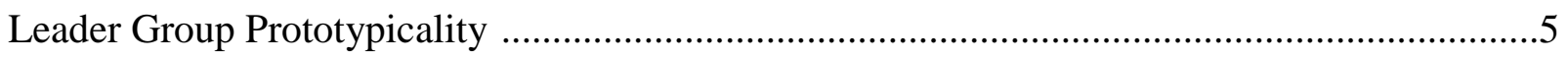

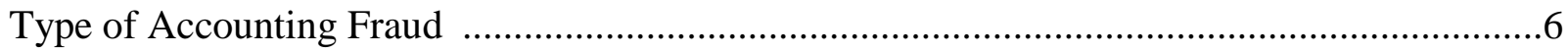

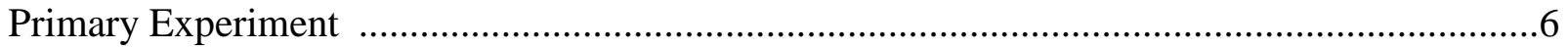

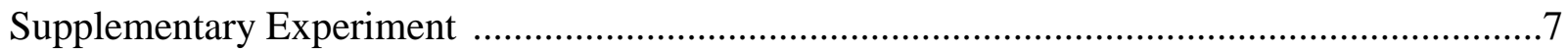

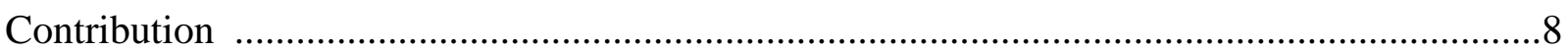

CHAPTER II. LITERATURE REVIEW AND HYPOTHESIS DEVELOPMENT ............10

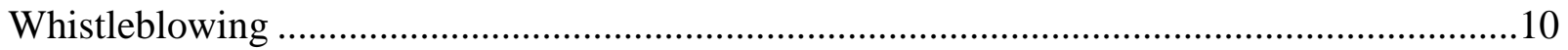

Management Whistleblowing Models ...................................................................... 10

1. Miceli et al. (2008) Model.................................................................................11

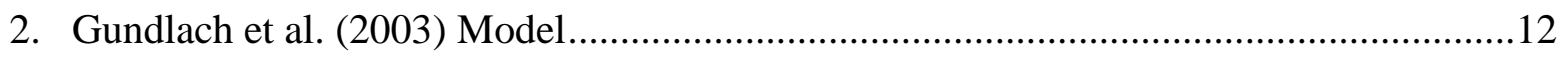

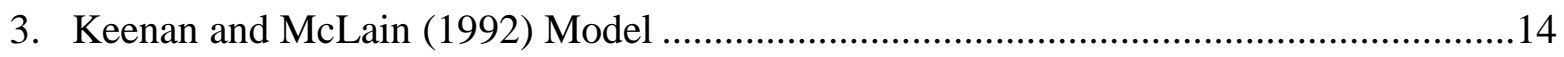

Accounting Whistleblowing Models ............................................................................... 16

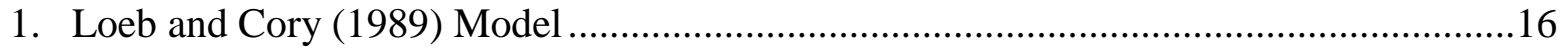

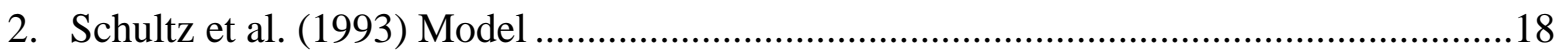

Whistleblowing Empirical Literature ........................................................................19

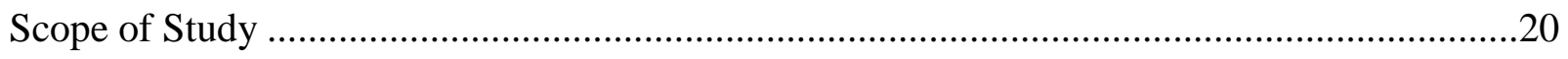

Emotional Intelligence of a Leader, Effective Leadership, and Leader-Member Exchange .....21

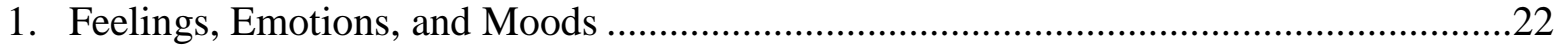

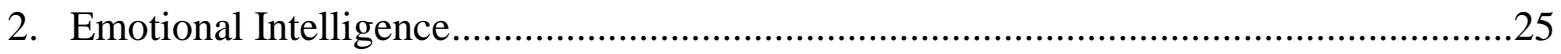

3. Emotional Intelligence, Effective Leadership, and Leader-Member Exchange..............26

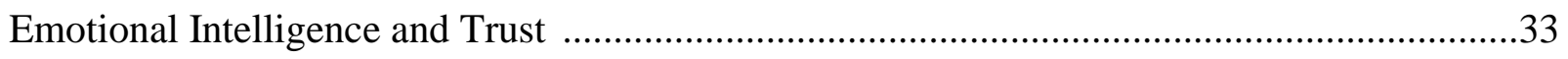




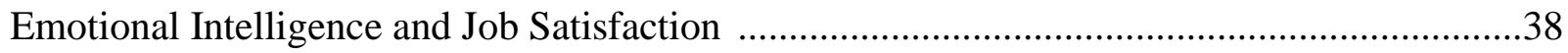

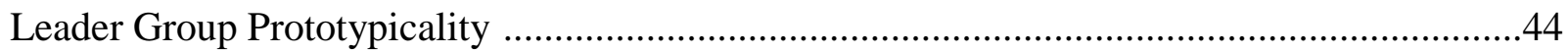

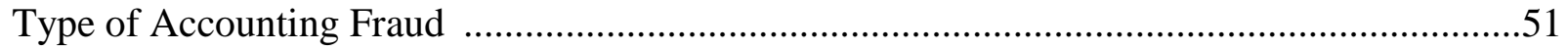

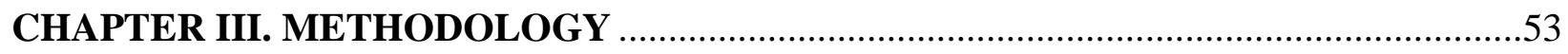

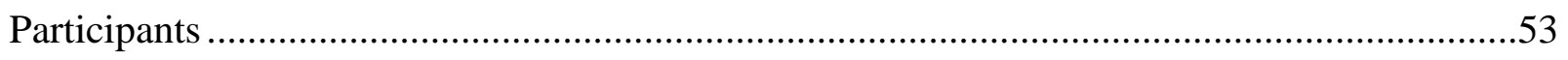

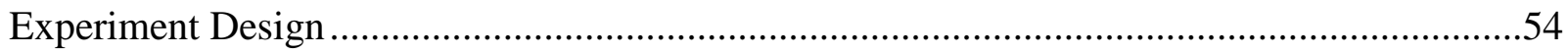

1. Leader Emotional Intelligence Manipulation ......................................................55

2. Leader Group Prototypicality Manipulation .........................................................55

3. Type of Accounting Fraud Manipulation .................................................................56

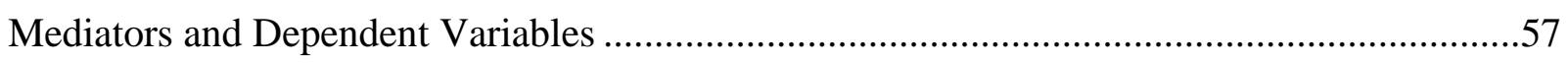

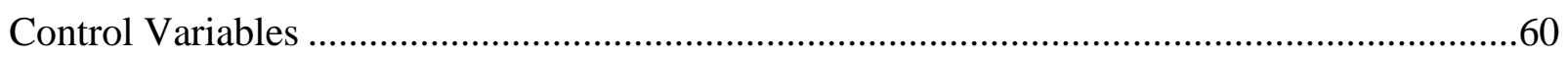

Post-Experiment Manipulation Check and Role Check ...................................................61

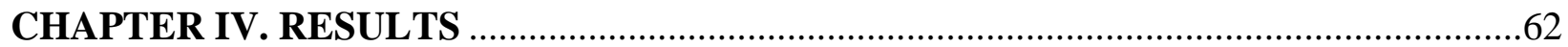

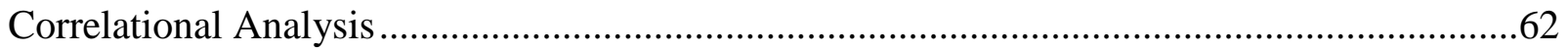

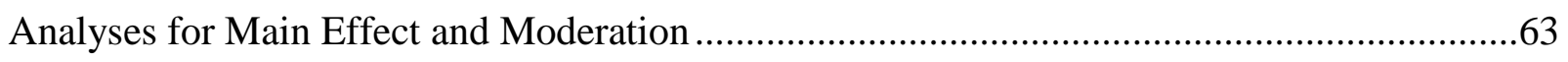

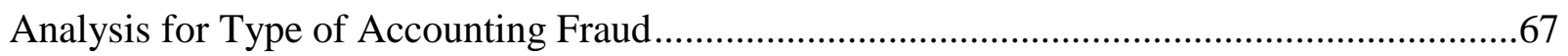

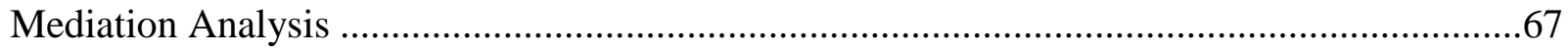

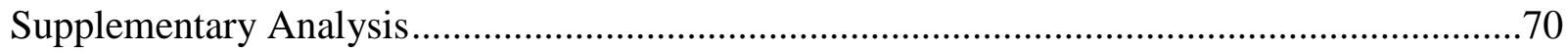

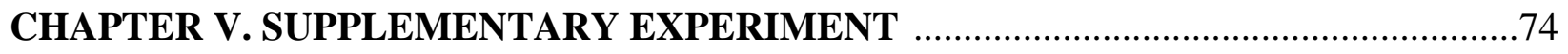

Literature Review and Hypothesis Development .........................................................74

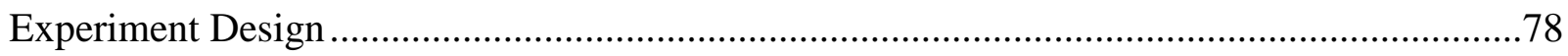

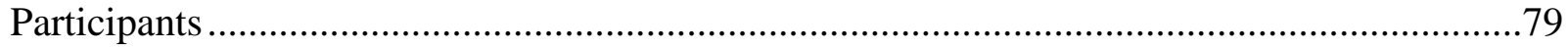

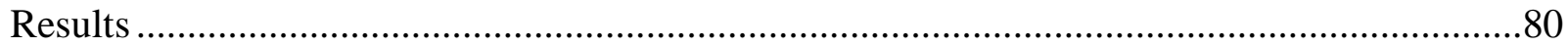

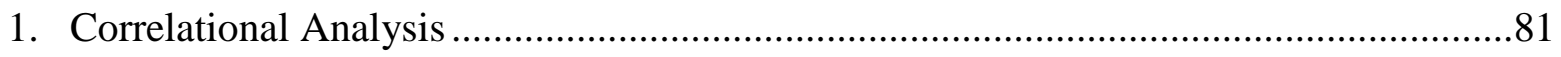

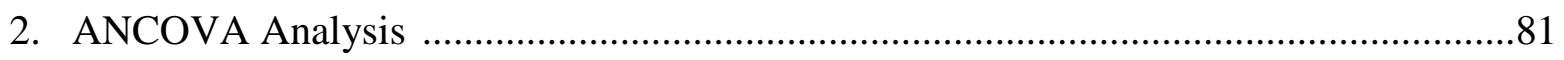

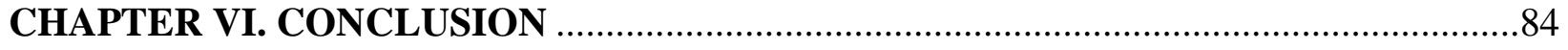


REFERENCES

APPENDIX I. LIST OF HYPOTHESES 155

APPENDIX II. EXPERIMENTAL INSTRUMENTS FOR PRIMARY EXPERIMENT .158

APPENDIX III. EXPERIMENTAL INSTRUMENTS FOR SUPPLEMENTARY

EXPERIMENT 


\section{LIST OF FIGURES}

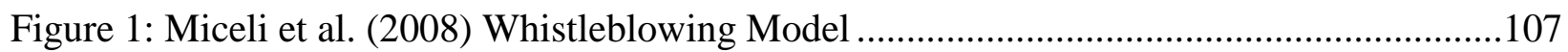

Figure 2: Partial Model for Primary Experiment - IV is Leader Emotional Intelligence ...........108

Figure 3: Partial Model for Primary Experiment - IV is Leader Group Prototypicality .............110

Figure 4: Complete Model for Primary Experiment .............................................................111

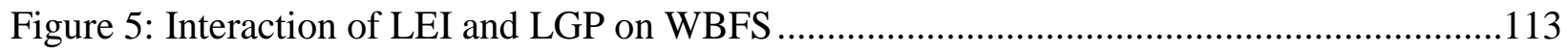

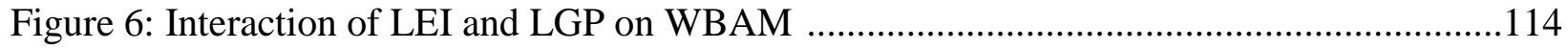

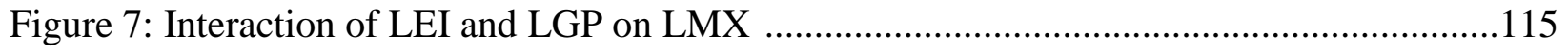

Figure 8: Interaction of LEI and LGP on Trust .........................................................116

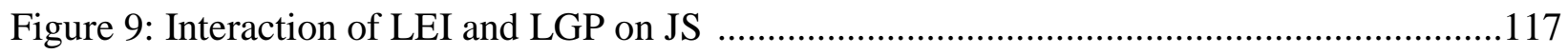

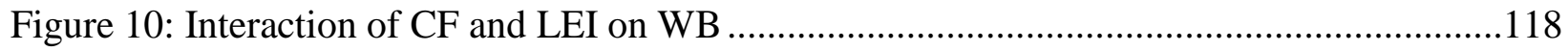

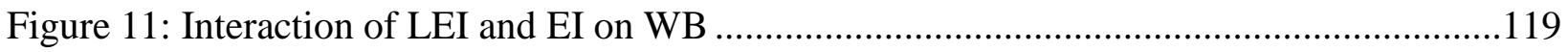




\section{LIST OF TABLES}

Table 1: Major Models of Whistleblowing in the Literature ..................................................120

Table 2: Recent Whistleblowing Studies in the Accounting Literature ..................................123

Table 3: Recent Affect-Related Studies in the Accounting Literature ....................................125

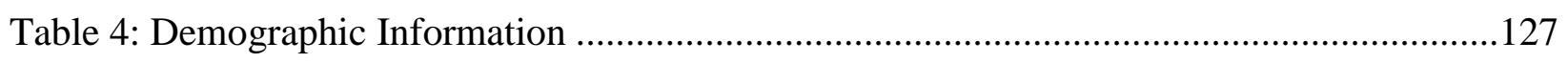

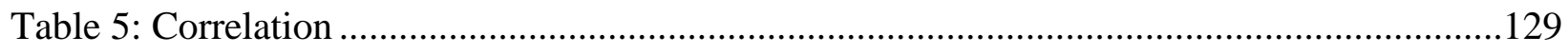

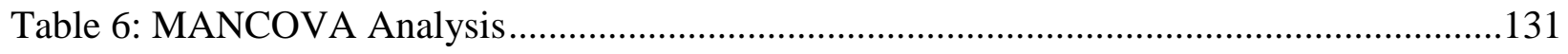

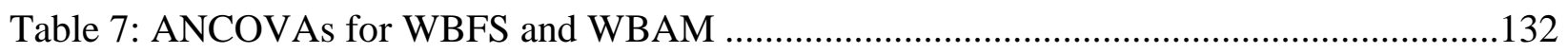

Table 8: ANCOVA for LMX as the Dependent Variable ....................................................135

Table 9: ANCOVA for TRUST as the Dependent Variable..................................................137

Table 10: ANCOVA for JS as the Dependent Variable ......................................................139

Table 11: Repeated Measures for Type of Accounting Fraud ................................................141

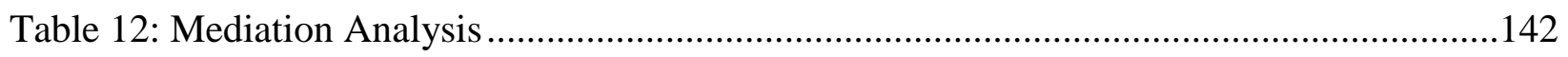

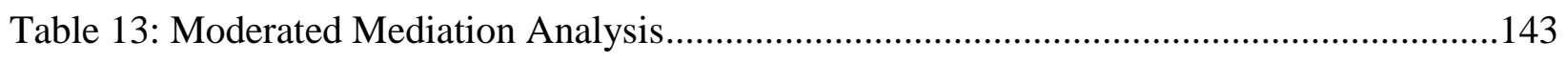

Table 14: Analysis for Participants' Assessments on Statements Related to Financial Statement Fraud and Asset Misappropriation Fraud .......................................................................145

Table 15: ANCOVA for Different Level of Participants' Emotional Intelligence ....................147

Table 16: Supplementary Experiment Demographic Information ..........................................150

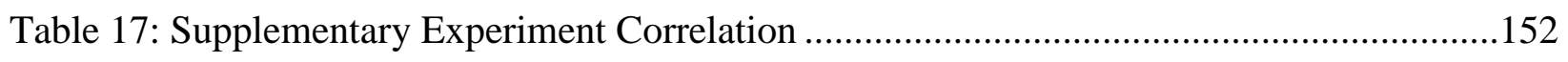

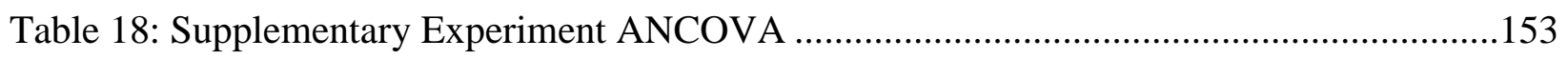




\section{CHAPTER I. INTRODUCTION}

Fraud imposes significant risks on all types of organizations, and many of those cases catch the public's attention in a negative way (e.g., Enron and Worldcom). Occupational fraud, which is the fraud committed by employees in their job, is very prevalent and costly (ACFE 2016). For example, according to the 2016 Association of Certified Fraud Examiner (ACFE) Report to Nations on Occupational Fraud and Abuse, asset misappropriation fraud accounts for $83 \%$ of total occupational fraud cases while financial statement fraud causes the highest loss with a median amount of $\$ 975,000$. One way to effectively prevent and detect fraud is to encourage whistleblowing (e.g., Near and Miceli 1995; ACFE 2016). Although the incidence of whistleblowing is dramatically increasing (Vinten 1994; Ewing 1983), when and why organizational employees blow the whistle is still an underexplored topic to be studied both in organizational and accounting contexts (see Kaplan et al. 2012 and Miceli and Near 1988 for some research examples). I conduct two experiments (one primary experiment and one supplementary experiment) in this dissertation to examine the effect of a leader's emotional intelligence on the subordinate's intention to whistleblow. Results suggest that when the leader has high emotional intelligence, the subordinate is more likely to whistleblow to the leader if the leader is not involved in the fraud, while the subordinate is less likely to whistleblow on the leader if the leader has high emotional intelligence but is involved in the fraud.

A modern corporation has a hierarchical structure (Eisenberg 1976). This implies that almost all employees in the corporation should have at least one leader and form a leadersubordinate relationship. The subordinate usually works closely with his ${ }^{1}$ leader on a frequent basis, and the resultant close interaction and communication could suggest that a leader's

\footnotetext{
${ }^{1}$ Due to the lack of epicene pronouns and possessives, "he" and "his" also refer to "she" and "her" in order to avoid too much frequent usage of s/he and his/her, which could cause confusion.
} 
characteristics, such as emotional intelligence, may influence the subordinate's ethical behavior and decision making in an ethical dilemma that generally occurs when people are going through certain scenarios which are inconsistent with their ethical belief, but pursuing the ethical belief will likely cause negative consequences for them. Deciding whether to report an observed accounting fraud ("Whistleblowing") could be such a serious ethical dilemma for an accountant because the act of reporting may provoke both favorable and unfavorable outcomes (MesmerMagnus and Viswesvaran 2005).

While whistleblowers may negatively affect the organization's authority structure and operation (Weinstein 2013), they may also enable organization management to correct practices that could harm the organization's employees, investors, customers, and clients (Near and Miceli 1985). Dozier et al. (1985) explain that the reason why some people try to blow the whistle is not due to pure altruism. Rather, the primary reason is prosocial behavior, which involves both selfish (egoistical) and unselfish (altruistic) motives on the part of the actor. Inspired by this argument, prior studies have found several factors affecting whistleblowing, but more research is still necessary. Open questions regarding whistleblowing include the understanding of the antecedents and consequences of whistleblowing and whether whistleblowing is context-specific. A leader's emotional intelligence, the subordinate's perceived leader-member exchange, trust in the leader, job satisfaction, and leader group prototypicality could potentially influence whistleblowing and thus are the focus of the primary experiment in this dissertation.

\section{Emotional Intelligence}

A leader's emotional intelligence could be a potential antecedent to his subordinates' intention to whistleblow. Emotional intelligence is first defined by Salovey and Mayer (1990) 
and has four dimensions: the appraisal and expression of emotion, the use of emotion to enhance cognitive processes and decision making, knowledge about emotions, and management of emotions (also see Mayer et al. 2001; Mayer et al. 1999; Mayer and Salovey 1997a, 1997b; Salovey and Mayer 1990). With the acceptance of the construct and its measurement scales (e.g. Mayer et al. 2003; Brackett et al. 2003; Tapia 2001; Schutte et al. 1998), leadership researchers begin examining the relationship between emotional intelligence and effective leadership. George (2000) proposes that a leader's emotional intelligence plays an important and significant role in his effective leadership, and empirical studies and business books (e.g., Goleman 2013) have demonstrated that emotional intelligence is closely related to effective leadership and is a necessary skill for successful leaders (Goleman 2013; Melati Prati et al. 2003; Barling et al. 2000). A leader with effective leadership could affect the subordinate's behaviors and decisions, including ethical decisions (Fu 2014). Therefore, high emotional intelligence of a leader may increase the likelihood for the subordinates to whistleblow through perceived effective leadership.

Researchers have noticed that leaders and followers always work together and could mutually affect each other (Howell and Shamir 2005). A leader's primary job and goal is "to influence, motivate, and enable others to contribute toward the effectiveness and success of the organizations of which they are members" (House et al. 2004, p.15). However, leadership effectiveness is a very broad concept and it has several different definitions and criteria (see Yukl 2012 and Hogan et al. 1994). Although understanding the relationship between a leader's emotional intelligence and the general effective leadership is important and useful, it could be more meaningful to look at other specific concepts which are closely related to or proxy for 
leadership effectiveness even if effective leadership is the ultimate goal for all leadership management.

\section{Leader-Member Exchange}

One concept that is closely related to effective leadership and could proxy for it is leadermember exchange (LMX). Since leaders need to play a role in followers' cognition and behavior to achieve effective leadership, the relationship between leaders and followers is extremely vital. The LMX construct captures and conceptualizes this relationship. It is essentially the quality of the leader-follower dyadic linkage and is first introduced by Dansereau et al. (1975). The antecedents, moderators, and consequences of LMX have been widely examined (see Martin et al. 2010 for a review). One consequence of LMX is organizational citizenship behavior (OCB), of which whistleblowing could be a type. Several studies (e.g., Ordun et al. 2014; Yunus et al. 2011; Jordan et al. 2011) have established the relationship between emotional intelligence, LMX, and other constructs, but most of them employ a survey method and focus on only one of the four dimensions of emotional intelligence and its relationship with other variables of interest (such as organizational citizenship behavior). In this dissertation, the leader's emotional intelligence is operationalized as one integrated construct to examine the hypothesized emotional intelligence-LMX-whistleblowing relationship.

\section{Trust}

In addition to LMX as a potential mediator, trust is potentially another mediator between a leader's emotional intelligence and his subordinate's whistleblowing intention. Trust is considered very important in an organizational setting (Jones and George 1998; Mayer et al. 1995). Based on McAllister (1995)'s study, trust has both affect and cognition bases. Emotional 
bonding between subordinates and their leader (affect base) and subordinates' perception of the leaders' reliability and dependability (cognition base) could result from the leader's emotional intelligence, and thus a leader's emotional intelligence may be associated with subordinates' trust in their leader. When a subordinate possesses trust in the leadership, the subordinate may be more willing to whistleblow because of the belief that the leader can be trusted to protect the subordinate from retaliation and take appropriate action against the reported unethical behavior (Memsmer-Meganus and Viswesvaran 2005; Near and Miceli 1986).

\section{Job Satisfaction}

A third potential mediator is a subordinate's job satisfaction. A number of studies have illustrated that a leaders' characteristics and behaviors could significantly influence subordinates' job satisfaction, which in turn could influence subordinates' judgments and behaviors, such as whistleblowing (e.g., Rotondi 1975; Mehrabian and Epstein 1972). When a leader has high emotional intelligence, the subordinates could identify themselves more with the organization, which may increase subordinates' job satisfaction. High job satisfaction might then induce subordinates to conduct organizational citizenship behavior, such as whistleblowing (Konovsky and Organ 1996; Organ 1990; Smith et al. 1983).

\section{Leader Group Prototypicality}

Since a leader's emotional intelligence could indicate his identity with the group and help his subordinates identify themselves with the group (Hogg 2001), any factor that explicitly changes the leader's representativeness of the group could modify the relationship between the leader's emotional intelligence and his subordinate's whistleblowing intention. Leader group prototypicality, which is the degree of how representative a leader is of his group, could be such 
a factor. When a leader has low group prototypciality, the effect of the leader's emotional intelligence may be seriously weakened while high group prototypicality will strengthen the effect. In other words, a leader's group prototypicality can moderate the relationship between his emotional intelligence and the subordinate's whistleblowing intention to the extent that the effect of the leader's emotional intelligence is stronger when he has high group prototypicality.

\section{Type of Accounting Fraud}

Professional standards and accounting literature (e.g., Kaplan et al. 2015) distinguish accounting fraud between financial statement fraud and asset misappropriation fraud. These two types of fraud are prevalent and significant in the accounting practice, and thus several studies have examined the effect of these two types of accounting fraud on the employee's intention to whistleblow when observing them. Results are mixed. Some studies (e.g., Robinson et al. 2012) find that employees are more likely to whistleblow when facing asset misappropriation fraud than financial statement fraud while others (e.g., Kaplan et al. 2015) find no difference between these two. In order to provide more evidence to the literature, this dissertation incorporates an exploratory examination on the relationship between the type of accounting fraud and the subordinate's intention to whistleblow.

\section{Primary Experiment}

An online vignette experiment is conducted on Qualtrics. 243 working professionals with basic understanding of accounting and business are recruited from Amazon Mechanical Turk, and 218 of them who pass role check questions are included in the analysis. The experiment includes four different vignettes which depict a leader with either high or low emotional intelligence and either high group prototypicality and low group prototypicality. Each vignette 
also contains two accounting fraud scenarios, one for financial statement fraud and one for asset misappropriation fraud. Participants' perceived LMX, trust in the leader, job satisfaction, own emotional intelligence, altruism, and demographic information are also measured.

Results from the primary experiment suggest that when the leader has high emotional intelligence, the subordinate is more likely to whislteblow to the leader in either case. This relationship is mediated by the subordinate's perceived LMX, trust in the leader, and job satisfaction, and it is stronger when the leader has high group prototypicality. However, supplementary analysis shows that the leader's emotional intelligence loses its effect when the participants have low emotional intelligence.

\section{Supplementary Experiment}

It is not uncommon for a subordinate to observe a fraud where his leader is directly involved. Such a case could complicate the whistleblowing decision due to the obvious power distance between the two parties (Taylor and Curtis 2013). On one hand, when a leader has high emotional intelligence, the subordinate could perceive him as having effective leadership and is thus less likely to whistleblow on him. On the other hand, if the consequence of whistleblowing is framed as being positive to the firm instead of being negative to the leader, the subordinate could be primed with the positive consequence. In other words, the positive consequence is emphasized subconsciously, and the subordinate could then be more likely to whistleblow on the leader.

In order to empirically examine the effect of leader emotional intelligence and consequence framing on the subordinate's intention to whistleblow if the leader is involved in the fraud, 193 working professionals are recruited from Amazon Mechanical Turk to participate 
in the experiment executed on Qualtrics, and 146 of them who pass role and manipulation check questions are included in the analysis. Overall, the supplementary experiment design is similar to that of the primary experiment, but the leader is now involved in the fraud. Results indicate that when the leader has high emotional intelligence, the subordinate is less likely to whistleblow on the leader. In addition, the effect of consequence framing on the subordinate's intention to whistleblow on the leader is stronger when the leader has high emotional intelligence.

\section{Contribution}

This dissertation makes several contributions to the accounting, emotional intelligence, leadership, trust, job satisfaction, framing effect, and whistleblowing literature. (1) It connects a leader's emotional intelligence to whistleblowing through subordinates' perceived LMX, trust in the leader, and job satisfaction. To the best knowledge of the author, this is the first research that does this connection in an accounting fraud context. (2) Emotional intelligence is not widely studied in the accounting literature yet. The only accounting area that tapped into this construct is accounting education (e.g., Bay and McKeage 2006; Ming Chia 2005; McPahil 2004). Hence, this dissertation could bring attention to this understudied construct and provide deeper insights on future accounting research. (3) Results about the effect of the type of accounting fraud on employees' intention to whistleblow are mixed. Thus, further research on this topic is necessary. This dissertation provides more evidence about this issue for the research community to consider, and a meta-analysis study could be a possibility in the future. (4) Prior literature often uses a leader's self-report emotional intelligence as the measurement of the construct, but subordinates' perception of their leader's emotional intelligence is rare. This dissertation explicitly examines the role of a leader's emotional intelligence from an interactive perspective by investigating a subordinate's perception of the leader's emotional intelligence and its effect 
on his perceived LMX, trust in the leader, job satisfaction, and intention to whistleblow. (5) Two experiments are conducted in this dissertation to control for other possible factors that may influence the results and to strengthen internal validity. There are few experimental studies in the leadership literature (Avolio et al. 2009), and thus several scholars call for more experiments in leadership-related research (Day et al. 2004; Day and O’Connor 2003). Miceli and Near (1984) advocate using experimental approach to complement other research approaches, such as survey and archival methods. (6) A leader's group prototypicality has been demonstrated to be a moderator in several leadership contexts (e.g., van Knippenberg and van Knippenberg 2005) but not in accounting fraud scenarios. This dissertation provides some evidence to bridge this gap. (7) Framing effect can influence numerous individual decisions and behaviors (Chong and Druckman 2007; Chang et al. 2002; Trotman and 1989). Results on its main and interactive effect with leader emotional intelligence could assist companies in formulating whistleblowing policies.

This dissertation is organized as follows: the second chapter summarizes relevant background literature and develops hypotheses; the third chapter describes the research method; the fourth chapter presents the results, the fifth chapter illustrates the supplementary experiment, and the sixth chapter concludes. ${ }^{2}$

\footnotetext{
${ }^{2}$ Chapter II, III, and IV are exclusively pertinent to the primary experiment while Chapter V only focuses on aspects of the supplementary experiment.
} 


\section{CHAPTER II. LITERATURE REVIEW AND HYPOTHESIS DEVELOPMENT}

\section{Whistleblowing}

Whistleblowing is defined as "the disclosure by organization members (former or current) of illegal, immoral, or illegitimate practices under the control of their employers, to persons or organizations that may be able to effect action" (Near and Miceli 1985, p. 4), which implies that whistleblowing deals with ethical dilemmas. An ethical dilemma generally occurs when people are going through certain events that are against their ethical belief, but simply following the ethical belief will provoke negative consequences on them. Whether to report an accounting fraud could pose a serious ethical dilemma for a regular accountant because merely reporting may cause ferocious retaliation and even collapse of the company. Weinstein (2013) suggests that while whistleblowers may have a negative influence on the organization's authority structure and operation, they may also enable organization management to correct practices that could harm organization's employees, investors, customers, and clients (Near and Miceli 1985). Dozier et al. (1985) explains that the reason why some people try to blow the whistle is not because of pure altruism, which is defined as "a desire within one organism to increase the welfare of another as an end-state goal" (Batson 1983, p. 1981). The primary reason is prosocial behavior, which involves both selfish (egoistical) and unselfish (altruistic) motives on the part of the actor. Utilizing this as a starting point, and in order to theorize whistleblowing in organization from much piecemeal evidence, Miceli et al. (2008) establish a prosocial organizational behavior model (see Miceli et al. 2008 for a complete illustration).

\section{Management Whistleblowing Models}




\section{Miceli et al. (2008) Model}

In their model, they propose that whistleblowing is actually a three-phase process for which this research has an interest in Phase 3. In Phase 1, employees decide whether the focal activity is wrongful. If the answer is "No", the process ends and there is no need to report. If the answer is "Yes", employees decide whether anyone has a responsibility to stop it. This influences whether the perceived wrongdoing has been reported or corrected, or not. In Phase 2, employees ask themselves in this phase whether the organization is signaling unresponsiveness and whether wrongdoing is demoralizing. Whistleblowers generally perceive less organizational support and lower channel justice than non-observers and inactive observers (Miceli et al. 2012). Moreover, having observed organizational wrongdoing negatively impacts how employees view their organization although this negative view could be mitigated if the wrongdoing has been reported or corrected (Miceli et al. 2008). If the negative view or previous experience makes the employees believe the organization will be unresponsive or the wrongdoing is demoralizing, they may decide to remain silent.

In Phase 3, employees will first ask two key questions whether it is their responsibility to act on it and whether there is an action available to them that they believe will likely stop the wrongdoing. If the answer is "No" to either question, there will be no whistleblowing and process ends. If the answer is "Yes" to both questions, then employees make the financial decision on what the expected costs and benefits of that action versus alternative actions (including doing nothing). If expected net benefits are the greatest for whistleblowing relative to other actions, there will be whistleblowing. This current dissertation is related to Phase 3, which 
deals with intentions and actions after focal activity is perceived wrongful and no corrective action is observed. ${ }^{3}$ Figure 1 depicts the Miceli et al. (2008) model.

[Figure 1]

\section{Gundlach et al. (2003) Model}

While Miceli et al. (2008)'s prosocial organizational behavior model is one of the most widely accepted models in the whistleblowing literature, there are several other models in the management and accounting literature that share similarities, but apply a new perspective or context. In the management literature, Gundlach et al. (2003) integrate power, justice, and prosocial literature on whistleblowing with research findings from attributions, emotions, and impression management, and then propose a social information processing whistleblowing framework to fill in the gap. Gundlach et al. (2003) note that there is a lack of theoretical models demonstrating "how individuals process information to arrive at causal explanations and judgments of responsibility for perceived wrongdoing that lead to decisions to blow the whistle" (p.107). Gundlach et al. (2003)'s model includes three sections. The first section deals with intrapersonal factors that include attribution, judgment of responsibility, emotions, and costbenefit analysis. In this section, the model proposes that to the extent potential whistleblowers attribute acts of perceived wrongdoing to internal, stable, controllable, and intentional causes, the employees will experience anger and resentment toward the perceived wrongdoer and hold wrongdoers responsible, after which they will then decide to blow the whistle. Meanwhile, the

\footnotetext{
${ }^{3}$ The current dissertation concentrate only on Phase 3 so that confounding factors from Phase 1 and Phase 2 should not be a concern and factors (i.e., a leader's emotional intelligence and leader group prototypicality) that may affect whistleblowing decision making in Phase 3 can be readily examined. This does not mean that these factors could not affect Phase 1 and Phase 2 decision making. In fact, testing the effects of these factors in Phase 1 and Phase 2 will definitely make contributions to the literature.
} 
potential whistleblowers need to conduct cost-benefit analysis. If being convinced that the costs of whistleblowing outweigh the benefits, the employees will decide not to blow the whistle.

The second section deals with interpersonal factors that include defensive impression management and offensive impression management. Whistleblowers and wrongdoers are social actors and whistleblowing is a social influence process in which social actors are motivated to change each other's perceptions and behaviors (Gundlach et al. 2003). Wrongdoers may use impression management in an attempt to change whistleblowers' opinion that blowing the whistle is the best available action. Defensive impression management is related to mitigating circumstances to repair perceptions of wrongdoing by lessening the intensity of affective responses that can entice reactions to wrongdoing (Gundlach et al. 2003; Bies and Shapiro 1987; Folger et al. 1983). The model proposes that through defensive impression management, wrongdoers' excuses, justifications, and apologies increase the probability that potential whistleblowers will make unpredictable and unstable attributions for wrongdoing behavior. Offensive impression management is a tactic that attempts to change a potential whistleblower's action by threats, intimidation, or actual retaliation. Since offensive impression management can alter whistleblowers' perception of costs and benefits associated with whistleblowing and their emotional reactions to these perceptions (Gundlach et al. 2003), the relationship between offensive impression management and whistleblowing decisions is partially mediated by both factors.

Section 3 in the model proposes two moderators that could influence the impression management and whistleblowing decision: credibility of presentation and power of wrongdoers and whistleblowers. Credibility of defensive impression management tactics might be more important than which tactic is actually chosen (Gundlach et al. 2003; Bies and Shapiro 1987; 
Folger et al. 1983). When credibility is high, wrongdoers' excuses, justifications, and apologies could significantly reduce whistleblowers' perception of responsibility and mollify emotions of anger and resentment from whistleblowers towards wrongdoers. If, though, the wrongdoer has more power than the whistleblower, the cost to blow the whistle may be very high because it is much easier for the powerful wrongdoer to retaliate against the whistleblower and the consequences for the whistleblower may be harsher. Thus, the probability that wrongdoer's offensive impression management causes cost-benefit analyses that induce fear will be stronger to the extent potential whistleblowers believe wrongdoers are more powerful.

Overall, Gundlach et al. (2003)'s model shares many common aspects with Miceli et al. (2008)'s model. For example, both models assume or start with the awareness of wrongdoing and consider cost-benefit analysis as a vital step right before the whistleblowing action. However, Gundlach et al. (2003)'s model focuses more on the cognitive and information processing/attribution part of the whistleblowing decision process and takes possible effects of emotions into account.

\section{Keenan and McLain (1992) Model}

Another whistleblowing model in the management literature that attracted much attention is Keenan and McLain (1992)'s interactionist model. This model indicates that whistleblowing is a process of interaction of an observer's characteristics, opportunities to observe misbehaviors, and perceived options for reducing the anxiety experienced by the observer. This model has seven stages and three possible moderating influences. The first stage involves wrongdoing awareness. Observers should judge whether the observed event is a wrongdoing. The second stage involves the assessment of the seriousness of the wrongdoing. Observers may refer to prior 
understandings with respect to formal policies, ethical codes, and even personal beliefs to determine the seriousness. The third stage involves the motivation to correct the wrongdoing. Motivations include a moral need to stop wrongdoing or the desire to reduce cognitive dissonance.

The fourth stage involves an assessment of personal influence over the situation. Possession of formal power could impact this assessment. If the observer does not possess sufficient power or is unwilling to take the risk of negative consequence, he may, in the fifth stage, search for others who are able to correct or stop the wrongdoing. Possible other report recipients include the wrongdoer's or the observer's immediate supervisor, coworkers, ombudsmen, or other parties that the observer has confidence in. The sixth stage involves an assessment of the consequences for self, others, and the wrongful behavior. There could be significantly negative costs associated with whistleblowing such as the wrongdoer's retaliation against the whistleblower or the whistleblower's loss of his current job. Modest benefits could also be available (Keenan and McLain 1992), but which weighs more is a complex personal decision. $^{4}$

The seventh stage presents four options that the observer can finally choose to settle his concern: suppression (silence), procedural reporting through prescribed channels, non-procedural reporting, or correcting the wrongdoing through direct intervention. Non-procedural reporting and procedural reporting are considered whistleblowing in this model. Further, an observer's

\footnotetext{
${ }^{4}$ Potential benefits could include monetary rewards and psychological satisfaction. Employees with different personal, cultural, and contextual factors could weigh the same cost or benefit extremely different, or even sometimes have opposite classification for the same action in terms of cost and benefit (Miceli et al. 2008). Whether an action can result in higher cost or benefit is a function of the three factors above, and thus there is no universal rule for every employee and action.
} 
reaction to the experienced consequence could later change his assessment of the wrongful behavior in the form of a feedback loop.

Individual differences, situational factors, and symbolic interpretative influences could moderate each stage in the model (Keenan and McLain 1992). Many studies have found that a whistleblower's attitudes and personalities (individual difference) (e.g., Miceli and Near 1988), and communication climate (situational factors) (Keenan 1988) are related to whistleblowing intentions and actions. Cultural-interpretive organizational theories (Ott 1989; Morgan 1986; Schein 1985) and processes of symbolic interaction (Blumber 1986) both suggest that individuals seek to make sense of situations around them before making decisions and thus prefer referring to prior personal experiences, moral beliefs, work group norms, local culture, and interpretations of how coworkers and other groups may view the situation (Keenan and McLain 1992). This leads to the conclusion that symbolic interpretation could affect whistleblowing process. As with Miceli et al. (2008)'s model, Keenan and McLain (1992)'s interactionist model includes awareness of wrongdoing, assessment of wrongdoing, determining personal influence, and costbenefit analysis. However, the interactionist model concentrates more on how different kinds of factors work together to influence the whistleblowing process, which is not strongly emphasized in Miceli et al. (2008)'s model.

\section{Accounting Whistleblowing Models}

\section{Loeb and Cory (1989) Model}

In addition to management literature, accounting literature also establishes several whistleblowing models related to accounting contexts. Loeb and Cory (1989) draw upon the work of De George (1981) and propose a three-step model that is applicable to management 
accountants. In step 1, management accountants who observe the potential wrongdoing should consult with an independent objective outside observer (e.g., independent CPA or attorney) to determine whether the matter under consideration is or potentially is material and whether it could result in harmful consequences. If the answer for either questions above is "NO", the process will end. If the answers for both questions are "YES", the management accountants will feel that they have the moral responsibility to report these concerns to appropriate individuals in the organization, or in other words, to internally whistleblow.

In step 2, management accountants consider the formal appeal procedures that are already established in the organization. If such procedures cannot resolve the concerns or do not exist, the management accountant should contact his immediate supervisor or other possibly responsible positions in the organization if the immediate supervisor is unresponsive or not a proper recipient to report to because the supervisor may be involved in the wrongdoing. If the appeal is successful, the process will end. If it fails to satisfy the management accountant, then in step 3, he may then consult with independent outside observers and determine whether harmful consequences can be prevented or stopped if the wrongdoing is made public, or externally whistleblown. If the answer is "YES", the management accountant will report the wrongdoing to the public while he may just remain silent if the answer is "NO".

As Loeb and Cory (1989) state, their three-step model is in accordance with the view which, as described by Miceli et al. (2008), considers whistleblowing as a process not as an event. However, their model distinguishes between internal whistleblowing and external whistleblowing and notes that internal whistleblowing should occur before external whistleblowing. Miceli et al. (2008) do not make this differentiation. Although Loeb and Cory 
(1989) limit their model to management accountants, it may also be applicable to other professionals, such as auditors.

\section{Schultz et al. (1993) Model}

Another accounting-related whistleblowing model is Schultz et al. (1993)'s reporting questionable acts model, which is adapted from Graham (1986). In this model, after the observer encounters the wrongdoing, he needs to consider three factors before making the reporting choice: the perceived seriousness of the irregularity, the attribution of personal responsibility for reporting, and the perceived personal cost of reporting (Schultz et al. 1993). The more serious the irregularity is, the more personal responsibility is attributed to the observer himself, and the less the personal cost of reporting is, the more possible for the observer to whistleblow. As with Miceli et al. (2008)'s model, Schultz et al. (1993)'s model also takes personal responsibility and cost-benefit analysis into account. However, their model considers neither the response from the organization nor the personal ability to stop the wrongdoing. Several studies have examined the validity of this model (e.g., Schultz et al. 1993; Curtis et al. 2012), and the results are robust. ${ }^{5}$ Table 1 summarizes the major models on whistleblowing in the literature.

\section{[Table 1]}

\footnotetext{
${ }^{5}$ Although Miceli et al. (2008)'s model and their works are well cited, each model has its own advantages. Which one to choose for a specific whistleblowing-related research depends on the focus of the study. If the study concentrates more on the entire process, Miceli et al. (2008)'s model may be a good reference since it explicitly point out that whistleblowing is a process, not an event. On the other hand, if the focal point of the study is the effect of interaction of several factors on whistleblowing, Keenan and McLain (1992)'s interactionist model may be a better choice. However, there are many similarities among these models. Therefore, which model to choose sometimes could just be a personal preference. Since this dissertation is only trying to find out factors that could affect whistleblowing decision making, all models could apply to some extent. It can be argued that Miceli et al. (2008)'s model could apply because the factors could affect Phase 3 whistleblowing decision making. Or Gundlach et al. (2003)'s model could apply as well because these factors are actually interpersonal (contextual) factors, which are a part of their model.
} 


\section{Whistleblowing Empirical Literature}

The incidence of whistleblowing is dramatically increasing (Vinten 1994; Ewing 1983), and the accounting community has focused a lot on whistleblowing research in accounting contexts since Sarbanes-Oxley Act, which requires all publicly traded firms to establish auditing committees and anonymous whistleblowing channels for employees to report questionable accounting matters, was passed. For example, Kaplan et al. (2009) demonstrate that respondents' intention to report a fraudulent act is greater under the weaker safeguards condition as compared with the stronger safeguards condition. Moreover, an externally administered anonymous hotline may not increase fraud reporting. Taylor and Curtis (2013) use 106 senior-level auditors as participants and find that auditors are more likely to report on their peers than on their superiors, but they are more likely to report on superiors when prior organizational response is strong than when it is weak. Applying justice theory to accounting whistleblowing contexts, Seifert et al. (2010) show that the three components of organizational justice (procedural fairness, distributive fairness, and interactive fairness) are positively related to employees' intention to whistleblow. Their study results have higher external validity because the sample is large and broad (447 internal auditors and management accountants).

In Bowen et al. (2010)'s archival study, whistleblowing data is collected from two sources, the Press and OSHA. This study illustrates that whistleblowing target firms do share some common characteristics in terms of growth, communication channel, size, and whistleblowers' ability to share the proceeds of any fraud-related settlement with the U.S. government. More specifically, they find that those target firms are large and successful firms with high growth. After the whistleblowing, those firms experience negative consequences such as stock price decrease and financial statements restatement. However, the future corporate 
governance gets improved. Although whistleblowing has caught much attention in the accounting literature, many mysteries still remain. For example, Near et al. (1993) note that whistleblowing laws that protect whistleblowers from retaliation do not increase the incidence of whistleblowing, which counter many people's intuition and the original intention of those laws. Drawing on power theory and justice theory, they propose that legalistic organizational response, which is defined as "mechanisms that are institutionalized, mimic legal forms, and exceed legal regulatory requirements" (Sitkin and Roth 1993, p. 367), could be an effective antecedent to whistleblowing instead (Near et al. 1993). Therefore, due to the existing unknowns and counterintuitive results (Near and Miceli 1996), Hogan et al. (2008) and Trompeter et al. (2013; 2014) call for further research on whistleblowing systems. Table 2 presents several recent whistleblowing empirical studies in the accounting literature.

\section{[Table 2]}

\section{Scope of Study}

Following prior research and due to the impossibilities of observing the actual whistleblowing action in the workplace (Victor et al. 1993), a vignette primary experiment is conducted and a subordinate's intention to whistleblow on accounting frauds to his leader is the primary dependent variable of interest. The actual reporting behavior may be different from the intention to report since there could be many factors that affect, mediate, or moderate the process in between (such as fear of retaliation) (Azjen 1991). Therefore, it is not the focus of the current study. ${ }^{6}$

\footnotetext{
${ }^{6}$ Observing actual behavior in the field and laboratory is extremely hard. Thus, most of the whistleblowing studies in the literature focus on the participants' intention to whistleblow. In this dissertation, this is the practice employed.
} 
In addition to only capturing the intention, the recipient of the subordinate's

whistleblowing is limited to his leader for three reasons. First, Miceli et al. (2008, p. 387) present that 80 percent of respondents of a survey conducted by KPMG would report observed wrongdoing to their supervisor or another manager if they decide to report (Kaplan et al. 2015). Moreover, Near and Miceli (1995) argue that whistleblowing will be more effective if the recipient of the whistleblowing is non-anonymous, such as a manager, rather than an anonymous internal hotline (Kaplan et al. 2015). Several recent empirical whistleblowing studies in the accounting literature have used the immediate supervisor or leader as the report recipient (e.g., Kaplan et al. 2015). Second, some whistleblowing models (e.g., Loeb and Cory 1989) propose that it is rational for a wrongdoing observer to report it to his immediate supervisor before reporting to other internal and external recipients. Since ecologically a subordinate works closely with his supervisor or leader on a daily basis, it is probable that the subordinate automatically thinks of his leader as the first potential whistleblowing recipient. Third, this dissertation looks at the effect of a leader's emotional intelligence on his subordinate's whistleblowing intention, so it is reasonable and natural to assign to the leader the recipient role.

\section{Emotional Intelligence of a Leader, Effective Leadership, and Leader-Member Exchange}

The relationship among a leaders' emotional intelligence, effective leadership, transformational leadership, LMX, and subordinates' performance has been widely discussed (see Mayer et al. 2008 for a review). Researchers have accepted that emotional intelligence of a leader may have an impact on many different outcomes. However, many open questions still remain on both emotional intelligence and its relationship with leadership. In this section, the primary focus is on a leader's emotional intelligence and its effect on LMX and subordinates' intention to whistleblow. Prior to discussing emotional intelligence, though, it is necessary to 
begin with the basic concepts of feeling, emotions, and moods. They help discover the complex relationship between a leader's emotional intelligence and leadership (George 2000).

\section{Feelings, Emotions, and Moods}

Emotional intelligence, as the name implies, is closely related to emotions, moods, and overall feelings in human being. ${ }^{7}$ When talking about feelings, we need to be clear that feelings include both moods and emotions, and these two concepts are different from each other in terms of intensity. Moods are feelings with low intensity that do not disturb ongoing activities (George 2000; Forgas 1992), while emotions are feelings with high intensity “that are triggered by specific stimuli (either internal or external to the individual), demand attention, and interrupt cognitive processes and behaviors" (George 2000, p. 1029; Forgas 1992; Morris 1989; Simon 1982). Feelings have been demonstrated to impact the human judgments, recalling from the memory, attributions, creativity, and reasoning (George 2000). It has also been shown that moods and emotions play a significant role in the thought processes and behaviors (e.g., George 2000; Leventhal et al. 1986; Bower et al. 1982; Bower 1981; Rosenhan et al. 1981). For example, positive moods can strengthen flexibility on categorization tasks and facilitate creativity and inductive reasoning (George 2000; Isen et al. 1987, 1985) while negative moods may foster deductive reasoning and more critical and detailed evaluations (George 2000; Salovey et al. 1993; Sinclair and Mark 1992).

In organizational behavior literature, Jones and George (1998) find that leaders who experience anger frequently may have a difficult time building good relationship with follower

\footnotetext{
${ }^{7}$ Detailed discussions about emotional intelligence and its role is in the next section. The purpose of this current section is to familiarize the readers with emotions, mood, feelings, which are the target of emotional intelligence. George (2000) insists that understanding the basic concept of emotion is necessary to understand the role of emotional intelligence.
} 
and impairing their trust. Moreover, George and Bettenhausen (1990) find that the degree to which leaders of existing teams experienced positive moods is positively related to levels of prosocial behavior performed by team members and negatively related to team turnover rates.

In the accounting literature, there is a growing body of studies suggesting that an auditor's general mood can affect his performance (Bhattacharjee and Moreno 2013). Bagley (2010) examines whether accountability to multiple parties, a pervasive aspect of the audit environment, will make auditors experience anxiety, and how this anxiety will influence audit performance. She concludes that multiple accountabilities can cause negative emotions and that the resulting negative reactions can harm low-complexity audit task performance. Chung et al. (2008) investigate the effect of different moods on professional auditors' judgment on inventory valuation and find that more disagreements are likely to occur with auditors in a positive mood than in a negative mood, suggesting that mood impacts information use. Cianci and Bierstaker (2009) demonstrate that auditors in the negative mood condition generate more correct explanations for fluctuations in the gross margin and inventory turnover ratio and make less ethical judgments on the ethical tasks executed in the experiment. Recently, Bhattacharjee et al. (2012) manipulate client competence (low and high) and auditors' affect (positive, neutral, and positive) among 174 auditors to examine their effects on auditors' inventory obsolescence judgment and evidence documentation. The results illustrate that auditors with negative affect toward a low competence client rate higher inventory obsolescence and document more items indicative of increased obsolescence while auditors with positive affect toward a low competence client rate similar inventory obsolescence and document more items of decreased obsolescence. However, under high client competence, affect does not have an effect on both inventory obsolescence judgments and documentations. 
Not only auditors' assessment on the clients' assertions but also their ethical decision making could be influenced by affect. Johnson et al. (2016) break down mood into arousal (positive mood), fear (negative mood), and insignificance (negative mood). They recruit 118 senior auditors and find that participants with high arousal, low fear, and low insignificance are more likely not to acquiesce to obedience pressure from their managers in six ethical dilemmas.

In addition to their effect on auditors, emotions and moods also play a role on managerial accounting decision making. Kida et al. (2001) conduct four experiments and demonstrate that managers consider both financial data and affective reactions when making capital budgeting decisions. More specifically, managers are more likely to reject decision alternatives that elicit negative emotion even if these alternatives have higher expected value in terms of finance. Because of the interesting results, they advocate that future research should consider both cognition and affect to fully understand decision making in accounting contexts. In another study, Moreno et al. (2002) find that when affect is induced, capital budgeting decision makers tend to reject investment alternatives that elicit negative affect and accept alternatives that elicit positive affect, which resulting in risk taking (avoiding) in gain (loss) contest, a finding which is in contradiction with Prospect Theory. ${ }^{8}$ These findings indicate a wider body of literature, which, though in diverse disciplines, such as accounting, psychology, and organizational behavior, points to a consistent conclusion: "feelings are intimately connected to the human experience" (George 2000, p. 1030). Table 3 presents major affect-related empirical studies in the accounting literature.

[Table 3]

\footnotetext{
${ }^{8}$ Prospect Theory, introduced by Kahneman and Tversky (1979), proposes that for the same amount of gain and loss, people make a less risky decision in a gain situation while making a more risky decision in a loss situation.
} 


\section{Emotional Intelligence}

The term "emotional" in emotional intelligence is used broadly to refer to moods as well as emotions. Rooted in social intelligence (Sternberg and Smith 1985; Ford and Tisak 1983; Walker and Foley 1973), emotional intelligence is "the ability to perceive emotions, to access and generate emotions so as to assist thought, to understand emotions and emotional knowledge, and to reflectively regulate emotions so as to promote emotional and intellectual growth" (Mayer and Salovey 1997b, p. 5). It essentially describes the ability to effectively synchronize emotions and reasoning, or more specifically, the ability to use emotions to facilitate reasoning and reason intelligently about emotions (Mayer and Salovey 1997b; George 2000). In other words, emotional intelligence deals with "the extent to which people's cognitive capabilities are informed by emotions and extent to which emotions are cognitively managed" (George 2000, pp. 1033-1034).

Emotional intelligence has four positively correlated dimensions: "the appraisal and expression of emotion, the use of emotion to enhance cognitive processes and decision making, knowledge about emotions, and management of emotions" (George 2000, p. 1034). Appraisal and expression of emotion involve both the self and other people. Accurately appraising emotion can help people form opinions and judgments, and accurate expression of emotion can help people "effectively communicate with others to meet their needs and accomplish their goals or objectives" (George 2000, p. 1034). Related to the appraisal and expression of emotion in others is the concept of empathy, which is the ability to understand and experience another person's feelings or emotions (George 2000; Mehrabian and Epstein 1972). It is a contributor to emotional intelligence and is a necessary skill to effectively interact with other people in the society (George 2000; Batson 1987; Kessler et al. 1985). 
Emotional intelligence also involves using emotions in functional ways. Emotions can assist in directing attention to alleviating concerns (George and Brief 1996; Frijda 1988), in facilitating cognitive processes (George 2000; Mayer 1986), and in searching for options and making decisions (Damasio 1994). Moreover, changes in emotions can improve planning, alternatives generation, and problem-solving skills (George 2000; Mayer 1986). Emotional knowledge deals with understanding both the antecedents and consequences of moods and emotions, and how they evolve and change over time (George 2000). Some people have a basic understanding about how they (and other people) are influenced by feelings and utilize this knowledge in functional ways while others do not have an insight into the effects and consequences of their feelings. Research studies have also demonstrated that people try to maintain positive moods and suppress negative moods (Morris and Reilly 1987; Clark and Isen 1982; Isen and Levin 1972) while their abilities differ due to disparity of emotional intelligence (Salovey et al. 1995).

\section{Emotional Intelligence, Effective Leadership, and Leader-Member Exchange}

Inspired by previous leadership and emotional intelligence research, George (2000) combines the core ideas of all and proposes a relationship between emotional intelligence and effective leadership. In order to understand this relationship, he notes five factors of effectively leadership, which, citing George (2000)'s own words (p. 1039), are:

- Development of a collective sense of goals and objectives and how to go about achieving them;

- Instilling in others knowledge and appreciation of the importance of work activities and behaviors; 
- Generating and maintaining excitement, enthusiasm, confidence, and optimism in an organization as well as cooperation and trust;

- Encouraging flexibility in decision making and change;

- Establishing and maintaining a meaningful identify for an organization.

Emotional intelligence of a leader contributes to developing an overarching vision for his groups or organizations. A leader needs to face a large amount of information which is full of uncertainty and ambiguity, and thus he is likely to take substantive processing action to determine the correct direction for their groups or organizations. Affect infusion model (Forgas 1995) suggests that current affective states can influence judgments and decisions during substantive processing through the mechanism of affect priming. High emotional intelligence can aid leaders in finding the best affective state under a specific situation. With respect to inoculation of knowledge and appreciation of the importance of work, George (2000) argues that "leaders need to ensure that followers are aware of problems and major issues facing an organization as well as potential opportunities while at the same time raising their confidence in their abilities to successfully overcome problems, meet challenges, and seize opportunities" (p. 1041). Leaders with high emotional intelligence may achieve this goal by effective emotional expression and regulation so that subordinates are aware of the serious nature of a problem and are enthusiastic about resolving the problem (George 2000).

Gerstner and Day (1997) and Graen and Uhl-Bien (1995) find that high quality interpersonal relationships between leaders and their followers can enormously benefit the organizations, leaders, and followers. Leaders with high emotional intelligence can use their ability to develop high interpersonal relationships with their followers to infuse in the organizations "a sense of enthusiasm, excitement, and optimism as well as an atmosphere of 
cooperation and trust" (George 2000, p. 1042). When leaders know and manage their emotions effectively, they are able to improve decision-making quality by directing their attention to pressing concerns (Mandler 1982; Easterbrook 1959), flexibly solving problems from incorporating alternatives, and avoiding rigidity effect (George 2000) because emotions provide leaders with information about drawbacks and opportunities (Schwarz 1990). Additionally, emotional intelligence may advance a leader's ability to successfully implement changes in an organization and acquire emotion-related skills (George 2000).

Leadership activities pertain to the development and expression of organizational culture (George 2000; Alvesson 1992; Trice and Beyer 1993), and organizational culture is embodied in shared beliefs, norms, and values (George 2000; Trice and Beyer 1993). Because values are emotion-laden and can evoke and appeal to emotions (George 2000), Trice and Beyer (1993) suggest that cultures are brimmed with emotions, and the allegiance to and identification with cultures result from people's emotional needs rather than from a more "rational" or instrumental perspective. Thus, management of organizational culture is, to some extent, management of emotions (George 2000; Van Maanen and Kunda 1989). Not only George (2000) but also other research studies (e.g. Wong and Law 2002; Palmer et al. 2001; Sosik and Megerian 1999) have found that emotional intelligence is positively related to effective leadership.

Although the relationship between leader emotional intelligence and effective leadership has been well established, effective leadership is a very broad concept and the definition of effective leadership is still under debate (Yukl 2012). Therefore, it may be more meaningful to investigate something that is specific and could proxy for effective leadership, such as leadermember exchange (LMX). 
LMX is first introduced by Dansereau et al. (1975) as a new perspective to conceptualize leadership, and it primarily deals with the quality of the relationship between leaders and followers. This theory makes a significant contribution to leadership literature because it proposes that leaders use different leadership styles to different followers while other prevailing approaches (behavioral and situational) to leadership assume leaders treat all his subordinates in the same way (Brower et al. 2000). A leader may have a good relationship with one follower but a very bad relationship with another one. This assumption of relationship heterogeneity distinguishes LMX from other traditional theories (trait and behavioral), which assume that leaders develop relatively homogeneous relationships with all other followers. A low LMX relationship is characterized by formal authority and mutually agreed-upon contract. Leader exercises contractual power for standard job performance and subordinates perform contractual duties for standard benefits (Graen and Uhl-Bien 1995). On the other hand, a high LMX relationship is suffused with mutual trust, respect, and obligation. Subordinates could receive special privileges in return for their exemplary performance which is highly appreciated by their leaders (Wang et al. 2005; Graen and Uhl-Bien 1995).

Theoretically and empirically, there is a strong linkage between a leader's emotional intelligence and LMX. Emotions of leaders have a relationship with followers' perception (Humphrey 2002), and if a leader's emotional intelligence is pertinent to his emotional control and management, it could then affect how followers perceive the relationship between the leader and themselves. LMX literature has already suggested that effective leadership could be achieved through the dyadic leader-follower relationship. Most of George (2000)'s arguments above focus on effective leadership through a leader-subordinate interaction, which is from a LMX perspective. Additionally, Howell and Hall-Merenda (1999) argue that a certain 
relationship between a leader and his subordinates should be assumed in leadership-related research, and it should also be further assumed that the nature and quality of this relationship is fundamental to linking a leader's behavior to followers' response (Wang et al. 2005). Uhl-Bien (2006) has tried to use relational leadership as a proxy for effective leadership. From a relational perspective, a good relationship between followers and leaders could motivate and enhance followers to achieve organizational and team goals through effective leadership.

Following on George (2000)'s argument that emotional intelligence of a leader is positively related to effective leadership, Melita Prati et al. (2003) propose that emotionally intelligent leaders benefit teams in two ways: motivating team members to work together toward team goals and serving as a transformational influence over team member. Both motivating team members and transformational influence could boost the perceived quality of a leadersubordinate relationship from a subordinate's perspective, and this relationship with high quality could be representative of effective leadership. Thus, it is reasonable to argue that LMX may be a manifestation of effective leadership.

Up to now, a tremendous number of studies have tried to find antecedents, consequences, and moderators for LMX, and many of them already successfully partitioned out these factors. Dulebohn et al. (2012) in their meta-analysis categorize LMX antecedents into three groups: follower characteristics such as competence, leader characteristics such as transformational leadership, and interpersonal relationships such as perceived similarity. The consequences of LMX include turnover intentions, actual turnover, organizational citizenship behavior (OCB), job performance, and so forth. Emotional intelligence is not included as an antecedent for LMX in this meta-analysis. However, several studies have attempted to establish a relationship between emotional intelligence and LMX. Ordun et al. (2014) find that regulations of emotions 
are important on the determination of both the loyalty and the contribution dimensions of the LMX. Deluga (1994) believes that individualized consideration and charisma are two factors that could predict LMX. A leader with high emotional intelligence is able to perceive, understand, and regulate his subordinate's emotions. This could generate effective and high-quality individualized consideration.

A leader with high emotional intelligence may also be perceived as charismatic by his subordinates. Jordan et al. (2010) demonstrate that the quality of LMX mediates the relationship between followers' emotional intelligence and both turnover intentions and job satisfaction, however, most of the studies that have already looked at emotional intelligence use a survey method and connect each dimension of emotional intelligence to each dimension of LMX (there is a debate whether LMX is a unidimensional factor or multidimensional factor; see Martin et al. 2010 for a review). This dissertation conducts a primary experiment and focuses on a leader's emotional intelligence and LMX as a whole respectively.

Theoretically, in LMX, the dyadic relationship will reach an equilibrium, which means both the leader and his subordinate should rate the quality of the relationship in a same degree, so a subordinate's perception of the relationship quality should capture the ultimate LMX quality between the leader and his subordinate, especially in the field. On the other hand, it makes more sense in this dissertation to examine the subordinate's perception of LMX because in order for LMX to play a role in the subordinate's whistleblowing decision making, it has to be perceived and processed by the subordinate. A person's perception of stimuli should be responsible for his decision making, not other people's perception. Therefore, I believe measuring the subordinate's perceived LMX in an experiment could be an appropriate representation of the construct and could enhance ecological validity. 
Because (1) emotional intelligence is closely related to leadership effectiveness that can be proxied by LMX, and (2) previous studies have found some evidence about the relationship between emotional intelligence and LMX, I have the following hypothesis:

H1: A subordinate perceives higher LMX when the leader has high emotional intelligence than low emotional intelligence.

As previously argued, effective leadership and high LMX can lead to many different consequences, such as subordinate effort on accounting work (Vance 2010), accounting reporting behavior (Jollineau et al. 2012), and OCB (Dulebohn et al. 2012). OCB is "individual behavior that is discretionary, not directly or explicitly recognized by the formal reward system, and that in the aggregate promotes the effective functioning of the organization" (Organ 1988, p. 4), and it could be classified into two subtypes: Organizational Citizenship BehaviorOrganization (OCBO) - behaviors that could benefit the organization as a whole (e.g., follow informal rules to maintain everything in order) and Organizational Citizenship Behavior Individual (OCBI) - behaviors that immediately benefit specific individuals (e.g., help other employees who cannot come to work even if it is not required by the organization to help the absent employee) (Williams and Anderson 1991; Smith et al. 1983). High LMX could lead subordinates to put organizational and collective well-being over their personal welfare because in a high LMX relationship, subordinates may feel that they need to fulfill reciprocity obligation to the leader and organization. Wang et al. (2005) hypothesize and find that LMX could mediate transformational leadership and OCB by testing their model on a Chinese sample. A few years later, Dulebohn et al. (2012) and Illies et al. (2007) reconfirm the significant and positive association between LMX and OCB. 
Whistleblowing could be a type of OCBO (Graham 1989). Although many corporations' accounting departments may strongly encourage their employees to report suspicious transactions and behaviors to proper internal authorities such as internal auditors or the accounting department head, they are not monitored to report all frauds that they encounter. In fact, companies are not technically able to force all employees to report an observed fraud and employees are generally not rewarded for the report that they submit. If employees choose to report the fraud, it is an extra-role behavior. The reporting behavior is not formally recognized by the company, but it will benefit the company directly and help the company function more effectively. Therefore, I have the following hypotheses:

H2: A subordinate's perceived LMX is positively related to his intention to report fraudulent behavior to his leader.

H3: A subordinate's perceived LMX positively mediates the relationship between his leader's emotional intelligence and his intention to report fraudulent behavior to the leader.

\section{Emotional Intelligence and Trust}

Trust is defined as "the willingness of a party to be vulnerable to the actions of another party based on the expectation that the other will perform a particular action important to the trustor, irrespective of the ability to monitor or control that other party" (Mayer et al. 1995, p. 712). Based on McAllister (1995), trust has both cognition-based foundation and affect-based foundation. The affect-based foundation consists of the emotional bonds between individuals (McAllister 1995; Lewis and Wiegert 1985). Jones and George (1998)'s interactionist model describes trust as a dynamic and evolving experience in which values, attitudes, moods, and emotions interact with each other to produce an overall state of trust. Therefore, trust is partially 
built on emotional bonds between individuals. An individual with high emotional intelligence is more able to sense others' feelings and use the information to promote comfortable and constructive relationships by regulating one's own emotions (Mayer et al. 2008). Although people with high emotional intelligence are not immune to negative emotions (Jordan et al. 2002), they are more likely to be able to manage the negative emotions and facilitate positive expressions and reactions in themselves and others (Jordan et al. 2002). Precise emotion understanding, proper regulation, and productive utilization are related to prosocial emotional reactions (Mayer and Salovey 1997), which are relevant to interactions such as bonding. Emotional bonds linking leader and subordinate can elicit affect-based foundation for building trust (McAllister 1995). On the other hand, when a leader makes emotional investments in the relationships and express genuine care and concern for the subordinates, the subordinates may then feel that these sentiments are reciprocated (McAllister 1995). These emotional ties provide the basis for affect-based trust.

Trust is also cognition-based in that "we choose from whom we will trust in which respects and under what circumstances, and we base the choice on what we take to be 'good reasons', constituting evidence of trustworthiness" (Lewis and Wiegert 1985, p. 970). McAllister (1995) argue that cognition-based trust is grounded in individual beliefs about peer reliability and dependability, and emotional intelligence of a leader could potentially help him manifest these two characteristics. Gross (1998)'s process model of emotional regulation describes a process in which emotional responses can be modulated in positive and prosocial manners through reevaluation of stressful situations and suppressions of negative emotions. This process should decrease the tendencies of a leader to display negative emotions. A leader's consistent display of wise emotional responses and positive emotions modulated by an accurate appraisal 
and appropriate regulation of emotions, which are characteristics of individuals with high emotional intelligence, could help subordinates perceive the leader's reliability and dependability, which provide cognitive base for trust in the leader. Above all, both bases of trust may be more frequently displayed by a leader with high emotional intelligence (Wolff et al. 2002). Some previous research (e.g., Chun et al. 2010) has studied the affect-base and the cognition-base of trust and found evidence that there could be a relationship between one party's (e.g., mentor's) emotional intelligence and the other party's (e.g., protégés') trust in the former party through surveys.

The importance of trust in both organizational and accounting settings has been empirically acknowledged (Shapiro 1987; Granovetter 1985). For example, Rose (2007) finds that auditors who trust others less attend more to evidence of aggressive financial reporting than auditor who trust others more. Rennie et al. (2010) use 48 partners and 23 managers of Canadian office of international accounting firms to explore the factors that can influence an auditor's trust of client's management. They find that auditors believe that it is vital to trust their clients and attempt to ensure this trust will not impair professional skepticism. Moreover, utilizing a sample of 226 internal auditors and 221 management accountants, Seifert et al. (2014) illustrate that both organizational and supervisor trust mediate the relationship between organizational justice and participants' likelihood of whistleblowing.

In addition to trust from an auditor's perspective, Rose et al. (2010) demonstrate that when the management has incentives to manage earnings, less trusting audit committee members are more likely to support the external auditor and perceive the management as being not credible and deceptive. Trust is also important in the financial market. Neu (1991) argue that trust is a necessary condition for economic exchanges and trust must exist prior to contracting, 
such as the prospectus process. Without trust, transactions could not be executed smoothly. It is very clear that interpersonal trust plays a promising role in numerous types of decision making, which may include ethical decision making, such as whistleblowing. Meanwhile, according to arguments above, a subordinate's trust in the leader could be established through the leader's emotional intelligence. Therefore, it is hypothesized that:

H4: A subordinate has higher trust in his leader when the leader has high emotional intelligence than low emotional intelligence.

Trust is important in a leader-subordinate relationship and is particularly vital for a subordinate's willingness to whistleblow. This is because trust increases one's confidence that the other will behave cooperatively and helpfully, which facilitates his own willingness to be exposed in risky conditions, such as whistleblowing. Whistleblowing could result in very negative consequences for the whistleblower, such as retaliation and termination of the current job (Parmerlee et al. 1982), and many employees actually have these concerns (King 1997; Near and Miceli 1996; Keenan 1995). After an employee blows the whistle on an organizational wrongdoing, management may need to decide: (1) whether to disregard the claim or take appropriate action, and (2) whether to reward or retaliate against the whistleblower (MesmerMagnus and Viswesvaran 2005; Near and Miceli 1986).

Taylor and Curtis (2013) demonstrate that auditors are more willing to whistleblow when firms have previous positive organizational response (i.e., the organization took appropriate action to solve the reported fraud). This could be because auditors have more trust in their leader and organization and expect that reporting fraud could result in appropriate remedial action. Negative organizational response or no response at all could seriously hurt the whistleblower's 
emotions, which is a risk for the whistleblower. Retaliation is not always initiated by the organizational top management, but other separate actions of retaliation may be initiated by the whistleblower's leader or coworkers with or without (formal or informal) approval by the top management (Mesmer-Magnus and Viswesvaran 2005). Leaders may be motivated to retaliate against whistleblowers for a number of reasons, but primarily they are afraid that a whistleblowing claim indicates their inability to maintain order within their departments, or they fear that valid complaints will result in the restriction of resources in their own departmental operations (Parmerlee et al. 1982; O’Day 1974). With trust in the leader, the subordinate may believe that they will not receive any form of retaliation from the organization and the leader, and the leader could protect them and not disclose their identity.

Whistleblowers who fail to remain anonymous during the whistleblowing process are more likely to be retaliated against (Miceli and Near 1994), and research has shown that anonymous whistleblowing channel could facilitate whistleblowing under retaliation possibilities (Kaplan et al. 2012). The subordinate could also believe that the leader may take appropriate actions against the fraud or he may likely ask the organization to take appropriate action against the fraud. Some evidence from the current literature (e.g., Gao et al. 2011) demonstrates that trust in the supervisor has a positive impact on employees' voice and risk-taking behaviors such as speaking up about workplace issues. Therefore, it is hypothesized that:

H5: A subordinate's trust in his leader is positively related to his intention to report fraudulent behavior to the leader.

H6: A subordinate's trust in his leader positively mediates the relationship between the leader's emotional intelligence and his intention to report fraudulent behavior to the leader. 


\section{Emotional Intelligence and Job Satisfaction}

Job satisfaction is defined as "a pleasurable or positive emotional state resulting from the appraisal of one's job or job experience" (Locke 1976, p. 1300). It generally has an individual rather than a group referent and a temporal orientation towards the past and present rather than the future, which distinguishes it from other similar constructs, such as morale (Locke 1976). Job satisfaction is a widely studied construct in psychology, management, and marketing. The antecedents and consequences, such as job performance (Judge et al. 2001), organizational commitment (Curry et al. 1986), and turnover (Johnston et al. 1990), have been discovered although the causal relationship between some of the constructs are still under debate (e.g., job satisfaction and organizational commitment; see Curry et al. 1986 for a discussion).

A few accounting studies have examined the role of job satisfaction in both corporate accounting and auditing settings. Frucot and Shearon (1991) utilize survey instruments to test the relationship between budgetary participation, locus of control, performance, and job satisfaction among 86 Mexican managers who work in 21 different companies varying in size, industry, and degree of foreign ownership. They find out that the effect of locus of control is significant on performance while it is not significantly related to managerial job satisfaction, which may indicate an apparent cultural difference. Another interesting finding in this study is that the performance of managers employed in companies with 100 percent foreign ownership is not discernibly affected by either budgetary participation or locus of control. The authors believe that this may be due to the cognitive dissimilarities that are related to the culture interface in these foreign-owned companies. 
Harrel et al. (1991) examine the relationship between organizational-professional conflict and job satisfaction among 67 internal auditors employed by three banks in a medium-sized southeastern city. Harrel et al. (1991) demonstrate that organizational-professional conflict is negatively related to job satisfaction while organizational commitment positively affects job satisfaction. Over a period of five years, Maupin and Lehman (1994) illustrate that a high stereotypical masculine sex-role orientation is significantly positively related to higher occupational status and job satisfaction, and lower turnover. This study, again, reveals that an ingrained stereotype exists for what high-level managers should look like and that female employees may encounter the promotion glass-ceiling in their career.

Although accounting-related job satisfaction literature is not as rich as other topics in accounting (e.g., earnings management), it still provides some interesting perspectives and important future research opportunities. The primary experiment in this dissertation will corroborate how a subordinate's job satisfaction is influenced by his leader's emotional intelligence and then how it leads to his intention to whistleblow.

Emotional intelligence of a leader could be positively related to his subordinate's job satisfaction in terms of its four dimensions. The first two dimensions, appraisal and expression of one's and others' emotions and knowledge of one's and others' emotions, could elicit strong social identity with the company from the subordinate and make the subordinate feel empathy from his leader. Social identity theory is first proposed by Tajfel and Turner (2004), and it states that people tend to classify themselves and others into different social categories based on organization membership, religion, age, gender, culture, etc. (Ashforth and Mael 1989). A category is a prototypical characteristics abstracted from the members (Turner 1987) and different people may utilize different methods to categorize. If a leader is very good at perceiving 
and understanding his subordinate's emotion, he may provide necessary help and advice or modify current work schedule to accommodate the subordinate's emotional needs. This could lead the subordinate to like the leader and company more. He could feel that his boss and company care for him and then feel that the company as a whole is like a family to him. This could shorten the psychological distance between the subordinate and the company and then strengthen the subordinate's social identity with the company. Therefore, based on in-group favorism (Tajfel and Turner 2004), subordinates with high identity with the company should have high job satisfaction with his job in the company (Rotondi 1975).

In addition to social identity, empathy, which is the ability to understand and experience another person's feelings and emotions (Mehrabian and Epstein 1972), could influence the relationship between the subordinate, the leader, and the company. There are two major types of empathy: cognitive empathy and emotional empathy (Duan and Hill 1996). Cognitive empathy refers to "standing in the shoe of the other" while emotional empathy could refer to experiencing (parallel empathy) or reacting to the emotional experiences of the other party (reactive empathy) (Duan and Hill 1996). When a subordinate realizes that his leader has empathy for his feelings no matter whether it is cognitive or emotional, he could believe that his leader categorizes him as an in-group member and will treat him fairly. This may then create a strong bond between the subordinate, his leader, and the company and thus increase the subordinate's job satisfaction.

The other two dimensions, use of emotions to enhance cognitive processes and decision making and management of emotions, could not only induce strong social identity with the company from the subordinate in terms of the similar arguments above, but also could induce perceived high competence of the leader in the subordinate's eyes. Much of the leadership literature (e.g., George 2000) believes that a competent leader who wants to have effective 
leadership must be able to use his emotions to facilitate thought and regulate his emotions when necessary. If a subordinate can see that his leader is capable of utilizing emotions to make good decisions for both him and the company, he will no doubt have confidence in the leader's leadership skills because one of the primary responsibilities for a leader is decision making. A leader with high ability to regulate his emotions, though, can always keep a positive emotion or affect, which is vital for effective leadership (Brown and Keeping 2005). It is very common that everybody may experience negative-emotion-induced events throughout the day, week, month, or year, but some people will not bring these negative emotions or affect to work while some will. Almost nobody likes to work in a negative-emotion-infused environment. A leader that can effectively manage his own emotions and thus always displays proper emotions can make him look more reliable and competent since positive affect can engender positive consequences and negative affect can engender negative consequences (Kelly and Barsade 2001).

A subordinate's job satisfaction could then increase as a result. Some limited evidence indicates that a leader's emotional intelligence could be a moderator for his subordinate's job satisfaction or job attitude (Sy et al. 2006; Wong and Law 2002). This dissertation applies a new and comprehensive theoretical argument that taps the four dimensions of emotional intelligence and provides experimental evidence for the relationship. Based on the arguments and evidence above, it is hypothesized that:

H7: A subordinate has higher job satisfaction when the leader has high emotional intelligence than low emotional intelligence.

Employees' job satisfaction is one of the most significant antecedents for OCB. The role of employees' job satisfaction on OCB is examined in many studies and a strong relationship has 
been identified regardless of the dimensionality of job satisfaction and OCB (e.g., Konovsky and Organ 1996; Organ 1990; Smith and Organ 1983). From the traditionally controversial satisfaction - performance linkage, Smith and Organ (1983) argue that the causal relationship between employees' job satisfaction and employees' performance may be blurry if the definition for performance is narrowly confined to quantity output or quality of craftsmanship. However, employees' job satisfaction may be a determinant for citizenship behavior or cause citizenship behavior, where citizenship behavior is defined as supra-role behavior - behavior that cannot be prescribed or required in advance for a given job. In order to support their argument, they utilize social exchange theory and evidence from several social psychological experiments.

Social exchange theory (Adams 1965; Blau 1964) suggests that under certain conditions, people will feel obliged to reciprocate those who benefit them. Since employees' job satisfaction could result from the efforts of their supervisors or other organizational members and such efforts could be interpreted as volitional and non-manipulative in intent, the employees will try to reciprocate those efforts. However, in reality, the employees may not have the ability or opportunity to increase work output and create innovative solutions for work problems. In such a situation, citizenship behavior may be a better way to reciprocate because it is more easily controlled and conducted by the employee.

Some social psychological experiments also endorse the satisfaction - citizenship behavior relationship. When people are experiencing positive affect, they are more likely to display prosocial gestures (Clark and Isen 1982). For job satisfaction is defined as a positive affective state, it is very likely that more satisfied people will conduct more prosocial citizenship behaviors. Positive affect could decrease the psychological distance between self and others, and it could also spread from the causing factor to other stimuli (notably people) in the temporal and 
social context (Smith and Organ 1983; Rosenhan et al. 1974). Using a citizenship behavior scale with 30 7-point items created by themselves and a cross-lagged pattern design, Smith and Organ (1983) find that job satisfaction is significantly positively related to citizenship behavior (although direction of causality could not be determined). In addition to social exchange theory, social identity theory and in-group favorism could also establish the theoretical foundation for the job satisfaction - OCB relationship. As discussed above, a leader's high emotional intelligence can strengthen a subordinate's identity with the organization, and this high identity will lead to in-group favorism with the organization and job satisfaction (Tajfel and Turner 2004). Job attitudes, which include job satisfaction, may cause a person to take a volunteer role, and taking the role creates a volunteer role-identity (Penner et al. 1997). When people internalize the identity, they will strive to engage in behaviors that sustain it and the associated relationship (Penner et al. 1997).

The group engagement model, which is established by Tyler and Blader (2000, 2003), proposes that due to high identification with the organization, people are inherently concerned with the welfare of the organization and are therefore likely to behave on behalf of the organization's interest (Blader and Tyler, 2009). Blader and Tyler (2009) survey 540 U.S. employees of a single division of an international financial services organization and find that employees' social identity is significantly positively related to extra-role behavior, of which OCB is a type. Finkelstein and Penner (2004) recruit 242 full-time county employees for a questionnaire study and demonstrate that role identity is positively related to OCBO and OCBI. Thus, it appears that an enormous amount of evidence suggests that job satisfaction could strengthen identification with the organization and is then positively related to OCB, which may include whistleblowing. Therefore, it is hypothesized that 
H8: A subordinate's job satisfaction is positively related to his intention to report fraudulent behavior to his leader.

H9: A subordinate's job satisfaction positively mediates the relationship between his leader's emotional intelligence and his intention to report fraudulent behavior to the leader.

Overall, based on the arguments above, it is hypothesized that

H10: A subordinate is more likely to report fraudulent behavior to his leader when his leader has high emotional intelligence than low emotional intelligence.

Figure 2 describes the theoretical model regarding the relationship among the leader's emotional intelligence, the subordinate's perceived LMX, trust in the leader, job satisfaction, and intention to whistleblow.

[Figure 2]

\section{Leader Group Prototypicality}

Leader group prototypicality refers to how representative a leader is of the group that he is leading (Hogg 2001). Based on social identity theory and self-categorization theory, prototypes are fuzzy sets of context-specific group norms, values, attributes, feeling, and attributes that characterize one group and differentiate it from another group (Hogg 2001). They are the basis for a group member to evaluate himself and others and then to establish identity with the group and alienate people who possess prototypes of a group that is considered outgroup (Hogg 2006; Hewstone et al. 2002; Hogg 2001). A group member who has the strongest prototypicality in a new group will acquire influence over other group members and thus emerge as the leader of the group (Hogg 2001). 
A leader in an established group who has strong prototypicality is more socially attractive, which suggests that he has significant influence in the group and may obtain conformance to the requests that he makes from his followers in the group. When a leader is perceived as prototypical of the group, he is also perceived as being informative and thus important. Social cognition research has demonstrated that people who are deemed important have disproportionate influential power (Erbert and Fiske 1984; Taylor and Fiske 1978). Because a leader with strong prototypicality is more socially attractive and has more influence over other members, he may be perceived to be a more effective leader.

Many empirical studies have demonstrated the important effect of leader group prototypicality on followers' perceived leadership effectiveness. For example, Pierro et al. (2005) conduct a survey study with 242 employees of three Italian companies and find that leader group prototypicality is positively related to followers' perceived leadership effectiveness, job satisfaction, and self-rated performance and is negatively related to followers' turnover intention. These relationships are moderated by followers' need for cognitive closure. Another study conducted by Platow and van Knippenberg (2001) find that a leader with high group prototypicality receive high endorsements from followers who highly identify themselves with the group regardless of the leader's in-group-favoring, outgroup-favoring, or fair intergroup behavior. In the accounting literature, Vance (2010) finds that whether the leader comes from an accounting program or not significantly affects participants' (accounting students) perceived LMX, which is closely related to perceived effective leadership.

A leader with low group prototypicality and who has high similarities with the out-group receives high endorsements from followers who highly identify themselves with the group only when the leader makes in-group-favoring distribution, though. In order to further explore the 
effect of leader group prototypicality on followers' endorsements for the leader, Giessner and van Knippenberg (2008) investigate how a leader's group prototypicality affects followers' endorsements for the leader after leader failure. They demonstrate that leader group prototypicality has a significant effect on followers' perceived leadership effectiveness after failure when goal definition is maximal while it has no effect when goal definition is minimal.

In addition, leader group prototypicality is related to followers' decision making in a social dilemma. Van Vugt and de Cremer (1999) execute two experiments with 189 participants and find that when encountering a social dilemma, followers tend to appoint an internal leader who is perceived to have similarities with group members in terms of attributes and attitudes (high prototypicality). They argue that a leader with high prototypicality is perceived with more legitimacy and thus attracts preferences from their followers. The actions that the group members take to solve the social dilemma is significantly influenced by the strength and quality of the social relationships among them (van Vugt and de Cremer 1999). Following on the prior study, these two authors (de Cremer and van Vugt 2002) examine the effect of leaders' ability to fulfill both instrumental needs and relational needs on group members' behavior in public good dilemmas. They find that leaders who express strong group commitment are more likely to raise contributions from their group members when group identity is salient. This is because leaders' strong group commitment stems from high leader group prototypicality and enhances the group identity (de Cremer and van Vugt 2002). Other studies that examine the effect of leadership on social dilemmas include Messick et al. (1983), Rutte and Wilke (1985), Samuelson (1991), Samuelson and Messick (1995, 1986), and Samuelson et al. (1984).

Since leader group prototypicality indicates how representative the leader is of the group and how much the leader identifies himself with the group, it ostensibly influences the 
perception of the group members about the leader, the group, and the relationship between the leader and the group member. When a leader has high group prototypicality, he represents the values, norms, attributes, and behaviors of the group. Thus, in such a case, group members or followers will have trust in this leader because they believe the leader, who strongly identifies himself with the group, will be more trustworthy and will treat his followers in a helpful, supportive, and fair way (Giessner and van Knippenberg 2008). Moreover, a group member will be more likely to follow his leader's request and perform well to reciprocate. The relationship between the leader and the group member will be perceived good and stable by the group member, which suggests a high perceived LMX. Therefore, under a high group prototypicality leader, the group member will feel more satisfied with his job.

Giessner and van Knippenberg (2008) propose and find that group members' trust in the leadership mediates the relationship between leader group prototypicality and group members' evaluation of leadership effectiveness. By conducting a broad-scope survey, Pierro et al. (2005) find that leader group prototypicality is positively related to subordinates' job satisfaction. Based on the arguments and evidence above, it is hypothesized that

H11: A subordinate perceives higher LMX when the leader has high group prototypicality than low group prototypicality.

H12: A subordinate has higher trust in his leader when the leader has high group prototypicality than low group prototypicality.

H13: A subordinate has higher job satisfaction when the leader has high group prototypicality than low group prototypicality. 
Following the same logic that applies to H3, H6, H9 - the mediation role of a subordinate's perceived LMX, trust in the leader, and job satisfaction between the leader's emotional intelligence and his intention to whistleblow, it is hypothesized that

H14: A subordinate's perceived LMX positively mediates the relationship between his leader's group prototypicality and his intention to report fraudulent behavior to the leader.

H15: A subordinate's trust in his leader positively mediates the relationship between the leader's group prototypicality and his intention to report fraudulent behavior to the leader.

H16: A subordinate's job satisfaction positively mediates the relationship between his leader's group prototypicality and his intention to report fraudulent behavior to the leader.

Overall, like H10, it is hypothesized that

H17: A subordinate is more likely to report fraudulent behavior when his leader has high group prototypicality than when his leader has low group prototypicality.

Figure 3 depicts the theoretical model regarding the relationships among the leader's group prototypicality, his subordinate's perceived LMX, trust in the leader, job satisfaction and intention to whistleblow.

[Figure 3]

A prototypical leader can reemphasize the group's norms and values to his subordinates and has the subordinates identify more with the group. The similarities that the leader has with his followers can lead the followers to have high perceived LMX, trust in the leader, and job satisfaction. On the other hand, as George (2000) proposes, leaders with high emotional intelligence can strengthen leadership effectiveness by "establishing and maintaining a 
meaningful identity for an organization" (p. 1039). In other words, a leader's representativeness of the group has a remarkable impact on his subordinates' perceived leadership effectiveness. This implies that if a leader possesses some characteristics that explicitly impair his representativeness of the group, his high emotional intelligence may not influence his subordinates' perceptions and behaviors. A leader's low group prototypicality can be such a characteristic. If a leader possesses low group prototypicality, his subordinates will not perceive him as being representative of the group and then as an effective leader, which in turn could nullify the effect of a leader's emotional intelligence on his subordinate's perceived LMX, trust in the leader, and job satisfaction. A breach of norms and values in a group can cause strong emotional reactions (George 2000). This also means that the leader's emotional intelligence will take effective on his subordinate's perceived LMX, trust in the leader, and job satisfaction only when the leader has high group prototypicality.

The moderating role of leader group prototypicality is demonstrated in many leadership studies. For instance, de Cremer et al. (2010) find that when the leader group prototypicality is high, the leader's procedural fair treatment on the subordinates can increase their cooperation to reach the group goal. Another study conducted by Seppala et al. (2012) with 176 employees within 30 work groups illustrates that perceived leader distributive, procedural, and interactional fairness is positively related to subordinates' trust in their coworkers. This relationship is stronger when the leader has high group prototypicality than low group prototypicality. In addition to subordinates' behavior and trust, a leader's group prototypicality can also moderate the relationship where the dependent variable is subordinates' perceived leadership effectiveness in the leader. Van Knippenberg and van Knippenberg (2005) execute two experiments and two surveys to find that self-sacrificing leaders are considered more effective and can improve their 
subordinates' performance to a higher level than non-self-sacrificing leader. This relationship is more pronounced when the leader has a high group prototypicality. The examples above suggest that a leader's group prototypicality can often modify the relationship between him and his subordinates. Therefore, it is hypothesized that

H18: The effect of a leader's emotional intelligence on his subordinate's perceived LMX is stronger when he has high group prototypicality than low group prototypicality.

H19: The effect of a leader's emotional intelligence on his subordinate's trust in him is stronger when he has high group prototypicality than low group prototypicality.

H20: The effect of a leader's emotional intelligence on his subordinate's job satisfaction is stronger when he has high group prototypicality than low group prototypicality.

Overall, it is hypothesized that

H21: The effect of a leader's emotional intelligence on his subordinate's intention to report fraudulent behavior is stronger when he has high group prototypicality than low group prototypicality.

H22: The mediated relationship between a leader's emotional intelligence and his subordinate's intention to report fraudulent behavior through the subordinate's perceived LMX is stronger when the leader has high group prototypicality than low group prototypicality.

H23: The mediated relationship between a leader's emotional intelligence and his subordinate's intention to report fraudulent behavior through the subordinate's trust in the leader is stronger when the leader has high group prototypicality than low group prototypicality. 
H24: The mediated relationship between a leader's emotional intelligence and his subordinate's intention to report fraudulent behavior through the subordinate's job satisfaction is stronger when the leader has high group prototypicality than low group prototypicality.

Figure 4 delineates the entire theoretical model regarding the relationships among the leader's emotional intelligence, leader group prototypicality, the subordinate' perceived LMX, trust in the leader, job satisfaction, and intention to whistleblow.

[Figure 4]

\section{Type of Accounting Fraud}

Professional standards and accounting literature distinguish between two types of accounting fraud: financial statement fraud ${ }^{9}$ and asset misappropriation fraud. Financial statement fraud is generally referred to "cooking the books". It involves fraudulently reporting financial results and financial position, most frequently by overstating income (Kaplan et al. 2009). Financial statement fraud is different from asset misappropriation in terms of the ways of wealth transfer. Assets misappropriation fraud typically involves the theft of real resources from the company, which is a direct wealth transfer. Fraudulent financial reporting typically involves no direct wealth transfer, but indirect wealth transfers through bonuses and other compensations could occur.

Previous literature has mixed evidence about the effect of types of accounting fraud on the whistleblower's intention to report fraud. Kaplan et al. (2009), Robinson et al. (2012) and Kaplan et al. (2015) find that participants in their experiments are more likely to blow the whistle

\footnotetext{
${ }^{9}$ In this dissertation, financial statement fraud and fraudulent financial reporting refer to the same practice and are thus used interchangeably.
} 
if the fraud is an asset misappropriation than if it is fraudulent financial reporting. Robinson et al. (2012) argue that people make different attributions on these two types of fraud. More specifically, people tend to attribute the fraudulent behavior to personal issues when it is an asset misappropriation fraud while they tend to attribute the fraudulent behavior to external pressure if it is a financial statement fraud (Robinson et al. 2012). Meanwhile, people may also reason that asset misappropriation fraud will only benefit the fraudster while fraudulent financial reporting could benefit the company and the public in the short run (Robinson et al. 2012; Kaplan et al. 2015). Thus, fraudsters for an asset misappropriation fraud may be treated more leniently than those for a financial statement fraud. However, results from Kaplan and Schultz (2007) and Kaplan et al. (2011) indicate that experiment participants do not have significantly different likelihoods of intentions to blow the whistle under financial statement fraud and asset misappropriation fraud. Although the arguments above do not predict any whistleblowing intention difference between financial statement fraud and asset misappropriation fraud, these two types of accounting fraud are still distinguished in this study as an exploration in order to provide more empirical evidence to the literature. 


\section{CHAPTER III. METHODOLOGY}

The hypotheses are tested by conducting a 2 (leader emotional intelligence, high vs. low, between-subject)*2 (leader group prototypicality, high vs. low, between-subject)*2 (type of accounting fraud, financial statement fraud vs. asset misappropriation fraud, within-subject) vignette experiment in Qualtrics on the internet. Leader emotional intelligence and leader group prototypicality are manipulated while whistleblowing intentions for both types of accounting fraud and mediators (i.e., the subordinate's perceived LMX, trust in the leader, and job satisfaction) are measured.

\section{Participants}

243 working professionals are recruited through Amazon Mechanical Turk on the internet to participate in this study. ${ }^{10}$ Amazon Mechanical Turk has been frequently used so far in accounting research (e.g., Farrell et al. 2017; Maksymov et al. 2017; Brasel et al. 2016; Rennekamp et al. 2015; Grenier et al. 2015), and its advantages include high efficiency and possible access to a large number of potential participants with different occupations and backgrounds (Brandon et al. 2013; Mason and Suri 2012). This could improve external validity of the current study. Participants recruited from Amazon Mechanical Turk are then redirected to Qualtrics, where the actual experiment is administered. Among the 243 participants, 25 of them fail at least one of the two role check questions. Therefore, a valid sample of 218 participants is used for further analysis. ${ }^{11}$

\footnotetext{
${ }^{10}$ In order to ensure participant quality and control for potential confounding cultural factors, only participants with approval rate greater than $80 \%$ and reside in American are allowed to participate in this experiment.

${ }^{11}$ One participant did not record occupation information and two participants did not answer one of the supplementary questions. These participants are only excluded when the affected variables are used in the analysis.
} 
Table 4 presents the demographic information of the participants. Overall, the participants have a mean of 34.87 years for age and a mean of 14.61 years for working experience, which indicates that a significant number of them have established a career.

Moreover, the means for number of accounting classes and for number of business classes that a participant has taken are 1.13 and 3.25 respectively, which implies that the participants have basic knowledge about accounting and business. Thus, I believe that my sample is appropriate for this current study that focuses on whistleblowing in the workplace.

$46.8 \%$ and $53.2 \%$ of the participants are male and female respectively, and most of them never report or actively participate in a fraud. $42.2 \%$ of the participants hold a bachelor degree and $19.3 \%$ of them have a major in business/management. Demographic variables neither have significant impact on other variables of interest nor differ between treatment groups. Therefore they are not included in further analyses. ${ }^{12}$

\section{[Table 4]}

\section{Experiment Design}

Each participant is randomly assigned to a description of a leader who has either high or low emotional intelligence and has either high or low group prototypicality. The overall background for the experiment is that Adrian (a gender-neutral name) is an accountant in the accounting department in ABC Company, which is a manufacturing company of consumer goods. The company had produced steady operating results but recently performed at slightly below the industry average (Kaplan et al. 2009). Bailey (a gender-neutral name) is the

\footnotetext{
${ }^{12}$ ANOVA is used for categorical demographic variables, and MANCOVA is used for continuous demographic variables which are included as covariates.
} 
accounting department head, who is the direct supervisor of Adrian and to whom Adrian is reporting to.

\section{Leader Emotional Intelligence Manipulation}

I use the definition of emotional intelligence and the Schutte (1998)'s 33-item scale as the reference to create a leader profile as this scale tests the emotional intelligence as a whole. In the high emotional intelligence leader scenario, Bailey can accurately appraise and express his emotions, can effectively use his emotions to enhance cognitive processes and decisions, has knowledge about his emotions, and can manage his emotions effectively. In the low emotional intelligence leader scenario, Bailey cannot accurately appraise and express his emotions, cannot effectively use his emotions to enhance cognitive processes and decisions, does not have knowledge about his emotions, and cannot manage his emotions effectively. This manipulation (denoted as "LEI") is executed randomly between subjects.

\section{Leader Group Prototypicality Manipulation}

The other manipulation, leader group prototypicality (denoted as “LGP”), follows van Knippenberg and van Knippenberg (2005) and is executed randomly between participants. Bailey is described as either an "outsider" (low group prototypicality) or "representative" of the people (high group prototypicality) in the accounting department in terms of backgrounds, interests, and attitudes towards life and work. This manipulation method has been used in many

prior studies (e.g., Giessner and van Knippenberg 2008; van Knippenberg and van Knippenberg 2005), and it has consistently yielded qualitatively same results in both laboratory experiments and field surveys (Giessner and van Knippenberg 2008; van Knippenberg and van Knippenberg 2005). 


\section{Type of Accounting Fraud Manipulation}

Each participant is provided with the same two accounting fraud cases - one is about financial statement fraud and the other one is about asset misappropriation fraud. Both cases are adapted from Kaplan et al. (2009) and presented to the participant in random order. Since my exploratory purpose is only to see whether type of accounting fraud plays a role in whistleblowing intentions and provide more empirical evidence to the literature, two cases are made as comparable as possible to the Kaplan et al. (2009) research cases. Both cases control the financial consequences of the fraud by stating that it involves approximately $\$ 800,000$ and affects earnings per share by approximately $\$ 0.02$. The certainty of the fraud is held constant across two cases that Adrian is "almost certain" that a fraud has been committed. This statement assures experiment participants that the fraud is actually committed and is certain in case they have doubt on the certainty of the case. The financial statement fraud case involves improper asset valuation, a frequent method of fraudulent financial reporting (ACFE 2016). In this case, Adrian discovers that $\$ 800,000$ of expense has been capitalized by a controller of a department, a "very skilled CPA". The misrecording increases earnings per share by $\$ 0.02$, which exactly meets financial analysts' expectations.

The asset misappropriation fraud case involves false billing scheme by creating a shell company. A false billing scheme is one of the most frequent schemes for asset misappropriation (the most frequent for manufacturing companies) and it always involves a substantial amount of cash. Specifically, the case notes that Adrian finds that several bills for services not rendered by a fictitious company (the shell company) has been paid to the fictitious company. Adrian then discovers that the vendor's post office box address is identical to the address of the purchasing 
manager. The total amount of all bills is $\$ 800,000$ in expenditure, which reduces earnings per share by $\$ 0.02$. See Appendix II for details of the instruments.

\section{Mediators and Dependent Variables}

Since this study focuses on the subordinate's opinion on the leader-subordinate dyadic and interactive relationship, all mediator and dependent variables are assessed from Adrian's perspective. Subordinate's perception of LMX (denoted as "LMX") is measured as the sum of assessments on six items including "If you were Adrian, you would perceive the working relationship with Bailey as effective", "If you were Adrian, you would believe that Bailey could understand your job problems and needs", "If you were Adrian, you would believe that Bailey could recognize your potential", "If you were Adrian, you would believe that regardless of how much formal authority Bailey has built into the position, it is possible that Bailey would use power to help you solve problems in your work", "If you were Adrian, you would believe that regardless of the amount of formal authority Bailey has, it is possible that Bailey would 'bail you out' at Bailey's expense", and "If you were Adrian, you would have enough confidence in Bailey that you mwould defend and justify Bailey’s decision if Bailey were not present to do so.” All six items are anchored from 1 (Strongly Disagree) to 7 (Strongly Agree).

There are different LMX measurement scales in the management and organizational behavior literature, such as the most frequently used LMX-7 scale (Graen et al. 1982a). ${ }^{13}$ Some of these scales' items do not make conceptual and practical sense in a controlled experimental setting, even if those items are very suitable for a field survey study, which is the primary research design and method used in management and organizational behavior studies (e.g.,

\footnotetext{
${ }^{13}$ Other LMX scales include LMX-5 (Graen et al. 1982a), LMX-4 (Liden and Graen 1980), LMX-10 (Ridolphi and Seers 1984), LMX-12 (Wakabayashi and Graen 1984), and LMX-16 (Wakabayashi et al.1990).
} 
Jordan and Troth 2011; Graen and Uhl-Bien 1995). The current six items used in this study to measure LMX are adapted from LMX-7 scale (Graen et al. 1982b), which include the "centroid item" that is proven by Keller and Dansereau (2001) to show consistent significant correlations with performance in all cases analyzed in their study. ${ }^{14}$ I believe that these six items make practical sense in this experiment and using multiple items could catch a larger portion of the LMX construct.

The subordinate's trust in the leader (denoted as "Trust) is measured by the Brockner et al. (1997) three-item scale. This scale has demonstrated acceptable psychometric properties in several studies (e.g., Bouquillon et al. 2005), and all of these questions make conceptual and practical sense in my experimental settings. The three items are as follows: "If you were Adrian, you can trust Bailey to do what is good for you," "If you were Adrian, you can trust Bailey to treat you fairly," and "If you were Adrian, Bailey can be trusted to make decisions that are good for you." These three items are anchored from 1 (Strongly Disagree) to 7 (Strongly Agree) and are expected to significantly correlate with each other, so they are combined into one score. The subordinate's job satisfaction (denoted as "JS") is measured by one item that "If you were Adrian, you are satisfied with your current job in the accounting department of ABC Company." anchored from 1 (Strongly Disagree) to 7 (Strongly Agree). Although there exist different job satisfaction measurement scales, this one-item overall job satisfaction scale possesses good psychometric properties (Wanous et al. 1997) and can loosen the cognitive burden on the participants and increase the efficiency of the experiment at the same time. Moreover, it has been used in many empirical studies including those in accounting (e.g., Harrell et al. 1986).

\footnotetext{
${ }^{14}$ Graen and Uhl-Bien (1995) have the same opinion on this issue.
} 
There are two dependent variables: WBAM and WBFS. WBAM (WBFS) is the participant's intention to whistleblow for the asset misappropriation (fraudulent financial statement reporting) case if he were Adrian. Following previous literature (Kaplan et al. 2011), both dependent variables are measured by using a seven-point Likert scale anchored from 1(Strongly Disagree) to 7 (Strongly Agree). The scale statement is "If you were Adrian, it is likely for you to report the fraud to Bailey.” Because of the arguments presented above in Chapter II, the report recipient is constrained to the leader.

After providing reporting intentions, participants are asked to respond to a series of ten statements about their perceptions of the fraudulent act and the potential consequences to the subordinate and the organization if the fraudulent act were reported (Kaplan et al. 2009). These data are used to investigate the differences in motivation, attitudes, opinions, and judgments of the participants with respect to the asset misappropriation case and fraudulent financial statement reporting case, which can then aid in better understanding their reporting decisions. The ten statements include: act is morally wrong; act seriousness; act is unethical (general consensus); act fairness, personal cost of reporting; responsibility to inform; company will discover act by itself; anonymity will be protected; act will be thoroughly investigated; corrective actions will be taken. The participants provide their assessment on ten nine-point items (from 1 to 9) with endpoints labeled "Very Low/Small/Unlikely/Unfair" and "Very High/Large/Likely/Fair". The wording of the statements and scale labels match the meaning of the specific scenario.

In addition, since Robinson et al. (2012) believe that people will make different whistleblowing decisions between financial statement fraud and asset misappropriation fraud due to disparate attributions, participants are asked to provide assessments on two statements for each type of accounting fraud to investigate this difference in attribution. The two statements are 
"This fraud should be attributed to the personal factors of the controller of the division (purchasing manager)" and "This fraud should be attributed to external factors." The assessment is nine-point anchored from 1 (Strongly Disagree) to 9 (Strongly Agree).

\section{Control Variables}

Social desirability bias is the "tendency of individuals to deny socially undesirable actions and behaviors and to admit to socially desirable ones" (Chung and Moroe 2003, p. 291). In other words, people usually overestimate their morality but underestimate others' morality in an undesirable scenario because people generally believe they are more ethical than their peers (Randall and Fernandes 1991). Since whistleblowing is a socially desirable action for most of the people when encountering accounting frauds, I believe that social desirability bias would play a role and thus needs to be controlled. Following prior literature, the participants are asked to indicate their assessments on Adrian's intention to whistleblow for financial statement fraud and asset misappropriate fraud respectively (denoted as "WBSFS" and "WBSAM"). The difference between WBFS (WBAM) and WBSFS (WBSAM) for each fraud type (denoted as "SDBFS and "SDBAM") are controlled in the analysis as social desirability bias (Cohen et al. 2007; Chung and Monroe 2003; Kaplan et al. 1997; Zerbe and Paulhus 1987).

Altruism (denoted as “ALT”), which is measured by a 20-item scale created by Rushton et al. (1981), is also included as control variable since whistleblowing could be a type of altruism and prosocial behavior. Emotional intelligence of the participants, which is measured by the Schutte et al. (1998) 33-item scale is incorporated (denoted as "EI") because prior literature has demonstrated that people's emotional intelligence is related to ethical decision making (e.g., Fu 2014). 


\section{Post-Experiment Manipulation Check and Role Check}

Two questions about the role of Adrian and Bailey are asked to determine whether the participants understand the role of each character in the experimental scenarios. As stated above, 25 participants fail these two questions. Four statements that respectively correspond to the four dimensions of the leader's emotional intelligence are also asked (e.g., "Bailey has the ability to perceive his/her and other's emotions."). These four statements are anchored from 1 (Strongly Disagree) to 9 (Strongly Agree). Another statement, "Bailey represents what is characteristic of the accounting department” (adapted from van Knippenberg and van Knippenberg 2005) anchored from 1 (Strongly Disagree) to 9 (Strongly Agree) is used to check the effectiveness of the manipulation of leader group prototypicality. 


\section{CHAPTER IV. RESULTS}

For the 218 participants who pass the role check, the t-test results (untabulated) on the five manipulation check questions are all significant ( $\mathrm{ps}<.001)$, which indicate that the leader emotional intelligence and leader group prototypicality manipulations are successful.

Multicollinearity is checked for all variables of interest. Variance inflation factors (VIF) for all variables are less than 10 except LMX, which is 10.149 and 10.023 when WBFS and WBAM are dependent variables respectively. Since the VIFs of all variables are less than or slightly higher than 10 and variables with the two highest VIFs (LMX and TRUST) are not included in the same model simultaneously, multicollinearity does not seem to be a serious statistical concern. ${ }^{15}$

Since measurements for leader-member exchange and trust in the leader have multiple items (6 and 3 respectively), separate principal component analyses is used to check their respective dimensionality. Both sets of items are loaded onto their corresponding constructs. Moreover, Cronbach's alphas are 0.957 and 0.960 for LMX and trust respectively, which provides strong support of reliability.

\section{Correlational Analysis}

Table 5 presents Pearson correlation among the independent variables, dependent variables, and control variables. LMX, TRUST, and JS are all significantly positively related to WBFS and WBAM (ps<0.01), which provides evidence supporting $\mathrm{H} 2, \mathrm{H} 5$, and $\mathrm{H} 8$ that the subordinate's perceived LMX (H2), trust in the leader (H5), and job satisfaction (H8) are

\footnotetext{
${ }^{15}$ When LMX and TRUST are separately included in the regression model for multicollinearity check, VIFs are all less than 3.5, which suggests that multicollinearity is not an issue.
} 
positively related to the subordinate's intention to whistleblow to the leader. Other significant correlations (two-tailed) exist among LMX, TRUST, and JS. LEI is significantly correlated with WBFS and WBAM ( $\mathrm{p}=0.062$ and 0.095 respectively, two-tailed; untabulated), and LGP is also significantly correlated with WBFS and WBAM ( $\mathrm{p}=0.039$ and $\mathrm{p}=0.037$ respectively, two-tailed;

untabulated). This indicates that further examination on these relationships are warranted;

\section{[Table 5]}

\section{Analyses for Main Effect and Moderation}

Table 6 presents MANCOVA results where LEI and LGP are independent variables, and WBFS, WBAM, LMX, TRUST, and JS are dependent variables with EI, ALT, SDBFS, and SDBAM as covariates. LEI, LGP, and LEI *LGP are all significant (ps $<0.05$, two-tailed), which implies that further breakdown is necessary for each dependent variable.

[Table 6]

Table 7 contains ANCOVAs for WBFS and WBAM as dependent variables. When WBFS is the dependent variable, LEI and LGP both have significant effects ( $\mathrm{p}=0.003$ and $\mathrm{p}=0.015$ respectively, one-tailed) while LEI*LGP is not significant at the traditional level ( $p=0.478$, one-tailed). Further decomposition of the LEI and LGP main effects indicates that the mean differences for whistleblowing intentions between high LEI (high LGP) and low LEI (low LGP) are positive and significant, which suggests that participants (subordinates) are more likely to whistleblow when LEI and LGP are high. When WBAM is the dependent variable, LEI and LGP also both have significant effects ( $\mathrm{p}=0.009$ and $\mathrm{p}=0.031$, one-tailed) while LEI*LGP is not significant at the traditional level ( $\mathrm{p}=0.199$, one-tailed). Further decomposition of the LEI and LGP main effects indicates as well that the mean differences for whistleblowing intentions 
between high LEI (high LGP) and low LEI (low LGP) are positive and significant, which suggests that participants (subordinates) are more likely to whistleblow when LEI and LGP are high. In terms of moderation, Buckless and Ravenscroft (1990) argue that ANOVA does not have strong power to detect ordinal interactions ${ }^{16}$ since ANOVA assign the same weigh to each treatment group by default. Thus, they recommend that in the presence of an ordinal interaction, a contrast with different weights assigned to treatment groups should be implemented. Following this suggestion, I conduct a special contrast for the interaction with weight -1 assigned to low LEI/low LGP, high LEI/low LGP, and low LEI/high LGP groups and 3 assigned to high LEI/high LGP group. Contrast results in Table 6 suggest that the interaction effects for both WBFS and WBAM are significant $(\mathrm{F}=8.024, \mathrm{p}=0.005$ and $\mathrm{F}=8.376, \mathrm{p}=0.004$ respectively, twotailed). Figure 5 and 6 visually illustrate that the relationship between LEI and WBFS/WBAM is stronger when LGP is higher. Overall, evidence above supports H10, H17, and H21 that when the leader has high emotional intelligence (H10)/group prototypicality (H17), the subordinate is more likely to whistleblow to the leader and that the effect of the leader's emotional intelligence on the subordinate's intention to whistleblow is stronger when the leader has high group prototypicality $(\mathrm{H} 21)$.

[Table 7]

[Figure 5]

[Figure 6]

\footnotetext{
${ }^{16}$ My moderations hypothesis (H21) implies an ordinal interaction since H10 and H17 suggest that high LEI and high LGP should have the highest reporting intention while the other three treatment groups could have similar reporting intentions.
} 
Table 8 presents the ANCOVA for LMX as the dependent variable. LEI, LGP, and LEI*LGP all have significant effects $(\mathrm{p}<0.001, \mathrm{p}=0.001$, and $\mathrm{p}=0.006$ respectively, one-tailed). Further decomposition of the LEI and LGP main effects indicates that the mean differences for LMX between high LEI (high LGP) and low LEI (low LGP) are positive and significant, which suggests that participants (subordinates) perceive more effective leader-subordinate relationship when LEI and LGP are high. Since the interaction LEI*LGP is significant, simple effects of LEI under each level of LGP are analyzed. From Table 7, the LMX mean difference between high LEI group and low LEI group is 16.611 when LGP is low ( $p<0.001$, one-tailed) and 20.789 when LGP is high ( $\mathrm{p}<0.001$, one-tailed). Figure 5 graphically shows the interaction. Overall, evidence above supports $\mathrm{H} 1, \mathrm{H} 11$, and $\mathrm{H} 18$ that when the leader has high emotional intelligence (H1)/group prototypicality (H11), the subordinate perceives higher LMX and that the effect of the leader's emotional intelligence on the subordinate's perceived LMX is stronger when the leader has high group prototypicality (H18).

[Table 8]

[Figure 7]

Table 9 presents the ANCOVA for TRUST as the dependent variable. LEI, LGP, and LEI*LGP all have significant effects $(\mathrm{p}<0.001, \mathrm{p}=0.065$, and $\mathrm{p}=0.030$ respectively, one-tailed). Further decomposition of the LEI and LGP main effects indicates that the mean differences for LMX between high LEI (high LGP) and low LEI (low LGP) are positive and significant, which suggests that participants (subordinates) establish higher trust in the leader when LEI and LGP are high. Since the interaction LEI*LGP is significant, simple effects of LEI under each level of LGP are analyzed. From Table 7, the LMX mean difference between high LEI group and low 
LEI group is 8.283 when LGP is low ( $\mathrm{p}<0.001$, one-tailed) and 10.133 when LGP is high ( $p<0.001$, one-tailed). Figure 6 graphically shows the interaction. Overall, evidence above supports H4, H12, and H19 that when the leader has high emotional intelligence (H4)/group prototypicality (H12), the subordinate has higher trust in the leader and that the effect of the leader's emotional intelligence on the subordinate's trust in the leader is stronger when the leader has high group prototypicality (H19).

[Table 9]

[Figure 8]

Table 10 presents the ANCOVA for JS as the dependent variable. LEI and LEI*LGP both have significant effects $(\mathrm{p}<0.001$ and $\mathrm{p}=0.001$ respectively, one-tailed) while LGP does not ( $p=0.259$, one-tailed). Further decomposition of the LEI main effect indicates that the mean differences for LMX between high LEI and low LEI are positive and significant, which suggests that participants (subordinates) feel more satisfied with the job when LEI is high. Since the interaction LEI*LGP is significant, simple effects of LEI under each level of LGP are analyzed. From Table 7, the LMX mean difference between high LEI group and low LEI group is 1.950 when LGP is low ( $\mathrm{p}<0.001$, one-tailed) and 3.027 when LGP is high ( $\mathrm{p}<0.001$, one-tailed). Figure 7 graphically shows the interaction. ${ }^{17}$ Overall, evidence above supports $\mathrm{H} 7$ and $\mathrm{H} 20$ that when the leader has high emotional intelligence, the subordinate has higher job satisfaction $(\mathrm{H} 7)$ and that the effect of a leader's emotional intelligence on his subordinate's job satisfaction is stronger when he has high group prototypicality than low group prototypicality $(\mathrm{H} 20)$. H13,

\footnotetext{
17 The figure seems to suggest a disordinal interaction, but since LGP does not have a statistically significant effect, it cannot be concluded so. Future research should investigate this interaction more.
} 
which is that when the leader has high group prototypicality, the subordinate has higher job satisfaction, is not supported.

[Table 10]

[Figure 9]

\section{Analysis for Type of Accounting Fraud}

Since each participant is provided with both financial statement fraud and asset misappropriation fraud cases, repeated-measures test is used to examine the effect of different types of accounting fraud on whistleblowing intentions. Table 11 presents the results. After controlling for EI and ALT, Type does not have a significant effect on whistleblowing intentions ( $p=0.931$, two-tailed). This is in line with the results of several previous research studies (e.g., Kaplan et al. 2011). However, untabulated results indicate that pairwise comparison between WBFS and WBAM is significant ( $\mathrm{p}=0.003)$, and this significance is weakened after EI and ALT are included the model, which suggests that the nonsignificant effect of Type between the two types of accounting fraud could be primarily attributed to these control variables.

[Table 11]

\section{Mediation Analysis}

Andrew Hayes' PROCESS (Hayes 2013), which adopts bootstrapping technique, is employed in this study to test mediations. ${ }^{18}$ PROCESS generates bootstrapping confidence intervals for mediational indirect effects. The inferential rule is that if this bootstrapping

\footnotetext{
${ }^{18}$ Mediation effects are production of direct effects. For example, the mediation effect of LEI on WBFS through LMX is the product of the effect of LEI on LMX and LMX on WBFS.
} 
confidence interval does not contain 0 and is in the predicted direction, the corresponding hypothesis will be supported. The default adopted bootstrapping confidence interval for this study is $90 \%$, one-tailed, and the number of iterations is $10,000 .{ }^{19}$ Table 12 displays the results of bootstrapping mediation analysis and Sobel tests. When LEI is the independent variable, LMX, TRUST, and JS are all mediators with positive effects for both WBFS and WBAM (all one-tailed bootstrapping $90 \%$ and $95 \%$ confidence intervals do not contain 0 ). When LGP is the independent variable, LMX is the mediator with positive effects for both WBFS and WBAM (one-tailed bootstrapping $90 \%$ and $95 \%$ confidence intervals do not contain 0 ). However, neither bootstrapping confidence interval nor Sobel test could provide support to the mediational roles of TRUST and JS for WBFS or WBAM. Overall, the mediational effect of each mediator is stronger when WBFS is the dependent variable than when WBAM is the dependent variable. This implies that a fairly large portion of the effect of LEI on WBFS "goes through" LMX, TRUST, and JS. Based on the findings summarized above, H3, H6, H9, and H14 that a subordinate's perceived LMX (H3)/trust in the leader (H6)/job satisfaction (H9) positively mediate the relationship between the leader's emotional intelligence and his intention to whistleblow to the leader and a subordinate's perceived LMX mediates the relationship between the leader's group prototypicality and his intention to whistleblow to the leader (H14) are supported while H15 and H16 which are that a subordinate's trust in his leader (H15)/job satisfaction (H16) positively mediate the relationship between the leader's group prototypicality and his intention to whistleblow to the leader, are not.

\footnotetext{
${ }^{19}$ One-tailed $95 \%$ bootstrapping confidence interval is also calculated for each potential mediator to strengthen the results and conclusions (detailed results are not tabulated). Mediational effect that is significant under this confidence level is starred in Table 12.
} 
[Table 12]

Since LPG is expected to positively moderate the mediational effects of LMX, TRUST, and JS, Table 13 presents "simple mediation effect" under each level of LGP. Andrew Hayes' PROCESS is employed in moderated mediation analysis as well. The default adopted bootstrapping confidence interval is $90 \%$, one-tailed, and the number of iterations is 10,000 . Results in Table 13 indicate that LMX, TRUST, and JS all have mediational indirect effects on both LEI-WBFS and LEI-WBAM relationships under high LGP and low LGP conditions respectively (one-tailed bootstrapping $90 \%$ and $95 \%$ confidence intervals do not contain 0 ). Moreover, the mediational effects of all mediators for both dependent variables are stronger under high LGP than under low LGP. In order to examine the moderating role of LGP on the mediational effect for each hypothesized mediator, Index of Moderated Mediation, which tests the difference in mediational effects under different levels of the moderator (high LGP vs. low LGP), is used. In the Index of Moderated Mediation, a bootstrapping confidence interval is calculated for the difference in the mediational effects under different levels of the moderator. If the moderator is dichotomous and if the confidence interval does not contain 0 , it provides evidence that the mediational effect under one level of the moderator is significantly different from that under the other level of the moderator. Following criteria used above, the default bootstrapping confidence interval for Index of Moderated Mediation is 90\%, one-tailed, and the number of iterations is 10,000. All bootstrapping confidence intervals for Index of Moderated Mediation in Table 12 do not contain 0 for all three mediators when the dependent variable is either WBFS or WBAM, which suggests that the difference in the mediational effects of each mediator under the two levels of LGP is significantly different from 0. Overall, based on the evidence gathered and summarized in Table 12, H22, $\mathrm{H} 23$, and $\mathrm{H} 24$ that the mediated 
relationship between a leader's emotional intelligence and the subordinate's intention to whistleblow to the leader through the subordinate's perceived LMX (H22)/trust in the leader (H23)/job satisfaction (H24) is stronger when the leader has high group prototypicality than low group prototypicality are supported.

[Table 13]

\section{Supplementary Analysis}

Following previous literature (Robinson et al. 2012; Kaplan et al 2009), 12 statements related to participants' opinions on attributions and several characteristics of the two types of accounting fraud are included in this study. Table 14 presents the paired t-tests results for these 12 statements. Paired t-tests are employed here because each participant is provided with vignettes of both types of accounting fraud. All means in Table 14 are mean differences between the assessment for financial statement fraud and the assessment for asset misappropriation fraud on each of the 12 statements. Robinson et al. (2012) reason that for asset misappropriation fraud, observers tend to attribute it to internal/personal factors of the fraudster while to external/environmental factors for financial statement fraud. Results in Table 14 support this argument. The mean difference for the statement "This fraud should be attributed to the personal factors of the controller of the division/purchasing manager" is $-0.35780(\mathrm{df}=217, \mathrm{p}=0.008$, twotailed), which suggests that participants have a stronger tendency to attribute the asset misappropriation fraud to the fraudster's personal factors than the financial statement fraud. On the other hand, the mean difference for the statement "This fraud should be attributed to external factors" provides direct support to the other part of Robinson et al. (2012)'s argument that participants tend to attribute financial statement fraud to the external/environmental factors that 
are out of the fraudster's control (mean difference $=0.24312, \mathrm{df}=217, \mathrm{p}=0.099$, two-tailed). The remaining 10 statements tap on participants' opinions related to other aspects of the two types of accounting fraud. Participants believe that asset misappropriation fraud is more morally wrong, unethical, and serious $(\mathrm{df}=217, \mathrm{p}=0.004,0.078$, and 0.016 respectively, two-tailed $)$ and that the responsibility to inform proper parties about the fraudulent act is higher for asset misappropriation fraud ( $\mathrm{df}=217, \mathrm{p}=0.020$, two-tailed). Moreover, it is more likely that Adrian's identity will be protected if the asset misappropriation fraud is reported ( $\mathrm{df}=217, \mathrm{p}=0.074$, twotailed), that asset misappropriation fraud will be thoroughly investigated ( $\mathrm{df}=217, \mathrm{p}=0.038$, twotailed), and that corrective action will be taken for asset misappropriation fraud ( $\mathrm{df}=217$, $\mathrm{p}=0.002$, two-tailed). In terms of fairness and personal cost of reporting, they are both rated by participants higher for financial statement fraud than asset misappropriation fraud $(\mathrm{df}=215$ and 217 respectively, $\mathrm{p}<0.001$ and $=0.003$, two-tailed). There is a significant difference in the assessment on the statement "ABC Company will discover this fraudulent act by itself" ( $\mathrm{df}=217$, $\mathrm{p}=0.182$, two-tailed).

[Table 14]

Since a participant's emotional intelligence could influence how he perceives, processes, and uses emotional cues and information from other people (Salovey and Mayer 1990), a median split is conducted for EI, and main effects are analyzed for each level of EI. Table 15 presents the results. When WBFS is the dependent variable, LEI has a significant effect only under high EI condition ( $\mathrm{p}=0.002$, one-tailed) and LGP has a significant effect only under low EI condition $(\mathrm{p}=0.058$, one-tailed). The interaction between LEI and LGP is not significant under either low EI or high EI condition. When WBAM is the dependent variable, similar to the results for WBFS, LEI has a significant effect only under high EI condition ( $p=0.002$, one-tailed) and LGP 
has a significant effect only under low EI condition ( $\mathrm{p}=0.064$, one-tailed). However, the interaction between LEI and LEP is now significant ( $p=0.086$, one-tailed). The absolute value of the mean difference (High LEI-Low LEI) when LGP is high is larger than that when LGP is low. This suggests that under the low EI condition, the relationship between LEI and WBAM is stronger when LGP is high than when LGP is low. Untabulated results show significant interactions between LEI and EI for both WBFS and WBAM ( $\mathrm{p}=0.065$ and 0.054 respectively, one-tailed). ${ }^{20}$ The evidence above implies that participants' emotional intelligence could play an important role in ethical decision making through influencing other factors, such as perceptions of other people's emotional intelligence.

[Table 15]

Because LMX, TRUST, and JS are significantly correlated with each other, a principal component analysis is conducted on all three mediators' items. Untabulated results indicate that all items could load onto one construct and that construct can explain $82 \%$ of the variance. Thus, all items are added to form one new construct. Andrew Hayes’ PROCESS bootstrapping mediation analysis is then employed on this new construct as a potential mediator called MEDIATOR. When LEI is the independent variable, MEDIATOR has significant indirect effects for both WBFS and WBAM at both $10 \%$ and $5 \%$ significance level, one-tailed. When LGP is the independent variable, MEDIATOR does not have a significant indirect effect for WBFS, one-tailed and has a significant indirect effect at $10 \%$ significance level, one-tailed for WBAM. LGP still significantly moderates the mediational effects of MEDIATOR at both $10 \%$ and 5\% significance levels for both WBFS and WBAM.

\footnotetext{
${ }^{20}$ One-tailed p-value is reported here because emotional intelligence theory suggests that when a participant has high emotional intelligence, he has better ability to perceive, process, and utilize emotional information and cues.
} 
Since LMX, TRUST, and JS have been hypothesized and tested for mediational effects separately, an interesting question is whether these three constructs would be parallel mediators in one model. To examine this exploratory model, Andrew Hayes' PROCESS bootstrapping mediation test is employed. Untabulated results indicate that only TRUST has a significant mediational effect at $10 \%$ significance level, one-tailed when WBFS is the dependent variable. 


\section{CHAPTER V. SUPPLEMENTARY EXPERIMENT}

The primary experiment above examines the effect of a leader's emotional intelligence on the subordinate's intention to whistleblow. There are still several remaining questions that cannot be answered by the primary experiment. For example, the leader in the scenarios of the primary experiment is not involved or committing the fraud. What if the leader himself is involved or committing the fraud? What if the consequence of this fraud is framed as either punishments for the leader or benefits that could be acquired by the company? Does the emotional intelligence of the subordinate affect his whistleblowing decision when the leader is involved in the fraud and when the consequences of whistleblowing are framed differently? The supplementary experiment tries to answer these questions.

\section{Literature Review and Hypothesis Development}

The fact that a subordinate's own direct supervisor gets involved in a fraud observed by the subordinate is not rare. In their report, Deloitte and Touche (2007) indicate that it is not infrequent for employees to observe their supervisor's wrongdoing. However, current literature has complex and mixed evidence about the likelihood that a subordinate will whistleblow on the fraud in which the leader in involved. More specifically, whether power distance (leader vs. peer) influences employees' whistleblowing decision is usually qualified by other factors. For instance, Taylor and Curtis (2013) find that auditors are more likely to whistleblow on their superiors than peers when prior organizational response is strong than weak. This current supplementary experiment finds that overall the subordinate is more likely to whistleblow on the leader when the leader has low emotional intelligence than when the leader has high emotional intelligence. Moreover, the effect of whistleblowing consequence framing (leader consequence 
vs. firm consequence) on the subordinate's whistleblowing intention is stronger when the leader has high emotional intelligence.

When the leader in involved in a fraud, his emotional intelligence is still able to play a role in whether the subordinate will blow the whistle or not. As argued in Chapter II, a leader's high emotional intelligence can establish the subordinate's high perceived LMX, trust, and job satisfaction. Even if the leader is involved in a fraud, the subordinate may still believe that the leader can benefit the company with his effective leadership in the future and he can be trusted to correct the mistake soon. Therefore, the subordinate is less likely to whistleblow on the leader when the leader has high emotional intelligence than low emotional intelligence

While stated above, the subordinate's own emotional intelligence can change his whistleblowing decision in such a case. Mesmer-Magnus et al. (2008) and Joseph et al. (2009) present evidence showing that recognition of emotions (a part of emotional intelligence) is highly related to perceptions of ethical behaviors of peers, and $\mathrm{Fu}$ (2014) finds that participants with higher emotional intelligence are more likely to behave ethically, probably including whistleblowing. However, on the other hand, when a leader with low emotional intelligence commits a fraud, the subordinate with high emotional intelligence could be unlikely to whistleblow because he is more able to perceive the leader as being less reliable and dependable (McAllister 1995). Therefore, the subordinate may not trust the leader, and the worries that the leader may retaliate increase. This then results in a disordinal interaction between the leader's emotional intelligence and the subordinate's emotional intelligence. Following previous arguments, it is hypothesized that 
H25: The subordinate is more likely to report the fraud committed by the leader when the leader has low emotional intelligence than when the leader has high emotional intelligence.

H26: The subordinate is more likely to report the fraud committed by the leader when the subordinate has low emotional intelligence than high emotional intelligence under low leader emotional intelligence condition while the subordinate is more likely to report the fraud committed by the leader when the subordinate has high emotional intelligence than low emotional intelligence under high leader emotional intelligence condition.

Framing effect has been demonstrated to affect decision making in many different scenarios (Levin et al. 1998). It was first introduced by Tversky and Kahneman (1981) and could be classified into three types: risky choice, attribute, and goal (Levin et al. 1998). Risky choice originates from the "Asian disease problem" and primarily focuses on the decision about gain or loss. Attribute framing is about "how descriptive valence influences information processing" (Leven et al. 1998, p. 158) and essentially deals with the two sides of the same coin. Goal framing, which is popular in persuasion literature, divides goals into two categories: "goal obtaining the positive consequences" and "avoiding the negative consequences" (Levin et al. 1998, p. 167). This current study focuses on how likely subordinates are to whistleblow when the consequences are framed as being either positive to the company or negative to the leader. This scenario could correspond to the attribute framing effect because either the positive valence or the negative valence of the consequence are emphasized. When subordinates are primed with the positive consequence of their whistleblowing to the firm, they may consider whistleblowing on their leader necessary and then be more likely to whistleblow while the likelihood may be lower if they are primed with the negative consequence of their whistleblowing to the leader since now whistleblowing is deemed harmful. 
Emotional intelligence includes the ability to perceive and understand one's own and others' emotions (Mayer and Salovey 1997), which implies that people with high emotional intelligence could have strong empathy (Mehrabian and Epstein 1972). As defined before, empathy is the ability to understand and experience another person's feelings or emotions (Mehrabian and Epstein 1972), and it could interact with the different framings of consequences. When the positive consequences to the company are primed, the subordinate with high empathy will strongly feel along with these positive consequences and then be likely to whistleblow in order to help the company. However, when the negative consequences to the leader are primed, the subordinate with high empathy will easily sense the pain of the leader and thus is reluctant to whistleblow in order to alleviate the potential calamity that may be experienced by the leader. Therefore, the subordinate with high emotional intelligence will be more likely to whistleblow if the positive consequences to the company are emphasized than if the negative consequences to the leader are emphasized since empathy will help the subordinate absorb and utilize the primed valence of consequences to make decisions. Following the previous lines of arguments, it is hypothesized that

H27: The subordinate is more likely to report the fraud committed by the leader when the whistleblowing consequence is framed positively to the company than when it is framed negatively to the leader.

H28: The subordinate is more likely to report the fraud committed by the leader when the subordinate has high emotional intelligence than low emotional intelligence under positive firm consequence framing condition while the subordinate is more likely to report the fraud committed by the leader when the subordinate has low emotional intelligence than high emotional intelligence under negative leader consequence framing condition. 
The relationship between consequence framing and the subordinate's whistleblowing intention hypothesized above is stronger when the leader has high emotional intelligence since in such a case, he is perceived of being a trustworthy and effective leader (George 2000), even if a fraud is clearly committed by him. The subordinate may then hold the leader much less accountable for the fraud because with the effective leadership, the leader may be assumed to possess high ethical standards (Fu 2014) and not to make this mistake again. Moreover, the subordinate is more likely to attribute this fraud to external factors when the leader has high emotional intelligence, and the negatively framed consequence to the leader could strengthen that attribution and elicit strong sympathy to the leader. On the other hand, when the leader has low emotional intelligence, the fraud committed by the leader serves as evidence to support the perception and attribution of the subordinate, and thus the positively framed consequence to the company will not significantly change the likelihood of whistleblowing. Following the arguments above, it is hypothesized that

H29: The effect of consequence framing on the subordinate's intention to report the fraud committed by the leader is stronger when the leader has high emotional intelligence than when the leader has low emotional intelligence.

\section{Experiment Design}

A 2 (leader emotional intelligence, between-subject)*2 (consequence framing, betweensubject) vignette experiment is conducted with participants randomly assigned to one of the four treatment groups. Since financial statement fraud is more serious in terms of amount (ACFE 2016), the financial statement case used in the primary experiment is adapted to create the new scenario in this supplementary experiment where the leader is involved in the fraud. Accounting 
whistleblowing literature (e.g., Kaplan et al. 2007) already finds that anonymous reporting channel could reduce whistleblowing cost, and Sarbanes-Oxley Act requires all public companies to have an anonymous reporting channel for employees to disclose observed unethical incidents. In order to provide ecological validity and persuasiveness for the results, an anonymous reporting channel is used as the legitimate recipient of whistleblowing in both the scenario and the scale statements. The leader's emotional intelligence is manipulated as before, and the whistleblowing consequences are manipulated as being either positive to the company or negative to the fraudster leader. In the positive consequence to the company treatment group, the consequence is that the company could avoid reputation impairment, future profit loss, and potential charge from government agencies, and future fraud could be deterred. In the negative consequence to the fraudster leader treatment group, the consequence is that the leader will lose his job and will probably never be hired again. One new manipulation check question on the framing of consequences is asked. Participants choose what the consequence of whistleblowing is from four options. Since the participant's emotional intelligence is hypothesized to interact with leader emotional intelligence and consequence framing, median split is conducted to break all participants down into high emotional intelligence group and low emotional intelligence group. All other measures are the same as those in the primary experiment. See Appendix III for details of the instruments.

\section{Participants}

The experiment is delivered in Qualtrics, and 193 participants from Amazon Mechanical Turk, the majority of which are working professionals, are recruited to participate in it. ${ }^{21}$ Among

\footnotetext{
${ }^{21}$ In order to ensure participant quality and control for potential confounding cultural factors, only participants with approval rate greater than $90 \%$ and reside in American are allowed to participate in this supplementary experiment.
} 
them, 47 failed at least one of the two role check questions and consequence framing manipulation check question, so 146 participants and their respective data are included for further analysis. ${ }^{22}$ Table 16 presents the demographic information. Overall, the participants have a mean of 36.25 for age and a mean of 15.16 years for working experience, which indicates that a majority of the participants have established a career and are experienced professionals.

Moreover, the means for number of accounting classes and for number of business classes that a participant has taken are 2.29 and 4.94 respectively, which suggests that the participants have basic knowledge about accounting and business. Therefore, I believe that my sample is appropriate for this study that focuses on whistleblowing in the workplace.

$45.9 \%$ and $54.1 \%$ of the participants are male and female respectively, and most of them have never reported or actively participated in a fraud. $43.3 \%$ of the participants hold a bachelor degree and $27.4 \%$ of them have a college major in business/ management. All demographic variables, except the number of accounting classes that a participant has taken, do not differ between manipulated treatment groups and thus are excluded from further analysis.

[Table 16]

\section{Results}

For the 146 participants who pass the role check and consequence framing manipulation check questions, the t-test results (untabulated) on the four leader emotional intelligence

\footnotetext{
${ }^{22}$ Given the role check and one manipulation check questions are multiple-choice in format, a $24 \%$ failing rate is not uncommon. For example, in Gimbar et al. (2016)'s study, 35\% and 40\% of the participants fail the first and second manipulation check questions in multiple-choice format respectively.
} 
manipulation check questions are all significant (p-values <0.001). This indicates that the leader emotional intelligence manipulation is successful.

\section{Correlational Analysis}

Table 17 presents Pearson correlation among the independent variables, the dependent variable, and control variables. Leader emotional intelligence and consequence framing are both significantly positively correlated with whistleblowing intentions ( $\mathrm{r}=-1.64$ and 1.70 respectively). This warrants that further analysis is necessary to investigate those effects.

[Table 17]

\section{ANCOVA Analysis}

Table 18, Panel A presents the results of an ANCOVA with social desirability bias, altruism, and the number of accounting classes that a participant has taken as covariates. Leader emotional intelligence has a significant main effect on whistleblowing intentions $(\mathrm{F}=6.718$, $\mathrm{p}=0.005$, one-tailed). Pairwise contrast indicates that when the leader has high emotional intelligence, the subordinate is less likely to whistleblow on the leader (mean difference $=0.527$, $\mathrm{p}=0.005$, one-tailed). This supports $\mathrm{H} 25$ that the subordinate is more likely to report the fraud committed by the leader when the leader has low emotional intelligence than when the leader has high emotional intelligence. However, consequence framing does not have a significant main effect on whistleblowing intentions $(\mathrm{F}=0.827, \mathrm{p}=0.182$, one-tailed $)$, and thus $\mathrm{H} 27$, which is that the subordinate is more likely to report the fraud committed by the leader when the whistleblowing consequence is framed positively to the company than when it is framed negatively to the leader, is not supported. 
In terms of hypothesized moderation effects, the three interaction terms (LEI*CP, LEI*EI, and $\mathrm{CP} * \mathrm{EI})$ are the primary focus. $\mathrm{H} 29$ predicts that the effect of consequence framing is stronger when the leader has high emotional intelligence. The interaction term between leader emotional intelligence and consequence framing is significant $(\mathrm{F}=2.184, \mathrm{p}=0.071$, one-tailed $)$, and simple effects in Panel B indicate that the subordinate's whistleblowing intention mean difference between positive consequence framing to the firm and negative consequence framing to the leader is -0.133 ( $\mathrm{p}=0.344$, one-tailed) when the leader has low emotional intelligence and $0.480(\mathrm{p}=0.049$, one-tailed $)$ when the leader has high emotional intelligence. Figure 10 graphically illustrates this interaction. ${ }^{23}$ Overall, $\mathrm{H} 29$ is supported. The interaction between leader emotional intelligence and participant emotional intelligence (i.e., LEI*EI) is close to be statistically significant ( $\mathrm{p}=0.111$, one-tailed) and in the hypothesized direction (as illustrated in Figure 11). A statistical power issue could exist here, and future research should conduct a deeper investigation on $\mathrm{H} 26$ that the subordinate is more likely to report the fraud committed by the leader when the subordinate has low emotional intelligence than high emotional intelligence under low leader emotional intelligence condition while the subordinate is more likely to report the fraud committed by the leader when the subordinate has high emotional intelligence than low emotional intelligence under high leader emotional intelligence condition. At last, the interaction between consequence framing and participant emotional intelligence is not statistically significant $(\mathrm{F}=0.442, \mathrm{p}=0.254$, one-tailed). Therefore, $\mathrm{H} 28$, which is that the subordinate is more likely to report the fraud committed by the leader when the subordinate has high emotional intelligence than low emotional intelligence under the positive firm consequence framing

\footnotetext{
${ }^{23}$ Although from Figure 10, the simple effect seems to have a negative slope when the leader has low emotional intelligence, the mean difference is not significant ( $\mathrm{p}=0.344$, one-tailed). Thus, the results and figure are not against the hypothesis and arguments.
} 
condition while the subordinate is more likely to report the fraud committed by the leader when the subordinate has low emotional intelligence than high emotional intelligence under the negative leader consequence framing condition, is not supported. ${ }^{24}$

\section{[Table 18]}

[Figure 10]

[Figure 11]

${ }^{24}$ A pilot study was conducted on student participants before, and the results indicated that the leader's emotional
intelligence is not statistically significant while the consequence framing is. This could be due to insufficient
attention to the case materials and lack of working experience. Future research should corroborate this difference. 


\section{CHAPTER VI. CONCLUSION}

This dissertation examines whether a leader's emotional intelligence impacts the likelihood of his subordinates' intention to whistleblow. Two experiments demonstrate that a subordinate's whistleblowing decision is significantly affected by his leader's emotional intelligence no matter whether the leader is involved in the fraud or not. Results from the primary experiment illustrate that when a leader has high emotional intelligence, the subordinate is more likely to whistleblow to the leader if the leader is not involved in the fraud. This relationship is mediated through the subordinate's perceived LMX, trust in the leader, and job satisfaction. At the same time, it is stronger when the leader has high group prototypicality. Although this relationship is statistically significant, supplementary analysis indicates that the leader's emotional intelligence loses effect when the participants have low emotional intelligence instead of high emotional intelligence. This warrants future investigation on the interactive role of the subordinate's own emotional intelligence with other constructs of interest. At last, consistent with some of the previous literature, types of accounting fraud do not affect participants' whistleblowing intention after control variables are included.

To further test the effect of the leader's emotional intelligence, a supplementary experiment is executed where the leader is directly involved in the fraud. In such a scenario, results demonstrate that the subordinate is less likely to whistleblow on the leader to the anonymous whistleblowing hotline if the leader has high emotional intelligence. Moreover, the effect of consequence framing is stronger when the leader has high emotional intelligence.

Emotional intelligence is considered a necessary characteristic for an effective and successful leader (George 2000), but its validity and importance are not without doubt 
(Antonakis et al. 2009). The results from the primary experiment can provide more evidence about the importance of a leader's emotional intelligence and help companies understand how and when a leader's emotional intelligence can affect a subordinate's ethical decision through perceived LMX, trust, and job satisfaction, which in turn helps companies prevent and detect accounting frauds. This dissertation has important practical implications that companies should put more weight on employees' emotional intelligence when recruiting, training, or promoting them and consider strategically assigning managers to a team where they share common characteristics with other team members while keeping in mind the importance of diversity. Certain forms of emotional intelligence training can be beneficial to both the employees and the company. Meanwhile, in order for the subordinates to perceive the emotional intelligence and group prototypicality of the leader, a manager should be encouraged to interact more often with his subordinates. For instance, out-of-workplace gatherings on a routine basis can help subordinates appreciate the characteristics of their leader, including emotional intelligence.

If the leader is involved in a fraud, the fact that a leader has high emotional intelligence could not be very favorable to the company because the subordinate may now decide to "cut some slack" for the leader. Thus, the company should take necessary actions to alleviate this problem, such as periodic ethical training and corporate policy education (Valentine and Fleischman 2004; Delaney and Sockell 1992). Results from the supplementary experiment suggest that the consequence of whistleblowing should be framed on the relevant corporate policy as being positive to the company instead of being negative to the leader if the leader has high emotional intelligence.

This dissertation makes several contributions to the current accounting and whistleblowing literature. First, this dissertation connects emotional intelligence to 
whistleblowing through subordinates' perceived LMX, trust in the leader, and job satisfaction. To the best knowledge of the author, no prior research has built this connection. Moreover, although other previous studies try to establish the relationship between a leader's emotional intelligence and the subordinate's perceived LMX, most of their theoretical arguments lack a broad overarching effective leadership concept that could guide the relationship establishment. Second, emotional intelligence has not been frequently examined in the accounting and whistleblowing literature. There are only a few accounting education studies involving the construct of emotional intelligence (McPahil 2004; Ming Chia 2005; Bay and McKeage 2006). This dissertation expands the application of emotional intelligence to more accounting contexts and could attract more accounting research on it. Third, this dissertation provides more evidence to the ongoing debate about the effect of the type of accounting fraud on the employee's intention to whistleblow when observing accounting frauds. Although some authors (e.g., Robinson et al. 2012) provide theoretical explanations for their hypothesized different effects of the two types of accounting fraud on the employee's intention to whistleblow, prior literature has mixed results. More evidence could help the research community gain a better and more comprehensive understanding of this issue. Fourth, this dissertation explicitly examines the subordinate's perception of the leader's emotional intelligence from an interactive perspective and its effect on the subordinate's perceived LMX, trust in the leader, job satisfaction, and intention to whistleblow. Most of the previous research studies just use self-report scales to measure the leader's emotional intelligence. Fifth, I incorporate two experiments in this dissertation to control for other possible factors that may influence the results. There are few experimental studies in leadership literature (Avolio et al. 2009), and several scholars call for more experimental research in this area (Day et al. 2004; Day et al. 2003). The advantage of an 
experimental study is to be able to provide confidence that there is a certain causal relationship between the constructs while many previous research studies that just use survey method to acquire data may only demonstrate associations. Sixth, I expand the important role of leader group prototypicality to the whistleblowing literature. Leader group prototypicality is a moderator in some leadership circumstances (e.g., van Knippenberg and van Knippenberg 2005), but its effect on whistleblowing has not been tested. This dissertation, to the best knowledge of the author, is the first one to investigate it in an accounting fraud context. Seventh, framing effect is prevalent in a number of fields (Chong and Druckman; 2007; Aerts 2005), but its interaction with other constructs has not been thoroughly corroborated. This dissertation documents that the relationship between consequence framing and the subordinate's intention to whistleblow is moderated by the leader's emotional intelligence, and this finding enriches both the emotional intelligence and framing effect literature, especially in the context of leadership.

This dissertation has several limitations. The first and most significant one is that both experiments in this dissertation adopt vignettes that describe fraud scenarios and the participants are regular business working professionals instead of professional accountants. Although I strongly believe that the designs and participants are appropriate for my original research motivation and purpose since the scenarios do not involve advanced task-specific accounting knowledge, it is still possible that using actual accountants and conducting field studies may generate results different from those in this dissertation.

The second limitation is that the fraudulent amount may matter when the participants make decisions on the accounting fraud cases. Robinson et al. (2012) have already demonstrated that materiality is closely related to whistleblowing intentions. It is possible that participants may make significantly different decisions if the amount changes (Robinson et al. 2012) and different 
participants could have different anchors in terms of what consists of a material amount. Future research could try to elaborate on this concern.

The third limitation is that the job satisfaction measurement has only one item, which could include confounding conceptual variances. Although I believe that this one item is the best measurement in this dissertation, it is still possible that it captures much noise. Future research could try to resolve this issue by using a multi-item job satisfaction measurement scale that is suitable for emotional intelligence experimental study.

The fourth limitation is that perceiving others' emotional intelligence could take some time and may not be as easy and direct as implied in this dissertation. However, the purpose of this dissertation is to find out the effect of a leader's emotional intelligence on the subordinate's intention to whistleblow, not how a leader's emotional intelligence could be perceived by the subordinate in the field. This latter question could be an interesting future research opportunity. Moreover, as Jollineau et al (2012) argue, allowing subordinates to interact with manager confederates could introduce confounding factors that impair internal validity. Therefore, some dynamic constructs that may develop over time, such as LMX, is experimentally manipulated successfully in accounting studies by descriptive scenarios (e.g., Jollineau et al. 2012; Vance 2010).

The fifth limitation is that this dissertation only captures participants' intention to whistleblow. Prior studies have found that the intention to whistleblow may not necessarily result in the whistleblowing action (Trevino et al. 2006; Mesmer-Magnus and Viswesvaran 2005). Future research could try to examine the effect of a leader's emotional intelligence on the actual whistleblowing action and if the hypothesized relationship still holds. 


\section{REFERENCES}

Adams, J. S. 1965. Inequity in social exchange. Advances in experimental social psychology 2:267-299.

Aerts, W. 2005. Picking up the pieces: impression management in the retrospective attributional framing of accounting outcomes. Accounting, Organizations and Society 30 (6):493-517.

Ajzen, I. 1991. The theory of planned behavior. Organizational behavior and human decision processes 50 (2):179-211.

Alvesson, M. 1992. Leadership as social integrative action. A study of a computer consultancy company. Organization Studies 13 (2):185-209.

Antonakis, J., N. M. Ashkanasy, and M. T. Dasborough. 2009. Does leadership need emotional intelligence? The Leadership Quarterly 20 (2):247-261.

Ashforth, B. E., and F. Mael. 1989. Social identity theory and the organization. Academy of management review 14 (1):20-39.

Association of Certified Fraud Examiner (ACFE). 2016. Report to the Nations on Occupational Fraud and Abuse.

Avolio, B. J., F. O. Walumbwa, and T. J. Weber. 2009. Leadership: Current theories, research, and future directions. Annual review of psychology 60:421-449.

Bagley, P. L. 2010. Negative affect: A consequence of multiple accountabilities in auditing. Auditing: A Journal of Practice \& Theory 29 (2):141-157.

Barling, J., F. Slater, and E. Kevin Kelloway. 2000. Transformational leadership and emotional intelligence: An exploratory study. Leadership \& Organization Development Journal 21 (3):157-161.

Batson, C. D. 1983. Sociobiology and the role of religion in promoting prosocial behavior: An alternative view.

- 1987. Prosocial motivation: Is it ever truly altruistic? Advances in experimental social psychology 20:65-122.

Bay, D., and K. McKeage. 2006. Emotional intelligence in undergraduate accounting students: Preliminary assessment. Accounting Education: an international journal 15 (4):439-454.

Bhattacharjee, S., and K. K. Moreno. 2013. The role of auditors' emotions and moods on audit judgment: A research summary with suggested practice implications. Current Issues in Auditing 7 (2):P1-P8. 
Bhattacharjee, S., K. K. Moreno, and T. Riley. 2012. The interplay of interpersonal affect and source reliability on auditors' inventory judgments. Contemporary Accounting Research 29 (4):1087-1108.

Bies, R. J., and D. L. Shapiro. 1987. Interactional fairness judgments: The influence of causal accounts. Social Justice Research 1 (2):199-218.

Blader, S. L., and T. R. Tyler. 2009. Testing and extending the group engagement model: linkages between social identity, procedural justice, economic outcomes, and extrarole behavior. Journal of Applied Psychology 94 (2):445.

Blau, P. M. 1964. Exchange and power in social life: Transaction Publishers.

Blumer, H. 1986. Symbolic interactionism: Perspective and method: Univ of California Press.

Bouquillon, E. A., J. J. Sosik, and D. Lee. 2005. 'It's only a phase': examining trust, identification and mentoring functions received across the mentoring phases. Mentoring \& Tutoring: Partnership in Learning 13 (2):239-258.

Bowen, R. M., A. C. Call, and S. Rajgopal. 2010. Whistle-blowing: Target firm characteristics and economic consequences. The Accounting Review 85 (4):1239-1271.

Bower, G. H. 1981. Mood and memory. American psychologist 36 (2):129-148.

Bower, G. H., and P. R. Cohen. 1982. Emotional influences in memory and thinking: Data and theory. Affect and cognition:291-331.

Brackett, M. A., S. E. Rivers, N. Lerner, P. Salovey, and S. Shiffman. 2006. Relating Emotional Abilities to Social Functioning: A Comparison of Self-Report and Performance Measures of Emotional Intelligence. Journal of Personality \& Social Psychology 91 (4):780-795.

Brandon, D. M., J. H. Long, T. M. Loraas, J. Mueller-Phillips, and B. Vansant. 2013. Online instrument delivery and participant recruitment services: Emerging opportunities for behavioral accounting research. Behavioral Research in Accounting 26 (1):1-23.

Brasel, K. R., M. M. Doxey, J. H. Grenier, and A. Reffett. 2016. Risk disclosure preceding negative outcomes: The effects of reporting critical audit matters on judgments of auditor liability. The Accounting Review (forthcoming).

Brockner, J., P. A. Siegel, J. P. Daly, T. Tyler, and C. Martin. 1997. When trust matters: The moderating effect of outcome favorability. Administrative Science Quarterly:558-583.

Brower, H. H., F. D. Schoorman, and H. H. Tan. 2000. A model of relational leadership: The integration of trust and leader-member exchange. The Leadership Quarterly 11 (2):227250. 
Brown, D. J., and L. M. Keeping. 2005. Elaborating the construct of transformational leadership: The role of affect. The Leadership Quarterly 16 (2):245-272.

Buckless, F. A., and S. P. Ravenscroft. 1990. Contrast coding: A refinement of ANOVA in behavioral analysis. Accounting Review:933-945.

Caruso, D. R., J. Mayer, and P. Salovey. 1999. Emotional intelligence meets traditional standards for an intelligence. Intelligence 27 (4):267-298.

Chang, C. J., S.-H. Yen, and R.-R. Duh. 2002. An empirical examination of competing theories to explain the framing effect in accounting-related decisions. Behavioral Research in Accounting 14 (1):35-64.

Chong, D., and J. N. Druckman. 2007. Framing theory. Annu. Rev. Polit. Sci. 10:103-126.

Chun, J. U., B. E. Litzky, J. J. Sosik, D. C. Bechtold, and V. M. Godshalk. 2010. Emotional intelligence and trust in formal mentoring programs. Group \& Organization Management 35 (4):421-455.

Chung, J., and G. S. Monroe. 2003. Exploring social desirability bias. Journal of Business Ethics 44 (4):291-302.

Chung, J. O., J. R. Cohen, and G. S. Monroe. 2008. The effect of moods on auditors' inventory valuation decisions. Auditing: A Journal of Practice \& Theory 27 (2):137-159.

Cianci, A. M., and J. L. Bierstaker. 2009. The impact of positive and negative mood on the hypothesis generation and ethical judgments of auditors. Auditing: A Journal of Practice \& Theory 28 (2):119-144.

Clark, M. S., and A. M. Isen. 1982. Toward understanding the relationship between feeling states and social behavior. Cognitive social psychology:73-108.

Cohen, J. R., L. Holder-Webb, D. J. Sharp, and L. W. Pant. 2007. The effects of perceived fairness on opportunistic behavior. Contemporary Accounting Research 24 (4):11191138.

Curry, J. P., D. S. Wakefield, J. L. Price, and C. W. Mueller. 1986. On the causal ordering of job satisfaction and organizational commitment. Academy of Management Journal 29 (4):847-858.

Curtis, M. B., T. L. Conover, and L. C. Chui. 2012. A cross-cultural study of the influence of country of origin, justice, power distance, and gender on ethical decision making. Journal of International Accounting Research 11 (1):5-34.

Damasio, A. R. 2006. Descartes' error: Random House. 
Dansereau, F., G. Graen, and W. J. Haga. 1975. A vertical dyad linkage approach to leadership within formal organizations: A longitudinal investigation of the role making process. Organizational behavior and human performance 13 (1):46-78.

Day, D. V., and P. M. O’Connor. 2003. Leadership development: Understanding the process. The future of leadership development:11-28.

Day, D. V., S. J. Zaccaro, and S. M. Halpin. 2004. Leader development for transforming organizations: Growing leaders for tomorrow: Psychology Press.

De Cremer, D., M. Van Dijke, and D. M. Mayer. 2010. Cooperating when "you" and "I" are treated fairly: The moderating role of leader group prototypicality. Journal of Applied Psychology 95 (6):1121.

De Cremer, D., and M. Van Vugt. 2002. Intergroup and intragroup aspects of leadership in social dilemmas: A relational model of cooperation. Journal of Experimental Social Psychology 38 (2):126-136.

De George, R. T. 1981. Ethical responsibilities of engineers in large organizations: The Pinto case. Business \& Professional Ethics Journal 1 (1):1-14.

Delaney, J. T., and D. Sockell. 1992. Do company ethics training programs make a difference? An empirical analysis. Journal of Business Ethics 11 (9):719-727.

Deloitte \& Touche. 2007 Available at http://www.deloitte.com/assets/DcomUnitedStates/Local\%20Assets/Documents/us_2007 _ethics_workplace_survey_011009.pdf.

Deluga, R. J. 1994. Supervisor trust building, leader-member exchange and organizational citizenship behaviour. Journal of occupational and Organizational Psychology 67 (4):315-326.

Dozier, J. B., and M. P. Miceli. 1985. Potential predictors of whistle-blowing: A prosocial behavior perspective. Academy of management review 10 (4):823-836.

Duan, C., and C. E. Hill. 1996. The current state of empathy research. Journal of counseling psychology 43 (3):261.

Dulebohn, J. H., W. H. Bommer, R. C. Liden, R. L. Brouer, and G. R. Ferris. 2012. A metaanalysis of antecedents and consequences of leader-member exchange integrating the past with an eye toward the future. Journal of Management 38 (6):1715-1759.

Easterbrook, J. A. 1959. The effect of emotion on cue utilization and the organization of behavior. Psychological review 66 (3):183-201.

Eisenberg, M. A. 1976. The structure of the corporation: A legal analysis: Beard Books. 
Erber, R., and S. T. Fiske. 1984. Outcome dependency and attention to inconsistent information. Journal of Personality and Social Psychology 47 (4):709-726.

Ewing, D. W. 1983. " Do it my way or you're fired!": employee rights and the changing role of management prerogatives: John Wiley \& Sons Inc.

Farrell, A. M., J. H. Grenier, and J. Leiby. 2017. Scoundrels or stars? Theory and evidence on the quality of workers in online labor markets. The Accounting Review 92 (1):93-114.

Finkelstein, M. A., and L. A. Penner. 2004. Predicting organizational citizenship behavior: Integrating the functional and role identity approaches. Social Behavior and Personality: an international journal 32 (4):383-398.

Folger, R., D. D. Rosenfield, and T. Robinson. 1983. Relative deprivation and procedural justifications. Journal of Personality and Social Psychology 45 (2):268-273.

Ford, M. E., and M. S. Tisak. 1983. A further search for social intelligence. Journal of Educational Psychology:196.

Forgas, J. P. 1992. Affect in social judgments and decisions: A multiprocess model. Advances in experimental social psychology 25:227-275.

Forgas, J. P. 1995. Mood and judgment: the affect infusion model (AIM). Psychological bulletin $117(1): 39$.

Frijda, N. H. 1988. The Laws of Emotion. American psychologist 43 (5):349-358.

Frucot, V., and W. T. Shearon. 1991. Budgetary participation, locus of control, and Mexican managerial performance and job satisfaction. Accounting Review:80-99.

Fu, W. 2014. The impact of emotional intelligence, organizational commitment, and job satisfaction on ethical behavior of Chinese employees. Journal of Business Ethics 122 (1):137-144.

Gao, L., O. Janssen, and K. Shi. 2011. Leader trust and employee voice: The moderating role of empowering leader behaviors. The Leadership Quarterly 22 (4):787-798.

George, J. M. 2000. Emotions and leadership: The role of emotional intelligence. Human relations 53 (8):1027-1055.

George, J. M., and K. Bettenhausen. 1990. Understanding prosocial behavior, sales performance, and turnover: A group-level analysis in a service context. Journal of Applied Psychology 75 (6):698. 
George, J. M., and A. P. Brief. 1996. Motivational agendas in the workplace: The effects of feelings on focus of attention and work motivation: Elsevier Science/JAI Press.

Gerstner, C. R., and D. V. Day. 1997. Meta-Analytic review of leader-member exchange theory: Correlates and construct issues. Journal of Applied Psychology 82 (6):827.

Giessner, S. R., and D. van Knippenberg. 2008. "License to fail": Goal definition, leader group prototypicality, and perceptions of leadership effectiveness after leader failure. Organizational behavior and human decision processes 105 (1):14-35.

Gimbar, C., B. Hansen, and M. E. Ozlanski. 2016. The effects of critical audit matter paragraphs and accounting standard precision on auditor liability. The Accounting Review 91 (6):1629-1646.

Goleman, D., R. Boyatzis, and A. McKee. 2013. Primal leadership: Unleashing the power of emotional intelligence: Harvard Business Press.

Graen, G., M. A. Novak, and P. Sommerkamp. 1982a. The effects of leader-member exchange and job design on productivity and satisfaction: Testing a dual attachment model. Organizational behavior and human performance 30 (1):109-131.

Graen, G. B., R. C. Liden, and W. Hoel. 1982b. Role of leadership in the employee withdrawal process. Journal of Applied Psychology 67 (6):868.

Graen, G. B., and M. Uhl-Bien. 1995. Relationship-based approach to leadership: Development of leader-member exchange (LMX) theory of leadership over 25 years: Applying a multilevel multi-domain perspective. The Leadership Quarterly 6 (2):219-247.

Graham, J. 1989. Whistle blowing as organizational citizenship behavior and/or civic duty. Paper read at annual meeting of the American Society of Criminology, Reno, NV.

Granovetter, M. 1985. Economic action and social structure: The problem of embeddedness. American journal of sociology:481-510.

Grenier, J. H., B. Pomeroy, and M. T. Stern. 2015. The effects of accounting standard precision, auditor task expertise, and judgment frameworks on audit firm litigation exposure. Contemporary Accounting Research 32 (1):336-357.

Gross, J. J. 1998. Antecedent- and response-focused emotion regulation: divergent consequences for experience, expression, and physiology. Journal of Personality and Social Psychology 74 (1):224-237.

Gundlach, M. J., S. C. Douglas, and M. J. Martinko. 2003. The decision to blow the whistle: A social information processing framework. Academy of management review 28 (1):107123. 
Harrell, A., E. Chewning, and M. Taylor. 1986. Organizational-professional conflict and the job satisfaction and turnover intentions of internal auditors: Auditing: A Journal of Practice \& Theory, 109-121.

Hayes, A. F. 2013. Introduction to mediation, moderation, and conditional process analysis: A regression-based approach: Guilford Press.

Hewstone, M., M. Rubin, and H. Willis. 2002. Intergroup bias. Annual review of psychology 53 (1):575-604 .

Hogan, C. E., Z. Rezaee, R. A. Riley Jr, and U. K. Velury. 2008. Financial statement fraud: Insights from the academic literature. Auditing: A Journal of Practice \& Theory 27 (2):231-252.

Hogan, R., G. J. Curphy, and J. Hogan. 1994. What we know about leadership: Effectiveness and personality. American psychologist 49 (6):493-504.

Hogg, M. A. 2001. A social identity theory of leadership. Personality and social psychology review 5 (3):184-200.

- 2006. Social identity theory. Contemporary social psychological theories 13:111-1369.

House, R. J., P. J. Hanges, M. Javidan, P. W. Dorfman, and V. Gupta. 2004. Culture, leadership, and organizations: The GLOBE study of 62 societies: Sage publications.

Howell, J. M., and K. E. Hall-Merenda. 1999. The ties that bind: The impact of leader-member exchange, transformational and transactional leadership, and distance on predicting follower performance. Journal of Applied Psychology 84 (5):680-694.

Howell, J. M., and B. Shamir. 2005. The role of followers in the charismatic leadership process: Relationships and their consequences. Academy of management review 30 (1):96-112.

Humphrey, R. H. 2002. The many faces of emotional leadership. The Leadership Quarterly 13 (5):493-504.

Ilies, R., J. D. Nahrgang, and F. P. Morgeson. 2007. Leader-member exchange and citizenship behaviors: a meta-analysis. Journal of Applied Psychology 92 (1):269-277.

Isen, A. M., K. A. Daubman, and G. P. Nowicki. 1987. Positive affect facilitates creative problem solving. Journal of Personality and Social Psychology 52 (6):1122-1131.

Isen, A. M., M. M. Johnson, E. Mertz, and G. F. Robinson. 1985. The influence of positive affect on the unusualness of word associations. Journal of Personality and Social Psychology 48 (6):1413-1426. 
Isen, A. M., and P. F. Levin. 1972. Effect of feeling good on helping: Cookies and kindness. Journal of Personality and Social Psychology 21 (3):384-388.

Johnson, E. N., D. J. Lowe, and P. M. J. Reckers. 2016. The Influence of Mood on Subordinates' Ability to Resist Coercive Pressure in Public Accounting. Contemporary Accounting Research 33 (1):261-287.

Johnston, M. W., A. Parasuraman, C. M. Futrell, and W. C. Black. 1990. A longitudinal assessment of the impact of selected organizational influences on salespeople's organizational commitment during early employment. Journal of Marketing Research:333-344.

Jollineau, S. J., T. W. Vance, and A. Webb. 2012. Subordinates as the first line of defense against biased financial reporting. Journal of Management Accounting Research 24 (1):124.

Jones, G. R., and J. M. George. 1998. The experience and evolution of trust: Implications for cooperation and teamwork. Academy of management review 23 (3):531-546.

Jordan, P. J., N. M. Ashkanasy, and C. E. Hartel. 2002. Emotional intelligence as a moderator of emotional and behavioral reactions to job insecurity. Academy of management review 27 (3):361-372.

Jordan, P. J., and A. Troth. 2011. Emotional intelligence and leader member exchange: The relationship with employee turnover intentions and job satisfaction. Leadership \& Organization Development Journal 32 (3):260-280.

Joseph, J., K. Berry, and S. P. Deshpande. 2009. Impact of emotional intelligence and other factors on perception of ethical behavior of peers. Journal of Business Ethics 89 (4):539546.

Judge, T. A., C. J. Thoresen, J. E. Bono, and G. K. Patton. 2001. The job satisfaction-job performance relationship: A qualitative and quantitative review. Psychological bulletin 127 (3):376-407.

Kahneman, D., and A. Tversky. 1979. Prospect theory: An analysis of decision under risk. Econometrica: Journal of the econometric society:263-291.

Kaplan, S. E., K. J. Newberry, and P. M. Reckers. 1997. The effect of moral reasoning and educational communications on tax evasion intentions. The Journal of the American Taxation Association 19 (2):38-54.

Kaplan, S. E., K. Pany, J. Samuels, and J. Zhang. 2012. An examination of anonymous and nonanonymous fraud reporting channels. Advances in accounting 28 (1):88-95. 
Kaplan, S. E., K. Pany, J. A. Samuels, and J. Zhang. 2009. An examination of the effects of procedural safeguards on intentions to anonymously report fraud. Auditing: A Journal of Practice \& Theory 28 (2):273-288.

Kaplan, S. E., K. R. Pope, and J. A. Samuels. 2011. An examination of the effect of inquiry and auditor type on reporting intentions for fraud. Auditing: A Journal of Practice \& Theory 30 (4):29-49.

Kaplan, S. E., K. R. Pope, and J. A. Samuels. 2015. An examination of the effects of managerial procedural safeguards, managerial likeability, and type of fraudulent act on intentions to report fraud to a manager. Behavioral Research in Accounting 27 (2):77-94.

Kaplan, S. E., and J. J. Schultz. 2007. Intentions to report questionable acts: An examination of the influence of anonymous reporting channel, internal audit quality, and setting. Journal of Business Ethics 71 (2):109-124.

Keenan, J. P. 1988. Communication Climate, Whistle-blowing, and the First-Level Manager: A Preliminary Study. Paper read at Academy of Management Proceedings.

- 1995. Whistleblowing and the first-level manager: Determinants of feeling obliged to blow the whistle. Journal of Social Behavior and Personality 10 (3):571-584.

Keenan, J. P., and D. L. McLain. 1992. Whistleblowing: a conceptualization and model Paper read at Academy of Management Proceedings.

Keller, T., and F. Dansereau. 2001. The effect of adding items to scales: An illustrative case of LMX. Organizational Research Methods 4 (2):131-143.

Kelly, J. R., and S. G. Barsade. 2001. Mood and emotions in small groups and work teams. Organizational behavior and human decision processes 86 (1):99-130.

Kessler, R. C., R. H. Price, and C. B. Wortman. 1985. Social factors in psychopathology: Stress, social support, and coping processes. Annual review of psychology 36 (1):531-572.

Kida, T. E., K. K. Moreno, and J. F. Smith. 2001. The Influence of Affect on Managers' CapitalBudgeting Decisions. Contemporary Accounting Research 18 (3):477-494.

King, G. 1997. The effects of interpersonal closeness and issue seriousness on blowing the whistle. Journal of Business Communication 34 (4):419-436.

Konovsky, M. A., and D. W. Organ. 1996. Dispositional and contextual determinants of organizational citizenship behavior. Journal of organizational behavior:253-266.

Leventhal, H., and A. J. Tomarken. 1986. Emotion: Today's problems. Annual review of psychology 37 (1):565-610. 
Levin, I. P., S. L. Schneider, and G. J. Gaeth. 1998. All frames are not created equal: A typology and critical analysis of framing effects. Organizational behavior and human decision processes 76 (2):149-188.

Lewis, J. D., and A. Weigert. 1985. Trust as a social reality. Social forces 63 (4):967-985.

Liden, R. C., and G. Graen. 1980. Generalizability of the vertical dyad linkage model of leadership. Academy of Management Journal 23 (3):451-465.

Locke, E. A.,(1976). The Nature and causes of job satisfaction. Handbook of industrial and organizational psychology:1297-1349.

Loeb, S. E., and S. N. Cory. 1989. Whistleblowing and management accounting: An approach. Journal of Business Ethics 8 (12):903-916.

Maksymov, E. M., and M. W. Nelson. 2017. Malleable standards of care required by jurors when assessing auditor negligence. The Accounting Review 92 (1):165-181.

Mandler, G. 1982. Mind and emotion: Krieger Publishing Company.

Martin, R., O. Epitropaki, G. Thomas, and A. Topakas. 2010. 2 A Review of Leader-Member Exchange Research: Future Prospects and Directions. International review of industrial and organizational psychology 25 (1):35-89.

Mason, W., and S. Suri. 2012. Conducting behavioral research on Amazon's Mechanical Turk. Behavior research methods 44 (1):1-23.

Maupin, R. J., and C. R. Lehman. 1994. Talking heads: Stereotypes, status, sex-roles and satisfaction of female and male auditors. Accounting, Organizations and Society 19 (45):427-437.

Mayer, J. D., R. D. Roberts, and S. G. Barsade. 2008. Human abilities: Emotional intelligence. Annu. Rev. Psychol. 59:507-536.

Mayer, J. D., and P. Salovey. 1997. Multifactor Emotioanl Intelligence Scale. Canaan, CT. 1997. What is emotioanl intelligence? In Emotional development and emotional intelligence: Educational implications, edited by P. SALONA and D. Sluyter: New York, Basic Books.

Mayer, J. D., P. Salovey, D. R. Caruso, and G. Sitarenios. 2001. Emotional intelligence as a standard intelligence. Emotion 1 (3):232-242.

- 2003. Measuring emotional intelligence with the MSCEIT V2. 0. Emotion 3 (1):97-105. 
Mayer, J. D., and N. Sharkey. 1986. How mood influences cognition. Advances in cognitive science 1:290-314.

Mayer, R. C., J. H. Davis, and F. D. Schoorman. 1995. An integrative model of organizational trust. Academy of management review 20 (3):709-734.

McAllister, D. J. 1995. Affect-and cognition-based trust as foundations for interpersonal cooperation in organizations. Academy of Management Journal 38 (1):24-59.

McPhail, K. 2004. An emotional response to the state of accounting education: developing accounting students' emotional intelligence. Critical Perspectives on Accounting 15 (4):629-648.

Mehrabian, A., and N. Epstein. 1972. A measure of emotional empathy. Journal of personality 40 (4):525-543.

Melita Prati, L., C. Douglas, G. R. Ferris, A. P. Ammeter, and M. R. Buckley. 2003. Emotional intelligence, leadership effectiveness, and team outcomes. The International Journal of Organizational Analysis 11 (1):21-40.

Mesmer-Magnus, J. R., and C. Viswesvaran. 2005. Whistleblowing in organizations: An examination of correlates of whistleblowing intentions, actions, and retaliation. Journal of Business Ethics 62 (3):277-297.

Messick, D. M., H. Wilke, M. B. Brewer, R. M. Kramer, P. E. Zemke, and L. Lui. 1983. Individual adaptations and structural change as solutions to social dilemmas. Journal of Personality and Social Psychology 44 (2):294.

Miceli, M. P., and J. P. Near. 1984. The relationships among beliefs, organizational position, and whistle-blowing status: A discriminant analysis. Academy of Management Journal 27 (4):687-705.

Miceli, M. P., and J. P. Near. 1988. Individual and situational correlates of whistle-blowing. Personnel Psychology 41 (2):267-281.

1994. Relationships among value congruence, perceived victimization, and retaliation against whistle-blowers. Journal of Management 20 (4):773-794.

Miceli, M. P., J. P. Near, and T. M. Dworkin. 2008. Whistle-blowing in Organizations: Routledge.

Miceli, M. P., J. P. Near, M. T. Rehg, and J. R. Van Scotter. 2012. Predicting employee reactions to perceived organizational wrongdoing: Demoralization, justice, proactive personality, and whistle-blowing. Human relations 65 (8):923-954. 
Ming Chia, Y. 2005. Job offers of multi-national accounting firms: The effects of emotional intelligence, extra-curricular activities, and academic performance. Accounting Education 14 (1):75-93.

Moreno, K., T. Kida, and J. F. Smith. 2002. The impact of affective reactions on risky decision making in accounting contexts. Journal of Accounting Research 40 (5):1331-1349.

Morgan, G. 1986. In Images of Organizations, 110-140.

Morris, W. N. 1989. The frame of mind. New York: Springer-Verlag.

Morris, W. N., and N. P. Reilly. 1987. Toward the self-regulation of mood: Theory and research. Motivation and emotion 11 (3):215-249.

Near, J. P., T. M. Dworkin, and M. P. Miceli. 1993. Explaining the whistle-blowing process: Suggestions from power theory and justice theory. Organization Science 4 (3):393-411.

Near, J. P., and M. P. Miceli. 1985. Organizational dissidence: The case of whistle-blowing. Journal of Business Ethics 4 (1):1-16.

- 1986. Retaliation against whistle blowers: Predictors and effects. Journal of Applied Psychology 71 (1):137-145.

- 1995. Effective-whistle blowing. Academy of management review 20 (3):679-708. 1996. Whistle-blowing: Myth and reality. Journal of Management 22 (3):507-526.

Neu, D. 1991. Trust, contracting and the prospectus process. Accounting, Organizations and Society 16 (3):243-256.

O'Day, R. 1974. Intimidation rituals: Reactions to reform. The Journal of Applied Behavioral Science 10 (3):373-386.

Ordun, G., and A. Beyhan Acar. 2014. Impact of emotional intelligence on the establishment and development of high quality leader member exchange (LMX). Advances in Management and Applied Economics 4 (2):111-129.

Organ, D. W. 1988. Organizational citizenship behavior: The good soldier syndrome: Lexington Books/DC Heath and Com.

- 1990. The motivational basis of organizational citizenship behavior. Research in organizational behavior 12 (1):43-72.

Ott, J. S. 1989. The organizational culture perspective: Dorsey Press. 
Palmer, B., M. Walls, Z. Burgess, and C. Stough. 2001. Emotional intelligence and effective leadership. Leadership \& Organization Development Journal 22 (1):5-10.

Parmerlee, M. A., J. P. Near, and T. C. Jensen. 1982. Correlates of whistle-blowers' perceptions of organizational retaliation. Administrative Science Quarterly:17-34.

Penner, L. A., A. R. Midili, and J. Kegelmeyer. 1997. Beyond job attitudes: A personality and social psychology perspective on the causes of organizational citizenship behavior. Human Performance 10 (2):111-131.

Pierro, A., L. Cicero, M. Bonaiuto, D. van Knippenberg, and A. W. Kruglanski. 2005. Leader group prototypicality and leadership effectiveness: The moderating role of need for cognitive closure. The Leadership Quarterly 16 (4):503-516.

Platow, M. J., and D. van Knippenberg. 2001. A social identity analysis of leadership endorsement: The effects of leader in-group prototypicality and distributive intergroup fairness. Personality and Social Psychology Bulletin 27 (11):1508-1519.

Randall, D. M., and M. F. Fernandes. 1991. The social desirability response bias in ethics research. Journal of Business Ethics 10 (11):805-817.

Rennekamp, K., K. K. Rupar, and N. Seybert. 2015. Impaired judgment: The effects of asset impairment reversibility and cognitive dissonance on future investment. The Accounting Review 90 (2):739-759.

Rennie, M. D., L. S. Kopp, and W. M. Lemon. 2010. Exploring trust and the auditor-client relationship: factors influencing the auditor's trust of a client representative. Auditing: A Journal of Practice \& Theory 29 (1):279-293.

Ridolphi, J., and A. Seers. 1984. Leader behavior versus leader-member exchange: A competitive test. Paper read at Southeast Decision Sciences meeting, Williamsburg, VA.

Robinson, S. N., J. C. Robertson, and M. B. Curtis. 2012. The effects of contextual and wrongdoing attributes on organizational employees' whistleblowing intentions following fraud. Journal of Business Ethics 106 (2):213-227.

Rose, A. M., J. M. Rose, and M. Dibben. 2010. The effects of trust and management incentives on audit committee judgments. Behavioral Research in Accounting 22 (2):87-103.

Rose, J. M. 2007. Attention to evidence of aggressive financial reporting and intentional misstatement judgments: Effects of experience and trust. Behavioral Research in Accounting 19 (1):215-229.

Rosenhan, D., P. Salovey, and K. Hargis. 1981. The joys of helping: Focus of attention mediates the impact of positive affect on altruism. Journal of Personality and Social Psychology 40 (5):899-905. 
Rosenhan, D. L., B. Underwood, and B. Moore. 1974. Affect moderates self-gratification and altruism. Journal of Personality and Social Psychology 30 (4):546.

Rotondi, T. 1975. Organizational identification: Issues and implications. Organizational behavior and human performance 13 (1):95-109.

Rushton, J. P., R. D. Chrisjohn, and G. C. Fekken. 1981. The altruistic personality and the selfreport altruism scale. Personality and individual differences 2 (4):293-302.

Rutte, C., and H. Wilke. 1985. Preference for decision structures in a social dilemma situation. European Journal of Social Psychology 15 (3):367-370.

Salovey, P., and J. D. Mayer. 1990. Emotional intelligence. Imagination, cognition and personality 9 (3):185-211.

Salovey, P., J. D. Mayer, S. L. Goldman, C. Turvey, and T. P. Palfai. 1995. Emotional attention, clarity, and repair: Exploring emotional intelligence using the Trait Meta-Mood Scale. In Emotion, disclosure, \& health., edited by J. W. Pennebaker and J. W. Pennebaker. Washington, DC, US: American Psychological Association, 125-154.

Salovy, P., C. K. Hsee, and J. D. Mayer. 1990. Emotional intelligence and the self-regulation of affect. In Handbook of mental control, edited by D. M. Wegner and J. W. Pennebaker. Englewood Cliffs, NJ: Prentice-Hall, 258-277.

Samuelson, C. D. 1991. Perceived task difficulty, causal attributions, and preferences for structural change in resource dilemmas. Personality and Social Psychology Bulletin 17 (2):181-187.

Samuelson, C. D., and D. M. Messick. 1986. Inequities in access to and use of shared resources in social dilemmas. Journal of Personality and Social Psychology 51 (5):960-967.

- 1995. When do people want to change the rules for allocating shared resources. Social dilemmas: Perspectives on individuals and groups:143-162.

Samuelson, C. D., D. M. Messick, C. Rutte, and H. Wilke. 1984. Individual and structural solutions to resource dilemmas in two cultures. Journal of Personality and Social Psychology 47 (1):94-104.

Schein, E. H. 2010. Organizational culture and leadership. Vol. 2: John Wiley \& Sons.

Schultz, J. J., D. A. Johnson, D. Morris, and S. Dyrnes. 1993. An investigation of the reporting of questionable acts in an international setting. Journal of Accounting Research:75-103. 
Schutte, N. S., J. M. Malouff, L. E. Hall, D. J. Haggerty, J. T. Cooper, C. J. Golden, and L. Dornheim. 1998. Development and validation of a measure of emotional intelligence. Personality and individual differences 25 (2):167-177.

Schwarz, N. 1990. Feelings as information: informational and motivational funtions of affective states Guilford Press.

Seifert, D. L., W. W. Stammerjohan, and R. B. Martin. 2014. Trust, Organizational Justice, and Whistleblowing: A Research Note. Behavioral Research in Accounting 26 (1):157-168.

Seifert, D. L., J. T. Sweeney, J. Joireman, and J. M. Thornton. 2010. The influence of organizational justice on accountant whistleblowing. Accounting, Organizations and Society 35 (7):707-717.

Seppälä, T., J. Lipponen, and A.-M. Pirttilä-Backman. 2012. Leader fairness and employees' trust in coworkers: The moderating role of leader group prototypicality. Group Dynamics: Theory, Research, and Practice 16 (1):35-49.

Shapiro, S. P. 1987. The social control of impersonal trust. American journal of sociology 93 (3):623-658.

- 1987. The social control of impersonal trust. American journal of sociology 93 (3):623658.

Simon, H. A. 1982. Comments. In Affect and Cogniton, edited by M. S. Clark and S. T. Fiske. Hilldale, NJ: Erlbaum, 333-342.

Sinclair, R. C., and M. M. Mark. 1992. The influence of mood state on judgment and action: Effects on persuasion, categorization, social justice, person perception, and judgmental accuracy. In The construction of social judgments, edited by L. L. Martin and A. Tesser. Hilldale, NJ: Erlbaum, 165-193.

Sitkin, S. B., and N. L. Roth. 1993. Explaining the limited effectiveness of legalistic "remedies" for trust/distrust. Organization Science 4 (3):367-392.

Smith, C., D. W. Organ, and J. P. Near. 1983. Organizational citizenship behavior: Its nature and antecedents. Journal of Applied Psychology 68 (4):653-663.

Sosik, J. J., and L. E. Megerian. 1999. Understanding leader emotional intelligence and performance the role of self-other agreement on transformational leadership perceptions. Group \& Organization Management 24 (3):367-390.

Sternberg, R. J., and C. Smith. 1985. Social intelligence and decoding skills in nonverbal communication. Social Cognition 3 (2):168-192. 
Sy, T., S. Tram, and L. A. O’Hara. 2006. Relation of employee and manager emotional intelligence to job satisfaction and performance. Journal of vocational behavior 68 (3):461-473.

Tajfel, H., and J. C. Turner. 2004. The Social Identity Theory of Intergroup Behavior.

Tapia, M. 2001. Measuring emotional intelligence. Psychological Reports 88 (2):353-364.

Taylor, E. Z., and M. B. Curtis. 2013. Whistleblowing in audit firms: Organizational response and power distance. Behavioral Research in Accounting 25 (2):21-43.

Taylor, S. E., and S. T. Fiske. 1978. Salience, attention, and attribution: Top of the head phenomena. Advances in experimental social psychology 11:249-288.

Treviño, L. K., G. R. Weaver, and S. J. Reynolds. 2006. Behavioral ethics in organizations: A review. Journal of Management 32 (6):951-990.

Trice, H. M., and J. M. Beyer. 1993. The cultures of work organizations: Prentice-Hall, Inc.

Trompeter, G. M., T. D. Carpenter, N. Desai, K. L. Jones, and R. A. Riley Jr. 2013. A synthesis of fraud-related research. Auditing: A Journal of Practice \& Theory 32 (sp1):287-321.

Trompeter, G. M., T. D. Carpenter, K. L. Jones, and R. A. Riley Jr. 2014. Insights for research and practice: What we learn about fraud from other disciplines. Accounting Horizons 28 (4):769-804.

Trotman, K. T., and J. Sng. 1989. The effect of hypothesis framing, prior expectations and cue diagnosticity on auditors' information choice. Accounting, Organizations and Society 14 (5):565-576.

Turner, J. C., M. A. Hogg, P. J. Oakes, S. D. Reicher, and M. S. Wetherell. 1987. Rediscovering the social group: A self-categorization theory: Basil Blackwell.

Tversky, A., and D. Kahneman. 1974. Judgment under uncertainty: heuristics and biases. Science 185:1124-1131.

Tversky, A., and D. Kahneman. 1981. Framing of decisions and the psychology of choice. Science 211:453-458.

Tyler, T. R., and S. L. Blader. 2000. Cooperation in groups: Procedural justice, social identity, and behavioral engagement: Psychology Press.

- 2003. The group engagement model: Procedural justice, social identity, and cooperative behavior. Personality and social psychology review 7 (4):349-361.

Uhl-Bien, M. 2006. Relational leadership theory: Exploring the social processes of leadership and organizing. The Leadership Quarterly 17 (6):654-676. 
Valentine, S., and G. Fleischman. 2004. Ethics training and businesspersons' perceptions of organizational ethics. Journal of Business Ethics 52 (4):391-400.

Van Knippenberg, B., and D. Van Knippenberg. 2005. Leader self-sacrifice and leadership effectiveness: the moderating role of leader group prototypicality. Journal of Applied Psychology 90 (1):25.

Van Vugt, M., and D. De Cremer. 1999. Leadership in social dilemmas: The effects of group identification on collective actions to provide public goods. Journal of Personality and Social Psychology 76 (4):587-599.

Vance, T. W. 2010. Subcertification and relationship quality: Effects on subordinate effort. Contemporary Accounting Research 27 (3):959-981.

VanMaanen, J., and G. Kunda. 1989. Real feelings-emotional expression and organizational culture. Research in organizational behavior 11:43-103.

Victor, B., L. K. Trevino, and D. L. Shapiro. 1993. Peer reporting of unethical behavior: The influence of justice evaluations and social context factors. Journal of Business Ethics 12 (4):253-263.

Vinten, G. 1994. Whistleblowing-fact and fiction. An introductory discussion. Whistleblowing: Subversion or corporate citizenship:3-20.

Wakabayashi, M., G. Graen, and M. Uhl-Bien. 1990. The generalizability of the hidden investment hypothesis in leading Japanese corporations. Human relations 43 (11):10991116.

Wakabayashi, M., and G. B. Graen. 1984. The Japanese Career Progress Study: A 7-Year Follow-Up. Journal of Applied Psychology 69 (4):603-614.

Walker, R. E., and J. M. Foley. 1973. Social intelligence: Its history and measurement. Psychological Reports 33 (3):839-864.

Wang, H., K. S. Law, R. D. Hackett, D. Wang, and Z. X. Chen. 2005. Leader-member exchange as a mediator of the relationship between transformational leadership and followers' performance and organizational citizenship behavior. Academy of Management Journal 48 (3):420-432.

Wanous, J. P., A. E. Reichers, and M. J. Hudy. 1997. Overall job satisfaction: how good are single-item measures? The Journal Of Applied Psychology 82 (2):247-252.

Weinstein, D. 2013. Bureaucratic opposition: Challenging abuses at the workplace: Elsevier. 
Williams, L. J., and S. E. Anderson. 1991. Job satisfaction and organizational commitment as predictors of organizational citizenship and in-role behaviors. Journal of Management 17 (3):601-617.

Wolff, S. B., A. T. Pescosolido, and V. U. Druskat. 2002. Emotional intelligence as the basis of leadership emergence in self-managing teams. The Leadership Quarterly 13 (5):505-522.

Wong, C.-S., and K. S. Law. 2002. The effects of leader and follower emotional intelligence on performance and attitude: An exploratory study. The Leadership Quarterly 13 (3):243274.

Yukl, G. 2012. Effective leadership behavior: What we know and what questions need more attention. The Academy of Management Perspectives 26 (4):66-85.

Yunus, N. H., K. Ghazali, and C. N. Hassan. 2011. The influence of leader's emotional intelligence: Mediating effect of leader-member exchange on employees' organizational citizenship behaviors. Interdisciplinary Journal of Contemporary Research in Business 3 (3):1125-1134.

Zerbe, W. J., and D. L. Paulhus. 1987. Socially desirable responding in organizational behavior: A reconception. Academy of management review 12 (2):250-264. 


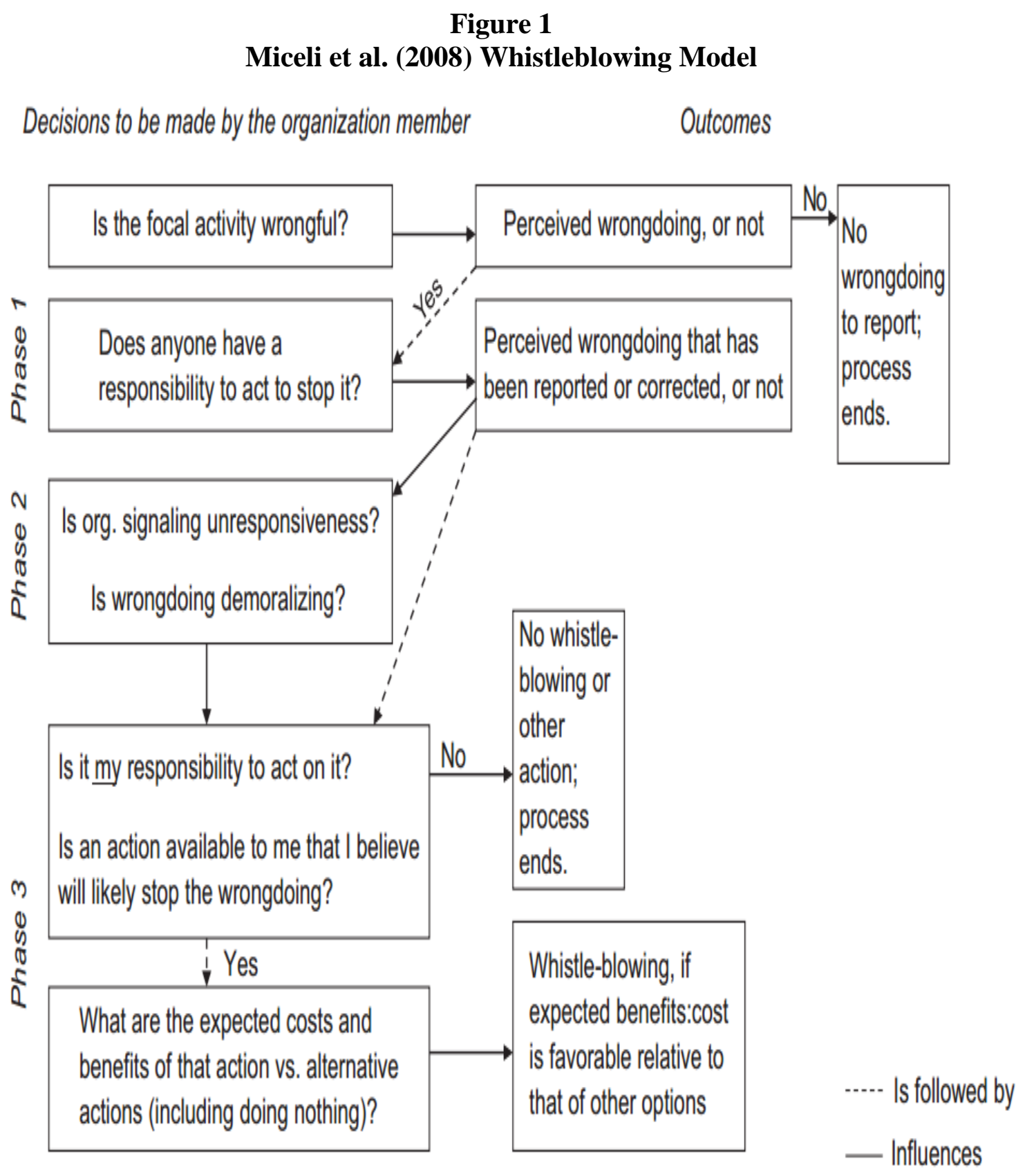

Adopted from Miceli et al. (2008) with permission from the authors. 
Figure 2

Partial Model for Primary Experiment - IV is Leader Emotional Intelligence ${ }^{a}$

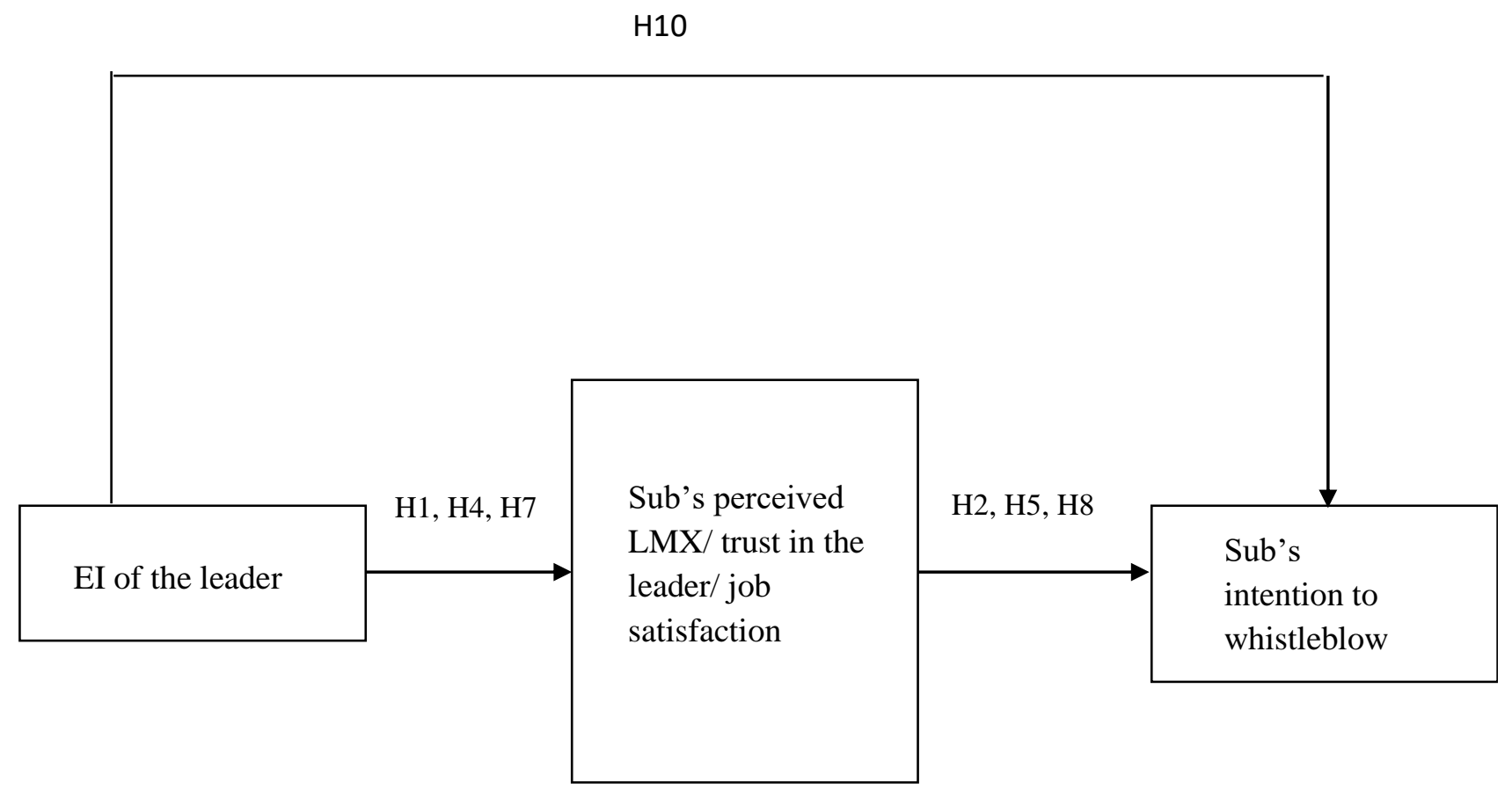

\footnotetext{
${ }^{a}$ Mediation-related hypotheses $\mathrm{H} 3, \mathrm{H} 6$, and $\mathrm{H} 9$ are not displayed in the figure due to space and layout limitations.
}

H1: A subordinate perceives higher LMX when the leader has high emotional intelligence than low emotional intelligence.

H2: A subordinate's perceived LMX is positively related to his intention to report fraudulent behavior to his leader.

H3: A subordinate's perceived LMX positively mediates the relationship between his leader's emotional intelligence and his intention to report fraudulent behavior to the leader.

H4: A subordinate has higher trust in his leader when the leader has high emotional intelligence than low emotional intelligence.

H5: A subordinate's trust in his leader is positively related to his intention to report fraudulent behavior to the leader.

H6: A subordinate's trust in his leader positively mediates the relationship between the leader's emotional intelligence and his intention to report fraudulent behavior to the leader. 
H7: A subordinate has higher job satisfaction when the leader has high emotional intelligence than low emotional intelligence.

H8: A subordinate's job satisfaction is positively related to his intention to report fraudulent behavior to his leader.

H9: A subordinate's job satisfaction positively mediates the relationship between his leader's emotional intelligence and his intention to report fraudulent behavior to the leader.

H10: A subordinate is more likely to report fraudulent behavior to his leader when his leader has high emotional intelligence than low emotional intelligence. 
Figure 3

Partial Model for Primary Experiment - IV is Leader Group Prototypicality ${ }^{\text {a }}$

H17

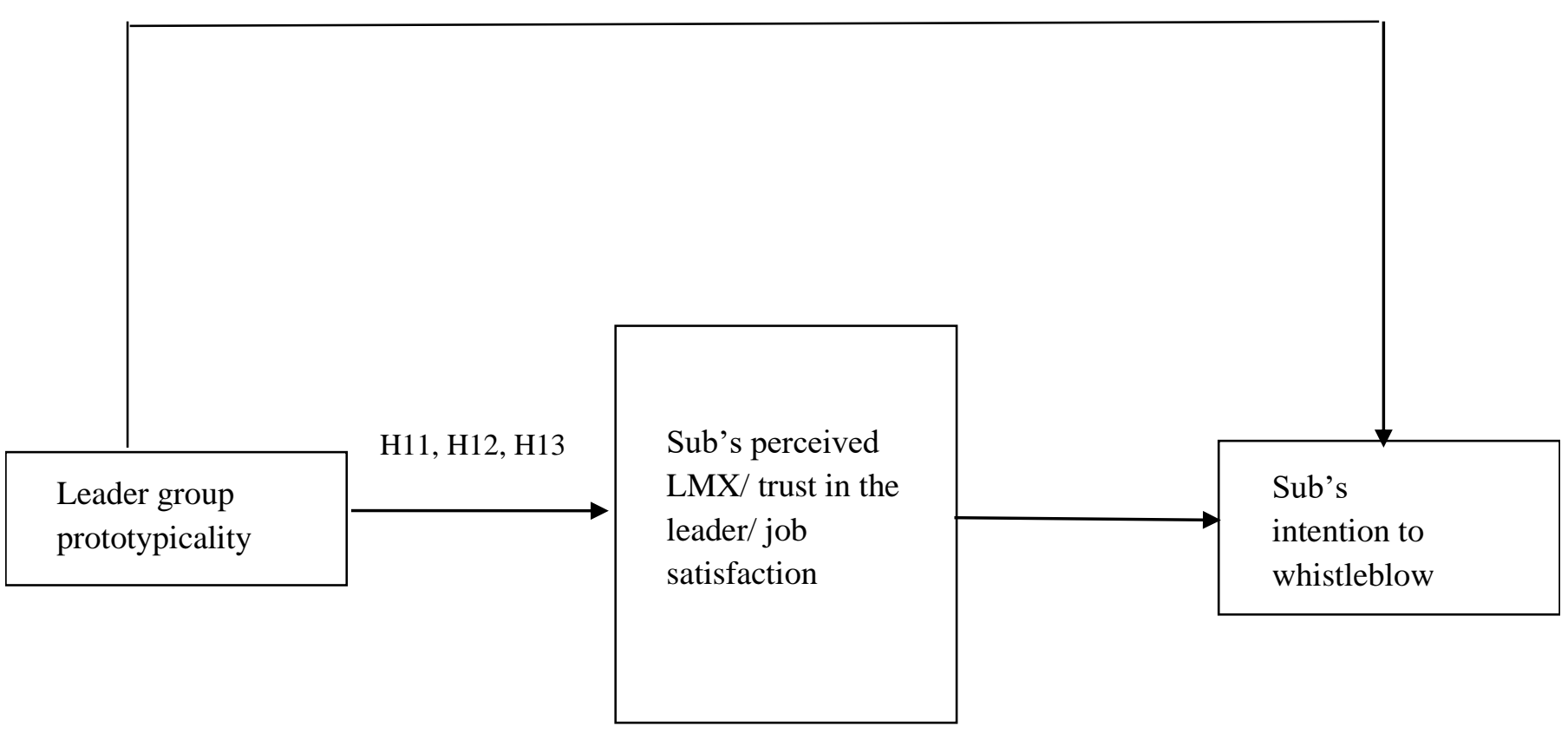

${ }^{a}$ Mediation-related hypotheses $\mathrm{H} 14, \mathrm{H} 15$, and $\mathrm{H} 16$ are not displayed in the figure due to space and layout limitations.

H11: A subordinate perceives higher LMX when the leader has high group prototypicality than low group prototypicality.

H12: A subordinate has higher trust in his leader when the leader has high group prototypicality than low group prototypicality.

H13: A subordinate has higher job satisfaction when the leader has high group prototypicality than low group prototypicality.

H14: A subordinate's perceived LMX positively mediates the relationship between his leader's group prototypicality and his intention to report fraudulent behavior to the leader.

H15: A subordinate's trust in his leader positively mediates the relationship between the leader's group prototypicality and his intention to report fraudulent behavior to the leader.

H16: A subordinate's job satisfaction positively mediates the relationship between his leader's group prototypicality and his intention to report fraudulent behavior to the leader.

H17: A subordinate is more likely to report fraudulent behavior when his leader has high group prototypicality than when his leader has low group prototypicality. 
Figure 4

Complete Model for Primary Experiment ${ }^{a, b}$

$\mathrm{H} 21$

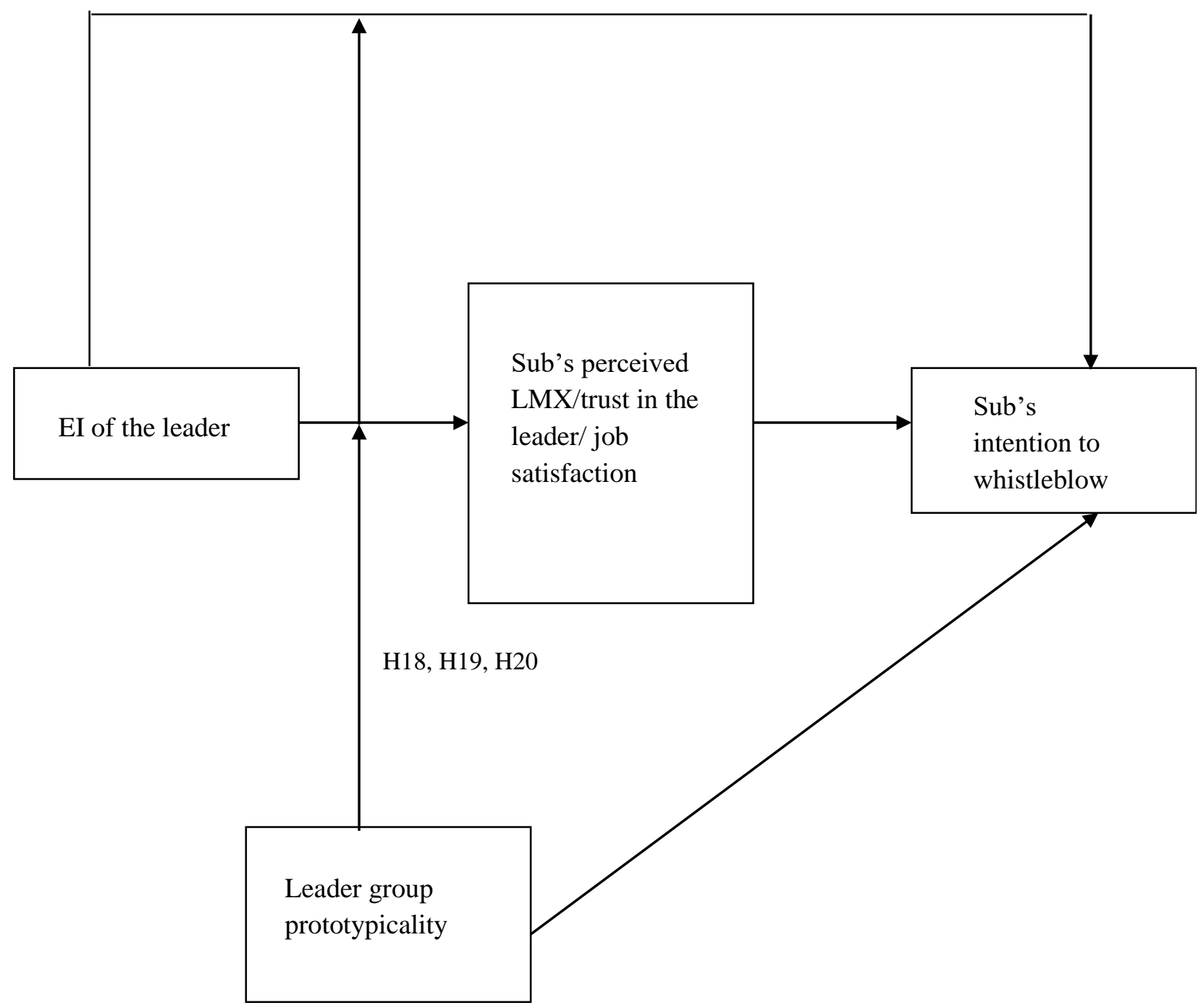

${ }^{a}$ Hypotheses that are already displayed and stated in Figure 2 and 3 are not marked in Figure 4 for the purpose of brevity. See Appendix I for a full list of hypotheses.

${ }^{b}$ Moderated mediation hypotheses $\mathrm{H} 22, \mathrm{H} 23$, and $\mathrm{H} 24$ are not displayed due to space and structure limitations.

H18: The effect of a leader's emotional intelligence on his subordinate's perceived LMX is stronger when he has high group prototypicality than low group prototypicality. 
H19: The effect of a leader's emotional intelligence on his subordinate's trust in him is stronger when he has high group prototypicality than low group prototypicality.

H20: The effect of a leader's emotional intelligence on his subordinate's job satisfaction is stronger when he has high group prototypicality than low group prototypicality.

H21: The effect of a leader's emotional intelligence on his subordinate's intention to report fraudulent behavior is stronger when he has high group prototypicality than low group prototypicality.

H22: The mediated relationship between a leader's emotional intelligence and his subordinate's intention to report fraudulent behavior through the subordinate's perceived LMX is stronger when the leader has high group prototypicality than low group prototypicality.

H23: The mediated relationship between a leader's emotional intelligence and his subordinate's intention to report fraudulent behavior through the subordinate's trust in the leader is stronger when the leader has high group prototypicality than low group prototypicality.

H24: The mediated relationship between a leader's emotional intelligence and his subordinate's intention to report fraudulent behavior through the subordinate's job satisfaction is stronger when the leader has high group prototypicality than low group prototypicality. 


\section{Figure 5 \\ Interaction of LEI and LGP on WBFS ${ }^{a}$}

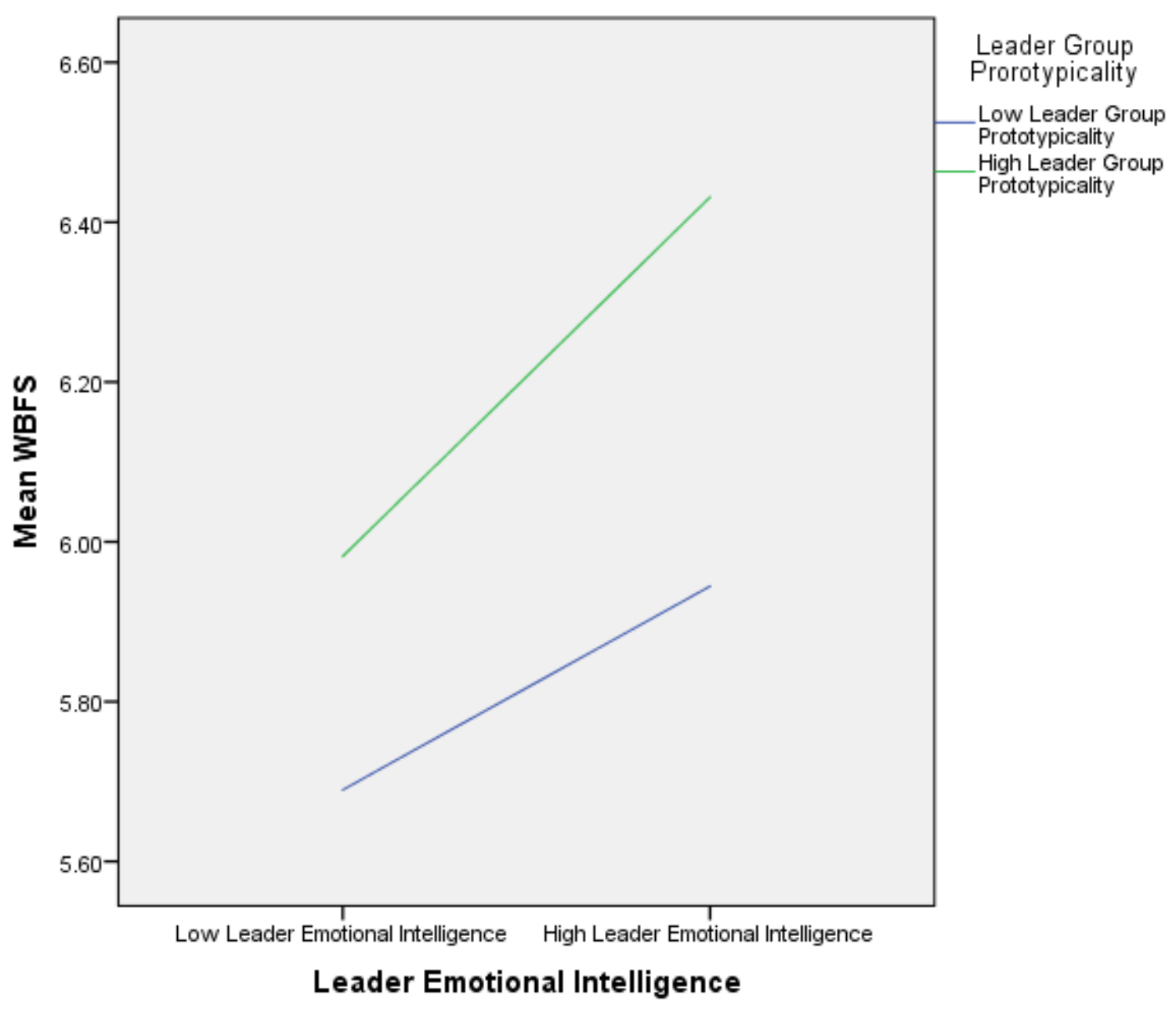

${ }^{\text {a }}$ Leader emotional intelligence and leader group prototypicality are manipulated at the level of high or low. WBFS is measured by the assessment on the statement "If you were Adrian, it is likely for you to report the fraud to Bailey" labeled from 1 (Strongly Disagree) to 7 (Strongly Agree) for the financial statement fraud. 
Figure 6

Interaction of LEI and LGP on WBAM ${ }^{\mathrm{a}}$

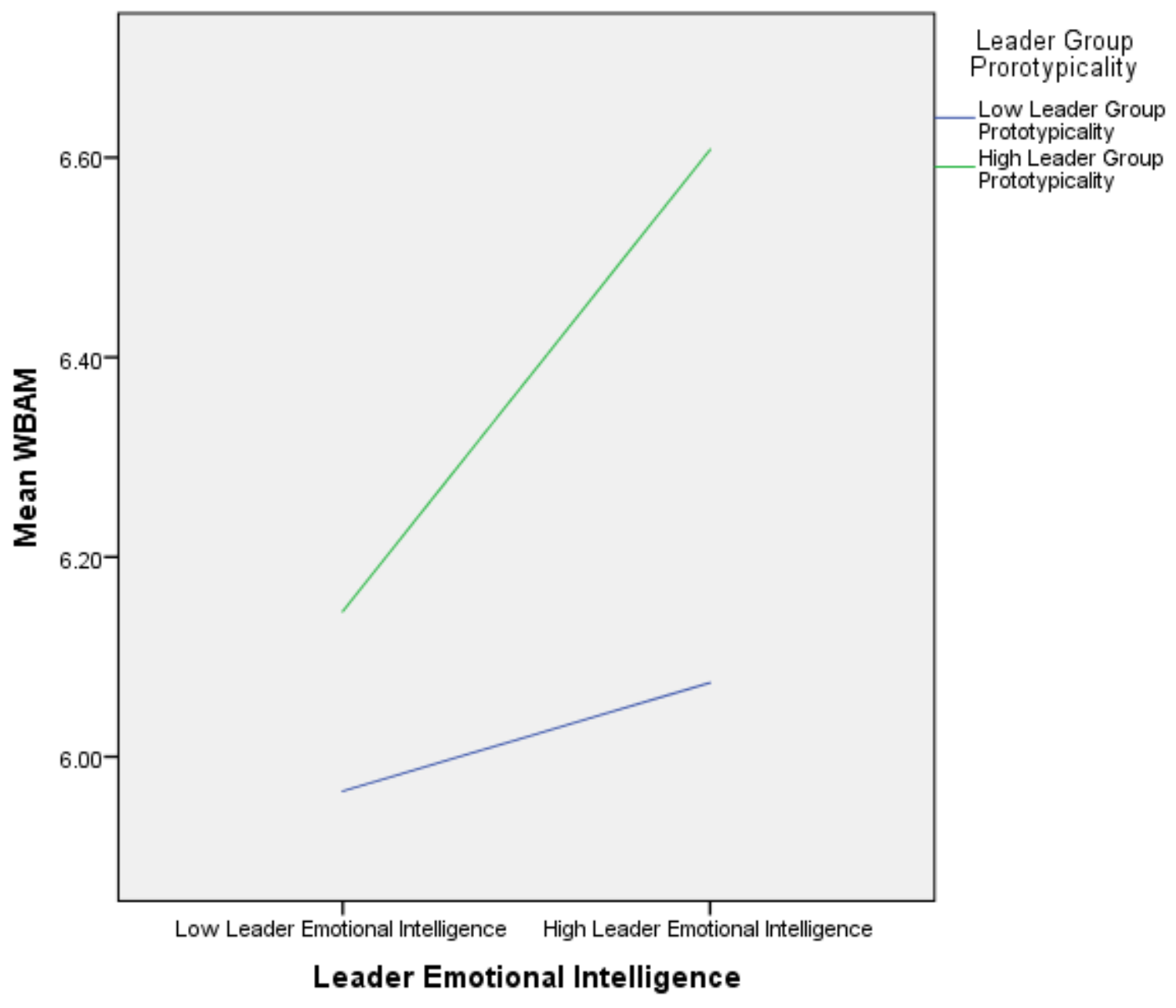

${ }^{a}$ Leader emotional intelligence and leader group prototypicality are manipulated at the level of high or low. WBAM is measured by the assessment on the statement "If you were Adrian, it is likely for you to report the fraud to Bailey" labeled from 1 (Strongly Disagree) to 7 (Strongly Agree) for the asset misappropriation fraud. 
Figure 7

Interaction of LEI and LGP on LMX

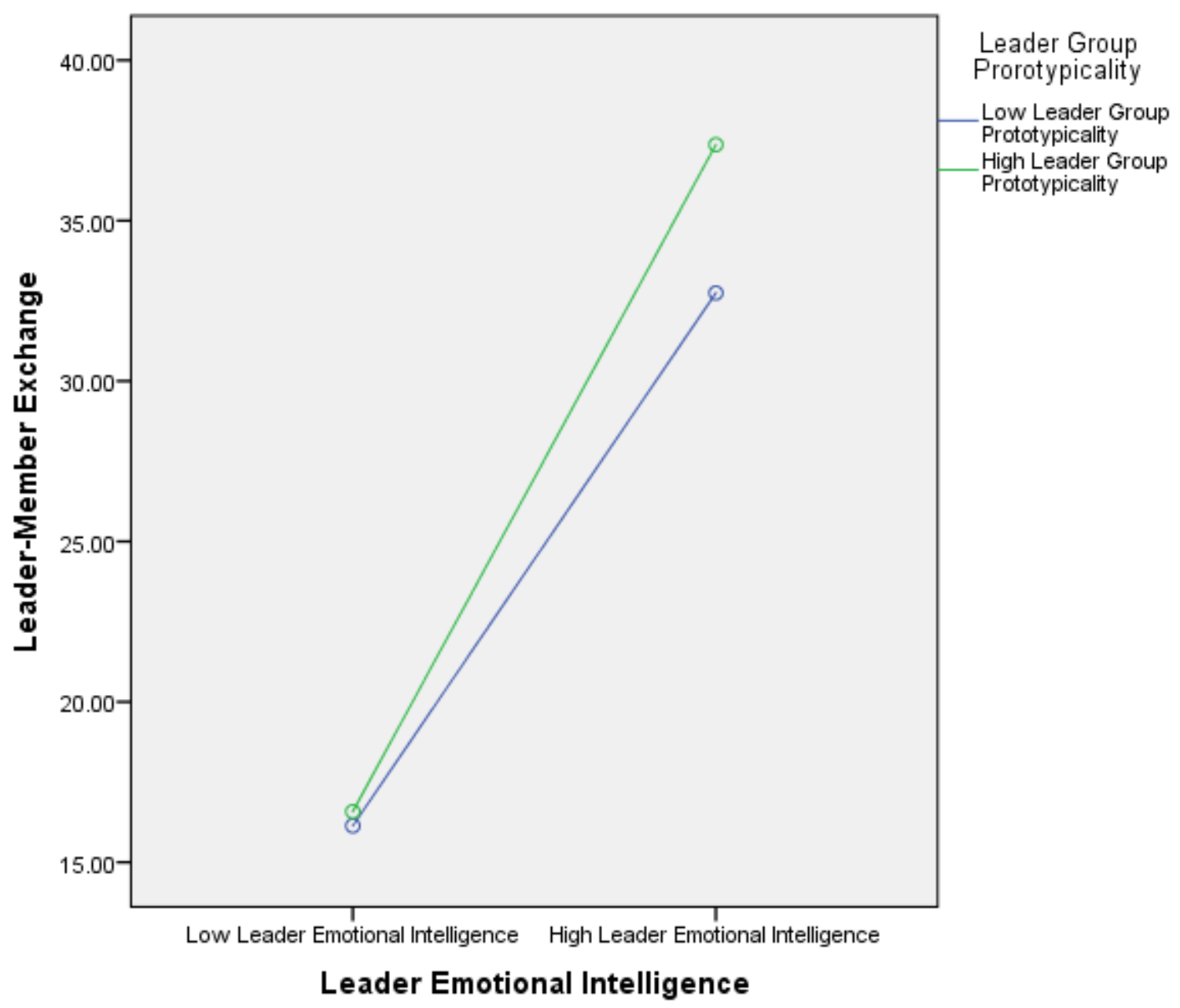

${ }^{a}$ Leader emotional intelligence and leader group prototypicality are manipulated at the level of high or low. Leader-member exchange is measured as the sum of six items of a Likert-scale labeled from 1 (Strongly Disagree) to 7 (Strongly Agree). 
Figure 8

Interaction of LEI and LGP on Trust ${ }^{\mathrm{a}}$

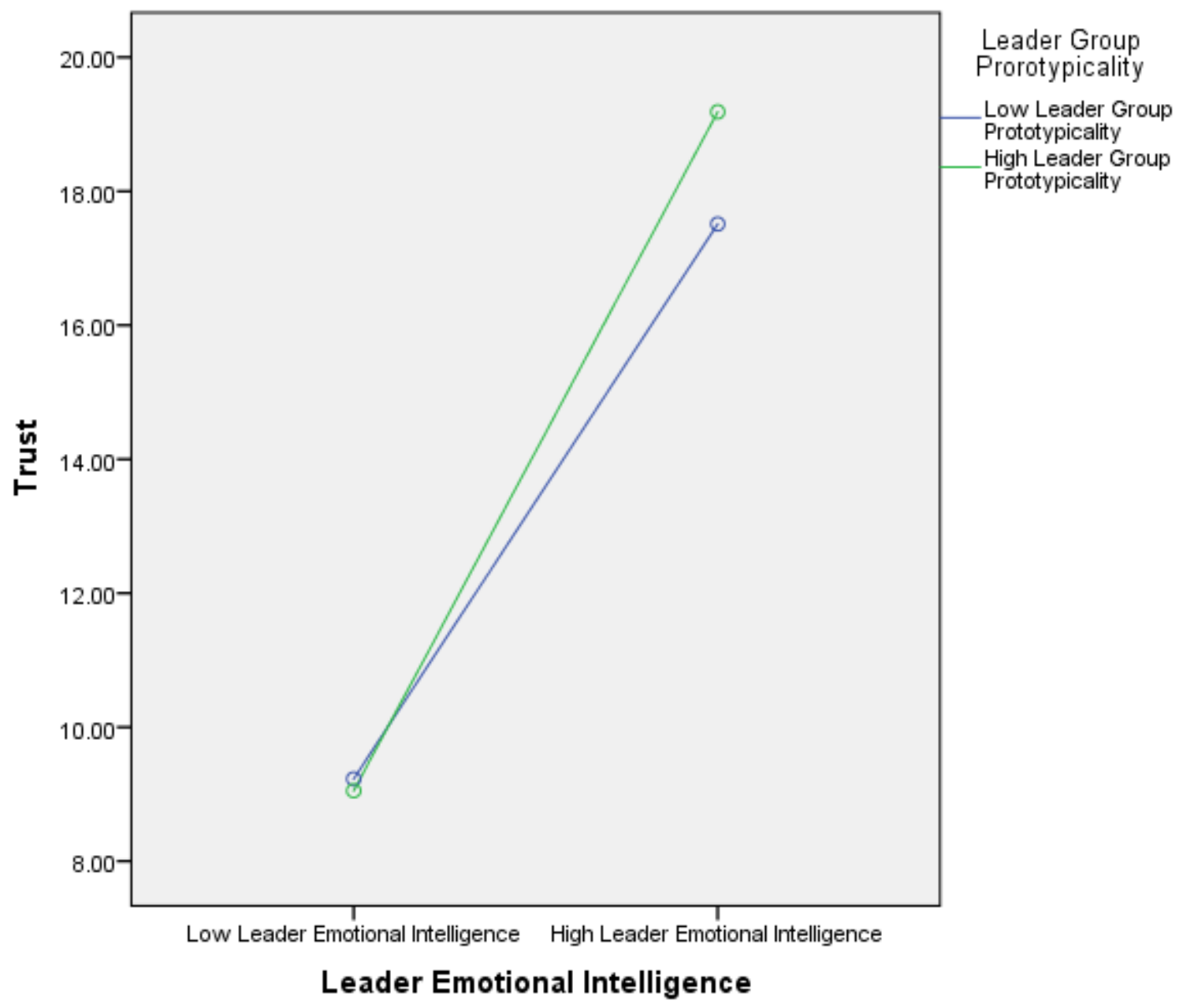

${ }^{a}$ Leader emotional intelligence and leader group prototypicality are manipulated at the level of high or low. Trust is measured as the sum of three items of a Likert-scale labeled from 1 (Strongly Disagree) to 7 (Strongly Agree). 
Figure 9

Interaction of LEI and LGP on JS $\mathbf{J S}^{\mathrm{a}}$

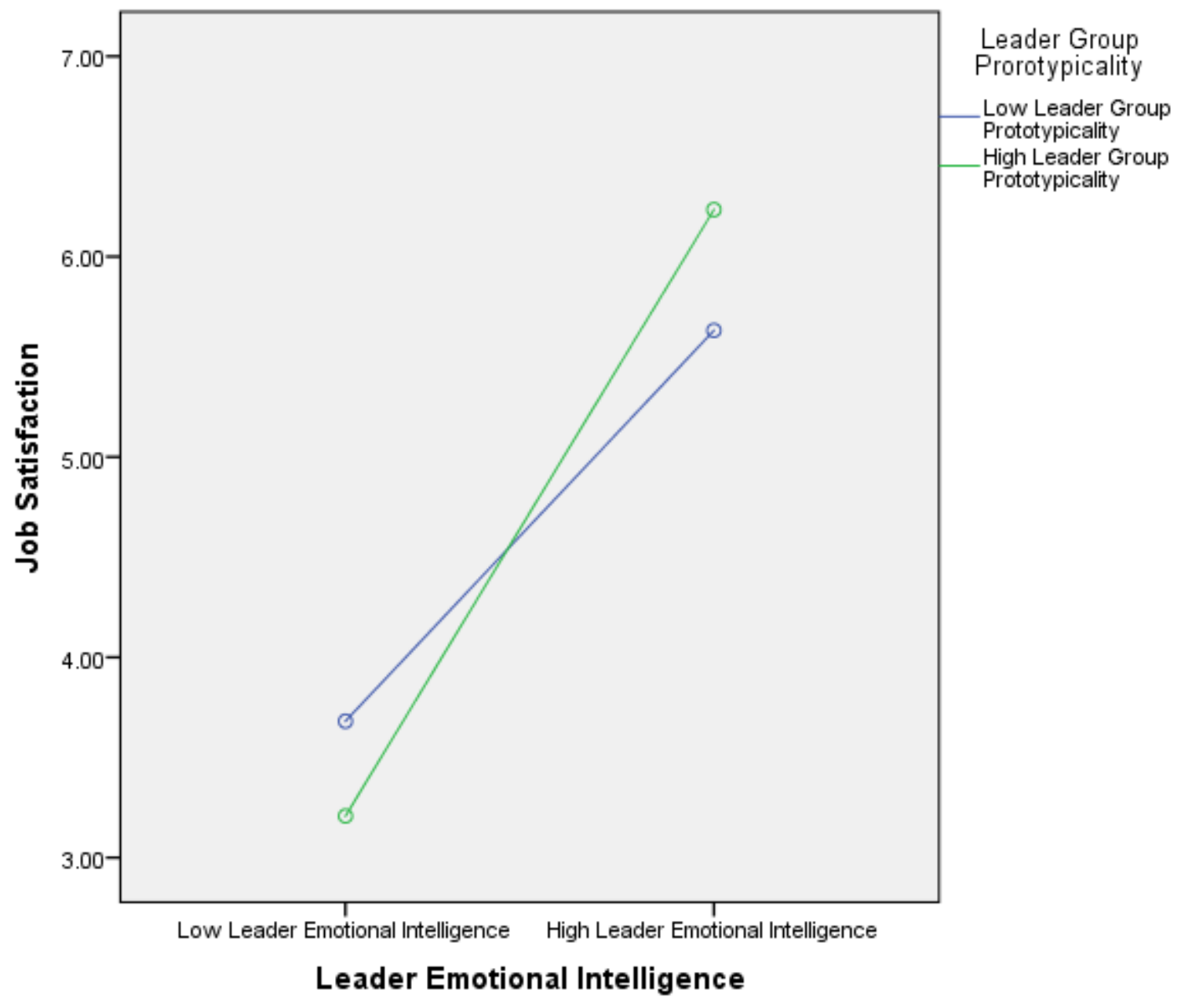

${ }^{a}$ Leader emotional intelligence and leader group prototypicality are manipulated at the level of high or low. Job satisfaction is measured by the assessment on the statement "If you were Adrian, you are satisfied with the job" labeled from 1 (Strongly Disagree) to 7 (Strongly Agree). 
Figure 10

Interaction of CF and LEI on WBa

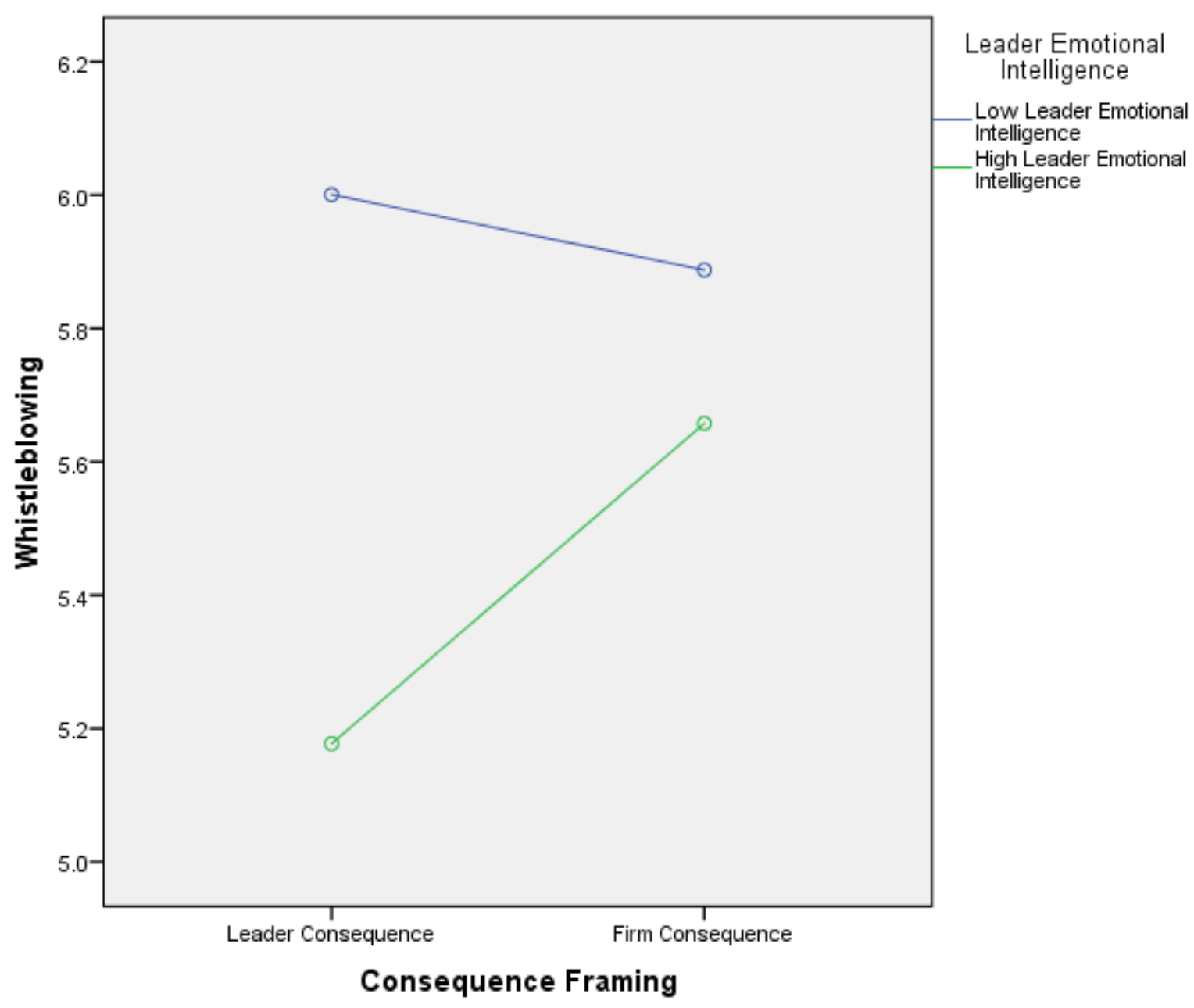

${ }^{a}$ Leader emotional intelligence is manipulated at the levels of high or low. Consequence framing is manipulated as leader consequence or firm consequence. Whistleblowing (WB) is measured by the assessment on the statement "If you were Adrian, it is likely for you to report the fraud to the anonymous whistleblowing hotline" labeled from 1 (Strongly Disagree) to 7 (Strongly Agree). 
Figure 11

Interaction of LEI and EI on WB $\mathrm{W}^{\mathrm{a}, \mathrm{b}}$

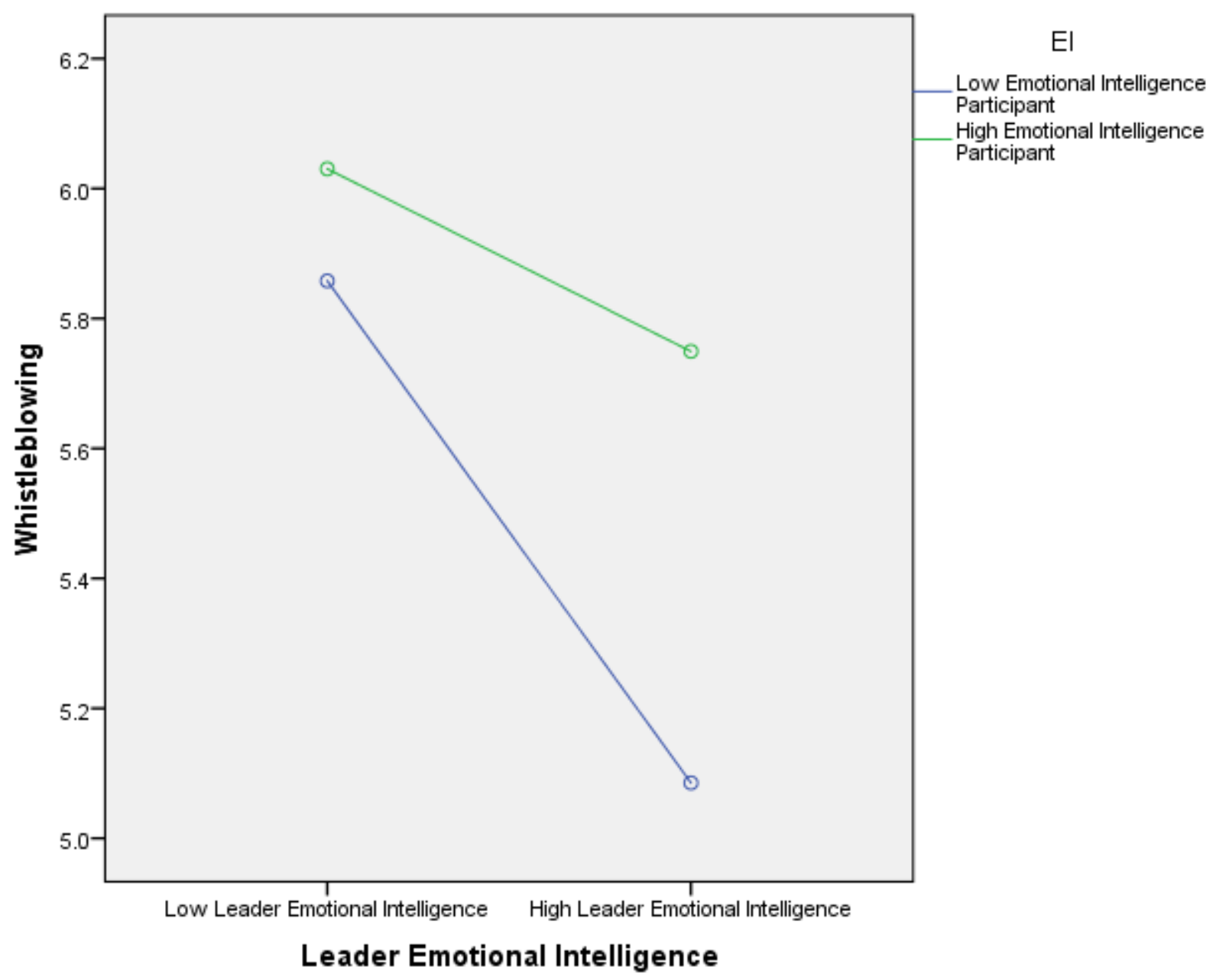

a Leader emotional intelligence is manipulated at the levels of high or low. Participants' emotional intelligence is measured by the sum of 33 items in the Schutte et al. (1998)'s emotional intelligence scale. Whistleblowing (WB) is measured by the assessment on the statement "If you were Adrian, it is likely for you to report the fraud to the anonymous whistleblowing hotline" labeled from 1 (Strongly Disagree) to 7 (Strongly Agree).

${ }^{\mathrm{b}}$ This interaction is close to be statistically significant ( $\mathrm{p}=0.111$, one-tailed). 
Table 1

\section{Major Models of Whistleblowing in the Literature}

\section{$\underline{\text { Authors }}$}

Field of Study

Miceli et al. (2008)

Management

Gundlach et al. (2003)
Management

\section{Key Points}

This model is a 3-phase model. In phase 1 , employees decide whether the focal activity is wrongful. In

phase 2, employees ask themselves whether the organization is signaling unresponsiveness and whether wrongdoing is demoralizing. In phase 3 , employees will decide whether it is their responsibility to act and whether there is an action that could stop the wrong doing. Questions in each phase must be answered before the employees can go to the next phase.

This model has three sets of factors that could potentially influence employees' whistleblowing decisionmaking process: intrapersonal

factors, interpersonal factors, and moderators. Intrapersonal factors include attribution, judgment of responsibility, emotions, and costbenefit analysis. Interpersonal factors include defensive impression management and offensive impression management. Moderators include credibility of presentation and power of wrongdoers. This model demonstrate how individuals process information to arrive at causal interpretation and judgments of responsibility for perceived wrong doing that leaders to decisions to whistleblow.

\section{Comparison with Miceli et al. (2008) Model}

N/A

Both models assume or start with awareness of wrongdoing and consider cost-benefit analysis as a vital step right before the whistleblowing action. However, the Gundlach et al. (2003)'s model concentrates more on the cognitive and information processing/attribution part of the whistleblowing decision process and takes possible effects of emotions into account 


\section{Authors}

\section{Field of Study}

Keenan and McLain (1992)

Management

\section{Key Points}

This model has seven stages and three possible moderating effects. The first stage is about wrongdoing awareness. The second stage involves the assessment of the seriousness of the wrongdoing. The third stage involves the motivation to

correct the wrongdoing. The fourth stage involves an assessment of personal influence over the situation. The sixth stage involves an assessment of the consequences of self. Others, and the wrongful behavior. The seventh stage presents four options that the observer can eventually choose to settle his concern: suppression (silence), procedural reporting through prescribed channels, nonprocedural reporting, or correcting the wrongdoing through direct intervention.

Potential moderators in this model include individual differences, situational factors, and symbolic interpretive influences. This model indicates that whistleblowing is a process of interaction of an observer's characteristics, opportunities to observe misbehavior, and perceived options for reducing the anxiety experienced by the observer.

\section{Comparison with Miceli et al. (2008) Model}

As with Miceli et al. (2008)'s model, this interactionist model includes awareness of wrongdoing, assessment of wrongdoing, determining personal influence, and cost-benefit analysis. However, the interactionist model focuses more on how different kinds of factors work together to influence the whistleblowing process, which is not strongly emphasized in Miceli et al. (2008)'s model. 


\section{Authors}

\section{Field of Study}

Loeb and Cory (1989) Accounting

\section{Key Points}

This model is a three-step model. In step 1, management accountants who observe the potential wrongdoing should consult with an independent objective outside observer to determine whether the matter under consideration is or potentially is and whether it could result in harmful consequences. In step 2, management accountants consider the formal appeal procedures that are already established in the organization. If the appeal is successful, the process will end. If it fails to satisfy the management accountants, then in step 3 , $\mathrm{s} / \mathrm{he}$ may then consult with independent outside observers and determine whether harmful consequences can be prevented or stopped if the wrongdoing is made public. If the answer is YES, the management accountant will whistleblow to the public while he may remain silence if the answer is NO.

In this model, after the observer encounters the wrongdoing, he needs to consider three factors before making the reporting choice: the perceived seriousness of the irregularity, the attribution of personal responsibility for reporting, and the perceived personal cost of reporting. The more serious the irregularity is, the more personal

responsibility is attributed to the observer him/herself, and the less the personal cost of reporting is, the more possible for the observer to whistleblow.

\section{Comparison with Miceli et al. (2008) Model}

This model is in accordance with the view of Miceli et al. (2008) that whistleblowing is a process not an event. However, it distinguishes between internal whistleblowing and external whistleblowing and they believe that internal whistleblowing should occur before external whistleblowing.

As with Miceli et al. (2008)'s model, this model takes personal responsibility and costbenefit analysis into account. However, this model considers neither the response from the organization nor the personal ability to stop the wrongdoing. 


\section{Table 2}

\section{Recent Whistleblowing Studies in the Accounting Literature}

\section{$\underline{\text { Authors }}$}

Kaplan et al. (2015)

Taylor and Curtis (2013)

Kaplan et al. (2012)

Kaplan et al. (2011)

Seifert et al. (2010)

Kaplan et al. (2009)

\section{Methodology}

Managerial likeability and the type of fraud significantly affect participants' intention to whistleblow to the manager. However, managerial procedural safeguard and its interaction with managerial likeability do not significantly influence participants' intention to whistleblow to the manager.

Auditors (106 senior-level auditors as participants) are more likely to report on their peers than on their superiors, but they are more likely to report superiors when prior organizational response is strong than when it is weak.

Negative outcomes from previous whistleblowing incident lower participants' intention to whistleblow to non-anonymous channel, but not to anonymous channel. However, if there are no such negative outcomes, there is no whistleblowing intention difference between anonymous and non-anonymous channels.

Participants are more likely to report fraud to inquiring auditors than noninquiring auditors and to internal auditors than external auditors. Meanwhile, different types of fraud do not have an effect on participants' whistleblowing intention.

The three components of organizational justice (procedural fairness, distributive fairness, and interactive fairness) are positively related to employees' (447 internal auditors and management accountants as participants) intention to whistleblow.

Participants' intention to report a fraudulent act is greater under the weaker safeguards conditions as compared with the stronger safeguards condition. Moreover, an externally administered anonymous hotline may not increase fraud reporting. 


\section{$\underline{\text { Authors }}$}

Bowen et al. (2010)

\section{$\underline{\text { Methodology }}$}

Whistleblowing target firms share some common characteristics in terms of growth, communication channel, size, and whistleblowers' ability to share the proceeds of any fraud-related settlement with the U.S. government. More specifically, those target firms are large and successful firms with high growth. After the whistleblowing, those firms experience negative consequences such as stock price decrease and financial statements restatement. However, the future corporate governance gets improved. 


\section{Table 3}

\section{Recent Affect-Related Studies in the Accounting Literature}

\section{Authors \\ Topic Methodology \\ $\underline{\text { Key Findings }}$}

Johnson et al. (2016)

Bhattacharjee et al. (2012)

Bagley (2010)

Cianci and Bierstaker (2009)

Chung et al. (2008)
Auditing

Experiment

Participants (118 senior auditors) with high arousal, low fear, and low significance are more likely not to acquiesce to obedience pressure from their managers in six ethical dilemmas.

Auditors with negative affect toward a low competence client rate higher inventory obsolescence and document more items indicative of increased obsolescence while auditors with positive affect toward low competence client rate similar inventory obsolescence and document more items of decreased obsolescence. However, under high client competence, affect does not have an effect on both inventory obsolescence judgment and documentation.

Multiple accountabilities can cause negative emotions and that the resulting negative reactions can harm low-complexity audit task performance.

Auditors in the negative mood condition generate more correct explanations Auditing Experiment for fluctuations in the gross margin and inventory turnover ratio and make less ethical judgments on the ethical tasks executed in the experiment

More disagreements are likely to occur with auditors in a positive mood than in a negative mood, suggesting that mood impacts information use. 


\section{Authors}

Moreno et al. (2002)

Kida et al. (2001) $\underline{\text { Topic }}$

Managerial

Accounting

Managerial

Accounting
Methodology

When affect is induced, capital budgeting decision makers tend to reject

Experiment

investment alternatives that elicit negative affect and accept alternatives that elicit positive affect, which is in contradict with prospect theory.

Managers consider both financial data and affective reactions when making capital budgeting decisions. More specifically, managers are more likely to reject decision alternatives that elicit negative emotion even if these alternatives have higher expected value in terms of finance. 
Table 4

Demographic Information $(\mathrm{N}=\mathbf{2 1 8})^{\mathrm{a}}$

\section{Panel A: Continuous Variables}

\begin{tabular}{|c|c|c|}
\hline & $\underline{\text { Mean }}$ & $\underline{\text { Standard }}$ \\
\hline Age & 34.87 & 10.34 \\
\hline Years of work experience & 14.61 & 10.34 \\
\hline $\begin{array}{l}\text { Number of accounting class that the participant has } \\
\text { taken }\end{array}$ & 1.13 & 1.87 \\
\hline $\begin{array}{l}\text { Number of business class that the participant has } \\
\text { taken }\end{array}$ & 3.25 & 5.75 \\
\hline
\end{tabular}

\section{Panel B: Dichotomous and Other Measures}

Gender

Occupation $(n=217)$

Highest degree
Male

Female

Umemployed/Retired

Non-Business/Non-

Management

Business/Management

High School Degree

Associate Degree

Bachelor Degree

Graduate Degree

\begin{tabular}{|c|c|}
\hline Number & $\underline{\text { Percentage }}$ \\
\hline 102 & $46.80 \%$ \\
\hline 116 & $53.20 \%$ \\
\hline 11 & $5.1 \%$ \\
\hline 170 & $78.3 \%$ \\
\hline 36 & $16.6 \%$ \\
\hline 63 & $28.9 \%$ \\
\hline 41 & $18.8 \%$ \\
\hline 92 & $42.2 \%$ \\
\hline 22 & $10.1 \%$ \\
\hline
\end{tabular}


College Major

Have you ever reported an observed accounting fraud?

Have you ever reported an observed fraud?

Have you ever actively participated in an account fraud?

Have you ever actively participated in a fraud?

N/A

Non-Business

Business

Yes

No

I can't remember

Yes

No

I can't remember

$$
\begin{aligned}
& \text { Yes } \\
& \text { No } \\
& \text { I can't remember }
\end{aligned}
$$

Yes

\begin{tabular}{|c|c|}
\hline Number & Percentag \\
\hline 44 & $18.8 \%$ \\
\hline 135 & $61.9 \%$ \\
\hline 42 & $19.3 \%$ \\
\hline
\end{tabular}

No

can't remember

$\begin{array}{cc}18 & 8.30 \% \\ 196 & 89.90 \% \\ 4 & 1.80 \% \\ & \\ 38 & 17.40 \% \\ 174 & 79.80 \% \\ 6 & 2.80 \%\end{array}$

217

0

$0.50 \%$

$99.50 \%$

$0.00 \%$

$\begin{array}{cc}7 & 3.20 \% \\ 210 & 96.30 \% \\ 1 & 0.50 \%\end{array}$

${ }^{\text {a }}$ Each variable/measurement contains 218 participants unless specified otherwise. 
Table 5

Correlation $^{\text {a }}$

\begin{tabular}{|l|l|l|l|l|l|l|l|l|l|l|l|}
\hline & LEI & LGP & LMX & TRUST & JS & WBFS & WBAM & EI & ALT & SDBFS & SDBAM \\
\hline LEI & 1 & & & & & & & & & & \\
\hline LGP & -0.001 & 1 & & & & & & & & & \\
\hline LMX & $0.828^{* *}$ & 0.116 & 1 & & & & & & & & \\
\hline TRUST & $0.784^{* *}$ & 0.066 & $0.927^{* *}$ & 1 & & & & & & & \\
\hline JS & $0.679^{* *}$ & 0.020 & $0.819^{* *}$ & $0.824^{* *}$ & 1 & & & & & & \\
\hline WBFS & 0.127 & $0.140^{*}$ & $0.268^{* *}$ & $0.258^{* *}$ & $0.241^{* *}$ & 1 & & & & & \\
\hline WBAM & 0.113 & $0.142^{*}$ & $0.221^{* *}$ & $0.212^{* *}$ & $0.205^{* *}$ & $0.770^{* *}$ & 1 & & & & \\
\hline EI & 0.002 & 0.090 & 0.103 & 0.077 & 0.105 & $0.230^{* *}$ & $0.248^{* *}$ & 1 & & & \\
\hline ALT & -0.041 & -0.022 & -0.007 & -0.015 & 0.006 & -0.031 & 0.043 & $0.295^{* *}$ & 1 & & \\
\hline SDBFS & $-0.135^{*}$ & -0.052 & -0.088 & -0.131 & -0.058 & $0.331^{* *}$ & $0.216^{* *}$ & 0.041 & 0.079 & 1 & \\
\hline SDBAM & -0.089 & 0.016 & -0.070 & -0.071 & -0.023 & $0.154^{*}$ & $0.364^{* *}$ & 0.007 & 0.069 & $0.449^{* *}$ & 1 \\
\hline
\end{tabular}

a $*$ and $* *$ indicate 0.05 and 0.01 significance level respectively (two-tailed).

\section{Variable Definitions:}

LEI - Dichotomous variable indicating the leader's emotional intelligence $(1=$ high leader emotional intelligence, $0=$ low leader emotional intelligence);

LGP - Dichotomous variable indicating leader group prototypicality $(1=$ high leader group prototypicality, $0=$ low leader group prototypicality);

LMX - Participants' assessment on how effective the relationship is between the subordinate (the participant) and the leader; sum of six items;

TRUST - Participants' assessment on how much trust the subordinate (the participant) has in the leader; sum of three items; 
JS - Participants' assessment on how satisfied the subordinate (the participant) is with his job in ABC company (1= very dissatisfied, $7=$ very satisfied);

WBFS - Participants' assessment on the statement that "If you were Adrian, it is likely for you to report the fraud to Bailey." financial statement fraud (1 = Strongly Disagree, 7 = Strongly Agree);

WBAM - Participants' assessment on the statement that "If you were Adrian, it is likely for you to report the fraud to Bailey." - asset misappropriation fraud ( 1 = Strongly Disagree, 7 = Strongly Agree $)$;

EI - Participants' emotional intelligence; sum of 33 items;

ALT - Participants' altruism; sum of 20 items;

SDBFS - Participants' social desirability bias for financial statement fraud. It is calculated as the difference between the assessments on "If you were Adrian, it is likely for you to report the fraud to Bailey" and "It is likely for Adrian to report the fraud to Bailey."

SDBAM - Participants' social desirability bias for asset misappropriation fraud. It is calculated as the difference between the assessments on "If you were Adrian, it is likely for you to report the fraud to Bailey" and "It is likely for Adrian to report the fraud to Bailey." 
Table 6

MANCOVA Analysis ${ }^{a}$,

$\begin{array}{lccccc} & \underline{V} \text { Value } & \underline{\mathrm{F}} & \underline{\mathrm{df}} & \underline{\text { Error df }} & \underline{\underline{\text { Sig. }}} \\ \text { Intercept } & 0.706 & 17.116 & 5 & 206 & 0.000 \\ \text { ALT } & 0.976 & 1.02 & 5 & 206 & 0.407 \\ \text { EI } & 0.917 & 3.706 & 5 & 206 & 0.003 \\ \text { SDBAM } & 0.779 & 11.688 & 5 & 206 & 0.000 \\ \text { SDBFS } & 0.798 & 10.43 & 5 & 206 & 0.000 \\ \text { LEI } & 0.290 & 100.855 & 5 & 206 & 0.000 \\ \text { LGP } & 0.924 & 3.411 & 5 & 206 & 0.006 \\ \text { LEI*LGP } & 0.946 & 2.354 & 5 & 206 & 0.042\end{array}$

a Wilk's Lambda is used to estimate value and significance for each variable.

${ }^{\mathrm{b}}$ All significance levels are two-tailed. 
Table 7

ANCOVAs for WBFS and WBAM ${ }^{\mathrm{a}}$

Panel A: WBFS as dependent variable

\begin{tabular}{|c|c|c|c|c|c|}
\hline \multirow[b]{3}{*}{ Source } & \multicolumn{4}{|c|}{ ANCOVA } & \multirow[b]{3}{*}{$\underline{\text { Sig. }}$} \\
\hline & $\underline{\text { Sum of }}$ & & Mean & & \\
\hline & $\underline{\text { Squares }}$ & $\underline{\mathrm{df}}$ & $\underline{\text { Square }}$ & $\underline{F}$ & \\
\hline $\begin{array}{l}\text { Corrected } \\
\text { Model }\end{array}$ & 90.324 & 6 & 15.054 & 9.814 & $0.000^{* * * *}$ \\
\hline Intercept & 74.139 & 1 & 74.139 & 48.330 & $0.000^{* * *}$ \\
\hline EI & 21.090 & 1 & 21.090 & 13.748 & $0.000^{* * * *}$ \\
\hline ALT & 5.379 & 1 & 5.379 & 3.507 & $0.063^{*}$ \\
\hline SDBFS & 52.215 & 1 & 52.215 & 34.038 & $0.000^{* * * *}$ \\
\hline $\mathrm{LGP}^{\mathrm{b}}$ & 7.407 & 1 & 7.407 & 4.829 & $0.015^{* *}$ \\
\hline $\mathrm{LEI}^{\mathrm{b}}$ & 11.721 & 1 & 11.721 & 7.641 & $0.003^{* * * *}$ \\
\hline $\mathrm{LGP}^{*} \mathrm{LEI}^{\mathrm{b}}$ & 0.005 & 1 & 0.005 & 0.003 & 0.478 \\
\hline Error & 323.676 & 211 & 1.534 & & \\
\hline Total & 8262.000 & 218 & & & \\
\hline $\begin{array}{l}\text { Corrected } \\
\text { Total }\end{array}$ & 414.000 & 217 & & & \\
\hline
\end{tabular}

R Squared $=0.218$ (Adjusted R Squared $=0.196)$

Pairwise Comparisons

\begin{tabular}{|c|c|c|c|c|c|c|}
\hline & & $\underline{\text { Mean }}$ & \multicolumn{2}{|l|}{$\underline{\text { Std. }}$} & Lower & Upper \\
\hline & & Difference & $\underline{\text { Error }}$ & $\underline{\text { Sig }}$ & $\underline{\text { Bound }}$ & Bound \\
\hline High LEI & Low LEI & 0.469 & 0.170 & $0.003^{* * *}$ & 0.134 & 0.803 \\
\hline High LGP & Low LGP & 0.372 & 0.169 & $0.015^{* *}$ & 0.038 & 0.705 \\
\hline
\end{tabular}


Contrast for LEI*LGP Interaction

Treatment Group

Low LEI and Low LGP

High LEI and Low LGP

Low LEI and High LGP

High LEI and High LGP

F Value

$P$ Value

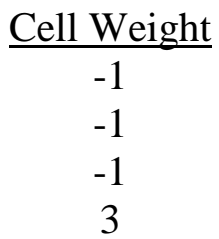

8.024

$0.005^{* * *}$

Panel B: WBAM as dependent variable

\begin{tabular}{|c|c|c|c|c|c|}
\hline \multirow[b]{3}{*}{ Source } & \multicolumn{4}{|c|}{ ANCOVA } & \multirow[b]{3}{*}{$\underline{\text { Sig. }}$} \\
\hline & $\underline{\text { Sum of }}$ & & $\underline{\text { Mean }}$ & & \\
\hline & $\overline{\text { Squares }}$ & $\underline{\mathrm{df}}$ & $\underline{\text { Square }}$ & $\underline{F}$ & \\
\hline $\begin{array}{l}\text { Corrected } \\
\text { Model }\end{array}$ & 77.115 & 6 & 12.853 & 10.586 & $0.000^{* * *}$ \\
\hline Intercept & 72.181 & 1 & 72.181 & 59.453 & $0.000^{* * *}$ \\
\hline EI & 18.215 & 1 & 18.215 & 15.003 & $0.000^{* * * *}$ \\
\hline ALT & 0.625 & 1 & 0.625 & 0.515 & $0.474^{* * *}$ \\
\hline SDBAM & 46.202 & 1 & 46.202 & 38.055 & $0.000^{* * * *}$ \\
\hline $\mathrm{LGP}^{\mathrm{b}}$ & 4.304 & 1 & 4.304 & 3.545 & $0.031^{* *}$ \\
\hline $\mathrm{LEI}^{\mathrm{b}}$ & 7.006 & 1 & 7.006 & 5.771 & $0.009^{* * *}$ \\
\hline $\mathrm{LGP} * \mathrm{LEI}^{\mathrm{b}}$ & 0.871 & 1 & 0.871 & 0.718 & 0.199 \\
\hline Error & 256.174 & 211 & 1.214 & & \\
\hline Total & 8681.000 & 218 & & & \\
\hline $\begin{array}{l}\text { Corrected } \\
\text { Total }\end{array}$ & 333.289 & 217 & & & \\
\hline
\end{tabular}

R Squared $=0.231($ Adjusted R Squared $=0.210)$

\section{Pairwise Comparisons}

\begin{tabular}{|c|c|c|c|c|c|c|}
\hline & & Mean & $\underline{\text { Std. }}$ & & Lower & Upper \\
\hline & & Difference & $\underline{\text { Error }}$ & $\underline{\text { Sig }}$ & Bound & $\underline{B o u n d}$ \\
\hline High LEI & Low LEI ${ }^{\mathrm{b}}$ & 0.361 & 0.150 & $0.009^{* * *}$ & 0.065 & 0.657 \\
\hline High LGP & Low LGP & 0.283 & 0.150 & $0.031^{* *}$ & -0.013 & 0.579 \\
\hline
\end{tabular}




\section{Contrast for LEI*LGP Interaction}

Treatment Group

Low LEI and Low LGP

High LEI and Low LGP

Low LEI and High LGP

High LEI and High LGP

F Value

$\mathrm{P}$ Value

\section{Cell Weight}

$-1$

$-1$

$-1$

3

8.376

$0.004^{* * *}$

a $* * *$, and $* * *$ indicate $0.1,0.05$, and 0.01 significance level respectively.

$\mathrm{b}$ indicates a hypothesized variable. P-values are one-tailed for hypothesized variables and are two-tailed for all other variables. 
Table 8

ANCOVA for LMX as the Dependent Variable ${ }^{a}$

\section{ANCOVA}

\begin{tabular}{|c|c|c|c|c|c|}
\hline & Sum of & & $\underline{\text { Mean }}$ & & \\
\hline Source & $\overline{\text { Squares }}$ & $\underline{\mathrm{df}}$ & $\overline{\text { Square }}$ & $\underline{F}$ & $\underline{\text { Sig. }}$ \\
\hline $\begin{array}{l}\text { Corrected } \\
\text { Model }\end{array}$ & 19745.708 & 5 & 3949.142 & 106.536 & $0.000^{* * *}$ \\
\hline Intercept & 1382.055 & 1 & 1382.055 & 37.284 & $0.000^{* * * *}$ \\
\hline EI & 184.262 & 1 & 184.262 & 4.971 & $0.027^{* *}$ \\
\hline ALT & 1.292 & 1 & 1.292 & 0.035 & 0.852 \\
\hline $\mathrm{LGP}^{\mathrm{b}}$ & 344.905 & 1 & 344.905 & 9.305 & $0.001^{\text {**** }}$ \\
\hline $\mathrm{LEI}^{\mathrm{b}}$ & 18978.206 & 1 & 18978.206 & 511.977 & $0.000^{* * * *}$ \\
\hline $\mathrm{LGP} * \mathrm{LEI}^{\mathrm{b}}$ & 236.360 & 1 & 236.360 & 6.376 & $0.006^{\text {*** }}$ \\
\hline Error & 7858.512 & 212 & 37.068 & & \\
\hline Total & 167478.000 & 218 & & & \\
\hline $\begin{array}{l}\text { Corrected } \\
\text { Total }\end{array}$ & 27604.220 & 217 & & & \\
\hline
\end{tabular}

R Squared $=0.715$ (Adjusted R Squared $=0.709)$

\section{Pairwise Comparisons for Main Effect}

\begin{tabular}{|c|c|c|c|c|}
\hline & & $\underline{\underline{\text { Mean }}}$ & $\underline{\text { Std. Error }}$ & $\underline{\text { Sig }}$ \\
\hline High LEI & Low LEI $^{\mathrm{b}}$ & 18.700 & 0.826 & $0.000^{* * *}$ \\
\hline High LGP & Low LGP & 2.532 & 0.830 & $0.001^{\text {*** }}$ \\
\hline
\end{tabular}

\section{Simple Effects for Interaction}

\section{$\underline{\text { High LEI - Low LEI }}$}

$\begin{array}{lcccc} & \underline{\text { Mean }} & & \underline{\text { Std. }} & \\ \text { Low LGP } & \underline{\text { Difference }} & & \underline{\text { Error }} & \underline{\text { Sig }} \\ \text { High LGP }^{\mathrm{b}} & 16.611 & & 1.152 & 0.000^{* * *} \\ & 20.789 & & 1.187 & 0.000^{* * *}\end{array}$

a $*, * *$, and $* * *$ indicate $0.1,0.05$, and 0.01 significance level respectively. 
$\mathrm{b}$ indicates a hypothesized variable. P-values are one-tailed for hypothesized variables and are two-tailed for all other variables. 
Table 9

ANCOVA for TRUST as the Dependent Variable ${ }^{\mathrm{a}}$

\begin{tabular}{|c|c|c|c|c|c|}
\hline & & ANC & & & \\
\hline & $\underline{\text { Sum of }}$ & & Mean & & \\
\hline Source & $\underline{\text { Squares }}$ & $\underline{\mathrm{df}}$ & Square & $\underline{F}$ & $\underline{\text { Sig. }}$ \\
\hline $\begin{array}{l}\text { Corrected } \\
\text { Model }\end{array}$ & 4705.144 & 5 & 941.029 & 72.165 & $0.000^{* * * *}$ \\
\hline Intercept & 480.279 & 1 & 480.279 & 36.832 & $0.000^{* * * *}$ \\
\hline EI & 29.712 & 1 & 29.712 & 2.279 & 0.133 \\
\hline ALT & 0.035 & 1 & 0.035 & 0.003 & 0.959 \\
\hline $\mathrm{LGP}^{\mathrm{b}}$ & 30.151 & 1 & 30.151 & 2.312 & $0.065^{*}$ \\
\hline $\mathrm{LEI}^{\mathrm{b}}$ & 4601.829 & 1 & 4601.829 & 352.904 & $0.000^{* * * *}$ \\
\hline LGP $* \mathrm{LEI}^{\mathrm{b}}$ & 46.360 & 1 & 46.360 & 3.555 & $0.030^{* *}$ \\
\hline Error & 2764.457 & 212 & 13.040 & & \\
\hline Total & 47579.000 & 218 & & & \\
\hline $\begin{array}{l}\text { Corrected } \\
\text { Total }\end{array}$ & 7469.601 & 217 & & & \\
\hline
\end{tabular}

R Squared $=0.630($ Adjusted R Squared $=0.621)$

\section{Pairwise Comparisons for Main Effect}

\begin{tabular}{|c|c|c|c|c|}
\hline & & $\begin{array}{c}\text { Mean } \\
\text { Difference }\end{array}$ & $\underline{\text { Std. Error }}$ & \\
\hline High LEI & Low LEI $^{\mathrm{b}}$ & 9.208 & 0.490 & $0.000^{* * * *}$ \\
\hline High LGP & Low LGP & 0.749 & 0.492 & $0.065^{*}$ \\
\hline
\end{tabular}

\section{Simple Effects for Interaction}

High LEI - Low LEI

$\begin{array}{lcccl} & \begin{array}{c}\text { Mean } \\ \text { Difference }\end{array} & & \underline{\underline{\text { Std. }}} & \\ \text { Low LGP }^{b} & 8.283 & & \text { Sig } \\ \text { High LGP }^{b} & 10.133 & & 0.704 & 0.000^{* * *} \\ & & 0.000^{* * *}\end{array}$

a $*$, **, and $* * *$ indicate $0.1,0.05$, and 0.01 significance level respectively. 
$\mathrm{b}$ indicates a hypothesized variable. P-values are one-tailed for hypothesized variables and are two-tailed for all other variables. 
Table 10

ANCOVA for JS as the Dependent Variable ${ }^{a}$

\begin{tabular}{|c|c|c|c|c|c|}
\hline \multirow[b]{3}{*}{ Source } & \multicolumn{3}{|c|}{ ANCOVA } & \multirow[b]{3}{*}{$\underline{F}$} & \multirow[b]{3}{*}{$\underline{\text { Sig. }}}$. \\
\hline & $\underline{\text { Sum of }}$ & & Mean & & \\
\hline & Squares & $\underline{\mathrm{df}}$ & $\underline{\text { Square }}$ & & \\
\hline $\begin{array}{l}\text { Corrected } \\
\text { Model }\end{array}$ & 356.24 & 5 & 71.247 & 41.285 & $0.000^{* * *}$ \\
\hline Intercept & 46.420 & 1 & 46.420 & 26.899 & $0.000^{* * *}$ \\
\hline $\mathrm{EI}$ & 5.642 & 1 & 5.642 & 3.269 & $0.072^{*}$ \\
\hline ALT & 0.104 & 1 & 0.140 & 0.060 & 0.806 \\
\hline $\mathrm{LGP}^{\mathrm{b}}$ & 0.227 & 1 & 0.277 & 0.131 & 0.359 \\
\hline $\mathrm{LEI}^{\mathrm{b}}$ & 336.130 & 1 & 336.130 & 194.774 & $0.000^{* * * *}$ \\
\hline LGP $*$ LEI $^{\mathrm{b}}$ & 15.683 & 1 & 15.683 & 9.088 & $0.001^{* * *}$ \\
\hline Error & 365.857 & 212 & 1.726 & & \\
\hline Total & 5420.000 & 218 & & & \\
\hline $\begin{array}{l}\text { Corrected } \\
\text { Total }\end{array}$ & 722.092 & 217 & & & \\
\hline
\end{tabular}

Pairwise Comparisons for Main Effect

\begin{tabular}{|c|c|c|c|c|}
\hline & & $\underline{\text { Mean }}$ & & \\
\hline & Low LEI $^{\mathrm{b}}$ & $\frac{2489}{248}$ & $\frac{\text { Sta. EIror }}{0.178}$ & $\underline{\underline{S 1 g}}$ \\
\hline & Low LGP & 0.065 & 0.179 & 0.359 \\
\hline
\end{tabular}

Simple Effects for Interaction

\section{High LEI - Low LEI}

\begin{tabular}{|c|c|c|c|}
\hline & $\underline{\text { Mean }}$ & $\underline{\text { Std. }}$ & \\
\hline & Difference & Error & $\underline{\operatorname{Sig}}$ \\
\hline Low LGP & 1.950 & 0.248 & $0.000 * * *$ \\
\hline High LGP & 3.027 & 0.256 & $0.000 * * *$ \\
\hline
\end{tabular}

a $*, * *$, and $* * *$ indicate $0.1,0.05$, and 0.01 significance level respectively. 
$\mathrm{b}$ indicates a hypothesized variable. P-values are one-tailed for hypothesized variables and are two-tailed for all other variables. 
Table 11

Repeated Measures for Type of Accounting Fraud ${ }^{a}$

\begin{tabular}{|c|c|c|c|c|c|}
\hline & $\frac{\text { Sum of }}{\underline{\text { Squares }}}$ & $\underline{\mathrm{df}}$ & $\frac{\text { Mean }}{\underline{\text { Square }}}$ & $\underline{F}$ & \\
\hline Type $^{\mathrm{b}}$ & 0.003 & $\overline{1}$ & 0.003 & 0.008 & $\overline{0.931}$ \\
\hline Type * EI & 0.179 & 1 & 0.179 & 0.442 & 0.507 \\
\hline Type * ALT & 1.169 & 1 & 1.169 & 2.878 & $0.091^{*}$ \\
\hline Type * LEI & 0.089 & 1 & 0.089 & 0.219 & 0.640 \\
\hline Type * LGP & 0.011 & 1 & 0.011 & 0.026 & 0.872 \\
\hline Type * LEI * LGP & 0.225 & 1 & 0.225 & 0.555 & 0.457 \\
\hline Error(Type) & 86.129 & 212 & 0.406 & 0 & \\
\hline
\end{tabular}

a $*$ indicates 0.1 significance level.

${ }^{b}$ Type is defined as the type of accounting fraud. 
Table 12

Mediation Analysis ${ }^{a}$, b, c

Panel A: LEI as the independent variable

\begin{tabular}{|c|c|c|c|c|c|c|}
\hline \multirow{2}{*}{$\underline{\text { Mediator }}$} & Dependent & & $\underline{\text { Boot }}$ & $\underline{\text { Boot }}$ & $\underline{\text { Boot }}$ & $\underline{\text { Sobel Test (p- }}$ \\
\hline & $\underline{\text { Variable }}$ & Effect & $\underline{\mathrm{SE}}$ & $\overline{\mathrm{LLCI}}$ & $\overline{\mathrm{ULCI}}$ & value) \\
\hline \multirow[t]{2}{*}{ LMX } & WBFS & 0.999 & $0 . \overline{286}$ & 0.662 & $1.392^{*}$ & $\overline{0.000}$ \\
\hline & WBAM & 0.675 & 0.251 & 0.372 & $1.009^{*}$ & 0.003 \\
\hline \multirow[t]{2}{*}{ TRUST } & WBFS & 0.853 & 0.242 & 0.559 & $1.174^{*}$ & 0.000 \\
\hline & WBAM & 0.537 & 0.215 & 0.274 & $0.827^{*}$ & 0.005 \\
\hline \multirow[t]{2}{*}{ JS } & WBFS & 0.435 & 0.162 & 0.239 & $0.647^{*}$ & 0.007 \\
\hline & WBAM & 0.285 & 0.139 & 0.111 & $0.464^{*}$ & 0.045 \\
\hline
\end{tabular}

Panel B: LGP as the independent variable

\begin{tabular}{|c|c|c|c|c|c|c|}
\hline \multirow{3}{*}{$\frac{\text { Mediator }}{\mathrm{IX}}$} & \multicolumn{2}{|l|}{ Dependent } & \multirow{2}{*}{$\frac{\text { Boot }}{\text { SE }}$} & \multirow{2}{*}{$\frac{\text { Boot }}{\underline{\text { LLCI }}}$} & \multirow{2}{*}{$\underline{\text { Boot }}$} & \multirow{2}{*}{$\frac{\text { Sobel Test (p- }}{\text { value) }}$} \\
\hline & Variable & $\underline{\text { Effect }}$ & & & & \\
\hline & WBFS & 0.074 & 0.055 & 0.016 & $0.155^{*}$ & 0.167 \\
\hline & WBAM & 0.056 & 0.042 & 0.014 & $0.121^{*}$ & 0.164 \\
\hline TRUST & WBFS & 0.040 & 0.056 & -0.022 & 0.118 & 0.468 \\
\hline & WBAM & 0.031 & 0.040 & -0.007 & 0.093 & 0.416 \\
\hline JS & WBFS & 0.004 & 0.046 & -0.050 & 0.064 & 0.932 \\
\hline & WBAM & 0.005 & 0.034 & -0.034 & 0.048 & 0.894 \\
\hline
\end{tabular}

\footnotetext{
a Andrew Hayes' PROCESS is used to test mediation effect. One-tailed 90\% confidence interval is displayed as default for the analysis. The number iterations is 10,000.

$\mathrm{b} *$ indicates that the mediation inferences hold for one-tailed $95 \%$ confidence interval as well.

${ }^{c}$ Two-tailed Sobel test results are also displayed.
} 
Table 13

Moderated Mediation Analysis ${ }^{\mathrm{a}, \mathrm{b}}$

Panel A: LMX as the mediator

\begin{tabular}{|c|c|c|c|c|c|}
\hline Dependent & Level of & & $\underline{\text { Boot }}$ & $\underline{\text { Boot }}$ & $\underline{\text { Boot }}$ \\
\hline Variable & Moderator & Effect & $\overline{\mathrm{SE}}$ & $\overline{\mathrm{LLCI}}$ & $\overline{\mathrm{ULCI}}$ \\
\hline \multirow[t]{2}{*}{$\overline{\text { WBFS }}$} & $\overline{\text { Low LGP }}$ & 0.849 & 0.281 & 0.514 & $1.237^{*}$ \\
\hline & High LGP & 1.059 & 0.335 & 0.650 & $1.058^{*}$ \\
\hline \multirow[t]{2}{*}{ WBAM } & Low LGP & 0.537 & 0.226 & 0.271 & $0.846^{*}$ \\
\hline & High LGP & 0.672 & 0.280 & 0.339 & $1.508^{*}$ \\
\hline
\end{tabular}

\section{Index of Moderated Mediation}

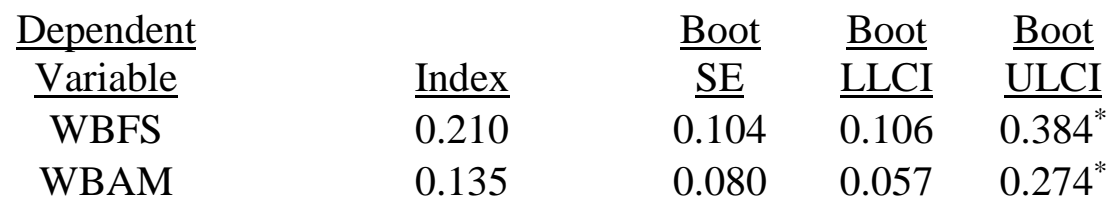

Panel B: TRUST as the mediator

\begin{tabular}{cccccc}
$\frac{\text { Dependent }}{\text { Variable }}$ & $\frac{\text { Level of }}{\text { Moderator }}$ & $\underline{\text { Effect }}$ & $\underline{\underline{\text { SE }}}$ & $\underline{\underline{\text { Boot }}}$ & $\underline{\underline{\text { Boot }}}$ \\
\cline { 2 - 2 } & $\begin{array}{l}\text { Low LGP } \\
\text { High LGP }\end{array}$ & 0.745 & 0.223 & 0.488 & $\underline{\text { ULCI }}$ \\
& & 0.917 & 0.279 & 0.589 & $1.303^{*}$ \\
WBAM & Low LGP & 0.447 & 0.195 & 0.208 & $0.704^{*}$ \\
& High LGP & 0.547 & 0.242 & 0.246 & $0.863^{*}$
\end{tabular}

\section{Index of Moderated Mediation}

\begin{tabular}{|c|c|c|c|c|}
\hline Dependent & & $\underline{\text { Boot }}$ & $\underline{\text { Boot }}$ & $\underline{\text { Boot }}$ \\
\hline$\underline{\text { Variable }}$ & Index & $\overline{\mathrm{SE}}$ & $\overline{\mathrm{LLCI}}$ & $\overline{\mathrm{ULCI}}$ \\
\hline WBFS & 0.171 & 0.107 & 0.066 & $0.347^{*}$ \\
\hline WBAM & 0.100 & 0.074 & 0.030 & $0.229^{*}$ \\
\hline
\end{tabular}


Panel C: JS at the mediator

\begin{tabular}{|c|c|c|c|c|c|}
\hline Dependent & Level of & & Boot & Boot & $\underline{\text { Boot }}$ \\
\hline Variable & $\overline{\text { Moderator }}$ & $\underline{\text { Effect }}$ & $\overline{\mathrm{SE}}$ & $\overline{\mathrm{LLCI}}$ & $\overline{\mathrm{ULCI}}$ \\
\hline \multirow{2}{*}{$\overline{\text { WBFS }}$} & Low LGP & 0.352 & 0.138 & 0.194 & $0.543^{*}$ \\
\hline & High LGP & 0.543 & 0.207 & 0.294 & $0.818^{*}$ \\
\hline \multirow[t]{2}{*}{ WBAM } & Low LGP & 0.212 & 0.115 & 0.076 & $0.367^{*}$ \\
\hline & High LGP & 0.328 & 0.175 & 0.106 & $0.550^{*}$ \\
\hline
\end{tabular}

\section{Index of Moderated Mediation}

\begin{tabular}{|c|c|c|c|c|}
\hline Dependent & & $\underline{\text { Boot }}$ & $\underline{\text { Boot }}$ & $\underline{\text { Boot }}$ \\
\hline Variable & Index & $\overline{\mathrm{SE}}$ & $\overline{\mathrm{LLCI}}$ & $\underline{\mathrm{ULCI}}$ \\
\hline WBFS & 0.191 & 0.098 & 0.093 & 0.352 \\
\hline WBAM & 0.116 & 0.075 & 0.039 & 0.239 \\
\hline
\end{tabular}

a Andrew Hayes' PROCESS is used to test mediation effect. One-tailed 90\% confidence interval is displayed as default for the analysis. The number iterations is 10,000.

$\mathrm{b} *$ indicates that the mediation inferences hold for one-tailed $95 \%$ confidence interval as well. 
Table 14

Analysis for Participants' Assessments on Statements Related to Financial Statement

Fraud and Asset Misappropriation Fraud ${ }^{a, b, c}$

$\begin{array}{cccccc} & \underline{\text { Mean }^{\mathrm{d}}} & \underline{\mathrm{SE}} & \underline{\mathrm{t}} & \underline{\mathrm{df}} & \underline{\text { Sig. }} \\ \begin{array}{c}\text { 1.This fraudulent act } \\ \text { is morally wrong }\end{array} & -0.20642 & 0.06999 & -2.949 & 217 & 0.004^{* * *}\end{array}$

2. This fraudulent act is unethical (general

$\begin{array}{lllll}-0.12844 & 0.07246 & -1.772 & 217 & 0.078^{*}\end{array}$ consensus).

3. This fraud should be attributed to the personal factors of the $\begin{array}{lllll}-0.35780 & 0.13468 & -2.657 & 217 & 0.008^{* * *}\end{array}$ controller of the division (purchasing manager).

4. This fraud should be attributed to $\begin{array}{lllll}0.24312 & 0.14685 & 1.656 & 217 & 0.099^{*}\end{array}$ external factors.

5. The fairness of this fraudulent act $\begin{array}{lllll}0.39352 & 0.09276 & 4.243 & 215 & 0.000^{* * *}\end{array}$

6. The personal cost of reporting this fraudulent act by

0.32569

$0.10742 \quad 3.032$

$2170.003^{* * *}$

Adrian.

7. The responsibility to inform proper parties about the $\begin{array}{lllll}-0.19725 & 0.08434 & -2.339 & 217 & 0.020^{* *}\end{array}$ fraudulent act.

8. The seriousness of $\begin{array}{lll}-0.17890 & 0.07357 & -2.432\end{array}$ $2170.016^{* *}$ this fraudulent act

9. ABC Company will discover this $\begin{array}{lll}-0.12844 & 0.09583 & -1.340\end{array}$

fraudulent act by itself

10. Adrian's anonymity will be protected if the fraud $\begin{array}{lllll}-0.16055 & 0.08932 & -1.798 & 217 & 0.074^{*}\end{array}$ is reported. 
$\underline{\text { Mean }^{\mathrm{d}}} \quad \underline{\mathrm{SE}} \quad \underline{\mathrm{t}} \quad \underline{\mathrm{df}} \quad \underline{\mathrm{Sig}}$.

11. This fraudulent act will be thoroughly $\begin{array}{lllll}-0.19725 & 0.09451 & -2.087 & 217 & 0.038^{* *}\end{array}$ investigated.

12. Corrective actions will be taken for this $\begin{array}{lllll}-0.31193 & 0.10018 & -3.114 & 217 & 0.002^{* * *}\end{array}$ fraudulent act.

\begin{abstract}
${ }^{a}$ Each participant is asked to provide their assessments on 12 statements that are related to the two types of accounting fraud: financial statement fraud and asset misappropriation fraud.

${ }^{\mathrm{b}}$ Since each participant is provided with vignettes of both types of accounting fraud, paired ttests are employed for the analysis.

$c *, * *$, and $* * *$ indicate $0.1,0.05$, and 0.01 significance level respectively; two-tailed.

${ }^{\mathrm{d}}$ All means in Table 14 are mean differences between the assessment for financial statement fraud and the assessment for asset misappropriation fraud on each of the 12 statements.
\end{abstract}


Table 15

ANCOVA for Different Level of Participants' Emotional Intelligence ${ }^{a}$

Panel A: WBFS as the dependent variable

Low Emotional Intelligence Participants ( $=116)$

\begin{tabular}{|c|c|c|c|c|c|}
\hline & $\underline{\text { Sum of }}$ & & Mean & & \\
\hline Source & $\underline{\text { Squares }}$ & $\underline{\mathrm{df}}$ & Square & $\underline{F}$ & $\underline{\text { Sig. }}$ \\
\hline $\begin{array}{l}\text { Corrected } \\
\text { Model }\end{array}$ & 61.195 & 6 & 10.199 & 6.617 & $0.000^{* * * *}$ \\
\hline Intercept & 43.135 & 1 & 43.135 & 27.986 & $0.000^{* * * *}$ \\
\hline EI & 2.444 & 1 & 2.444 & 1.586 & 0.211 \\
\hline ALT & 9.543 & 1 & 9.543 & 6.191 & $0.014^{* *}$ \\
\hline SDBFS & 41.069 & 1 & 41.069 & 26.645 & $0.000^{* * * *}$ \\
\hline LEI $^{\mathrm{b}}$ & 0.909 & 1 & 0.909 & 0.589 & 0.222 \\
\hline $\mathrm{LGP}^{\mathrm{b}}$ & 3.883 & 1 & 3.883 & 2.519 & $0.058^{*}$ \\
\hline LEI * LGP & 0.039 & 1 & 0.039 & 0.025 & 0.437 \\
\hline Error & 168.004 & 109 & 1.541 & & \\
\hline Total & 4157.000 & 116 & & & \\
\hline $\begin{array}{l}\text { Corrected } \\
\text { Total }\end{array}$ & 229.198 & 115 & & & \\
\hline
\end{tabular}

High Emotional Intelligence Participants ( $\mathrm{N}=102)$

\begin{tabular}{|c|c|c|c|c|c|}
\hline & $\underline{\text { Sum of }}$ & & Mean & & \\
\hline Source & $\underline{\text { Squares }}$ & $\underline{\mathrm{df}}$ & Square & $\underline{F}$ & $\underline{\text { Sig. }}$ \\
\hline $\begin{array}{l}\text { Corrected } \\
\text { Model }\end{array}$ & 30.679 & 6 & 5.113 & 3.327 & $0.005^{* * *}$ \\
\hline Intercept & 5.413 & 1 & 5.413 & 3.522 & $0.064^{*}$ \\
\hline EI & 6.624 & 1 & 6.624 & 4.310 & $0.041^{* *}$ \\
\hline ALT & 0.352 & 1 & 0.352 & 0.229 & 0.633 \\
\hline SDBFS & 9.677 & 1 & 9.677 & 6.296 & $0.014^{* *}$ \\
\hline $\mathrm{LEI}^{\mathrm{b}}$ & 13.219 & 1 & 13.219 & 8.601 & $0.002^{* * *}$ \\
\hline $\mathrm{LGP}^{\mathrm{b}}$ & 1.595 & 1 & 1.595 & 1.038 & 0.155 \\
\hline LEI $*$ LGP $^{b}$ & 0.029 & 1 & 0.029 & 0.019 & 0.446 \\
\hline Error & 145.998 & 95 & 1.537 & & \\
\hline Total & 4105.000 & 102 & & & \\
\hline $\begin{array}{l}\text { Corrected } \\
\text { Total }\end{array}$ & 176.676 & 101 & & & \\
\hline
\end{tabular}


Panel B: WBAM as the dependent variable

Low Emotional Intelligence Participants ( $=116)$

$\begin{array}{lccccl}\text { Source } & \underline{\text { Sum of }} & & \underline{\text { Mean }} & & \\ \text { Corrected } & \underline{\text { Squares }} & \underline{\text { df }} & \underline{\text { Square }} & \underline{F} & \underline{\text { Sig. }} \\ \text { Model } & 43.858 & 6 & 7.310 & 5.505 & 0.000^{* * *} \\ \text { Intercept } & 42.098 & 1 & 42.098 & 31.707 & 0.000^{* * *} \\ \text { EI } & 1.840 & 1 & 1.840 & 1.385 & 0.242 \\ \text { ALT } & 2.725 & 1 & 2.725 & 2.052 & 0.155 \\ \text { SDBAM } & 29.956 & 1 & 29.956 & 22.563 & 0.000^{* * *} \\ \text { LEI }^{\text {b }} & 0.313 & 1 & 0.313 & 0.236 & 0.314 \\ \text { LGP }^{b} & 3.121 & 1 & 3.121 & 2.350 & 0.064^{*} \\ \text { LEI }{ }^{*} \text { LGP } & 2.498 & 1 & 2.498 & 1.882 & 0.086^{*} \\ \text { Error } & 144.720 & 109 & 1.328 & & \\ \text { Total } & 4281.000 & 116 & & & \\ \text { Corrected } & 188.578 & 115 & & & \\ \text { Total } & & & & & \\ \text { R Squared }=0.233 \text { (Adjusted R Squared }=0.190) & & \end{array}$

\section{Pairwise Comparison}

High LEI - Low LEI

\begin{tabular}{|c|c|c|c|}
\hline & $\underline{\text { Mean }}$ & Std. & \\
\hline Leader Group Prototypicality & Difference & $\overline{\text { Error }}$ & Sig. \\
\hline Low LGP & -0.191 & $\overline{0.292}$ & 0.258 \\
\hline High LGP ${ }^{b}$ & 0.405 & 0.326 & 0.108 \\
\hline
\end{tabular}

\section{$\underline{\text { High LGP - Low LGP }}$}

Mean $\quad \underline{\text { Std. }}$

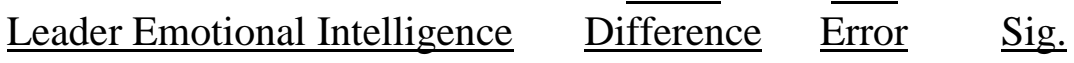

$\begin{array}{lllc}\text { Low LEI } & 0.039 & 0.297 & 0.896 \\ \text { High LEI } & 0.635 & 0.320 & 0.050^{* *}\end{array}$




\section{High Emotional Intelligence Participants ( $\mathrm{N}=102)$}

\begin{tabular}{|c|c|c|c|c|c|}
\hline \multirow{2}{*}{ Source } & \multicolumn{2}{|l|}{$\underline{\text { Sum of }}$} & \multicolumn{2}{|l|}{ Mean } & \multirow[b]{2}{*}{$\underline{\text { Sig. }}$} \\
\hline & $\overline{\text { Squares }}$ & $\underline{\mathrm{df}}$ & $\overline{\text { Square }}$ & $\underline{\mathrm{F}}$ & \\
\hline $\begin{array}{l}\text { Corrected } \\
\text { Model }\end{array}$ & 27.621 & 6 & 4.604 & 4.296 & $0.001^{* * *}$ \\
\hline Intercept & 9.157 & 1 & 9.157 & 8.546 & $0.004^{* * *}$ \\
\hline EI & 3.402 & 1 & 3.402 & 3.175 & $0.078^{*}$ \\
\hline ALT & 0.001 & 1 & 0.001 & 0.001 & 0.979 \\
\hline SDBAM & 12.670 & 1 & 12.670 & 11.825 & $0.001^{* * *}$ \\
\hline $\mathrm{LEI}^{\mathrm{b}}$ & 9.730 & 1 & 9.730 & 9.081 & $0.002^{* * *}$ \\
\hline $\mathrm{LGP}^{\mathrm{b}}$ & 0.620 & 1 & 0.620 & 0.579 & 0.224 \\
\hline $\mathrm{LEI} * \mathrm{LGP}^{\mathrm{b}}$ & 0.179 & 1 & 0.179 & 0.167 & 0.342 \\
\hline Error & 101.791 & 95 & 1.071 & & \\
\hline Total & 4400.000 & 102 & & & \\
\hline $\begin{array}{l}\text { Corrected } \\
\text { Total }\end{array}$ & 129.412 & 101 & & & \\
\hline R Squared & 13 (Ad & & -0 & & \\
\hline
\end{tabular}

a $* * *$, and $* * *$ indicate $0.1,0.05$, and 0.01 significance level respectively.

$\mathrm{b}$ indicates a hypothesized variable. P-values are on-tailed for hypothesized variables and are two-tailed for all other variables. 
Table 16

Supplementary Experiment Demographic Information ( $=146)$

\section{Panel A: Continuous Variables}

$\begin{array}{lcc} & \underline{\text { Mean }} & \underline{\underline{\text { Standard }}} \\ \text { Age } & 36.25 & 10.99 \\ \text { Years of work experience } & 15.16 & 10.68 \\ \begin{array}{l}\text { Number of accounting class that the } \\ \text { participant has taken }\end{array} & 2.29 & 3.85 \\ \begin{array}{l}\text { Number of business class that the } \\ \text { participant has taken }\end{array} & 4.94 & 7.33\end{array}$

Panel B: Dichotomous and Other Measures

Gender

Occupation

Highest degree

College Major

Male

Female

Unemployed/Retired

Non-Business/Non-

Management

Business/Management

High School Degree

Associate Degree

Bachelor Degree

Graduate Degree

N/A

Non-Business

Business

Yes

No

I can't remember

Have you ever rep
accounting fraud?

Have you ever reported an observed fraud?
Yes

No

I can't remember
Number $\quad \underline{\text { Percentage }}$

67

79

$45.9 \%$

$54.1 \%$

$7 \quad 4.8 \%$

$99 \quad 67.8 \%$

$40 \quad 27.4 \%$

36

$24.7 \%$

21

$14.4 \%$

$43.2 \%$

$17.8 \%$

26

$18.5 \%$

27

$55.5 \%$

38

$26.0 \%$

10

$6.8 \%$

$136 \quad 93.2 \%$

$0 \quad 0.0 \%$

25

$17.1 \%$

121

$82.9 \%$

0

$0.0 \%$ 
Have you ever actively participated in an account fraud?
Yes

No

I can't remember

Have you ever actively participated in a fraud?
Number Percentage

3

$2.1 \%$

$142 \quad 97.3 \%$

$1 \quad 0.7 \%$

5

$3.4 \%$

139

$95.2 \%$

I can't remember
2

$1.4 \%$ 
Table 17

Supplementary Experiment Correlationa

\begin{tabular}{|l|l|l|l|l|l|l|l|}
\hline & \multicolumn{1}{|c|}{ LEI } & \multicolumn{1}{c}{ CF } & \multicolumn{1}{c|}{ WB } & SDB & ALT & EIMS & ACCT \\
\hline LEI & 1 & & & & & & \\
\hline CF & 0.001 & 1 & & & & & \\
\hline WB & $-0.164^{*}$ & $0.170^{*}$ & 1 & & & & \\
\hline SDB & 0.040 & $0.168^{*}$ & $0.584^{* *}$ & 1 & & & \\
\hline ALT & 0.113 & 0.002 & -0.028 & -0.156 & 1 & & \\
\hline EI & -0.080 & -0.015 & 0.069 & $-0.175^{*}$ & $0.290^{* *}$ & 1 & \\
\hline ACCT & 0.155 & -0.054 & $-0.171^{*}$ & -0.032 & 0.084 & -0.085 & 1 \\
\hline
\end{tabular}

a $*$ and $* *$ indicate 0.05 and 0.01 significance level respectively (two-tailed).

\section{Variable Definitions:}

LEI - Dichotomous variable indicating the leader's emotional intelligence $(1=$ high leader emotional intelligence, $0=$ low leader emotional intelligence);

$\mathrm{CF}-$ Dichotomous variable indicating the framings of consequences $(1=$ firm consequence, $0=$ leader consequence);

WB - Participants' assessment on the statement that "If you were Adrian, it is likely for you to report the fraud to the anonymous whistleblowing hotline $(1=$ Strongly Disagree, $7=$ Strongly Agree);

EI - Median split of participants' emotional intelligence, which is calculated as the sum of 33 items;

ALT - Participants' altruism, which is calculated as the sum of 20 items;

SDB - Participants' social desirability bias for financial statement fraud. It is calculated as the difference between the assessments on "If you were Adrian, it is likely for you to report the fraud to the anonymous whistleblowing hotline" and "It is likely for Adrian to report the fraud to the anonymous whistleblowing hotline." 
Table 18

Panel A: ANCOVA

\section{Supplementary Experiment ANCOVA ${ }^{\mathrm{a}}$}

\begin{tabular}{|c|c|c|c|c|c|}
\hline \multirow{2}{*}{ Source } & \multirow[b]{2}{*}{$\underline{\text { Sum of Squares }}$} & \multicolumn{2}{|r|}{ Mean } & \multirow[b]{2}{*}{$\underline{F}$} & \multirow[b]{2}{*}{ Sig. } \\
\hline & & $\underline{\mathrm{df}}$ & $\underline{\text { Square }}$ & & \\
\hline Corrected Model & 152.978 & 10 & 15.298 & 10.748 & $0.000^{* * * *}$ \\
\hline Intercept & 157.993 & 1 & 157.993 & 111.001 & $0.000 * * *$ \\
\hline SDB & 117.524 & 1 & 117.524 & 82.569 & $0.000^{* * *}$ \\
\hline ALT & 0.984 & 1 & 0.984 & 0.692 & 0.407 \\
\hline ACCT & 5.191 & 1 & 5.191 & 3.647 & $0.058^{*}$ \\
\hline $\mathrm{LEI}^{\mathrm{b}}$ & 9.562 & 1 & 9.562 & 6.718 & $0.005^{* * *}$ \\
\hline $\mathrm{CF}^{\mathrm{b}}$ & 1.178 & 1 & 1.178 & 0.827 & 0.182 \\
\hline EI & 5.511 & 1 & 5.511 & 3.872 & $0.026^{* *}$ \\
\hline LEI $* \mathrm{CF}^{\mathrm{b}}$ & 3.109 & 1 & 3.109 & 2.184 & $0.071^{*}$ \\
\hline $\mathrm{LEI} * \mathrm{EI}^{\mathrm{b}}$ & 2.144 & 1 & 2.144 & 1.506 & 0.111 \\
\hline $\mathrm{CF} * \mathrm{EI}^{\mathrm{b}}$ & 0.629 & 1 & 0.629 & 0.442 & 0.254 \\
\hline LEI $* \mathrm{CF} * \mathrm{EI}$ & 1.704 & 1 & 1.704 & 1.197 & 0.276 \\
\hline Error & 192.152 & 135 & 1.423 & & \\
\hline Total & 5075.000 & 146 & & & \\
\hline Corrected Total & 345.130 & 145 & & & \\
\hline
\end{tabular}

R Squared $=0.443$ (Adjusted R Squared $=0.402$ )

\section{Panel B: Main Effect Pairwise Comparison}

\begin{tabular}{|c|c|c|c|c|}
\hline & & $\underline{\text { Mean }}$ & & \\
\hline & & Difference & Std. Error & $\underline{\text { Sig }}$ \\
\hline Low LEI & High LEI & 0.527 & 0.203 & $0.005^{* * *}$ \\
\hline Firm Consequence & Leader Consequence & 0.184 & 0.202 & 0.182 \\
\hline
\end{tabular}

Panel C: Simple Effects for Interaction

\begin{tabular}{|c|c|c|c|}
\hline & & equence - & Consequ \\
\hline & Mean & & \\
\hline ader Emotional Intelligence & Difference & Std. Error & $\underline{\text { Sig }}$ \\
\hline Low LEI & -0.133 & 0.281 & $\overline{0.344}$ \\
\hline High LEI & 0.480 & 0.288 & $0.049^{* *}$ \\
\hline
\end{tabular}


a $*, * *$, and $* * *$ indicate $0.1,0.05$, and 0.01 significance level respectively.

$\mathrm{b}$ indicates a hypothesized variable. P-values are one-tailed for hypothesized variables and are two-tailed for all other variables. 


\section{APPENDIX I. LIST OF HYPOTHESES}

H1: A subordinate perceives higher LMX when the leader has high emotional intelligence than low emotional intelligence.

H2: A subordinate's perceived LMX is positively related to his intention to report fraudulent behavior to his leader.

H3: A subordinate's perceived LMX positively mediates the relationship between his leader's emotional intelligence and his intention to report fraudulent behavior to the leader.

H4: A subordinate has higher trust in his leader when the leader has high emotional intelligence than low emotional intelligence.

H5: A subordinate's trust in his leader is positively related to his intention to report fraudulent behavior to the leader.

H6: A subordinate's trust in his leader positively mediates the relationship between the leader's emotional intelligence and his intention to report fraudulent behavior to the leader.

H7: A subordinate has higher job satisfaction when the leader has high emotional intelligence than low emotional intelligence.

H8: A subordinate's job satisfaction is positively related to his intention to report fraudulent behavior to his leader.

H9: A subordinate's job satisfaction positively mediates the relationship between his leader's emotional intelligence and his intention to report fraudulent behavior to the leader.

H10: A subordinate is more likely to report fraudulent behavior to his leader when his leader has high emotional intelligence than low emotional intelligence.

H11: A subordinate perceives higher LMX when the leader has high group prototypicality than low group prototypicality.

H12: A subordinate has higher trust in his leader when the leader has high group prototypicality than low group prototypicality.

H13: A subordinate has higher job satisfaction when the leader has high group prototypicality than low group prototypicality.

H14: A subordinate's perceived LMX positively mediates the relationship between his leader's group prototypicality and his intention to report fraudulent behavior to the leader.

H15: A subordinate's trust in his leader positively mediates the relationship between the leader's group prototypicality and his intention to report fraudulent behavior to the leader. 
H16: A subordinate's job satisfaction positively mediates the relationship between his leader's group prototypicality and his intention to report fraudulent behavior to the leader.

H17: A subordinate is more likely to report fraudulent behavior when his leader has high group prototypicality than when his leader has low group prototypicality.

H18: The effect of a leader's emotional intelligence on his subordinate's perceived LMX is stronger when he has high group prototypicality than low group prototypicality.

H19: The effect of a leader's emotional intelligence on his subordinate's trust in him is stronger when he has high group prototypicality than low group prototypicality.

H20: The effect of a leader's emotional intelligence on his subordinate's job satisfaction is stronger when he has high group prototypicality than low group prototypicality.

H21: The effect of a leader's emotional intelligence on his subordinate's intention to report fraudulent behavior is stronger when he has high group prototypicality than low group prototypicality.

H22: The mediated relationship between a leader's emotional intelligence and his subordinate's intention to report fraudulent behavior through the subordinate's perceived LMX is stronger when the leader has high group prototypicality than low group prototypicality.

H23: The mediated relationship between a leader's emotional intelligence and his subordinate's intention to report fraudulent behavior through the subordinate's trust in the leader is stronger when the leader has high group prototypicality than low group prototypicality.

H24: The mediated relationship between a leader's emotional intelligence and his subordinate's intention to report fraudulent behavior through the subordinate's job satisfaction is stronger when the leader has high group prototypicality than low group prototypicality.

H25: The subordinate is more likely to report the fraud committed by the leader when the leader has low emotional intelligence than when the leader has high emotional intelligence.

H26: The subordinate is more likely to report the fraud committed by the leader when the subordinate has low emotional intelligence than high emotional intelligence under low leader emotional intelligence condition while the subordinate is more likely to report the fraud committed by the leader when the subordinate has high emotional intelligence than low emotional intelligence under high leader emotional intelligence condition.

H27: The subordinate is more likely to report the fraud committed by the leader when the whistleblowing consequence is framed positively to the company than when it is framed negatively to the leader.

H28: The subordinate is more likely to report the fraud committed by the leader when the subordinate has high emotional intelligence than low emotional intelligence under positive firm consequence framing condition while the subordinate is more likely to report the fraud committed by the leader when the subordinate has low emotional intelligence than high emotional intelligence under negative leader consequence framing condition. 
H29: The effect of consequence framing on the subordinate's intention to report the fraud committed by the leader is stronger when the leader has high emotional intelligence than when the leader has low emotional intelligence. 


\section{APPENDIX II. EXPERIMENTAL INSTRUMENTS FOR PRIMARY EXPERIMENT}

\section{High leader emotional intelligence and high leader group prototypicality scenario}

Please read the following background information about ABC Company, Adrian, and Bailey, and then answer the questions that follow. The questions should take you approximately 20 - 30 minutes.

ABC Company is a manufacturing company of consumer goods. It had produced steady operating results but recently performed at slightly below the industry average. Adrian is an accountant in the accounting department of ABC Company and directly reports to Bailey, who is the department head of the accounting department and is Adrian's direct supervisor. Adrian has been working in ABC Company's accounting department under Bailey's direct supervision for two years.

Bailey is able to perceive the emotions of others, including Adrian's. It is easy for Bailey to understand the non-verbal messages of Adrian and other people, and Bailey is always aware of the non-verbal messages sent to others including Adrian and the emotions experienced by him/herself. Bailey is also able to access and generate emotions to make effective decisions. Bailey arranges activities that make him/her, Adrian, and others happy, and when in positive emotion, Bailey can quickly solve problems and come up with new ideas. Moreover, Bailey is able to understand the emotions of Adrian, others, and oneself. Bailey knows why his/her emotions and emotions of people around change, and when another person, such as Adrian, tells Bailey about an important event in their life, Bailey can almost feel the experience. Finally, Bailey is able to manage the emotions of Adrian, others, and him/herself. No matter how much work pressure there is on Bailey, a positive emotion is always maintained. Bailey also can help others, including Adrian, feel better when they are down.

It seems that Bailey is very representative of the department. Bailey is very similar to Adrian and other members in the department in terms of backgrounds, interests, values, norms, and cultures. Bailey, Adrian, and most of the other members attended the same university on the east coast and have an accounting degree. They all like outdoor sports such as mountain biking and climbing. Every year, new employees join the accounting department. Bailey, Adrian, and all other members believe that the best way to train those new folks are to pair each of them with a senior member in the department and provide on-site mentoring. None of them believe in sending new employees to the corporate training center that primarily uses in-class lectures and exercise.

\section{High leader emotional intelligence and low leader group prototypicality scenario}


Please read the following background information about $\mathrm{ABC}$ Company, Adrian, and Bailey, and then answer the questions that follow. The questions should take you approximately 20 - 30 minutes.

ABC Company is a manufacturing company of consumer goods. It had produced steady operating results but recently performed at slightly below the industry average. Adrian is an accountant in the accounting department of ABC Company and directly reports to Bailey, who is the department head of the accounting department and is Adrian's direct supervisor. Adrian has been working in ABC Company's accounting department under Bailey's direct supervision for two years.

Bailey is able to perceive the emotions of others, including Adrian's. It is easy for Bailey to understand the non-verbal messages of Adrian and other people, and Bailey is always aware of the non-verbal messages sent to others including Adrian and the emotions experienced by him/herself. Bailey is also able to access and generate emotions to make effective decisions. Bailey arranges activities that make him/her, Adrian, and others happy, and when in positive emotion, Bailey can quickly solve problems and come up with new ideas. Moreover, Bailey is able to understand the emotions of Adrian, others, and oneself. Bailey knows why his/her emotions and emotions of people around change, and when another person, such as Adrian, tells Bailey about an important event in their life, Bailey can almost feel the experience. Finally, Bailey is able to manage the emotions of Adrian, others, and him/herself. No matter how much work pressure there is on Bailey, a positive emotion is always maintained. Bailey also can help others, including Adrian, feel better when they are down.

It seems that Bailey is an "outsider" of the department. Bailey is very dissimilar to Adrian and other members in the department in terms of backgrounds, interests, values, norms, and cultures. Adrian and most of the other members attended the same university on the east coast and have an accounting degree, but Bailey attended another university on the west coast and holds a degree in mathematics. Adrian and all other members in the department like outside sports such as mountain biking and climbing. However, Bailey is not a big fan of outdoor sports. Instead, Bailey likes reading books and listening to music at home. Every year, new employees join the accounting department. Adrian and all other members believe that the best way to train those new folks are to pair each of them with a senior member in the department and provide onsite mentoring. However, Bailey believes that the best way is to send the new employees to the corporate training center that primarily uses in-class lectures and exercise.

\section{Low leader emotional intelligence and high leader group prototypicality scenario}

Please read the following background information about ABC Company, Adrian, and Bailey, and then answer the questions that follow. The questions should take you approximately 20 - 30 minutes. 
ABC Company is a manufacturing company of consumer goods. It had produced steady operating results but recently performed at slightly below the industry average. Adrian is an accountant in the accounting department of ABC Company and directly reports to Bailey, who is the department head of the accounting department and is Adrian's direct supervisor. Adrian has been working in ABC Company's accounting department under Bailey’s direct supervision for two years.

Bailey is unable to perceive the emotions of others, including Adrian's. It is hard for Bailey to understand the non-verbal messages of Adrian and other people, and Bailey is always unaware of the non-verbal messages sent to others including Adrian and unaware of the emotions experienced by him/herself. Bailey is also unable to access and generate emotions to make effective decisions. Bailey cannot arrange activities that make him/her, Adrian, and others happy, and even when in positive emotion, Bailey cannot quickly solve problems and come up with new ideas. Moreover, Bailey is unable to understand the emotions of Adrian, others, and oneself. Bailey cannot figure out why his/her emotions and emotions of people around change, and when another person, such as Adrian, tells Bailey about an important event in their life, Bailey cannot feel the experience at all. Finally, Bailey is unable to manage the emotions of Adrian, others, and him/herself. Work pressure can easily throw Bailey into a negative mood. Bailey also cannot help others, including Adrian, feel better when they are down.

It seems that Bailey is very representative of the department. Bailey is very similar to Adrian and other members in the department in terms of backgrounds, interests, values, norms, and cultures. Bailey, Adrian, and most of the other members attended the same university on the east coast and have an accounting degree. They all like outdoor sports such as mountain biking and climbing. Every year, new employees join the accounting department. Bailey, Adrian, and all other members believe that the best way to train those new folks are to pair each of them with a senior member in the department and provide on-site mentoring. None of them believe in sending new employees to the corporate training center that primarily uses in-class lectures and exercise.

\section{Low leader emotional intelligence and low leader group prototypicality scenario}

Please read the following background information about ABC Company, Adrian, and Bailey, and then answer the questions that follow. The questions should take you approximately 20 - 30 minutes.

ABC Company is a manufacturing company of consumer goods. It had produced steady operating results but recently performed at slightly below the industry average. Adrian is an accountant in the accounting department of ABC Company and directly reports to Bailey, who is the department head of the accounting department and is Adrian's direct supervisor. Adrian has been working in ABC Company's accounting department under Bailey's direct supervision for two years. 
Bailey is unable to perceive the emotions of others, including Adrian's. It is hard for Bailey to understand the non-verbal messages of Adrian and other people, and Bailey is always unaware of the non-verbal messages sent to others including Adrian and unaware of the emotions experienced by him/herself. Bailey is also unable to access and generate emotions to make effective decisions. Bailey cannot arrange activities that make him/her, Adrian, and others happy, and even when in positive emotion, Bailey cannot quickly solve problems and come up with new ideas. Moreover, Bailey is unable to understand the emotions of Adrian, others, and oneself. Bailey cannot figure out why his/her emotions and emotions of people around change, and when another person, such as Adrian, tells Bailey about an important event in their life, Bailey cannot feel the experience at all. Finally, Bailey is unable to manage the emotions of Adrian, others, and him/herself. Work pressure can easily throw Bailey into a negative mood. Bailey also cannot help others, including Adrian, feel better when they are down.

It seems that Bailey is an "outsider" of the department. Bailey is very dissimilar to Adrian and other members in the department in terms of backgrounds, interests, values, norms, and cultures. Adrian and most of the other members attended the same university on the east coast and have an accounting degree, but Bailey attended another university on the west coast and holds a degree in mathematics. Adrian and all other members in the department like outdoor sports such as mountain biking and climbing. However, Bailey is not a big fan of outside sports. Instead, Bailey likes reading books and listening to music at home. Every year, new employees join the accounting department. Adrian and all other members believe that the best way to train those new folks are to pair each of them with a senior member in the department and provide onsite mentoring. However, Bailey believes that the best way is to send the new employees to the corporate training center that primarily uses in-class lectures and exercise.

\section{Scales and questions following each leader description scenario}

1. In a few sentences, please briefly describe what kind of a person Bailey is.

2. If you were Adrian, you would perceive the working relationship with Bailey as effective.

\begin{tabular}{|c|c|c|c|c|c|c|}
\hline 1 & 2 & 3 & 4 & 5 & 6 & 7 \\
\hline Strongly & Moderately & Slightly & Neither & Slightly & Moderately & Strongly \\
\hline Disagree & Disagree & Disagree & $\begin{array}{l}\text { Disagree nor } \\
\text { Agree }\end{array}$ & Agree & Agree & Agree \\
\hline
\end{tabular}

3. If you were Adrian, you would believe that Bailey could understand your job problems and needs.

$\begin{array}{ccccccc}1 & 2 & 3 & 4 & 5 & 6 & 7 \\ \text { Strongly } & \text { Moderately } & \text { Slightly } & \text { Neither } & \text { Slightly } & \text { Moderately } & \text { Strongly } \\ \text { Disagree } & \text { Disagree } & \text { Disagree } & \text { Disagree nor } & \text { Agree } & \text { Agree } & \text { Agree } \\ & & & \text { Agree } & & & \end{array}$


4. If you were Adrian, you would believe that Bailey could recognize your potential.

$\begin{array}{clccccc}1 & 2 & 3 & 4 & 5 & 6 & 7 \\ \text { Strongly } & \text { Moderately } & \text { Slightly } & \text { Neither } & \text { Slightly } & \text { Moderately } & \text { Strongly } \\ \text { Disagree } & \text { Disagree } & \text { Disagree } & \begin{array}{c}\text { Disagree nor } \\ \text { Agree }\end{array} & \text { Agree } & \text { Agree } & \text { Agree } \\ & & & & & \end{array}$

5. If you were Adrian, you would believe that regardless of how much formal authority Bailey has built into the position, it is possible that Bailey would use power to help you solve problems in your work.

$\begin{array}{clccccc}1 & 2 & 3 & 4 & 5 & 6 & 7 \\ \text { Strongly } & \text { Moderately } & \text { Slightly } & \text { Neither } & \text { Slightly } & \text { Moderately } & \text { Strongly } \\ \text { Disagree } & \text { Disagree } & \text { Disagree } & \begin{array}{c}\text { Disagree nor } \\ \text { Agree }\end{array} & \text { Agree } & \text { Agree } & \text { Agree }\end{array}$

6. If you were Adrian, you would believe that regardless of the amount of formal authority Bailey has, it is possible that Bailey would "bail you out" at Bailey's expense.

$\begin{array}{clccccc}1 & 2 & 3 & 4 & 5 & 6 & 7 \\ \text { Strongly } & \text { Moderately } & \text { Slightly } & \text { Neither } & \text { Slightly } & \text { Moderately } & \text { Strongly } \\ \text { Disagree } & \text { Disagree } & \text { Disagree } & \begin{array}{c}\text { Disagree nor } \\ \text { Agree }\end{array} & \text { Agree } & \text { Agree } & \text { Agree } \\ & & & & & & \end{array}$

7. If you were Adrian, you would have enough confidence in Bailey that you would defend and justify Bailey's decision if Bailey were not present to do so.

$\begin{array}{clccccc}1 & 2 & 3 & 4 & 5 & 6 & 7 \\ \text { Strongly } & \text { Moderately } & \text { Slightly } & \text { Neither } & \text { Slightly } & \text { Moderately } & \text { Strongly } \\ \text { Disagree } & \text { Disagree } & \text { Disagree } & \begin{array}{c}\text { Disagree nor } \\ \text { Agree }\end{array} & \text { Agree } & \text { Agree } & \text { Agree } \\ & & & & & \end{array}$

8. If you were Adrian, you can trust Bailey to do what is good for you.

\begin{tabular}{|c|c|c|c|c|c|c|}
\hline 1 & 2 & 3 & 4 & 5 & 6 & 7 \\
\hline Strongly & Moderately & Slightly & Neither & Slightly & Moderately & Strongly \\
\hline Disagree & Disagree & Disagree & $\begin{array}{l}\text { Disagree nor } \\
\text { Agree }\end{array}$ & Agree & Agree & Agree \\
\hline
\end{tabular}

9. If you were Adrian, you can trust Bailey to treat you fairly.

$\begin{array}{ccccccc}1 & 2 & 3 & 4 & 5 & 6 & 7 \\ \text { Strongly } & \text { Moderately } & \text { Slightly } & \text { Neither } & \text { Slightly } & \text { Moderately } & \text { Strongly } \\ \text { Disagree } & \text { Disagree } & \text { Disagree } & \begin{array}{c}\text { Disagree nor } \\ \text { Agree }\end{array} & \text { Agree } & \text { Agree } & \text { Agree } \\ & & & & & \end{array}$


10. If you were Adrian, Bailey can be trusted to make decisions that are good for you.

$\begin{array}{ccccccc}1 & 2 & 3 & 4 & 5 & 6 & 7 \\ \text { Strongly } & \text { Moderately } & \text { Slightly } & \text { Neither } & \text { Slightly } & \text { Moderately } & \text { Strongly } \\ \text { Disagree } & \text { Disagree } & \text { Disagree } & \begin{array}{c}\text { Disagree nor } \\ \text { Agree }\end{array} & \text { Agree } & \text { Agree } & \text { Agree }\end{array}$

11. If you were Adrian, you are satisfied with your current job in the accounting department of ABC Company?

$\begin{array}{ccccccc}1 & 2 & 3 & 4 & 5 & 6 & 7 \\ \text { Strongly } & \text { Moderately } & \text { Slightly } & \text { Neither } & \text { Slightly } & \text { Moderately } & \text { Strongly } \\ \text { Disagree } & \text { Disagree } & \text { Disagree } & \begin{array}{c}\text { Disagree nor } \\ \text { Agree }\end{array} & \text { Agree } & \text { Agree } & \text { Agree }\end{array}$

\section{Fraud cases and related scales.}

Please read the following two cases that happen in ABC Company, and answer the questions or give opinions on statements that follow. Please remember that all previous background information about ABC Company, Adrian, and Bailey applies to the following cases.

Case 1

Adrian is working on a review of the general journal entries that are needed to prepare the financial statements, and Adrian finds that one division improperly valued its assets. $\$ 800,000$ of expenses has been capitalized by the controller of the division, who is a "very skilled" accountant. After talking with some friends in that division, Adrian is almost certain that this is a fraud that has been committed. The mis-recording increases ABC Company's earnings per share by $\$ 0.02$, which exactly meets financial analysts' expectations.

1. It is likely for Adrian to report the fraud to Bailey

\begin{tabular}{|c|c|c|c|c|c|c|}
\hline 1 & 2 & 3 & 4 & 5 & 6 & 7 \\
\hline Strongly & Moderately & Slightly & Neither & Slightly & Moderately & Strongly \\
\hline Disagree & Disagree & Disagree & $\begin{array}{l}\text { Disagree nor } \\
\text { Agree }\end{array}$ & Agree & Agree & Agree \\
\hline
\end{tabular}

2. If you were Adrian, it is likely for you to report the fraud to Bailey.

$\begin{array}{ccccccc}1 & 2 & 3 & 4 & 5 & 6 & 7 \\ \text { Strongly } & \text { Moderately } & \text { Slightly } & \text { Neither } & \text { Slightly } & \text { Moderately } & \text { Strongly } \\ \text { Disagree } & \text { Disagree } & \text { Disagree } & \begin{array}{c}\text { Disagree nor } \\ \text { Agree }\end{array} & \text { Agree } & \text { Agree } & \text { Agree }\end{array}$


3. This fraudulent act is morally wrong.

\begin{tabular}{|c|c|c|c|c|c|c|c|c|}
\hline 1 & 2 & 3 & 4 & 5 & 6 & 7 & 8 & 9 \\
\hline Strongly & Mostly & Somewhat & Slightly & Neither & Slightly & Somewhat & Mostly & Strongly \\
\hline Disagree & Disagree & Disagree & Disagree & $\begin{array}{l}\text { Disagree nor } \\
\text { Agree }\end{array}$ & Agree & Agree & Agree & Agree \\
\hline
\end{tabular}

4. The seriousness of this fraudulent act is

\begin{tabular}{llllclccl}
\multicolumn{1}{c}{1} & 2 & 3 & 4 & 5 & 6 & 7 & 8 & 9 \\
Extremely & Mostly & Very & Low & About as & High & Very & Mostly & Extremely \\
Low & Low & Low & & High & & High & High & High \\
& & & & as Not & & & &
\end{tabular}

5. This fraudulent act is unethical (general consensus).

\begin{tabular}{|c|c|c|c|c|c|c|c|c|}
\hline 1 & 2 & 3 & 4 & 5 & 6 & 7 & 8 & 9 \\
\hline Strongly & Mostly & Somewhat & Slightly & Neither & Slightly & Somewhat & Mostly & Strongly \\
\hline Disagree & Disagree & Disagree & Disagree & $\begin{array}{l}\text { Disagree nor } \\
\text { Agree }\end{array}$ & Agree & Agree & Agree & Agree \\
\hline
\end{tabular}

6. The fairness of this fraudulent act is

\begin{tabular}{llllccccc}
\multicolumn{1}{c}{1} & 2 & 3 & 4 & 5 & 6 & 7 & 8 & 9 \\
Extremely & Mostly & Very & Unfair & About as & Fair & Very & Mostly & Extremely \\
Unfair & Unfair & Unfair & & Fair & & Fair & Fair & Fair \\
& & & & as Not & & & &
\end{tabular}

7. The personal cost of reporting this fraudulent act by Adrian is

\begin{tabular}{llllccccl}
\multicolumn{1}{c}{1} & 2 & 3 & 4 & 5 & 6 & 7 & 8 & 9 \\
Extremely & Mostly & Very & Low & About as & High & Very & Mostly & Extremely \\
Low & Low & Low & & High & & High & High & High \\
& & & & as Not & & & &
\end{tabular}

8. The responsibility to inform proper parties about the fraudulent act is

$\begin{array}{llllccccl}1 & 2 & 3 & 4 & 5 & 6 & 7 & 8 & 9 \\ \text { Extremely } & \text { Mostly } & \text { Very } & \text { Low } & \text { About as } & \text { High } & \text { Very } & \text { Mostly } & \text { Extremely } \\ \text { Low } & \text { Low } & \text { Low } & & \text { High } & & \text { High } & \text { High } & \text { High } \\ & & & & \text { as Not } & & & & \end{array}$

9. ABC Company will discover this fraudulent act by itself.

$\begin{array}{lcccccccc}1 & 2 & 3 & 4 & 5 & 6 & 7 & 8 & 9 \\ \text { Extremely } & \text { Mostly } & \text { Very } & \text { Unlikely } & \text { About as } & \text { Likely } & \text { Very } & \text { Mostly } & \text { Extremely } \\ \text { Unlikely } & \text { Unlikely } & \text { Unlikely } & & \text { Likely } & & \text { Likely } & \text { Likely } & \text { Likely } \\ & & & & & & \end{array}$


10. Adrian's anonymity will be protected if the fraud is reported.

$\begin{array}{lcccccccc}1 & 2 & 3 & 4 & 5 & 6 & 7 & 8 & 9 \\ \text { Extremely } & \text { Mostly } & \text { Very } & \text { Unlikely } & \text { About as } & \text { Likely } & \text { Very } & \text { Mostly } & \text { Extremely } \\ \text { Unlikely } & \text { Unlikely } & \text { Unlikely } & & \text { Likely } & & \text { Likely } & \text { Likely } & \text { Likely } \\ & & & & & & & \end{array}$

11. This fraudulent act will be thoroughly investigated.

$\begin{array}{lcccccccc}1 & 2 & 3 & 4 & 5 & 6 & 7 & 8 & 9 \\ \text { Extremely } & \text { Mostly } & \text { Very } & \text { Unlikely } & \text { About as } & \text { Likely } & \text { Very } & \text { Mostly } & \text { Extremely } \\ \text { Unlikely } & \text { Unlikely } & \text { Unlikely } & & \text { Likely } & & \text { Likely } & \text { Likely } & \text { Likely } \\ & & & & \text { as Not } & & & & \end{array}$

12. Corrective actions will be taken for this fraudulent act.

$\begin{array}{lcccccccc}1 & 2 & 3 & 4 & 5 & 6 & 7 & 8 & 9 \\ \text { Extremely } & \text { Mostly } & \text { Very } & \text { Unlikely } & \text { About as } & \text { Likely } & \text { Very } & \text { Mostly } & \text { Extremely } \\ \text { Unlikely } & \text { Unlikely } & \text { Unlikely } & & \text { Likely } & & \text { Likely } & \text { Likely } & \text { Likely } \\ & & & & & \text { as Not } & & & \end{array}$

13. This fraud should be attributed to the personal factors of the controller of the division.

\begin{tabular}{|c|c|c|c|c|c|c|c|c|}
\hline 1 & 2 & 3 & 4 & 5 & 6 & 7 & 8 & $\begin{array}{c}9 \\
\text { Strongly }\end{array}$ \\
\hline $\begin{array}{l}\text { Strongly } \\
\text { Disagree }\end{array}$ & Mostly & Somewhat & Slightly & Neither & Slightly & Somewhat & Mostly & $\begin{array}{l}\text { Strongly } \\
\text { Agree }\end{array}$ \\
\hline Disagree & & & Disagree & $\begin{array}{l}\text { Disagree nor } \\
\text { Agree }\end{array}$ & Agree & & & \\
\hline
\end{tabular}

14. This fraud should be attributed to external factors.

\begin{tabular}{|c|c|c|c|c|c|c|c|c|}
\hline 1 & 2 & 3 & 4 & 5 & 6 & 7 & 8 & 9 \\
\hline Strongly & Mostly & Somewhat & Slightly & Neither & Slightly & Somewhat & Mostly & Strongly \\
\hline Disagree & Disagree & Disagree & Disagree & $\begin{array}{l}\text { Disagree nor } \\
\text { Agree }\end{array}$ & Agree & Agree & Agree & Agree \\
\hline
\end{tabular}

Case 2

Adrian has reviewed some bills that have been paid by the company. During the review, Adrian suspects that the services listed on these bills may have not been performed by the vendor. Additionally, Adrian finds that the vendor's post office box address on the bill is identical to the ABC Company's purchasing manager's address in the company system. After consulting other people in the company about the existence of the service, Adrian is almost certain that this is a fraud that has been committed. The total amount of these bills is $\$ 800,000$ and the result of this payment reduces $\mathrm{ABC}$ Company's earnings per share by $\$ 0.02$, which exactly meets the financial analysts' expectations. 
15. It is likely for Adrian to report the fraud to Bailey

\begin{tabular}{|c|c|c|c|c|c|c|}
\hline 1 & 2 & 3 & 4 & 5 & 6 & 7 \\
\hline Strongl & Moderately & Slightly & Neither & Slightly & Moderately & Strongly \\
\hline 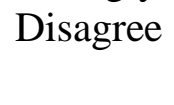 & Disagree & Disagree & $\begin{array}{c}\text { Disagree nor } \\
\text { Agree }\end{array}$ & Agree & Agree & Agree \\
\hline
\end{tabular}

16. If you were Adrian, it is likely for you to report the fraud to Bailey.

$\begin{array}{ccccccc}1 & 2 & 3 & 4 & 5 & 6 & 7 \\ \text { Strongly } & \text { Moderately } & \text { Slightly } & \text { Neither } & \text { Slightly } & \text { Moderately } & \text { Strongly } \\ \text { Disagree } & \text { Disagree } & \text { Disagree } & \begin{array}{c}\text { Disagree nor } \\ \text { Agree }\end{array} & \text { Agree } & \text { Agree } & \text { Agree } \\ & & & \text { Agree } & & \end{array}$

17. This fraudulent act is morally wrong.

\begin{tabular}{|c|c|c|c|c|c|c|c|c|}
\hline 1 & 2 & 3 & 4 & 5 & 6 & 7 & 8 & 9 \\
\hline Strongly & Mostly & Somewhat & Slightly & Neither & Slightly & Somewhat & Mostly & Strongly \\
\hline Disagree & Disagree & Disagree & Disagree & $\begin{array}{l}\text { Disagree nor } \\
\text { Agree }\end{array}$ & Agree & Agree & Agree & Agree \\
\hline
\end{tabular}

18. The seriousness of this fraudulent act is

$\begin{array}{llllclccl}1 & 2 & 3 & 4 & 5 & 6 & 7 & 8 & 9 \\ \text { Extremely } & \text { Mostly } & \text { Very } & \text { Low } & \text { About as } & \text { High } & \text { Very } & \text { Mostly } & \text { Extremely } \\ \text { Low } & \text { Low } & \text { Low } & & \text { High } & & \text { High } & \text { High } & \text { High } \\ & & & & \text { As Not } & & & & \end{array}$

19. This fraudulent act is unethical (general consensus).

\begin{tabular}{|c|c|c|c|c|c|c|c|c|}
\hline 1 & $\begin{array}{c}2 \\
\text { Mostly }\end{array}$ & $\begin{array}{c}3 \\
\text { Somewhat }\end{array}$ & $\begin{array}{c}4 \\
\text { Slightly }\end{array}$ & $\begin{array}{c}5 \\
\text { Neither }\end{array}$ & $\begin{array}{c}6 \\
\text { Slightly }\end{array}$ & $\begin{array}{c}7 \\
\text { Somewhat }\end{array}$ & 8 & $\begin{array}{c}9 \\
\text { Strongly }\end{array}$ \\
\hline $\begin{array}{l}\text { Strongly } \\
\text { Disagree }\end{array}$ & $\begin{array}{c}\text { Mostly } \\
\text { Disagree }\end{array}$ & $\begin{array}{l}\text { Somewhat } \\
\text { Disagree }\end{array}$ & $\begin{array}{r}\text { Slightly } \\
\text { Disagree }\end{array}$ & $\begin{array}{l}\text { Neither } \\
\text { Disagree nor } \\
\text { Agree }\end{array}$ & $\begin{array}{l}\text { Slightly } \\
\text { Agree }\end{array}$ & $\begin{array}{l}\text { Somewhat } \\
\text { Agree }\end{array}$ & $\begin{array}{l}\text { Mostly } \\
\text { Agree }\end{array}$ & $\begin{array}{l}\text { Strongly } \\
\text { Agree }\end{array}$ \\
\hline
\end{tabular}

20. The fairness of this fraudulent act is

\begin{tabular}{llllllccc}
\multicolumn{1}{c}{1} & 2 & 3 & 4 & 5 & 6 & 7 & 8 & 9 \\
Extremely & Mostly & Very & Unfair & About as & Fair & Very & Mostly & Extremely \\
Unfair & Unfair & Unfair & & Fair & & Fair & Fair & Fair \\
& & & & as Not & & & &
\end{tabular}

21. The personal cost of reporting this fraudulent act by Adrian is

$\begin{array}{llllccccl}1 & 2 & 3 & 4 & 5 & 6 & 7 & 8 & 9 \\ \text { Extremely } & \text { Mostly } & \text { Very } & \text { Low } & \text { About as } & \text { High } & \text { Very } & \text { Mostly } & \text { Extremely } \\ \text { Low } & \text { Low } & \text { Low } & & \text { High } & & \text { High } & \text { High } & \text { High } \\ & & & & & & & \end{array}$


22. The responsibility to inform proper parties about the fraudulent act is

$\begin{array}{lllcccccl}1 & 2 & 3 & 4 & 5 & 6 & 7 & 8 & 9 \\ \text { Extremely } & \text { Mostly } & \text { Very } & \text { Low } & \text { About as } & \text { High } & \text { Very } & \text { Mostly } & \text { Extremely } \\ \text { Low } & \text { Low } & \text { Low } & & \text { High } & & \text { High } & \text { High } & \text { High } \\ & & & & \text { as Not } & & & & \end{array}$

23. ABC Company will discover this fraudulent act by itself.

$\begin{array}{lccclcccc}1 & 2 & 3 & 4 & 5 & 6 & 7 & 8 & 9 \\ \text { Extremely } & \text { Mostly } & \text { Very } & \text { Unlikely } & \text { About as } & \text { Likely } & \text { Very } & \text { Mostly } & \text { Extremely } \\ \text { Unlikely } & \text { Unlikely } & \text { Unlikely } & & \text { Likely } & & \text { Likely } & \text { Likely } & \text { Likely } \\ & & & & \text { as Not } & & & & \end{array}$

24. Adrian's anonymity will be protected if the fraud is reported.

$\begin{array}{lcccccccc}1 & 2 & 3 & 4 & 5 & 6 & 7 & 8 & 9 \\ \text { Extremely } & \text { Mostly } & \text { Very } & \text { Unlikely } & \text { About as } & \text { Likely } & \text { Very } & \text { Mostly } & \text { Extremely } \\ \text { Unlikely } & \text { Unlikely } & \text { Unlikely } & & \text { Likely } & & \text { Likely } & \text { Likely } & \text { Likely } \\ & & & & \text { as Not } & & & & \end{array}$

25. This fraudulent act will be thoroughly investigated.

$\begin{array}{lccclcccc}1 & 2 & 3 & 4 & 5 & 6 & 7 & 8 & 9 \\ \text { Extremely } & \text { Mostly } & \text { Very } & \text { Unlikely } & \text { About as } & \text { Likely } & \text { Very } & \text { Mostly } & \text { Extremely } \\ \text { Unlikely } & \text { Unlikely } & \text { Unlikely } & & \text { Likely } & & \text { Likely } & \text { Likely } & \text { Likely } \\ & & & & \text { as Not } & & & & \end{array}$

26. Corrective actions will be taken for this fraudulent act.

$\begin{array}{lccclcccc}1 & 2 & 3 & 4 & 5 & 6 & 7 & 8 & 9 \\ \text { Extremely } & \text { Mostly } & \text { Very } & \text { Unlikely } & \text { About as } & \text { Likely } & \text { Very } & \text { Mostly } & \text { Extremely } \\ \text { Unlikely } & \text { Unlikely } & \text { Unlikely } & & \text { Likely } & & \text { Likely } & \text { Likely } & \text { Likely } \\ & & & & \text { as Not } & & & & \end{array}$

27. This fraud should be attributed to the purchasing manager's personal factors.

\begin{tabular}{|c|c|c|c|c|c|c|c|c|}
\hline 1 & 2 & 3 & 4 & 5 & 6 & 7 & 8 & 9 \\
\hline Strongly & Mostly & Somewhat & Slightly & Neither & Slightly & Somewhat & Mostly & Strongly \\
\hline Disagree & Disagree & Disagree & Disagree & $\begin{array}{l}\text { Disagree nor } \\
\text { Agree }\end{array}$ & Agree & Agree & Agree & Agree \\
\hline
\end{tabular}

28. This fraud should be attributed to external factors.

\begin{tabular}{|c|c|c|c|c|c|c|c|c|}
\hline 1 & 2 & 3 & 4 & 5 & 6 & 7 & 8 & 9 \\
\hline Strongly & Mostly & Somewhat & Slightly & Neither & Slightly & Somewhat & Mostly & Strongly \\
\hline Disagree & Disagree & Disagree & Disagree & $\begin{array}{l}\text { Disagree nor } \\
\text { Agree }\end{array}$ & Agree & Agree & Agree & Agree \\
\hline
\end{tabular}




\section{Post-experiment questionnaire}

Thank you very much for your participation and cooperation, and we gratefully appreciate your time and support. There are only a few questions remaining in which we are interested in. Please read and answer the following questions regarding ABC Company, Adrian, and Bailey. Circle the answer that you would like to choose.

1. What is the role of Adrian in ABC Company?
A. Accountant in the accounting department
B. Accounting department head.
C. Purchasing manager
D. External vendor for ABC Company

2. What is the role of Bailey in ABC Company?
A. Accountant in the accounting department
B. Accounting department head.
C. Purchasing manager
D. External vendor for ABC Company

3. What gender do you believe Bailey to be?
A. Male
B. Female
C. Indeterminable

4. Bailey has the ability to perceive his/her and other's emotion.

\begin{tabular}{|c|c|c|c|c|c|c|c|c|}
\hline 1 & 2 & 3 & 4 & 5 & 6 & 7 & 8 & 9 \\
\hline Strongly & Mostly & Somewhat & Slightly & Neither & Slightly & Somewhat & Mostly & Strongly \\
\hline Disagree & Disagree & Disagree & Disagree & $\begin{array}{l}\text { Disagree nor } \\
\text { Agree }\end{array}$ & Agree & Agree & Agree & Agree \\
\hline
\end{tabular}

5. Bailey has ability to access and generate emotions to make effective decisions.

\begin{tabular}{|c|c|c|c|c|c|c|c|c|}
\hline 1 & 2 & 3 & 4 & 5 & 6 & 7 & 8 & 9 \\
\hline Strongly & Mostly & Somewhat & Slightly & Neither & Slightly & Somewhat & Mostly & Strongly \\
\hline Disagree & Disagree & Disagree & Disagree & $\begin{array}{l}\text { Disagree nor } \\
\text { Agree }\end{array}$ & Agree & Agree & Agree & Agree \\
\hline
\end{tabular}

6. Bailey has the ability to understand his/her own and other's emotion.

\begin{tabular}{|c|c|c|c|c|c|c|c|c|}
\hline 1 & 2 & 3 & 4 & 5 & 6 & 7 & 8 & $\begin{array}{c}9 \\
\text { Strongly }\end{array}$ \\
\hline Strongly & Mostly & Somewhat & Slightly & Neither & Slightly & Somewhat & Mostly & Strongly \\
\hline Disagree & Disagree & Disagree & Disagree & $\begin{array}{l}\text { Disagree nor } \\
\text { Agree }\end{array}$ & Agree & Agree & Agree & Agree \\
\hline
\end{tabular}


7. Bailey has the ability to manage his/her own and other's emotion.

\begin{tabular}{|c|c|c|c|c|c|c|c|c|}
\hline 1 & 2 & 3 & 4 & 5 & 6 & 7 & 8 & 9 \\
\hline Strongly & Mostly & Somewhat & Slightly & Neither & Slightly & Somewhat & Mostly & Strongly \\
\hline Disagree & Disagree & Disagree & Disagree & $\begin{array}{l}\text { Disagree nor } \\
\text { Agree }\end{array}$ & Agree & Agree & Agree & Agree \\
\hline
\end{tabular}

8. Bailey represents what is characteristic of the accounting department.

\begin{tabular}{|c|c|c|c|c|c|c|c|c|}
\hline 1 & 2 & 3 & 4 & 5 & 6 & 7 & 8 & 9 \\
\hline Strongly & Mostly & Somewhat & Slightly & Neither & Slightly & Somewhat & Mostly & Strongly \\
\hline Disagree & Disagree & Disagree & Disagree & $\begin{array}{l}\text { Disagree nor } \\
\text { Agree }\end{array}$ & Agree & Agree & Agree & Agree \\
\hline
\end{tabular}

\section{Demographic items}

1. What is your gender?

\section{Male}

$\square$ Female

2. What is your age?

3. How many years of business-related work experience do you have so far?

4. What is your occupation?

5. What is your achieved highest education level?

High school degree

Associate degree

Bachelor degree

Graduate degree

6. What is/was your college major (if applicable)?

7. How many accounting classes have you taken? (Please give a specific number to your best knowledge)

8. How many business-related classes (including accounting classes) have you taken? (Please give a specific number to your best knowledge) 
9. Have you ever reported an observed accounting fraud?

$$
\begin{aligned}
& \text { Yes } \\
& \text { No } \\
& \text { I can't remember }
\end{aligned}
$$

10. Have you ever reported an observed fraudulent act (including accounting fraud)?

$$
\begin{aligned}
& \text { Yes } \\
& \text { No } \\
& \text { I can't remember }
\end{aligned}
$$

11. Have you ever actively participated in an accounting fraud?

$$
\begin{aligned}
& \text { Yes } \\
& \text { No } \\
& \text { I can't remember }
\end{aligned}
$$

12. Have you ever actively participated in any fraud (including accounting fraud)?

$$
\begin{aligned}
& \text { Yes } \\
& \text { No } \\
& \text { I can't remember }
\end{aligned}
$$

13. Including yourself, how many siblings do you have in your family?

14. What is your birth order in your family (e.g., first, second, third, etc.)?

\section{Schutte et al. (1998) emotional intelligence scale}

For each statement, please circle the number in the 5-level scale that you believe most accurately describes your situation: $1=$ Strongly Disagree; $2=$ Disagree; $3=$ Neutral; 4 = Agree; 5 = Strongly Agree

1. I know when to speak about my personal problems to others.

$\begin{array}{ccccc}1 & 2 & 3 & 4 & 5 \\ \text { Strong Disagree } & \text { Disagree } & \text { Neutral } & \text { Agree } & \text { Strongly Agree }\end{array}$

2. When I am faced with obstacles, I remember times I faced obstacles and overcame them.
Strong Disagree
2
3
4
Agree Strongly Agree 
3. I expect that I will do well on most things I try.

$\begin{array}{ccccc}1 & 2 & 3 & 4 & 5 \\ \text { Strong Disagree } & \text { Disagree } & \text { Neutral } & \text { Agree } & \text { Strongly Agree }\end{array}$

4. Other people find it safe to confide me.

$\begin{array}{ccccc}1 & 2 & 3 & 4 & 5 \\ \text { Strong Disagree } & \text { Disagree } & \text { Neutral } & \text { Agree } & \text { Strongly Agree }\end{array}$

5. I find it hard to understand the non-verbal messages of other people.
Strong Disagree
2
3
4
5
Disagree
Neutral
Agree
Strongly Agree

6. Some of the major events of my life have led me to re-evaluate what is important and not important.

$\begin{array}{ccccc}1 & 2 & 3 & 4 & 5 \\ \text { Strong Disagree } & \text { Disagree } & \text { Neutral } & \text { Agree } & \text { Strongly Agree }\end{array}$

7. When my mood changes, I see new possibilities.

$\begin{array}{ccccc}1 & 2 & 3 & 4 & 5 \\ \text { Strong Disagree } & \text { Disagree } & \text { Neutral } & \text { Agree } & \text { Strongly Agree }\end{array}$

8. Emotions are one of the things that make my life worth living.
Strong Disagree
2
3
4
Neutral Agree
5
Strongly Agree

9. I am aware of my emotions as I experience them.

$\begin{array}{ccccc}1 & 2 & 3 & 4 & 5 \\ \text { Strong Disagree } & \text { Disagree } & \text { Neutral } & \text { Agree } & \text { Strongly Agree }\end{array}$

10. I expect good things to happen.

$\begin{array}{ccccc}1 & 2 & 3 & 4 & 5 \\ \text { Strong Disagree } & \text { Disagree } & \text { Neutral } & \text { Agree } & \text { Strongly Agree }\end{array}$

11. I like to share my emotions with others.

$\begin{array}{ccccc}1 & 2 & 3 & 4 & 5 \\ \text { Strong Disagree } & \text { Disagree } & \text { Neutral } & \text { Agree } & \text { Strongly Agree }\end{array}$

12. When I experience a positive emotion, I know how to make it last.

$\begin{array}{ccccc}1 & 2 & 3 & 4 & 5 \\ \text { Strong Disagree } & \text { Disagree } & \text { Neutral } & \text { Agree } & \text { Strongly Agree }\end{array}$

13. I arrange events others enjoy.

$1 \quad 2$

Strong Disagree

Disagree
34

Neutral Agree
5

Strongly Agree 
14. I seek out activities that make me happy.

$\begin{array}{ccccc}1 & 2 & 3 & 4 & 5 \\ \text { Strong Disagree } & \text { Disagree } & \text { Neutral } & \text { Agree } & \text { Strongly Agree }\end{array}$

15. I am aware of the non-verbal messages I send to others.

$\begin{array}{ccccc}1 & 2 & 3 & 4 & 5 \\ \text { Strong Disagree } & \text { Disagree } & \text { Neutral } & \text { Agree } & \text { Strongly Agree }\end{array}$

16. I present myself in a way that makes a good impression on others.

$\begin{array}{ccccc}1 & 2 & 3 & 4 & 5 \\ \text { Strong Disagree } & \text { Disagree } & \text { Neutral } & \text { Agree } & \text { Strongly Agree }\end{array}$

17. When I am in a positive mood, solving problems is easy for me.
1 2 3
4 Strong Disagree
Disagree
Neutral
Agree
5
Strongly Agree

18. By looking at their facial expressions, I recognize the emotions people are experiencing.
1
2
3
4 5

Strong Disagree

Disagree

Neutral

Agree

Strongly Agree

19. I know why emotions change.
1
2
3
4
5
Strong Disagree
Disagree
Neutral
Agree
Strongly Agree

20. When I am in a positive mood, I am able to come up with new ideas.

$\begin{array}{ccccc}1 & 2 & 3 & 4 & 5 \\ \text { Strong Disagree } & \text { Disagree } & \text { Neutral } & \text { Agree } & \text { Strongly Agree }\end{array}$

21. I have control over my emotions.

$\begin{array}{ccccc}1 & 2 & 3 & 4 & 5 \\ \text { Strong Disagree } & \text { Disagree } & \text { Neutral } & \text { Agree } & \text { Strongly Agree }\end{array}$

22. I easily recognize my emotions as I experience them.
Strong Disagree
2
3
4
5
Agree Strongly Agree

23. I motivate myself by imagining a good outcome to tasks I take on.
1
2
3
4
Strong Disagree
Disagree
Neutral
Agree
5
Strongly Agree

24. I compliment others when they have done something well.
1
Strong Disagree
2
Disagree
3
Neutral
4
Agree
5
Strongly Agree 
25. I am aware of the non-verbal messages other people send.

$\begin{array}{ccccc}1 & 2 & 3 & 4 & 5 \\ \text { Strong Disagree } & \text { Disagree } & \text { Neutral } & \text { Agree } & \text { Strongly Agree }\end{array}$

26. When another person tells me about an important event in his or her life, I almost feel as though I have experienced this event myself.
Strong Disagree
2
Disagree
4
Neutral Agree Strongly Agree
5

27. When I feel a change in emotions, I tend to come up with new ideas.

$\begin{array}{ccccc}1 & 2 & 3 & 4 & 5 \\ \text { Strong Disagree } & \text { Disagree } & \text { Neutral } & \text { Agree } & \text { Strongly Agree }\end{array}$

28. When I am faced with a challenge, I give up because I believe I will fail.

$\begin{array}{ccccc}1 & 2 & 3 & 4 & 5 \\ \text { Strong Disagree } & \text { Disagree } & \text { Neutral } & \text { Agree } & \text { Strongly Agree }\end{array}$

29. I know what other people are feeling just by looking at them.

$\begin{array}{ccccc}1 & 2 & 3 & 4 & 5 \\ \text { Strong Disagree } & \text { Disagree } & \text { Neutral } & \text { Agree } & \text { Strongly Agree }\end{array}$

30. I help other people feel better when they are down.
Strong Disagree
Disagree
3
4
5
Neutral Agree Strongly Agree

31. I use good moods to help myself keep trying in the face of obstacles.
Strong Disagree
2
3
4
5
Disagree
Neutral
Agree
Strongly Agree

32. I can tell how people are feeling by listening to the tone of their voice.
1
2
3
4
5
Strong Disagree
Disagree
Neutral
Agree
Strongly Agree

33. It is difficult for me to understand why people feel the way they do.

$\begin{array}{ccccc}1 & 2 & 3 & 4 & 5 \\ \text { Strong Disagree } & \text { Disagree } & \text { Neutral } & \text { Agree } & \text { Strongly Agree }\end{array}$

\section{Rushton et al. (1981) altruism scale}

For each statement, please circle the number in the scale that you believe most properly describes your situation: $1=$ =verer; $2=$ Once; $3=$ More than once; $4=0$ Often; $5=$ Very often. 
1. I have helped push a stranger's car that was broken down or out of gas.

$\begin{array}{lcccc}1 & 2 & 3 & 4 & 5 \\ \text { Never } & \text { Once } & \text { More than Once } & \text { Often } & \text { Very Often }\end{array}$

2. I have given directions to a stranger.

$\begin{array}{lcccc}1 & 2 & 3 & 4 & 5 \\ \text { Never } & \text { Once } & \text { More than Once } & \text { Often } & \text { Very Often }\end{array}$

3. I have made change for a stranger.

$\begin{array}{lcccc}1 & 2 & 3 & 4 & 5 \\ \text { Never } & \text { Once } & \text { More than Once } & \text { Often } & \text { Very Often }\end{array}$

4. I have given money to a charity.

$\begin{array}{lcccc}1 & 2 & 3 & 4 & 5 \\ \text { Never } & \text { Once } & \text { More than Once } & \text { Often } & \text { Very Often }\end{array}$

5. I have given money to a stranger who needed it (or asked me for it).

$\begin{array}{lcccc}1 & 2 & 3 & 4 & 5 \\ \text { Never } & \text { Once } & \text { More than Once } & \text { Often } & \text { Very Often }\end{array}$

6. I have donated goods or clothes to a charity.

$\begin{array}{lcccc}1 & 2 & 3 & 4 & 5 \\ \text { Never } & \text { Once } & \text { More than Once } & \text { Often } & \text { Very Often }\end{array}$

7. I have done volunteer work for a charity.

$\begin{array}{lcccc}1 & 2 & 3 & 4 & 5 \\ \text { Never } & \text { Once } & \text { More than Once } & \text { Often } & \text { Very Often }\end{array}$

8. I have donated blood.

$\begin{array}{lcccc}1 & 2 & 3 & 4 & 5 \\ \text { Never } & \text { Once } & \text { More than Once } & \text { Often } & \text { Very Often }\end{array}$

9. I have helped carry a stranger's belongings (books, parcels, etc.).

$\begin{array}{lcccc}1 & 2 & 3 & 4 & 5 \\ \text { Never } & \text { Once } & \text { More than Once } & \text { Often } & \text { Very Often }\end{array}$


10. I have delayed an elevator and held the door open for a stranger.

$\begin{array}{lcccc}1 & 2 & 3 & 4 & 5 \\ \text { Never } & \text { Once } & \text { More than Once } & \text { Often } & \text { Very Often }\end{array}$

11. I have allowed someone to go ahead of me in a lineup (at a copy machine, in the supermarket, at a fast-food restaurant, etc.).

$\begin{array}{lcccc}1 & 2 & 3 & 4 & 5 \\ \text { Never } & \text { Once } & \text { More than Once } & \text { Often } & \text { Very Often }\end{array}$

12. I have given a stranger a lift in my car.

$\begin{array}{lcccc}1 & 2 & 3 & 4 & 5 \\ \text { Never } & \text { Once } & \text { More than Once } & \text { Often } & \text { Very Often }\end{array}$

13. I have pointed out a clerk's error (in a bank, at the supermarket, etc.) in undercharging me for an item.

$\begin{array}{lcccc}1 & 2 & 3 & 4 & 5 \\ \text { Never } & \text { Once } & \text { More than Once } & \text { Often } & \text { Very Often }\end{array}$

14. I have let a neighbor whom I did not know too well borrow an item of some value to me (e.g., a dish, tools, etc.).
12
3
Never Once
More than Once
4
5
Very Often

15. I have bought "charity" Christmas cards deliberately because I knew it was a good cause.

$\begin{array}{lcccc}1 & 2 & 3 & 4 & 5 \\ \text { Never } & \text { Once } & \text { More than Once } & \text { Often } & \text { Very Often }\end{array}$

16. I have helped a classmate who I did not know that well with a homework assignment when my knowledge was greater than his or hers.

$\begin{array}{lcccc}1 & 2 & 3 & 4 & 5 \\ \text { Never } & \text { Once } & \text { More than Once } & \text { Often } & \text { Very Often }\end{array}$

17. I have before being asked, voluntarily looked after a neighbor's pets or children without being paid for it.

$\begin{array}{lcccc}1 & 2 & 3 & 4 & 5 \\ \text { Never } & \text { Once } & \text { More than Once } & \text { Often } & \text { Very Often }\end{array}$


18. I have offered to help a handicapped or elderly stranger across a street.

$\begin{array}{lcccc}1 & 2 & 3 & 4 & 5 \\ \text { Never } & \text { Once } & \text { More than Once } & \text { Often } & \text { Very Often }\end{array}$

19. I have offered my seat on a bus or train to a stranger who was standing.

$\begin{array}{lcccc}1 & 2 & 3 & 4 & 5 \\ \text { Never } & \text { Once } & \text { More than Once } & \text { Often } & \text { Very Often }\end{array}$

20. I have helped an acquaintance to move households.

$\begin{array}{lcccc}1 & 2 & 3 & 4 & 5 \\ \text { Never } & \text { Once } & \text { More than Once } & \text { Often } & \text { Very Often }\end{array}$




\section{APPENDIX III. EXPERIMENTAL INSTRUMENTS FOR SUPPLEMENTARY EXPERIMENT}

\section{High leader emotional intelligence and firm consequence frame}

Please read the following background information about ABC Company, Adrian, and Bailey, and then answer the questions that follow. The questions should take you approximately 20 - 30 minutes.

ABC Company is a manufacturing company of consumer goods. It had produced steady operating results but recently performed at slightly below the industry average. Adrian is an accountant in the production division of ABC Company and directly reports to Bailey, who is the department head of the production division and is Adrian's direct supervisor. Adrian has been working in ABC Company's production division under Bailey's direct supervision for two years.

Bailey is able to perceive the emotions of others, including Adrian's. It is easy for Bailey to understand the non-verbal messages of Adrian and other people, and Bailey is always aware of the non-verbal messages sent to others including Adrian and the emotions experienced by himself. Bailey is also able to access and generate emotions to make effective decisions. Bailey arranges activities that make him, Adrian, and others happy, and when in positive emotion, Bailey can quickly solve problems and come up with new ideas. Moreover, Bailey is able to understand the emotions of Adrian, others, and himself. Bailey knows why his emotions and emotions of people around change, and when another person, such as Adrian, tells Bailey about an important event in their life, Bailey can almost feel the experience. Finally, Bailey is able to manage the emotions of Adrian, others, and himself. No matter how much work pressure there is on Bailey, a positive emotion is always maintained. Bailey also can help others, including Adrian, feel better when they are down.

1. In a few sentences, please briefly describe what kind of a person Bailey is.

Please read the following case that happens in ABC Company, and answer the questions or give opinions on statements that follow. Please remember that all previous background information about ABC Company, Adrian, and Bailey applies to the following cases.

Adrian is working on a review of the general journal entries that are needed to prepare the production division's financial statements, and Adrian finds that the assets in the division are improperly valued. $\$ 800,000$ of expenses has been capitalized (recorded as assets instead of expense) by Bailey. After talking with some friends in the division, Adrian is almost certain that this is a fraud that has been committed, and it is extremely probable that Bailey is intentionally involved. The mis-recording increases the production division's earnings per share by $\$ 0.02$, which exactly meets financial analysts' expectations. ABC Company has an anonymous whistleblowing hotline, which can strictly protect the whistleblower's identity. If Adrian reports this fraud through the hotline, $\mathrm{ABC}$ Company could get to know this incident in a 


\section{timely manner and thus avoid reputation impairment, future profit loss, and potential charge from government agency. Future potential fraud could also be deterred.}

1. Based on the case above, please describe the consequences if Adrian report this fraud through the hot line.

2. If you were Adrian, it is likely that you will report the fraud to ABC Company's anonymous whistleblowing hotline.

\begin{tabular}{ccccccc}
1 & 2 & 3 & 4 & 5 & 6 & 7 \\
Strongly & Moderately & Slightly & Neither & Slightly & Moderately & Strongly \\
Disagree & Disagree & Disagree & $\begin{array}{c}\text { Disagree nor } \\
\text { Agree }\end{array}$ & Agree & Agree & Agree \\
& & \multicolumn{3}{c}{ Agrase } & &
\end{tabular}

3. It is likely that Adrian will report the fraud to ABC Company's anonymous whistleblowing hotline.

$\begin{array}{ccccccc}1 & 2 & 3 & 4 & 5 & 6 & 7 \\ \text { Strongly } & \text { Moderately } & \text { Slightly } & \text { Neither } & \text { Slightly } & \text { Moderately } & \text { Strongly } \\ \text { Disagree } & \text { Disagree } & \text { Disagree } & \begin{array}{c}\text { Disagree nor } \\ \text { Agree }\end{array} & \text { Agree } & \text { Agree } & \text { Agree }\end{array}$

4. If you were Adrian, you would perceive the working relationship with Bailey as effective.

$\begin{array}{ccccccc}1 & 2 & 3 & 4 & 5 & 6 & 7 \\ \text { Strongly } & \text { Moderately } & \text { Slightly } & \text { Neither } & \text { Slightly } & \text { Moderately } & \text { Strongly } \\ \text { Disagree } & \text { Disagree } & \text { Disagree } & \text { Disagree nor } & \text { Agree } & \text { Agree } & \text { Agree }\end{array}$

5. If you were Adrian, you would believe that Bailey could understand your job problems and needs.

$\begin{array}{cllcccc}1 & 2 & 3 & 4 & 5 & 6 & 7 \\ \text { Strongly } & \text { Moderately } & \text { Slightly } & \text { Neither } & \text { Slightly } & \text { Moderately } & \text { Strongly } \\ \text { Disagree } & \text { Disagree } & \text { Disagree } & \text { Disagree nor } & \text { Agree } & \text { Agree } & \text { Agree } \\ & & & \text { Agree } & & & \end{array}$

6. If you were Adrian, you would believe that Bailey could recognize your potential.

$\begin{array}{cllcccc}1 & 2 & 3 & 4 & 5 & 6 & 7 \\ \text { Strongly } & \text { Moderately } & \text { Slightly } & \text { Neither } & \text { Slightly } & \text { Moderately } & \text { Strongly } \\ \text { Disagree } & \text { Disagree } & \text { Disagree } & \begin{array}{c}\text { Disagree nor } \\ \text { Disaree }\end{array} & \begin{array}{c}\text { Agree } \\ \text { Agree }\end{array} & \text { Agree } \\ & & & & & \text { Agred }\end{array}$


7. If you were Adrian, you would believe that regardless of how much formal authority Bailey has built into the position, it is possible that Bailey would use power to help you solve problems in your work.

$\begin{array}{clccccc}1 & 2 & 3 & 4 & 5 & 6 & 7 \\ \text { Strongly } & \text { Moderately } & \text { Slightly } & \text { Neither } & \text { Slightly } & \text { Moderately } & \text { Strongly } \\ \text { Disagree } & \text { Disagree } & \text { Disagree } & \begin{array}{c}\text { Disagree nor } \\ \text { Agree }\end{array} & \text { Agree } & \text { Agree } & \text { Agree }\end{array}$

8. If you were Adrian, you would believe that regardless of the amount of formal authority Bailey has, it is possible that Bailey would "bail you out" at Bailey's expense.

$\begin{array}{clccccc}1 & 2 & 3 & 4 & 5 & 6 & 7 \\ \text { Strongly } & \text { Moderately } & \text { Slightly } & \text { Neither } & \text { Slightly } & \text { Moderately } & \text { Strongly } \\ \text { Disagree } & \text { Disagree } & \text { Disagree } & \begin{array}{c}\text { Disagree nor } \\ \text { Agree }\end{array} & \text { Agree } & \text { Agree } & \text { Agree } \\ & & & & & \end{array}$

9. If you were Adrian, you would have enough confidence in Bailey that you would defend and justify Bailey's decision if Bailey were not present to do so.

$\begin{array}{cllcccc}1 & 2 & 3 & 4 & 5 & 6 & 7 \\ \text { Strongly } & \text { Moderately } & \text { Slightly } & \text { Neither } & \text { Slightly } & \text { Moderately } & \text { Strongly } \\ \text { Disagree } & \text { Disagree } & \text { Disagree } & \begin{array}{c}\text { Disagree nor } \\ \text { Agree }\end{array} & \text { Agree } & \text { Agree } & \text { Agree }\end{array}$

10. If you were Adrian, you can trust Bailey to do what is good for you.

$\begin{array}{ccccccc}1 & 2 & 3 & 4 & 5 & 6 & 7 \\ \text { Strongly } & \begin{array}{c}\text { Moderately } \\ \text { Disagree }\end{array} & \begin{array}{c}\text { Disagree } \\ \text { Disagree }\end{array} & \begin{array}{c}\text { Neither } \\ \text { Disagree nor } \\ \text { Dgree }\end{array} & \begin{array}{c}\text { Slightly } \\ \text { Agree }\end{array} & \begin{array}{c}\text { Moderately } \\ \text { Agree }\end{array} & \begin{array}{c}\text { Strongly } \\ \text { Agree }\end{array} \\ & & & & & \end{array}$

11. If you were Adrian, you can trust Bailey to treat you fairly.

$$
\begin{array}{lllllll}
1 & 2 & 3 & 4 & 5 & 6 & 7
\end{array}
$$

Strongly Moderately Slightly Neither Slightly Moderately Strongly

Disagree Disagree Disagree Disagree nor Agree Agree Agree Agree

12. If you were Adrian, Bailey can be trusted to make decisions that are good for you.

\begin{tabular}{ccccccc}
1 & 2 & 3 & 4 & 5 & 6 & 7 \\
Strongly & Moderately & Slightly & Neither & Slightly & Moderately & Strongly \\
Disagree & Disagree & Disagree & $\begin{array}{c}\text { Disagree nor } \\
\text { Agree }\end{array}$ & Agree & Agree & Agree \\
& & \multicolumn{3}{c}{ Agras } & &
\end{tabular}


13. If you were Adrian, you are satisfied with your current job in the accounting department of ABC Company?

\begin{tabular}{ccccccc}
1 & 2 & 3 & 4 & 5 & 6 & 7 \\
Strongly & Moderately & Slightly & Neither & Slightly & Moderately & Strongly \\
Disagree & Disagree & Disagree & $\begin{array}{c}\text { Disagree nor } \\
\text { Agree }\end{array}$ & Agree & Agree & Agree \\
& & \multicolumn{3}{c}{ Agras } & &
\end{tabular}

14. This fraudulent act is morally wrong.

\begin{tabular}{|c|c|c|c|c|c|c|c|c|}
\hline 1 & 2 & 3 & 4 & 5 & 6 & 7 & 8 & 9 \\
\hline Strongly & Mostly & Somewhat & Slightly & Neither & Slightly & Somewhat & Mostly & Strongly \\
\hline Disagree & Disagree & Disagree & Disagree & $\begin{array}{l}\text { Disagree nor } \\
\text { Agree }\end{array}$ & Agree & Agree & Agree & Agree \\
\hline
\end{tabular}

15. The seriousness of this fraudulent act is

$\begin{array}{llllccccc}1 & 2 & 3 & 4 & 5 & 6 & 7 & 8 & 9 \\ \text { Extremely } & \text { Mostly } & \text { Very } & \text { Low } & \text { About as } & \text { High } & \text { Very } & \text { Mostly } & \text { Extremely } \\ \text { Low } & \text { Low } & \text { Low } & & \text { High } & & \text { High } & \text { High } & \text { High } \\ & & & & \text { as Not } & & & & \end{array}$

16. This fraudulent act is unethical (general consensus).

\begin{tabular}{|c|c|c|c|c|c|c|c|c|}
\hline 1 & 2 & 3 & 4 & 5 & 6 & 7 & 8 & 9 \\
\hline Strongly & Mostly & Somewhat & Slightly & Neither & Slightly & Somewhat & Mostly & Strongly \\
\hline Disagree & Disagree & Disagree & Disagree & $\begin{array}{l}\text { Disagree nor } \\
\text { Agree }\end{array}$ & Agree & Agree & Agree & Agree \\
\hline
\end{tabular}

17. The fairness of this fraudulent act is

\begin{tabular}{lllllclcl}
\multicolumn{1}{c}{1} & 2 & 3 & 4 & 5 & 6 & 7 & 8 & 9 \\
Extremely & Mostly & Very & Unfair & About as & Fair & Very & Mostly & Extremely \\
Unfair & Unfair & Unfair & & Fair & & Fair & Fair & Fair \\
& & & & as Not & & & &
\end{tabular}

18. The personal cost of reporting this fraudulent act by Adrian is

$\begin{array}{llllccccc}1 & 2 & 3 & 4 & 5 & 6 & 7 & 8 & 9 \\ \text { Extremely } & \text { Mostly } & \text { Very } & \text { Low } & \text { About as } & \text { High } & \text { Very } & \text { Mostly } & \text { Extremely } \\ \text { Low } & \text { Low } & \text { Low } & & \text { High } & & \text { High } & \text { High } & \text { High } \\ & & & & \text { as Not } & & & & \end{array}$

19. The responsibility to inform proper parties about the fraudulent act is

$\begin{array}{lllcccccc}1 & 2 & 3 & 4 & 5 & 6 & 7 & 8 & 9 \\ \text { Extremely } & \text { Mostly } & \text { Very } & \text { Low } & \text { About as } & \text { High } & \text { Very } & \text { Mostly } & \text { Extremely } \\ \text { Low } & \text { Low } & \text { Low } & & \text { High } & & \text { High } & \text { High } & \text { High } \\ & & & & \text { as Not } & & & & \end{array}$


20. ABC Company will discover this fraudulent act by itself.

$\begin{array}{lcccccccc}1 & 2 & 3 & 4 & 5 & 6 & 7 & 8 & 9 \\ \text { Extremely } & \text { Mostly } & \text { Very } & \text { Unlikely } & \text { About as } & \text { Likely } & \text { Very } & \text { Mostly } & \text { Extremely } \\ \text { Unlikely } & \text { Unlikely } & \text { Unlikely } & & \text { Likely } & & \text { Likely } & \text { Likely } & \text { Likely } \\ & & & & \text { as Not } & & & & \end{array}$

21. Adrian's anonymity will be protected if the fraud is reported.

$\begin{array}{lcccccccc}1 & 2 & 3 & 4 & 5 & 6 & 7 & 8 & 9 \\ \text { Extremely } & \text { Mostly } & \text { Very } & \text { Unlikely } & \text { About as } & \text { Likely } & \text { Very } & \text { Mostly } & \text { Extremely } \\ \text { Unlikely } & \text { Unlikely } & \text { Unlikely } & & \text { Likely } & & \text { Likely } & \text { Likely } & \text { Likely } \\ & & & & \text { as Not } & & & & \end{array}$

22. This fraudulent act will be thoroughly investigated.

$\begin{array}{lcccccccc}1 & 2 & 3 & 4 & 5 & 6 & 7 & 8 & 9 \\ \text { Extremely } & \text { Mostly } & \text { Very } & \text { Unlikely } & \text { About as } & \text { Likely } & \text { Very } & \text { Mostly } & \text { Extremely } \\ \text { Unlikely } & \text { Unlikely } & \text { Unlikely } & & \text { Likely } & & \text { Likely } & \text { Likely } & \text { Likely } \\ & & & & & & \end{array}$

23. Corrective actions will be taken for this fraudulent act.

$\begin{array}{lcccccccc}1 & 2 & 3 & 4 & 5 & 6 & 7 & 8 & 9 \\ \text { Extremely } & \text { Mostly } & \text { Very } & \text { Unlikely } & \text { About as } & \text { Likely } & \text { Very } & \text { Mostly } & \text { Extremely } \\ \text { Unlikely } & \text { Unlikely } & \text { Unlikely } & & \begin{array}{c}\text { Likely } \\ \text { as Not }\end{array} & & \text { Likely } & \text { Likely } & \text { Likely }\end{array}$

24. This fraud should be attributed to the personal factors of the Bailey.

\begin{tabular}{|c|c|c|c|c|c|c|c|c|}
\hline 1 & 2 & 3 & 4 & 5 & 6 & 7 & 8 & 9 \\
\hline Strongly & Mostly & Somewhat & Slightly & Neither & Slightly & Somewhat & Mostly & Strongly \\
\hline Disagree & Disagree & Disagree & Disagree & $\begin{array}{c}\text { Disagree nor } \\
\text { Agree }\end{array}$ & Agree & Agree & Agree & Agree \\
\hline
\end{tabular}

25. This fraud should be attributed to external factors.

\begin{tabular}{|c|c|c|c|c|c|c|c|c|}
\hline 1 & 2 & 3 & 4 & 5 & 6 & 7 & 8 & 9 \\
\hline Strongly & Mostly & Somewhat & Slightly & Neither & Slightly & Somewhat & Mostly & Strongly \\
\hline Disagree & Disagree & Disagree & Disagree & $\begin{array}{l}\text { Disagree nor } \\
\text { Agree }\end{array}$ & Agree & Agree & Agree & Agree \\
\hline
\end{tabular}

\section{High leader emotional intelligence and leader consequence frame}

Please read the following background information about ABC Company, Adrian, and Bailey, and then answer the questions that follow. The questions should take you approximately 20 - 30 minutes. 
ABC Company is a manufacturing company of consumer goods. It had produced steady operating results but recently performed at slightly below the industry average. Adrian is an accountant in the production division of $\mathrm{ABC}$ Company and directly reports to Bailey, who is the department head of the production division and is Adrian's direct supervisor. Adrian has been working in ABC Company's production division under Bailey's direct supervision for two years.

Bailey is able to perceive the emotions of others, including Adrian's. It is easy for Bailey to understand the non-verbal messages of Adrian and other people, and Bailey is always aware of the non-verbal messages sent to others including Adrian and the emotions experienced by himself. Bailey is also able to access and generate emotions to make effective decisions. Bailey arranges activities that make him, Adrian, and others happy, and when in positive emotion, Bailey can quickly solve problems and come up with new ideas. Moreover, Bailey is able to understand the emotions of Adrian, others, and himself. Bailey knows why his emotions and emotions of people around change, and when another person, such as Adrian, tells Bailey about an important event in their life, Bailey can almost feel the experience. Finally, Bailey is able to manage the emotions of Adrian, others, and himself. No matter how much work pressure there is on Bailey, a positive emotion is always maintained. Bailey also can help others, including Adrian, feel better when they are down.

1. In a few sentences, please briefly describe what kind of a person Bailey is.

Please read the following case that happen in ABC Company, and answer the questions or give opinions on statements that follow. Please remember that all previous background information about ABC Company, Adrian, and Bailey applies to the following cases.

Adrian is working on a review of the general journal entries that are needed to prepare the production division's financial statements, and Adrian finds that the assets in the division are improperly valued. $\$ 800,000$ of expenses has been capitalized (recorded as assets instead of expense) by Bailey. After talking with some friends in the division, Adrian is almost certain that this is a fraud that has been committed, and it is extremely probable that Bailey is intentionally involved. The mis-recording increases the production division's earnings per share by $\$ 0.02$, which exactly meets financial analysts' expectations. ABC Company has an anonymous whistleblowing hotline, which can strictly protect the whistleblower's identity. If Adrian reports this fraud through the hotline, Bailey could probably be fired, economically and judicially punished, and never get hired by another company.

1. Based on the case above, please describe the consequence if Adrian reports this fraud through the hotline. 
2. If you were Adrian, it is likely for you to report the fraud to ABC Company's anonymous whistleblowing hotline.

\begin{tabular}{ccccccc}
1 & 2 & 3 & 4 & 5 & 6 & 7 \\
Strongly & Moderately & Slightly & Neither & Slightly & Moderately & Strongly \\
Disagree & Disagree & Disagree & $\begin{array}{c}\text { Disagree nor } \\
\text { Agree }\end{array}$ & Agree & Agree & Agree \\
& & \multicolumn{3}{c}{ Agras } & &
\end{tabular}

3. It is likely for Adrian to report the fraud to ABC Company's anonymous whistleblowing hotline.

$\begin{array}{ccccccc}1 & 2 & 3 & 4 & 5 & 6 & 7 \\ \text { Strongly } & \text { Moderately } & \text { Slightly } & \text { Neither } & \text { Slightly } & \text { Moderately } & \text { Strongly } \\ \text { Disagree } & \text { Disagree } & \text { Disagree } & \begin{array}{c}\text { Disagree nor } \\ \text { Agree }\end{array} & \text { Agree } & \text { Agree } & \text { Agree }\end{array}$

4. If you were Adrian, you would perceive the working relationship with Bailey as effective.
1
2
3
4
5
6
7
Strongly Moderately
Slightly Neither
Slightly Moderately Strongly
Disagree Disagree
Disagree Disagree nor
Agree
Agree Agree

5. If you were Adrian, you would believe that Bailey could understand your job problems and needs.
$\begin{array}{lllllll}1 & 2 & 3 & 4 & 5 & 6 & 7\end{array}$
Strongly Moderately Slightly Neither Slightly Moderately Strongly
Disagree Disagree Disagree Disagree nor Agree Agree Agree Agree

6. If you were Adrian, you would believe that Bailey could recognize your potential.

$\begin{array}{clccccc}1 & 2 & 3 & 4 & 5 & 6 & 7 \\ \text { Strongly } & \text { Moderately } & \text { Slightly } & \text { Neither } & \text { Slightly } & \text { Moderately } & \text { Strongly } \\ \text { Disagree } & \text { Disagree } & \text { Disagree } & \begin{array}{c}\text { Disagree nor } \\ \text { Agree }\end{array} & \text { Agree } & \text { Agree } & \text { Agree } \\ & & & & & \end{array}$

7. If you were Adrian, you would believe that regardless of how much formal authority Bailey has built into the position, it is possible that Bailey would use power to help you solve problems in your work.

$\begin{array}{cllcccc}1 & 2 & 3 & 4 & 5 & 6 & 7 \\ \text { Strongly } & \text { Moderately } & \text { Slightly } & \text { Neither } & \text { Slightly } & \text { Moderately } & \text { Strongly } \\ \text { Disagree } & \text { Disagree } & \text { Disagree } & \begin{array}{c}\text { Disagree nor } \\ \text { Agree }\end{array} & \text { Agree } & \text { Agree } & \text { Agree } \\ & & & & & \end{array}$


8. If you were Adrian, you would believe that regardless of the amount of formal authority Bailey has, it is possible that Bailey would "bail you out" at Bailey's expense.

$\begin{array}{cllcccc}1 & 2 & 3 & 4 & 5 & 6 & 7 \\ \text { Strongly } & \text { Moderately } & \text { Slightly } & \text { Neither } & \text { Slightly } & \text { Moderately } & \text { Strongly } \\ \text { Disagree } & \text { Disagree } & \text { Disagree } & \begin{array}{c}\text { Disagree nor } \\ \text { Disaree }\end{array} & \begin{array}{c}\text { Agree } \\ \text { Agree }\end{array} & \text { Agree } & \text { Agree }\end{array}$

9. If you were Adrian, you would have enough confidence in Bailey that you would defend and justify Bailey's decision if Bailey were not present to do so.

$\begin{array}{cllcccc}1 & 2 & 3 & 4 & 5 & 6 & 7 \\ \text { Strongly } & \text { Moderately } & \text { Slightly } & \text { Neither } & \text { Slightly } & \text { Moderately } & \text { Strongly } \\ \text { Disagree } & \text { Disagree } & \text { Disagree } & \begin{array}{c}\text { Disagree nor } \\ \text { Disaree }\end{array} & \begin{array}{c}\text { Agree } \\ \text { Agree }\end{array} & \text { Agree } \\ & & & & & \text { Agree }\end{array}$

10. If you were Adrian, you can trust Bailey to do what is good for you.

$\begin{array}{ccccccc}1 & 2 & 3 & 4 & 5 & 6 & 7 \\ \text { Strongly } & \text { Moderately } & \text { Slightly } & \text { Neither } & \text { Slightly } & \text { Moderately } & \text { Strongly } \\ \text { Disagree } & \text { Disagree } & \text { Disagree } & \begin{array}{c}\text { Disagree nor } \\ \text { Agree }\end{array} & \text { Agree } & \text { Agree } & \text { Agree }\end{array}$

11. If you were Adrian, you can trust Bailey to treat you fairly.

$\begin{array}{ccccccc}1 & 2 & 3 & 4 & 5 & 6 & 7 \\ \text { Strongly } & \text { Moderately } & \text { Slightly } & \text { Neither } & \text { Slightly } & \text { Moderately } & \text { Strongly } \\ \text { Disagree } & \text { Disagree } & \text { Disagree } & \begin{array}{c}\text { Disagree nor } \\ \text { Agree }\end{array} & \begin{array}{c}\text { Agree } \\ \text { Agree }\end{array} & \text { Agree } & \text { Agree } \\ & & & \text { Agree } & & \end{array}$

12. If you were Adrian, Bailey can be trusted to make decisions that are good for you.

$\begin{array}{ccccccc}1 & 2 & 3 & 4 & 5 & 6 & 7 \\ \text { Strongly } & \text { Moderately } & \text { Slightly } & \text { Neither } & \text { Slightly } & \text { Moderately } & \text { Strongly } \\ \text { Disagree } & \text { Disagree } & \text { Disagree } & \begin{array}{c}\text { Disagree nor } \\ \text { Agree }\end{array} & \text { Agree } & \text { Agree } & \text { Agree }\end{array}$

13. If you were Adrian, you are satisfied with your current job in the accounting department of ABC Company?

\begin{tabular}{ccccccc}
1 & 2 & 3 & 4 & 5 & 6 & 7 \\
Strongly & Moderately & Slightly & Neither & Slightly & Moderately & Strongly \\
Disagree & Disagree & Disagree & $\begin{array}{c}\text { Disagree nor } \\
\text { Agree }\end{array}$ & Agree & Agree & Agree \\
& & \multicolumn{3}{c}{ Agrase } & &
\end{tabular}


14. This fraudulent act is morally wrong.

\begin{tabular}{|c|c|c|c|c|c|c|c|c|}
\hline 1 & 2 & 3 & 4 & 5 & 6 & 7 & 8 & 9 \\
\hline Strongly & Mostly & Somewhat & Slightly & Neither & Slightly & Somewhat & Mostly & Strongly \\
\hline Disagree & Disagree & Disagree & Disagree & $\begin{array}{l}\text { Disagree nor } \\
\text { Agree }\end{array}$ & Agree & Agree & Agree & Agree \\
\hline
\end{tabular}

15. The seriousness of this fraudulent act is

$\begin{array}{llccccccc}1 & 2 & 3 & 4 & 5 & 6 & 7 & 8 & 9 \\ \text { Extremely } & \text { Mostly } & \text { Very } & \text { Low } & \text { About as } & \text { High } & \text { Very } & \text { Mostly } & \text { Extremely } \\ \text { Low } & \text { Low } & \text { Low } & & \text { High } & & \text { High } & \text { High } & \text { High }\end{array}$

16. This fraudulent act is unethical (general consensus).

\begin{tabular}{|c|c|c|c|c|c|c|c|c|}
\hline 1 & 2 & 3 & 4 & 5 & 6 & 7 & 8 & 9 \\
\hline Strongly & Mostly & Somewhat & Slightly & Neither & Slightly & Somewhat & Mostly & Strongly \\
\hline Disagree & Disagree & Disagree & Disagree & $\begin{array}{l}\text { Disagree nor } \\
\text { Agree }\end{array}$ & Agree & Agree & Agree & Agree \\
\hline
\end{tabular}

17. The fairness of this fraudulent act is

$\begin{array}{llllccccc}1 & 2 & 3 & 4 & 5 & 6 & 7 & 8 & 9 \\ \text { Extremely } & \text { Mostly } & \text { Very } & \text { Unfair } & \text { About as } & \text { Fair } & \text { Very } & \text { Mostly } & \text { Extremely } \\ \text { Unfair } & \text { Unfair } & \text { Unfair } & & \begin{array}{c}\text { Fair } \\ \text { as Not }\end{array} & & \text { Fair } & \text { Fair } & \text { Fair }\end{array}$

18. The personal cost of reporting this fraudulent act by Adrian is

$\begin{array}{llllccccc}1 & 2 & 3 & 4 & 5 & 6 & 7 & 8 & 9 \\ \text { Extremely } & \text { Mostly } & \text { Very } & \text { Low } & \text { About as } & \text { High } & \text { Very } & \text { Mostly } & \text { Extremely } \\ \text { Low } & \text { Low } & \text { Low } & & \text { High } & & \text { High } & \text { High } & \text { High } \\ & & & \text { as Not } & & & & \end{array}$

19. The responsibility to inform proper parties about the fraudulent act is

$\begin{array}{llccccccc}1 & 2 & 3 & 4 & 5 & 6 & 7 & 8 & 9 \\ \text { Extremely } & \text { Mostly } & \text { Very } & \text { Low } & \text { About as } & \text { High } & \text { Very } & \text { Mostly } & \text { Extremely } \\ \text { Low } & \text { Low } & \text { Low } & & \text { High } & & \text { High } & \text { High } & \text { High } \\ & & & & \text { as Not } & & & & \end{array}$

20. ABC Company will discover this fraudulent act by itself.

$\begin{array}{lcccccccc}1 & 2 & 3 & 4 & 5 & 6 & 7 & 8 & 9 \\ \text { Extremely } & \text { Mostly } & \text { Very } & \text { Unlikely } & \text { About as } & \text { Likely } & \text { Very } & \text { Mostly } & \text { Extremely } \\ \text { Unlikely } & \text { Unlikely } & \text { Unlikely } & & \text { Likely } & & \text { Likely } & \text { Likely } & \text { Likely } \\ & & & & & & \end{array}$


21. Adrian's anonymity will be protected if the fraud is reported.

$\begin{array}{lcccccccc}1 & 2 & 3 & 4 & 5 & 6 & 7 & 8 & 9 \\ \text { Extremely } & \text { Mostly } & \text { Very } & \text { Unlikely } & \text { About as } & \text { Likely } & \text { Very } & \text { Mostly } & \text { Extremely } \\ \text { Unlikely } & \text { Unlikely } & \text { Unlikely } & & \text { Likely } & & \text { Likely } & \text { Likely } & \text { Likely } \\ & & & & & & \end{array}$

22. This fraudulent act will be thoroughly investigated.

$\begin{array}{lccclcccc}1 & 2 & 3 & 4 & 5 & 6 & 7 & 8 & 9 \\ \text { Extremely } & \text { Mostly } & \text { Very } & \text { Unlikely } & \text { About as } & \text { Likely } & \text { Very } & \text { Mostly } & \text { Extremely } \\ \text { Unlikely } & \text { Unlikely } & \text { Unlikely } & & \text { Likely } & & \text { Likely } & \text { Likely } & \text { Likely } \\ & & & & & & \end{array}$

23. Corrective actions will be taken for this fraudulent act.

$\begin{array}{lccclcccc}1 & 2 & 3 & 4 & 5 & 6 & 7 & 8 & 9 \\ \text { Extremely } & \text { Mostly } & \text { Very } & \text { Unlikely } & \text { About as } & \text { Likely } & \text { Very } & \text { Mostly } & \text { Extremely } \\ \text { Unlikely } & \text { Unlikely } & \text { Unlikely } & & \text { Likely } & & \text { Likely } & \text { Likely } & \text { Likely } \\ & & & & & & & \end{array}$

24. This fraud should be attributed to the personal factors of Bailey.

\begin{tabular}{|c|c|c|c|c|c|c|c|c|}
\hline 1 & 2 & $\begin{array}{c}3 \\
\text { Somot }\end{array}$ & $\begin{array}{c}4 \\
\text { Slightly }\end{array}$ & $\begin{array}{c}5 \\
\text { Neither }\end{array}$ & $\begin{array}{c}6 \\
\text { Sliobtly }\end{array}$ & $\begin{array}{c}7 \\
\text { Sompurt }\end{array}$ & $\begin{array}{c}8 \\
\text { Mostly }\end{array}$ & $\begin{array}{c}9 \\
\text { Strongly }\end{array}$ \\
\hline $\begin{array}{l}\text { Strongiy } \\
\text { Disagree }\end{array}$ & $\begin{array}{l}\text { Mosiny } \\
\text { Disagree }\end{array}$ & $\begin{array}{l}\text { Domewhat } \\
\text { Disagree }\end{array}$ & $\begin{array}{l}\text { Dingnuy } \\
\text { Disagree }\end{array}$ & $\begin{array}{l}\text { Disagree nor } \\
\text { Agree }\end{array}$ & Agree & $\begin{array}{l}\text { Agree } \\
\text { Anewnat }\end{array}$ & $\begin{array}{l}\text { Mostry } \\
\text { Agree }\end{array}$ & $\begin{array}{l}\text { Strongiy } \\
\text { Agree }\end{array}$ \\
\hline
\end{tabular}

25. This fraud should be attributed to external factors.

\begin{tabular}{|c|c|c|c|c|c|c|c|c|}
\hline 1 & 2 & 3 & 4 & 5 & 6 & 7 & 8 & 9 \\
\hline Strongly & Mostly & Somewhat & Slightly & Neither & Slightly & Somewhat & Mostly & Strongly \\
\hline Disagree & Disagree & Disagree & Disagree & $\begin{array}{l}\text { Disagree nor } \\
\text { Agree }\end{array}$ & Agree & Agree & Agree & Agree \\
\hline
\end{tabular}

\section{Low leader emotional intelligence and firm consequence frame}

Please read the following background information about ABC Company, Adrian, and Bailey, and then answer the questions that follow. The questions should take you approximately 20 - 30 minutes.

ABC Company is a manufacturing company of consumer goods. It had produced steady operating results but recently performed at slightly below the industry average. Adrian is an accountant in the production division of ABC Company and directly reports to Bailey, who is the department head of the production division and is Adrian's direct supervisor. Adrian has been working in $\mathrm{ABC}$ Company's production division under Bailey's direct supervision for two years.

Bailey is unable to perceive the emotions of others, including Adrian's. It is hard for Bailey to understand the non-verbal messages of Adrian and other people, and Bailey is always 
unaware of the non-verbal messages sent to others including Adrian and unaware of the emotions experienced by himself. Bailey is also unable to access and generate emotions to make effective decisions. Bailey cannot arrange activities that make him, Adrian, and others happy, and even when in positive emotion, Bailey cannot quickly solve problems and come up with new ideas. Moreover, Bailey is unable to understand the emotions of Adrian, others, and himself. Bailey cannot figure out why his emotions and emotions of people around change, and when another person, such as Adrian, tells Bailey about an important event in their life, Bailey cannot feel the experience at all. Finally, Bailey is unable to manage the emotions of Adrian, others, and himself. Work pressure can easily throw Bailey into a negative mood. Bailey also cannot help others, including Adrian, feel better when they are down.

1. In a few sentences, please briefly describe what kind of a person Bailey is.

Please read the following case that happen in ABC Company, and answer the questions or give opinions on statements that follow. Please remember that all previous background information about ABC Company, Adrian, and Bailey applies to the following cases.

Adrian is working on a review of the general journal entries that are needed to prepare the production division's financial statements, and Adrian finds that the assets in the division are improperly valued. $\$ 800,000$ of expenses has been capitalized (recorded as assets instead of expense) by Bailey. After talking with some friends in the division, Adrian is almost certain that this is a fraud that has been committed, and it is extremely probable that Bailey is intentionally involved. The mis-recording increases the production division's earnings per share by $\$ 0.02$, which exactly meets financial analysts' expectations. ABC Company has an anonymous whistleblowing hotline, which can strictly protect the whistleblower's identity. If Adrian reports this fraud through the hotline, $\mathrm{ABC}$ Company could get to know this incident in a timely manner and thus avoid reputation impairment, future profit loss, and potential charge from government agency. Future potential fraud could also be deterred.

1. Based on the case above, please describe the consequence if Adrian reports this fraud through the hotline.

2. If you were Adrian, it is likely that you will report the fraud to the anonymous whistleblowing hotline.

\begin{tabular}{ccccccc}
1 & 2 & 3 & 4 & 5 & 6 & 7 \\
Strongly & Moderately & Slightly & Neither & Slightly & Moderately & Strongly \\
Disagree & Disagree & Disagree & $\begin{array}{c}\text { Disagree nor } \\
\text { Agree }\end{array}$ & Agree & Agree & Agree \\
& & \multicolumn{3}{c}{ Agree } & &
\end{tabular}


3. It is likely that Adrian will report the fraud to the anonymous whistleblowing hotline.

\begin{tabular}{ccccccc}
1 & 2 & 3 & 4 & 5 & 6 & 7 \\
Strongly & Moderately & Slightly & Neither & Slightly & Moderately & Strongly \\
Disagree & Disagree & Disagree & $\begin{array}{c}\text { Disagree nor } \\
\text { Agree }\end{array}$ & Agree & Agree & Agree \\
& & \multicolumn{3}{c}{ Agras } & &
\end{tabular}

4. If you were Adrian, you would perceive the working relationship with Bailey as effective.

$$
\begin{array}{llllllll}
1 & 2 & 3 & 4 & 5 & 6 & 7
\end{array}
$$

Strongly Moderately Slightly Neither Slightly Moderately Strongly

Disagree Disagree Disagree Disagree nor Agree Agree Agree Agree

5. If you were Adrian, you would believe that Bailey could understand your job problems and needs.

$\begin{array}{clccccl}1 & 2 & 3 & 4 & 5 & 6 & 7 \\ \text { Strongly } & \text { Moderately } & \text { Slightly } & \text { Neither } & \text { Slightly } & \text { Moderately } & \text { Strongly } \\ \text { Disagree } & \text { Disagree } & \text { Disagree } & \begin{array}{c}\text { Disagree nor } \\ \text { Agree }\end{array} & \text { Agree } & \text { Agree } & \text { Agree }\end{array}$

6. If you were Adrian, you would believe that Bailey could recognize your potential.

\begin{tabular}{|c|c|c|c|c|c|c|}
\hline 1 & 2 & 3 & 4 & 5 & 6 & 7 \\
\hline Stro & Moderately & Slightly & Neither & Slightly & Moderately & Strongly \\
\hline isa & Disagree & Disagree & $\begin{array}{l}\text { Disagree nor } \\
\text { Agree }\end{array}$ & Agree & Agree & Agree \\
\hline
\end{tabular}

7. If you were Adrian, you would believe that regardless of how much formal authority Bailey has built into the position, it is possible that Bailey would use power to help you solve problems in your work.

\begin{tabular}{cllcccc}
1 & 2 & 3 & 4 & 5 & 6 & 7 \\
Strongly & Moderately & Slightly & Neither & Slightly & Moderately & Strongly \\
Disagree & Disagree & Disagree & $\begin{array}{c}\text { Disagree nor } \\
\text { Agree }\end{array}$ & Agree & Agree & Agree \\
& & \multicolumn{3}{c}{ Aggen } & &
\end{tabular}

8. If you were Adrian, you would believe that regardless of the amount of formal authority Bailey has, it is possible that Bailey would "bail you out" at Bailey's expense.

$\begin{array}{cllcccc}1 & 2 & 3 & 4 & 5 & 6 & 7 \\ \text { Strongly } & \text { Moderately } & \text { Slightly } & \text { Neither } & \text { Slightly } & \text { Moderately } & \text { Strongly } \\ \text { Disagree } & \text { Disagree } & \text { Disagree } & \begin{array}{c}\text { Disagree nor } \\ \text { Agree }\end{array} & \text { Agree } & \text { Agree } & \text { Agree }\end{array}$


9. If you were Adrian, you would have enough confidence in Bailey that you would defend and justify Bailey's decision if Bailey were not present to do so.

\begin{tabular}{|c|c|c|c|c|c|c|}
\hline 1 & 2 & 3 & 4 & 5 & 6 & 7 \\
\hline Strongly & Moderately & Slightly & Neither & Slightly & Moderately & Strongly \\
\hline Disagree & Disagree & Disagree & $\begin{array}{l}\text { Disagree nor } \\
\text { Agree }\end{array}$ & Agree & Agree & Agree \\
\hline
\end{tabular}

10. If you were Adrian, you can trust Bailey to do what is good for you.

$$
\begin{array}{lllllll}
1 & 2 & 3 & 4 & 5 & 6 & 7
\end{array}
$$

Strongly Moderately Slightly Neither Slightly Moderately Strongly

Disagree Disagree Disagree Disagree nor Agree Agree Agree Agree

11. If you were Adrian, you can trust Bailey to treat you fairly.

\begin{tabular}{ccccccc}
1 & 2 & 3 & 4 & 5 & 6 & 7 \\
Strongly & Moderately & Slightly & Neither & Slightly & Moderately & Strongly \\
Disagree & Disagree & Disagree & $\begin{array}{c}\text { Disagree nor } \\
\text { Agree }\end{array}$ & Agree & Agree & Agree \\
& & \multicolumn{3}{c}{ Agree } & &
\end{tabular}

12. If you were Adrian, Bailey can be trusted to make decisions that are good for you.

$$
\begin{array}{llllllll}
1 & 2 & 3 & 4 & 5 & 6 & 7
\end{array}
$$

Strongly Moderately Slightly Neither Slightly Moderately Strongly

Disagree Disagree Disagree Disagree nor Agree Agree Agree Agree

13. If you were Adrian, you are satisfied with your current job in the accounting department

\begin{tabular}{|c|c|c|c|c|c|c|}
\hline 1 & 2 & 3 & 4 & 5 & 6 & 7 \\
\hline Strongly & Moderately & Slightly & Neither & Slightly & Moderately & Strongly \\
\hline Disagree & Disagree & Disagree & $\begin{array}{l}\text { Disagree nor } \\
\text { Agree }\end{array}$ & Agree & Agree & Agree \\
\hline
\end{tabular}
of ABC Company?

14. This fraudulent act is morally wrong.

$\begin{array}{ccccccccc}1 & 2 & 3 & 4 & 5 & 6 & 7 & 8 & 9 \\ \text { Strongly } & \text { Mostly } & \text { Somewhat } & \text { Slightly } & \text { Neither } & \text { Slightly } & \text { Somewhat } & \text { Mostly } & \text { Strongly } \\ \text { Disagree } & \text { Disagree } & \text { Disagree } & \text { Disagree } & \begin{array}{c}\text { Disagree nor } \\ \text { Agree }\end{array} & \text { Agree } & \text { Agree } & \text { Agree } & \text { Agree }\end{array}$


15. The seriousness of this fraudulent act is

$\begin{array}{llllccccc}1 & 2 & 3 & 4 & 5 & 6 & 7 & 8 & 9 \\ \text { Extremely } & \text { Mostly } & \text { Very } & \text { Low } & \text { About as } & \text { High } & \text { Very } & \text { Mostly } & \text { Extremely } \\ \text { Low } & \text { Low } & \text { Low } & & \text { High } & & \text { High } & \text { High } & \text { High } \\ & & & & \text { as Not } & & & & \end{array}$

16. This fraudulent act is unethical (general consensus).

\begin{tabular}{|c|c|c|c|c|c|c|c|c|}
\hline 1 & 2 & $\begin{array}{c}3 \\
\text { come }\end{array}$ & $\begin{array}{c}4 \\
\text { c1. }\end{array}$ & $\begin{array}{c}5 \\
\end{array}$ & $\begin{array}{c}6 \\
\text { slichtly }\end{array}$ & $\begin{array}{c}7 \\
\end{array}$ & 8 & $\begin{array}{c}9 \\
\text { Strongly }\end{array}$ \\
\hline $\begin{array}{l}\text { Strongly } \\
\text { Disagree }\end{array}$ & $\begin{array}{c}\text { Mostly } \\
\text { Disagree }\end{array}$ & $\begin{array}{l}\text { Somewhat } \\
\text { Disagree }\end{array}$ & $\begin{array}{r}\text { Slightly } \\
\text { Disagree }\end{array}$ & $\begin{array}{l}\text { Neither } \\
\text { Disagree nor } \\
\text { Agree }\end{array}$ & $\begin{array}{c}\text { Slightly } \\
\text { Agree }\end{array}$ & $\begin{array}{c}\text { Somewhat } \\
\text { Agree }\end{array}$ & $\begin{array}{l}\text { Mostly } \\
\text { Agree }\end{array}$ & $\begin{array}{c}\text { Strongly } \\
\text { Agree }\end{array}$ \\
\hline
\end{tabular}

17. The fairness of this fraudulent act is

\begin{tabular}{llllccccc}
\multicolumn{1}{c}{1} & 2 & 3 & 4 & 5 & 6 & 7 & 8 & 9 \\
Extremely & Mostly & Very & Unfair & About as & Fair & Very & Mostly & Extremely \\
Unfair & Unfair & Unfair & & $\begin{array}{l}\text { Fair } \\
\text { as Not }\end{array}$ & & Fair & Fair & Fair
\end{tabular}

18. The personal cost of reporting this fraudulent act by Adrian is

$\begin{array}{llllccccl}1 & 2 & 3 & 4 & 5 & 6 & 7 & 8 & 9 \\ \text { Extremely } & \text { Mostly } & \text { Very } & \text { Low } & \text { About as } & \text { High } & \text { Very } & \text { Mostly } & \text { Extremely } \\ \text { Low } & \text { Low } & \text { Low } & & \text { High } & & \text { High } & \text { High } & \text { High } \\ & & & & \text { as Not } & & & & \end{array}$

19. The responsibility to inform proper parties about the fraudulent act is

$\begin{array}{llllccccl}1 & 2 & 3 & 4 & 5 & 6 & 7 & 8 & 9 \\ \text { Extremely } & \text { Mostly } & \text { Very } & \text { Low } & \text { About as } & \text { High } & \text { Very } & \text { Mostly } & \text { Extremely } \\ \text { Low } & \text { Low } & \text { Low } & & \text { High } & & \text { High } & \text { High } & \text { High } \\ & & & & \text { as Not } & & & & \end{array}$

20. ABC Company will discover this fraudulent act by itself.

$\begin{array}{lcccccccc}1 & 2 & 3 & 4 & 5 & 6 & 7 & 8 & 9 \\ \text { Extremely } & \text { Mostly } & \text { Very } & \text { Unlikely } & \text { About as } & \text { Likely } & \text { Very } & \text { Mostly } & \text { Extremely } \\ \text { Unlikely } & \text { Unlikely } & \text { Unlikely } & & \text { Likely } & & \text { Likely } & \text { Likely } & \text { Likely } \\ & & & & & & & \end{array}$

21. Adrian's anonymity will be protected if the fraud is reported.

$\begin{array}{lcccccccc}1 & 2 & 3 & 4 & 5 & 6 & 7 & 8 & 9 \\ \text { Extremely } & \text { Mostly } & \text { Very } & \text { Unlikely } & \text { About as } & \text { Likely } & \text { Very } & \text { Mostly } & \text { Extremely } \\ \text { Unlikely } & \text { Unlikely } & \text { Unlikely } & & \text { Likely } & & \text { Likely } & \text { Likely } & \text { Likely } \\ & & & & \text { as Not } & & & & \end{array}$


22. This fraudulent act will be thoroughly investigated.

$\begin{array}{lcccccccc}1 & 2 & 3 & 4 & 5 & 6 & 7 & 8 & 9 \\ \text { Extremely } & \text { Mostly } & \text { Very } & \text { Unlikely } & \text { About as } & \text { Likely } & \text { Very } & \text { Mostly } & \text { Extremely } \\ \text { Unlikely } & \text { Unlikely } & \text { Unlikely } & & \text { Likely } & & \text { Likely } & \text { Likely } & \text { Likely } \\ & & & & \text { As Not } & & & & \end{array}$

23. Corrective actions will be taken for this fraudulent act.

$\begin{array}{lcccccccc}1 & 2 & 3 & 4 & 5 & 6 & 7 & 8 & 9 \\ \text { Extremely } & \text { Mostly } & \text { Very } & \text { Unlikely } & \text { About as } & \text { Likely } & \text { Very } & \text { Mostly } & \text { Extremely } \\ \text { Unlikely } & \text { Unlikely } & \text { Unlikely } & & \text { Likely } & & \text { Likely } & \text { Likely } & \text { Likely } \\ & & & & & & \end{array}$

24. This fraud should be attributed to the personal factors of Bailey.

\begin{tabular}{|c|c|c|c|c|c|c|c|c|}
\hline 1 & 2 & 3 & 4 & 5 & 6 & 7 & 8 & 9 \\
\hline Strongly & Mostly & Somewhat & Slightly & Neither & Slightly & Somewhat & Mostly & Strongly \\
\hline Disagree & Disagree & Disagree & Disagree & $\begin{array}{l}\text { Disagree nor } \\
\text { Agree }\end{array}$ & Agree & Agree & Agree & Agree \\
\hline
\end{tabular}

25. This fraud should be attributed to external factors.

\begin{tabular}{|c|c|c|c|c|c|c|c|c|}
\hline 1 & 2 & 3 & 4 & 5 & 6 & 7 & 8 & $\begin{array}{c}9 \\
\text { Strongly }\end{array}$ \\
\hline $\begin{array}{l}\text { Strongly } \\
\text { Disagree }\end{array}$ & $\begin{array}{c}\text { Mostly } \\
\text { Disagree }\end{array}$ & $\begin{array}{c}\text { Somewhat } \\
\text { Disagree }\end{array}$ & $\begin{array}{c}\text { Slightly } \\
\text { Disagree }\end{array}$ & $\begin{array}{l}\text { Neither } \\
\text { Disagree nor } \\
\text { Agree }\end{array}$ & $\begin{array}{c}\text { Slightly } \\
\text { Agree }\end{array}$ & $\begin{array}{c}\text { Somewhat } \\
\text { Agree }\end{array}$ & $\begin{array}{l}\text { Mostly } \\
\text { Agree }\end{array}$ & $\begin{array}{c}\text { Strongly } \\
\text { Agree }\end{array}$ \\
\hline
\end{tabular}

\section{Low leader emotional intelligence and leader consequence frame}

Please read the following background information about ABC Company, Adrian, and Bailey, and then answer the questions that follow. The questions should take you approximately 20 - 30 minutes.

ABC Company is a manufacturing company of consumer goods. It had produced steady operating results but recently performed at slightly below the industry average. Adrian is an accountant in the production division of ABC Company and directly reports to Bailey, who is the department head of the production division and is Adrian's direct supervisor. Adrian has been working in $\mathrm{ABC}$ Company's production division under Bailey's direct supervision for two years.

Bailey is unable to perceive the emotions of others, including Adrian's. It is hard for Bailey to understand the non-verbal messages of Adrian and other people, and Bailey is always unaware of the non-verbal messages sent to others including Adrian and unaware of the emotions experienced by himself. Bailey is also unable to access and generate emotions to make effective decisions. Bailey cannot arrange activities that make him, Adrian, and others happy, and even when in positive emotion, Bailey cannot quickly solve problems and come up with new ideas. Moreover, Bailey is unable to understand the emotions of Adrian, others, and himself. Bailey cannot figure out why his emotions and emotions of people around change, and when another 
person, such as Adrian, tells Bailey about an important event in their life, Bailey cannot feel the experience at all. Finally, Bailey is unable to manage the emotions of Adrian, others, and himself. Work pressure can easily throw Bailey into a negative mood. Bailey also cannot help others, including Adrian, feel better when they are down.

1. In a few sentences, please briefly describe what kind of a person Bailey is.

Please read the following case that happen in ABC Company, and answer the questions or give opinions on statements that follow. Please remember that all previous background information about ABC Company, Adrian, and Bailey applies to the following cases.

Adrian is working on a review of the general journal entries that are needed to prepare the production division's financial statements, and Adrian finds that the assets in the division are improperly valued. $\$ 800,000$ of expenses has been capitalized (recorded as assets instead of expense) by Bailey. After talking with some friends in the division, Adrian is almost certain that this is a fraud that has been committed, and it is extremely probable that Bailey is intentionally involved. The mis-recording increases the production division's earnings per share by $\$ 0.02$, which exactly meets financial analysts' expectations. ABC Company has an anonymous whistleblowing hotline, which can strictly protect the whistleblower's identity. If Adrian reports this fraud through the hotline, Bailey could probably be fired, economically and judicially punished, and never get hired by another company.

1. Based on the case above, please describe the consequence if Adrian reports this fraud through the hotline.

2. If you were Adrian, it is likely that you will report the fraud to the anonymous whistleblowing hotline.

$\begin{array}{ccccccc}1 & 2 & 3 & 4 & 5 & 6 & 7 \\ \text { Strongly } & \text { Moderately } & \text { Slightly } & \text { Neither } & \text { Slightly } & \text { Moderately } & \text { Strongly } \\ \text { Disagree } & \text { Disagree } & \text { Disagree } & \begin{array}{c}\text { Disagree nor } \\ \text { Agree }\end{array} & \text { Agree } & \text { Agree } & \text { Agree } \\ & & & & & \end{array}$

3. It is likely that Adrian will report the fraud to the anonymous whistleblowing hotline.

$\begin{array}{ccccccc}1 & 2 & 3 & 4 & 5 & 6 & 7 \\ \text { Strongly } & \text { Moderately } & \text { Slightly } & \text { Neither } & \text { Slightly } & \text { Moderately } & \text { Strongly } \\ \text { Disagree } & \text { Disagree } & \text { Disagree } & \begin{array}{c}\text { Disagree nor } \\ \text { Agree }\end{array} & \begin{array}{c}\text { Agree } \\ \text { Agree }\end{array} & \text { Agree } & \text { Agree } \\ & & & \text { Agred } & & \end{array}$


4. If you were Adrian, you would perceive the working relationship with Bailey as effective.

$\begin{array}{ccccccc}1 & 2 & 3 & 4 & 5 & 6 & 7 \\ \text { Strongly } & \text { Moderately } & \text { Slightly } & \text { Neither } & \text { Slightly } & \text { Moderately } & \text { Strongly } \\ \text { Disagree } & \text { Disagree } & \text { Disagree } & \begin{array}{c}\text { Disagree nor } \\ \text { Agree }\end{array} & \text { Agree } & \text { Agree } & \text { Agree } \\ & & & & & \end{array}$

5. If you were Adrian, you would believe that Bailey could understand your job problems and needs.

\begin{tabular}{|c|c|c|c|c|c|c|}
\hline 1 & 2 & 3 & 4 & 5 & 6 & 7 \\
\hline Strongly & Moderately & Slightly & Neither & Slightly & Moderately & Strongly \\
\hline Disagree & Disagree & Disagree & $\begin{array}{c}\text { Disagree nor } \\
\text { Agree }\end{array}$ & Agree & Agree & Agree \\
\hline
\end{tabular}

6. If you were Adrian, you would believe that Bailey could recognize your potential.

$\begin{array}{cllcccc}1 & 2 & 3 & 4 & 5 & 6 & 7 \\ \text { Strongly } & \text { Moderately } & \text { Slightly } & \text { Neither } & \text { Slightly } & \text { Moderately } & \text { Strongly } \\ \text { Disagree } & \text { Disagree } & \text { Disagree } & \begin{array}{c}\text { Disagree nor } \\ \text { Disaree }\end{array} & \text { Agree } & \text { Agree } & \text { Agree }\end{array}$

7. If you were Adrian, you would believe that regardless of how much formal authority Bailey has built into the position, it is possible that Bailey would use power to help you solve problems in your work.

\begin{tabular}{|c|c|c|c|c|c|c|}
\hline 1 & 2 & 3 & 4 & 5 & 6 & 7 \\
\hline Strongly & Moderately & Slightly & Neither & Slightly & Moderately & Strongly \\
\hline Disagree & Disagree & Disagree & $\begin{array}{l}\text { Disagree nor } \\
\text { Agree }\end{array}$ & Agree & Agree & Agree \\
\hline
\end{tabular}

8. If you were Adrian, you would believe that regardless of the amount of formal authority Bailey has, it is possible that Bailey would "bail you out" at Bailey's expense.

\begin{tabular}{|c|c|c|c|c|c|c|}
\hline 1 & 2 & 3 & 4 & 5 & 6 & 7 \\
\hline Strongly & Moderately & Slightly & Neither & Slightly & Moderately & Strongly \\
\hline Disagree & Disagree & Disagree & $\begin{array}{l}\text { Disagree nor } \\
\text { Agree }\end{array}$ & Agree & Agree & Agree \\
\hline
\end{tabular}


9. If you were Adrian, you would have enough confidence in Bailey that you would defend and justify Bailey's decision if Bailey were not present to do so.

\begin{tabular}{|c|c|c|c|c|c|c|}
\hline 1 & 2 & 3 & 4 & 5 & 6 & 7 \\
\hline Strongly & Moderately & Slightly & Neither & Slightly & Moderately & Strongly \\
\hline Disagree & Disagree & Disagree & $\begin{array}{c}\text { Disagree nor } \\
\text { Agree }\end{array}$ & Agree & Agree & Agree \\
\hline
\end{tabular}

10. If you were Adrian, you can trust Bailey to do what is good for you.

$$
\begin{array}{lllllll}
1 & 2 & 3 & 4 & 5 & 6 & 7
\end{array}
$$

Strongly Moderately Slightly Neither Slightly Moderately Strongly

Disagree Disagree Disagree Disagree nor Agree Agree Agree Agree

11. If you were Adrian, you can trust Bailey to treat you fairly.

$\begin{array}{ccccccc}1 & 2 & 3 & 4 & 5 & 6 & 7 \\ \text { Strongly } & \text { Moderately } & \text { Slightly } & \text { Neither } & \text { Slightly } & \text { Moderately } & \text { Strongly } \\ \text { Disagree } & \text { Disagree } & \text { Disagree } & \begin{array}{c}\text { Disagree nor } \\ \text { Agree }\end{array} & \text { Agree } & \text { Agree } & \text { Agree } \\ & & & & & \end{array}$

12. If you were Adrian, Bailey can be trusted to make decisions that are good for you.

$$
\begin{array}{llllllll}
1 & 2 & 3 & 4 & 5 & 6 & 7
\end{array}
$$

Strongly Moderately Slightly Neither Slightly Moderately Strongly

Disagree Disagree Disagree Disagree nor Agree Agree Agree Agree

13. If you were Adrian, you are satisfied with your current job in the accounting department

\begin{tabular}{|c|c|c|c|c|c|c|}
\hline 1 & 2 & 3 & 4 & 5 & 6 & 7 \\
\hline Strongly & Moderately & Slightly & Neither & Slightly & Moderately & Strongly \\
\hline Disagree & Disagree & Disagree & $\begin{array}{l}\text { Disagree nor } \\
\text { Agree }\end{array}$ & Agree & Agree & Agree \\
\hline
\end{tabular}
of ABC Company?

14. This fraudulent act is morally wrong.

$\begin{array}{ccccccccc}1 & 2 & 3 & 4 & 5 & 6 & 7 & 8 & 9 \\ \text { Strongly } & \text { Mostly } & \text { Somewhat } & \text { Slightly } & \text { Neither } & \text { Slightly } & \text { Somewhat } & \text { Mostly } & \text { Strongly } \\ \text { Disagree } & \text { Disagree } & \text { Disagree } & \text { Disagree } & \begin{array}{c}\text { Disagree nor } \\ \text { Agree }\end{array} & \text { Agree } & \text { Agree } & \text { Agree } & \text { Agree }\end{array}$


15. The seriousness of this fraudulent act is

$\begin{array}{llllccccc}1 & 2 & 3 & 4 & 5 & 6 & 7 & 8 & 9 \\ \text { Extremely } & \text { Mostly } & \text { Very } & \text { Low } & \text { About as } & \text { High } & \text { Very } & \text { Mostly } & \text { Extremely } \\ \text { Low } & \text { Low } & \text { Low } & & \text { High } & & \text { High } & \text { High } & \text { High } \\ & & & & \text { as Not } & & & & \end{array}$

16. This fraudulent act is unethical (general consensus).

\begin{tabular}{|c|c|c|c|c|c|c|c|c|}
\hline 1 & 2 & 3 & 4 & 5 & 6 & 7 & 8 & 9 \\
\hline Strongly & Mostly & Somewhat & Slightly & Neither & Slightly & Somewhat & Mostly & Strongly \\
\hline Disagree & Disagree & Disagree & Disagree & $\begin{array}{l}\text { Disagree nor } \\
\text { Agree }\end{array}$ & Agree & Agree & Agree & Agree \\
\hline
\end{tabular}

17. The fairness of this fraudulent act is

\begin{tabular}{|c|c|c|c|c|c|c|c|c|}
\hline 1 & 2 & 3 & 4 & 5 & 6 & 7 & 8 & 9 \\
\hline Extremely & Mostly & Very & Unfair & About as & Fair & Very & Mostly & Extremely \\
\hline Unfair & Unfair & Unfair & & $\begin{array}{l}\text { Fair } \\
\text { as Not }\end{array}$ & & Fair & Fair & Fair \\
\hline
\end{tabular}

18. The personal cost of reporting this fraudulent act by Adrian is

$\begin{array}{llllccccl}1 & 2 & 3 & 4 & 5 & 6 & 7 & 8 & 9 \\ \text { Extremely } & \text { Mostly } & \text { Very } & \text { Low } & \text { About as } & \text { High } & \text { Very } & \text { Mostly } & \text { Extremely } \\ \text { Low } & \text { Low } & \text { Low } & & \text { High } & & \text { High } & \text { High } & \text { High } \\ & & & & \text { as Not } & & & & \end{array}$

19. The responsibility to inform proper parties about the fraudulent act is

$\begin{array}{llllccccl}1 & 2 & 3 & 4 & 5 & 6 & 7 & 8 & 9 \\ \text { Extremely } & \text { Mostly } & \text { Very } & \text { Low } & \text { About as } & \text { High } & \text { Very } & \text { Mostly } & \text { Extremely } \\ \text { Low } & \text { Low } & \text { Low } & & \text { High } & & \text { High } & \text { High } & \text { High } \\ & & & & \text { as Not } & & & & \end{array}$

20. ABC Company will discover this fraudulent act by itself.

$\begin{array}{lcccccccc}1 & 2 & 3 & 4 & 5 & 6 & 7 & 8 & 9 \\ \text { Extremely } & \text { Mostly } & \text { Very } & \text { Unlikely } & \text { About as } & \text { Likely } & \text { Very } & \text { Mostly } & \text { Extremely } \\ \text { Unlikely } & \text { Unlikely } & \text { Unlikely } & & \text { Likely } & & \text { Likely } & \text { Likely } & \text { Likely } \\ & & & & \text { as Not } & & & & \end{array}$

21. Adrian's anonymity will be protected if the fraud is reported.

$\begin{array}{lcccccccc}1 & 2 & 3 & 4 & 5 & 6 & 7 & 8 & 9 \\ \text { Extremely } & \text { Mostly } & \text { Very } & \text { Unlikely } & \text { About as } & \text { Likely } & \text { Very } & \text { Mostly } & \text { Extremely } \\ \text { Unlikely } & \text { Unlikely } & \text { Unlikely } & & \text { Likely } & & \text { Likely } & \text { Likely } & \text { Likely } \\ & & & & \text { as Not } & & & & \end{array}$


22. This fraudulent act will be thoroughly investigated.

$\begin{array}{lcccccccc}1 & 2 & 3 & 4 & 5 & 6 & 7 & 8 & 9 \\ \text { Extremely } & \text { Mostly } & \text { Very } & \text { Unlikely } & \text { About as } & \text { Likely } & \text { Very } & \text { Mostly } & \text { Extremely } \\ \text { Unlikely } & \text { Unlikely } & \text { Unlikely } & & \text { Likely } & & \text { Likely } & \text { Likely } & \text { Likely } \\ & & & & \text { as Not } & & & & \end{array}$

23. Corrective actions will be taken for this fraudulent act.

$\begin{array}{lccclcccc}1 & 2 & 3 & 4 & 5 & 6 & 7 & 8 & 9 \\ \text { Extremely } & \text { Mostly } & \text { Very } & \text { Unlikely } & \text { About as } & \text { Likely } & \text { Very } & \text { Mostly } & \text { Extremely } \\ \text { Unlikely } & \text { Unlikely } & \text { Unlikely } & & \text { Likely } & & \text { Likely } & \text { Likely } & \text { Likely } \\ & & & & & & \end{array}$

24. This fraud should be attributed to the personal factors of Bailey.

\begin{tabular}{|c|c|c|c|c|c|c|c|c|}
\hline 1 & 2 & 3 & 4 & 5 & 6 & 7 & 8 & 9 \\
\hline Strongly & Mostly & Somewhat & Slightly & Neither & Slightly & Somewhat & Mostly & Strongly \\
\hline Disagree & Disagree & Disagree & Disagree & $\begin{array}{l}\text { Disagree nor } \\
\text { Agree }\end{array}$ & Agree & Agree & Agree & Agree \\
\hline
\end{tabular}

25. This fraud should be attributed to external factors.

\begin{tabular}{|c|c|c|c|c|c|c|c|c|}
\hline 1 & 2 & $\begin{array}{c}3 \\
\text { Some }\end{array}$ & $\begin{array}{c}4 \\
\text { Cliphtly }\end{array}$ & $\begin{array}{c}5 \\
\text { Neither }\end{array}$ & $\begin{array}{c}6 \\
\text { Sliohtly }\end{array}$ & $\begin{array}{c}7 \\
\text { Somewhat }\end{array}$ & 8 & $\begin{array}{c}9 \\
\text { Stronoly }\end{array}$ \\
\hline $\begin{array}{l}\text { Strongly } \\
\text { Disagree }\end{array}$ & $\begin{array}{c}\text { Mostly } \\
\text { Disagree }\end{array}$ & $\begin{array}{l}\text { Somewhat } \\
\text { Disagree }\end{array}$ & $\begin{array}{l}\text { Slightly } \\
\text { Disagree }\end{array}$ & $\begin{array}{l}\text { Neither } \\
\text { Disagree nor } \\
\text { Agree }\end{array}$ & $\begin{array}{l}\text { Slightly } \\
\text { - Agree }\end{array}$ & $\begin{array}{l}\text { Somewhat } \\
\text { Agree }\end{array}$ & $\begin{array}{l}\text { Mostly } \\
\text { Agree }\end{array}$ & $\begin{array}{c}\text { Strongly } \\
\text { Agree }\end{array}$ \\
\hline
\end{tabular}

\section{Post-experiment questionnaire}

Thank you very much for your participation and cooperation, and we gratefully appreciate your time and support. There are only a few questions remaining in which we are interested in. please read and answer the following questions regarding ABC company, Adrian, and Bailey. Circle the answer that you would like to choose.

1. What is the role of Adrian in ABC Company?
A. Accountant in the production division
B. Production division head
C. Purchasing manager
D. External vendor for ABC Company

2. What is the role of Bailey in ABC Company?
A. Accountant in the production division
B. Production division head.
C. Purchasing manager
D. External vendor for ABC Company 
3. According to the descriptions in the scenario that you have read before, what is the potential consequence of Adrian reporting the fraud to the anonymous hotline?

A. ABC Company could get to know this incident in a timely manner and thus avoid reputation impairment, future profit loss, and potential charge from government agency. Future potential fraud could also be deterred.

B. Bailey could probably be fired, be economically and judicially punished, and never get hired by another company.

C. The board of directors of ABC Company could discuss this issue and then start an internal investigation on the fraud.

D. No specific consequences are described in the scenario.

4. Bailey has the ability to perceive his and other's emotion.

\begin{tabular}{|c|c|c|c|c|c|c|c|c|}
\hline 1 & 2 & 3 & 4 & 5 & 6 & 7 & 8 & 9 \\
\hline Strongly & Mostly & Somewhat & Slightly & Neither & Slightly & Somewhat & Mostly & Strongly \\
\hline Disagree & Disagree & Disagree & Disagree & $\begin{array}{c}\text { Disagree nor } \\
\text { Agree }\end{array}$ & Agree & Agree & Agree & Agree \\
\hline
\end{tabular}

5. Bailey has ability to access and generate emotions to make effective decisions.

\begin{tabular}{|c|c|c|c|c|c|c|c|c|}
\hline 1 & 2 & 3 & 4 & 5 & 6 & 7 & 8 & $\begin{array}{c}9 \\
\text { Strongly }\end{array}$ \\
\hline Strongly & Mostly & Somewhat & Slightly & Neither & Slightly & Somewhat & Mostly & Strongly \\
\hline Disagree & Disagree & Disagree & Disagree & $\begin{array}{c}\text { Disagree nor } \\
\text { Agree }\end{array}$ & Agree & Agree & Agree & Agree \\
\hline
\end{tabular}

6. Bailey has the ability to understand his own and other's emotion.

\begin{tabular}{|c|c|c|c|c|c|c|c|c|}
\hline 1 & 2 & 3 & 4 & 5 & 6 & 7 & 8 & 9 \\
\hline Strongly & Mostly & Somewhat & Slightly & Neither & Slightly & Somewhat & Mostly & Strongly \\
\hline Disagree & Disagree & Disagree & Disagree & $\begin{array}{c}\text { Disagree nor } \\
\text { Agree }\end{array}$ & Agree & Agree & Agree & Agree \\
\hline
\end{tabular}

7. Bailey has the ability to manage his own and other's emotion.

$\begin{array}{ccccccccc}1 & 2 & 3 & 4 & 5 & 6 & 7 & 8 & 9 \\ \text { Strongly } & \text { Mostly } & \text { Somewhat } & \text { Slightly } & \text { Neither } & \text { Slightly } & \text { Somewhat } & \text { Mostly } & \text { Strongly } \\ \text { Disagree } & \text { Disagree } & \text { Disagree } & \text { Disagree } & \begin{array}{c}\text { Disagree nor } \\ \text { Agree }\end{array} & \text { Agree } & \text { Agree } & \text { Agree } & \text { Agree }\end{array}$

\section{Demographic items}

1. What is your gender?

Male

Female

2. What is your age? 
3. How many years of work experience do you have so far?

4. What is your occupation?

5. What is your achieved highest education level?
High school degree
Associate degree
Bachelor degree
Graduate degree

6. What is/was your college major (if applicable)?

7. How many accounting classes have you taken? (Please give a specific number to your best knowledge)

8. How many business-related classes (including accounting classes) have you taken? (Please give a specific number to your best knowledge)

9. Have you ever reported an observed accounting fraud?
Yes
No
I can't remember

10. Have you ever reported an observed fraudulent act (including accounting fraud)?
Yes
No
I can't remember

11. Have you ever actively participated in an accounting fraud?
Yes
No
I can't remember

12. Have you ever actively participated in any fraud (including accounting fraud)?
Yes
No
$\square \quad$ I can't remember

13. Including yourself, how many siblings do you have in your family? 
14. What is your birth order in your family (e.g., first, second, third, etc.)?

7. Schutte et al. (1998) emotional intelligence scale (please refer to item 9 in Appendix II)

8. Rushton et al. (1981) altruism scale (please refer to item 10 in Appendix II) 